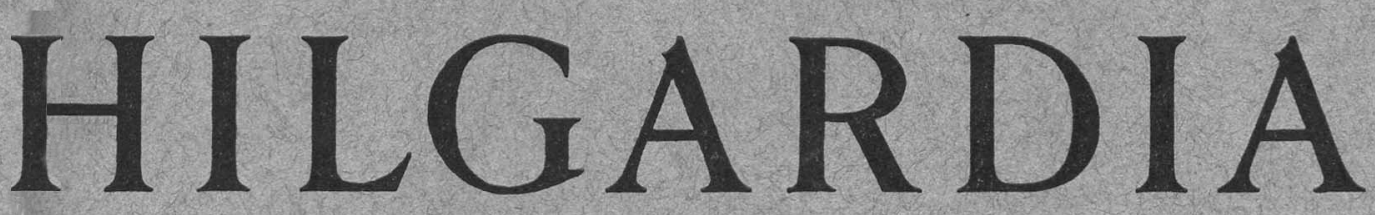

A Journal of Agricultural Science Published by the California Agricultural Experiment Station

CONTENTS

COMPOSITION AND QUALITY OF MUSTS AND WINES OF CALIFORNIA GRAPES

M. A. AMERINE and A. J. WINKLER 
A Journal of Agricultural Science Published by

the California Agricultural Experiment Station

VoL. 15

FEBRUARY, 1944

No. 6

\title{
COMPOSITION AND QUALITY OF MUSTS AND WINES OF CALIFORNIA GRAPES ${ }^{1}$
}

\author{
M. A. AMERINE2 AND A. J. WINKLER ${ }^{3}$
}

\section{INTRODUCTION}

THE UTILITY of a given variety of grapes for wine making depends upon several factors. These include production factors such as scion-stock interrelationship, susceptibility to disease, inherent vigor of the vine, resistance to frost (which depends on the time of leafing out, the vine's ability to produce crops after frost injury, and the like), and the yield and composition of the grapes under various soil and climatic conditions. One must also carefully evaluate: (1) the influence of environmental conditions (rainfall, wind, fogs, humidity, exposure, mean daily temperature, and time of maturity) ; (2) the adaptability of the must to various vinification and amelioration practices (temperature, type of yeast, aeration, and other variations) ; (3) the suitability of the wine for aging in the wood and in the bottle (rate of clarification, bouquet development, and resistance to disease) ; and (4) the basic quality of the wine produced by the variety. The production of wine may be considered as the complex interrelation, interaction, and mutual influence of all these factors with and upon each other. In order to study wine-grape-variety adaptation in California, one must consider each of these critically and separately.

The primary problem in enology is to determine the influences which affect the quality of a wine. Since grapes are the raw material, a study of the various varieties is the starting point. Because of the numerous variations in environmental conditions in California, the experiments must be repeated with each variety in as many different localities as possible.

Several previous studies and publications have been devoted to the winegrape variety situation in California. Haraszthy's importations in $1860^{4,5}$ and

\footnotetext{
${ }^{1}$ Received for publication August 15, 1942.

${ }^{2}$ Assistant Professor of Enology and Assistant Enologist in the Experiment Station.

${ }^{3}$ Professor of Viticulture and Viticulturist in the Experiment Station.

- Haraszthy, Agoston. Report of the commissioners on the culture of the grapevine. Appendix to Senate and Assembly journals. Vol. III, 13th Session, 1862. 30 p. State Printing Office, Sacramento, Calif. 1862.

${ }^{5}$ Arpad Haraszthy reported in 1888 (Annual Report of the Board of State Viticultural Commissioners for 1887, p. 7, State Printing Office, Sacramento, Calif., 1888) that there were 200,000 cuttings and rooted vines in Agoston Haraszthy's importation of 1862. Charles Wetmore in 1880 (First Annual Report of the Board of State Viticultural Commissioners. $66+91$ p., see especially p. 48, Edward Bosqui and Co., San Francisco, 1881) reports: "The collection [of varieties] made by Col. Aguston [sic] Haraszthy has not been preserved; the names of varieties have been confounded in many cases; and there is now a pressing need for a new and complete collection."
} 
those of numerous private individuals ${ }^{8}$ had brought many varieties into the state before 1880. Even before this latter date the University of California had begun to view the viticulture industry with special consideration.

Hilgard's Work.-Dean Hilgard, in his report ${ }^{7}$ as the Professor of Agriculture to the President of the University, remarked in 1879 that the industry was improving because of the introduction of varieties better than the previously used Mission and because of the adaptation of better methods of vinification to California conditions. ${ }^{8}$

The real beginning of the work of the University on wine-grape varieties began in the fall of 1880, when the Legislature appropriated $\$ 3,000$ for enological work at Berkeley. A 20 by 46 foot brick cellar was constructed on the campus. Professor Hilgard was in charge of the experiments. His report for $1880^{10}$ summarizes his aims and purposes :

Included in this report were analyses of eleven musts of five common varieties of grapes, including the Mission and Zinfandel, the two most important in this state at the time.

Another report was made in 1882 , based on the vintage of $1881 .^{11} \mathrm{~A}$ few more musts of common varieties were made into wine at Berkeley, and tasting of the wines produced had begun.

${ }^{6}$ Leggett, Herbert B. The early history of wine production in California. Thesis for the degree of Master of Arts, University of California. 1939. Copy on file in the University of California Library, Berkeley. Mimeographed copy distributed by the Wine Institute, San Francisco.

${ }^{7}$ Hilgard, E. W. Report of the Professor of Agriculture to the President of the University. University of California, College of Agriculture. Supplement to the Biennial Report of the Board of Regents. 113 p. (See Part VI. Viticulture, p. 61-68.) State Printing Office, Sacramento, Calif. 1879.

${ }^{8}$ Even at this early date, Hilgard was not unmindful of the climatic handicaps of California, since he writes in the report: "I have heretofore suggested that this peculiarity (high alcohol and less acid) might, in a measure, be modified by not allowing the grape to become as 'dead ripe' as is usually done. This would tend to increase the acid at the expense of the sugar, which is in excess at best, thus producing the excessive headiness for which California wines are thus far noted. The vintners object to this course on the ground of the European precedent, according to which every additional day of sun is accounted so much gain to the quality of the wine. But what is true in the cloudy climate of Europe is not, therefore, necessarily true in sunny California."

This advice is still timely, and consistent neglect of the importance of harvesting at the proper stage of maturity causes many of the ills of California wines.

${ }^{9}$ The Board of State Viticultural Commissioners came into existence by the same act of the Legislature, receiving $\$ 4,000$ for their work.

${ }^{10}$ Hilgard, E. W. Report of the professor in charge to the Board of Regents. University of California, College of Agriculture. 108 p. (See viticultural appendices no. 8, p. 83-91.) State Printing Office, Sacramento, Calif. 1880.

The plan adopted in this matter is in conformity with my view, expressed in my previous report, and shared by the best vintners in the state, viz.: that among the first necessities of the present situation of California wines in the world's market is the establishment of more definite qualities and brands, resulting from a definite knowledge of the qualities of each of the prominent grape varieties, and of their influence upon the kind and quality of the wine, in blending before, or as the case may be, after fermentation; of the treatment required by each in the cellar, during the time of ripening; and finally, of the differences caused by difference of location, climate, etc., as well as by different treatments of the vines themselves.

${ }^{11}$ Hilgard, E. W. Report of professor in charge to the President, University of California. (See appendix 4. Report of work done in viticultural laboratory with record and discussion of results, p. 122-70.) State Printing Office, Sacramento, Calif. 1882. 
No further summary was published until $1886,{ }^{12}$ although in the meantime several bulletins on the wine-grape studies were issued..$^{13}$

In the 1886 report can be noted the beginnings of a system of classifying the grapes being studied. This classification continued in the reports for another twelve years. Briefly, it was based on the geographical origin of the grapesthat is, an arrangement of varieties according to the district abroad where they were best known. Another development noted in this report is the establishment of test blocks. In an analysis of the factors influencing the quality of California wines made for the State Viticultural Commission in 1885 and reproduced in the 1886 report, Hilgard clearly states (p. 41) the interrelations existing between the intrinsic quality of a grape and the care that must be exercised in excluding unsound grapes from the crusher, preventing excessive fermentation temperatures, and preventing undue access of air.

If what I have stated at the beginning of this report be admitted, viz.: that the wines of California must in the main seek their market outside of the State, and must therefore be adapted to shipment to long distances; then it follows that, if we adopt the wine-making processes of southern France, Portugal, and Italy, we must adopt the all but universal practice of fortifying export wines. If, on the contrary, we wish, in our climate, to produce also wines similar to those of Bordeaux and northward to the Moselle, we must of necessity so vary our practice that with grapes of a more or less southern character we may nevertheless be able to impart the characters of the cooler climates to our products. To this end we must distinctly deviate, in some respects, from the exact practice of either the southern or northern region of Europe.

Our wine-makers should be made to distinctly understand these differences, arising from the management of fermentation nearly as much as from the character of the grapes used. While some of these latter, as, e.g., the Malvoisie, cannot safely form an ingredient of any dry wine, and others, like the Burger, and apparently the Mondeuse, will stand unharmed any reasonable amount of stress; yet the great majority will depend upon their mode of fermentation for their claim to greater or less stability under favorable influences; and hence the destination of the product should be definitely considered when handling it. Of the numerous grape varieties now being naturalized in California, from all parts of the earth's vine-growing belt, each one yields its commercially known product not merely by virtue of its intrinsic qualities, but largely as the result of certain methods of treatment to which it is habitually subjected, and among which the mode of fermentation is doubtless the most important. Southern countries have, by a natural process of selection, adopted those varieties which yield desirable results with the rapid fermentation, which is the natural outcome of the high temperature prevailing at the vintage season; while northern countries, as naturally, have chosen prevalently those grape varieties that yield the best results under slow fermentation, upon the maintenance of which the peculiarities of their products largely depend. If then, we desire to reproduce the wines of other countries exactly, we must adopt not only their grape varieties, but also their methods of treatment in fermentation espec-

${ }^{12}$ Hilgard, E. W. Report of the viticultural work during the seasons 1883-4 and 1884-5, being appendix no. IV to the report for the year 1884. With notes regarding the vintage of 1885-6. University of California, College of Agriculture. 210 p. State Printing Office, Sacramento, Calif. 1886.

${ }^{13}$ Hilgard, E. W. Comparative examination of claret grapes from Fresno and Livermore Valley. California Agr. Exp. Sta. Bul. 6:1. 1884.

Hilgard, E. W. Examination of Zinfandel wines. California Agr. Exp. Sta. Bul. 9:1. 1884.

Hilgard, E. W. Examination of Zinfandel wines. California Agr. Exp. Sta. Bul. 12:1-4. 1884.

Hilgard, E. W. Examination of red or claret wines from Mr. H. W. Crabb, Oakville, Napa County. California Agr. Exp. Sta. Bul. 13:1. 1884.

Hilgard, E. W. Examination of red wines from Sonoma and Napa counties. California Agr. Exp. Sta. Bul. 21:1. 1885.

Hilgard, E. W. Analyses of Santa Clara Valley red wines. California Agr. Exp. Sta. Bul. 43:1. 1885 .

Hilgard, E. W. The wines of 1885. California Agr. Exp. Sta. Bul. 51:1. 1886. 
ially. A different treatment may produce wines intrinsically good, but after all, resembling only remotely the type it was intended to duplicate. It will not, then, do to prescribe uniform conditions and methods of fermentation for all alike. When a Riesling must is rushed through a four or five days' fermentation, under the influence of a hot September in the Napa Valley, it is no wonder that its relationship to the produce of Johannisberg is scarcely suspected; while, had the fermentation been carried out in one of the cool, rock cellars, its true nature would as surely have been revealed.

It is clear, then, that our wine-makers must learn to keep clearly in mind, not only the grape variety they have in hand, but also the use they expect to make of it, from the very outset.

Nowadays, however, all fermentations can be conducted under controlled environmental conditions. The rate of fermentation should therefore be a less critical factor. On the other hand, for producing special types of wines important changes may be possible with special fermentation procedures.

A large number of small-scale (5-gallon) experiments were being conducted by the University at this time, although Hilgard indicated that he would have liked to use larger cooperage. ${ }^{14}$ Hilgard also demonstrated that such experiments must be conducted by some responsible organization over a period of several years.

The work accomplished in 1880 and 1884 with the limited facilities available induced the State Viticultural Convention held in San Francisco in December, 1884 , to request $\$ 10,000$ from the State Legislature to further the enological research of the University. This work was to have been under the "joint control" of the Regents and the State Viticultural Commission. Although the proposed dual control did not succeed, the University's work was pushed with renewed vigor under the stimulus of additional funds.

Bioletti's Work.-Additional and more complete reports were published four years later, ${ }^{15}$ in which Bioletti's name appeared for the first time. Bioletti also helped in the summary report in $1896 .{ }^{16} \mathrm{He}$ wrote the Experiment Station report of $1897,{ }^{17}$ and later, on his return from South Africa and Europe, published in bulletins $193^{18}$ and $197^{19}$ further summaries of variety recommendations.

Although these early experiments were limited as to districts and varieties, abundant information was collected. The utility of many grape varieties was

${ }^{14} \mathrm{He}$ also indicates some of his difficulties: "It is, perhaps, scarcely necessary to state that while, in accordance with the provisions of the law, instruction in the science and art of wine-making is given to those desiring it, yet the wines made or received for examination are rigorously reserved for the purposes defined by the law, and that neither students nor other persons can obtain them for any other purpose. Reports to the contrary that have been circulated, whether by word of mouth, or through the press, are simply and unqualifiedly untrue." This statement also applies to the post-Prohibition experiments.

${ }^{15}$ Hilgard, E. W. Report of the viticultural work during the seasons 1887-89 with data regarding the vintage of 1890 . Part I. Red-wine grapes, by L. Paparelli. California Agr. Exp. Sta. Rept. 1892:1-345. State Printing Office, Sacramento, Calif. 1892.

${ }_{16}$ Hilgard, E. W. Report of the viticultural work during the seasons 1887-93, with data regarding the vintages of 1894-95. Part I. a. Red-wine grapes (continued from report of 1892). b. White-wine grapes. c. Raisin and table grapes, by F. T. Bioletti. California Agr. Exp. Sta. Rept. 1896:1-374. State Printing Office, Sacramento, Calif. 1896.

${ }_{17}$ Bioletti, F. T. Memoranda on wine, table, and raisin grapes. Partial report of work of the [California] agricultural experiment stations for the years 1895-96 and 1896-97.455 p. (See p. 245-53.) University Press, Berkeley, Calif. 1898.

${ }_{18}$ Bioletti, F. T. The best wine grapes for California. California Agr. Exp. Sta. Bul. 193:141-60. 1907.

${ }^{19}$ Bioletti, F. T. Grape culture in California. California Agr. Exp. Sta. Bul. 197:115-60. 1908 . 
established, and the reports had an important influence in encouraging the planting of better ones. Because of the restrictions in districts and varieties tested, Bioletti was not able to eliminate as many varieties as he probably would have liked to do. Furthermore, the steady demand for ordinary wines led the Experiment Station to investigate methods more than varieties after 1900, and the threat of Prohibition gradually eliminated the wine-grape studies. The data of Hilgard and Bioletti clearly demonstrated the important differences in composition of the grapes that existed between the hot, warm, and cool districts of California. Bioletti's report of 1907 divides the state into coast counties and interior valleys. In the present report this subdivision has been expanded into five climatic zones; and later investigators may make further subdivisions, since the state is amazingly rich in distinct climatic regions.

Later Work.-Since 1934 the California Agricultural Experiment Station has again systematically investigated the wine-grape variety problem. Because of marked improvements in facilities, such as transportation, temperature control, and analytical methods, the scope of this research was extended to include typical climatic regions in all parts of the state where grapes are grown, a larger number of varieties, and a more complete sampling of each variety; as well as to enlarge upon and refine the observations and analyses that were made on the musts and wines. As the work has progressed, additional varieties have been established in various localities to further test their adaptation, and other varieties, which have shown promise abroad, have been imported for testing under California conditions.

The data collected on a large number of varieties has very definitely indicated their worth under California conditions. There has been no hesitation in condemning varieties whose basic composition and character do not appear to be useful to the California wine industry. Wherever possible, data previously published by this experiment station and by the United States Department of Agriculture ${ }^{20,21,22}$ have been utilized in arriving at the final recommendation for the individual varieties. Results with tentative adaptations and probable limitations are also given for a number of varieties that have not been tested under sufficiently varied environmental conditions or that have been only recently introduced.

\section{METHOD OF PROCEDURE}

The experimental procedure used has not differed widely from that followed by Hilgard from 1880 to 1896 . The biological controls have been stricter, however, and the chemical and organoleptic tests applied have been more complete.

\section{COLLECTING SAMPLES}

Except for a few samples early in the 1935 season, all grapes tested have been transported to Davis for crushing. These few exceptions were crushed and stemmed at the vineyard. Experience showed, however, that with due

${ }^{20}$ Bigelow, W. D. The composition of American wines. U. S. Dept. Agr. Bur. Chem. Bul. $59: 1-76.1900$.

${ }^{21}$ Husman, George C. Testing grape varieties in the vinifera regions of the United States. U. S. Dept. Agr. Bul. $209: 1-157.1915$.

${ }^{22}$ Husman, George C. Grape districts and varieties in the United States. U. S. Dept. Agr. Farmers' Bul. 1689:1-32. 1932. 
care in picking, grapes could be harvested in the most important districts of the state during the morning and erushed in Davis 24 hours after picking. From 50 to 500 pounds constituted a sample; over 90 per cent weighed at least 100 pounds. These grapes were picked from representative vines of solid blocks or from vines characteristic of the variety where they had to be taken from mixed blocks. Samples were secured from variety collections at Guasti, Delano, Sanger, Lodi, Davis, and Oakville, and from commercial vineyards in other parts of the state. Numerous vineyard owners coöperated in furnishing grape samples. Where experience indicated that testing should be conducted on varieties not previously planted in the district, trial blocks were established.

\section{WINE MAKING}

Crushing.-In 1935 the grapes were crushed between rollers and stemmed by hand. Since then a Garola combined erusher and stemmer has been used. By operating the machine at a high speed and feeding the grapes slowly, it would crush adequately even the thick-skinned varieties such as Palomino. The separation of berries and stems was satisfactory in nearly all varieties.

Fermentation.-The crushed, stemmed mass was placed in an open oak fermenting tank. In a few cases with white grapes, or where it was desired to produce a white wine from black grapes, the pressing took place immediately after crushing. Ordinarily, however, the crushed mass was placed in a fermenting tank, a sample of juice withdrawn for analyses, and sulfur dioxide added to the remainder. The sulfur dioxide was used to inhibit the activity of the natural microflora and to permit all samples to start fermentation at approximately the same biological purity. Grapes in sound condition received 50 to 150 parts per million of sulfur dioxide. The pure yeast culture was added shortly afterwards. Fermentations usually started within a few hours. The usual University of California "Burgundy" strain of yeast was used for all fermentations. Other strains might, perhaps, have given better results with particular musts; but the use of one strain insured a uniformity of comparison between wines of the same variety of grapes from different regions.

The fermentation of the pressed white juice and the red wines after suffcient color was extracted was completed in oak containers closed with fermentation traps. Daily records were made of the temperature and Balling readings.

Must Analyses.-The sample removed for analysis was allowed to stand until the coarse sediment had settled. It was then pipetted into a cylinder, and a Balling or Brix hydrometer floated in it. In a few cases, notably with American varieties, the thick, high-pectin juice did not settle clear. It had then to be filtered or a drop of clear solution used for a refractometer reading. A sample of the clear juice was titrated with sodium hydroxide to a phenolphthalein end point to measure the acidity. The $\mathrm{pH}$ was determined with a quinhydrone electrode or a Beckman $\mathrm{pH}$ meter.

Pressing.-The white musts were pressed within 12 hours of crushing. Too much tannin was extracted in some of the 1935 experiments by having the juice and skins in contact too long. In later years this fault was eliminated. If the pressing was done immediately after crushing, the yields were reduced.

Red musts were pressed when visual inspection showed sufficient color, by 
the fourth to sixth day with most varieties. If the grapes had raisined berries, the pressing was done earlier in order to reduce the extraction of sugar and of raisin flavors. Occasionally fermentations were conducted on the skins for 8 to 12 days.

Temperature Control.- -Until the 1939 season control of temperature during fermentation was not sufficiently uniform. The 1935 fermentations were conducted in an underground cellar that reached $75^{\circ}$ to $80^{\circ} \mathrm{F}$. The 1936 to 1938 fermentations were conducted in a shed whose roof was sometimes cooled by sprinklers. A moderate control of the air temperature in the room was maintained. The 1939 to 1941 fermentations were conducted in rooms maintained at $72^{\circ}$; and if the grapes were too warm on delivery, they were cooled to below $70^{\circ}$ before crushing. Despite the lack of control in the 1935 to 1938 experiments, the fermentation temperatures exceeded $90^{\circ}$ on very few occasions. This was because most of the fermentations were conducted on only about 125 pounds of fruit in 15-gallon containers. The large surface/volume ratio in this case permitted rapid radiation losses from the containers. With slow fermentations the percentage heat loss probably exceeded 50 per cent. Since all varieties from all districts were subjected to approximately the same treatments and temperature conditions, the comparisons remain valid. Daily temperature records were obtained during the fermentations.

Storage.-The clear wine was racked off the yeast into full containers within a week of the completion of fermentation (usually about a month after crushing). The wines from 1935 to 1938, inclusive, were stored in an underground cellar whose temperature was $65^{\circ}$ to $70^{\circ} \mathrm{F}$ in the summer and fall and about $60^{\circ}$ in the winter and spring. Since May, 1939, the white wines have been aged in a refrigerated cellar at $55^{\circ}$, and the red wines at about $59^{\circ}$.

During the first year of aging the wines were racked two and occasionally three times after being taken to the cellar. Between rackings the ullage of the barrels was replaced with wine of the same lot, which was kept in glass. At the time of each racking the material in glass was racked and mixed with the wine from the wood. The white wines, in 5-gallon containers, were bottled 8 to 12 months after the vintage; while most of the red wines were bottled after 12 to 24 months.

\section{CHEMICAL AND ORGANOLEPTIC TESTS}

Periodical analyses and tasting of all samples has been followed. The earliest tasting took place before the first of the year following the vintage. Immediately thereafter, all the wines prepared in the preceding vintage were analyzed. Since this procedure has been followed each year, the analytical results are strictly comparable. Re-tastings were made at least once annually of wines which were still improving or which were still in good condition. It is estimated that over 15,000 taste records have been made.

Chemical Procedures.-During the midwinter rackings, samples were drawn from each container before racking. The analyses were conducted within 12 hours. ${ }^{23}$ The analytical procedures were simplified somewhat from the most accurate methods in order to facilitate making the large number of analyses and also because extreme accuracy was unnecessary.

${ }^{23}$ The authors wish to thank the following for assistance in carrying out most of the analyses reported here: Frank Bergthold, William Dietrich, Bernard Fries, George Gribkoff, Jack Hagerud, Uriel Nielson, and W. O. Williams. 
The wine was brought to a standard temperature (about $63^{\circ} \mathrm{F}$ ), and $100 \mathrm{ce}$ pipetted into an 800-ce Kjeldahl flask. To this, 50 ec of water was added, and nearly 100 ce distilled into a 100-ce volumetric flask. The residue was then washed into a volumetric flask. The distillate was cooled to temperature. The alcohol content was measured with the hydrometer, and in 1935, 1936, and 1937 also with a dipping refractometer ; it is reported as per cent by volume in the tables. The residue was used for an extract determination by means of a special $0^{\circ}$ to $8^{\circ}$ Balling hydrometer. It was also saved for tannin and sugar determinations; those for tannin were made by the Association of Official Agricultural Chemists method, ${ }^{24}$ and those for sugar by a modification of Hassid's ferricyanide method..$^{25}$ For the iron determination, either the extract or the original wine was used. Iron was determined by the orthophenanthroline colorimetric ${ }^{28}$ procedure, care being taken that sufficient hydroxylamine was present.

The original wine was used for $\mathrm{pH}$, color, total, and volatile acid determinations. The $\mathrm{pH}$ was measured with a quinhydrone electrode or, in 1939 to 1941, with a glass electrode in a Beckman $\mathrm{pH}$ meter. The color was determined both by the Dujardin-Salleron vino-colorimeter and in a color comparator with standard dye solutions. ${ }^{27}$ A mixture of Eastman A, B, C dyes has been used for white wines since 1938. It was made as follows : Standard solutions of Eastman A, B, C dyes were prepared by dissolving $500 \mathrm{mg}$ of each in $100 \mathrm{cc}$ of water. Ten ce of the red solution and 5 ce each of the blue and yellow solutions were brought to volume with water in a 300-cc volumetric flask. This solution was stable for several months. The plunger of the colorimeter was set at 3 or $6 \mathrm{~mm}$ for the standard. The depth of the plunger in the wine tube was multiplied, respectively, by 600 or 300 to give the relative color value.

The total acidity of white wines was determined by titration with phenolphthalein as an indicator. A 5-cc portion of red wines was titrated to a blue-black, red-black, or green-black color, according to the variety, and then phenolphthalein was added and the titration continued until a reddish tinge could be detected. The acidity is reported as grams tartaric acid per $100 \mathrm{cc}$, in the tables.

The volatile acid was determined by method II of the Association of Official Agricultural Chemists, using $10 \mathrm{ce}$ of wine and distilling off $100 \mathrm{cc}$. The distillate was heated to boiling for 20 to 30 seconds to rid it of carbon dioxide and titrated to a phenolphthalein end point.

Notes on Analyses.-Occasionally, the fixed acid (total acid minus volatile acid calculated as tartaric) content of the wine was found to be higher than the total acid content of the must. This was contrary to expectations, since no acid was added to the musts. Usually this occurred in musts of high $\mathrm{pH}$ and low acidity and may be caused by the activity of acid-forming microörganisms. Other factors which may explain this condition are inadvertent addition

\footnotetext{
${ }^{24}$ Association of Official Agricultural Chemists. Official and tentative methods of analysis. 5th ed. 757 p. Published by the Association, Washington, D. C. 1940.

${ }^{25}$ In unpublished manuscript by $M$. A. Amerine.

${ }^{28}$ Saywell, L. G., and B. B. Cunningham. Determination of iron. Indus. and Engin. Chem., Analyt. ed. 9:67-69. 1937.

${ }^{27}$ Winkler, A. J., and M. A. Amerine. Color in California wines. I. Methods for measuring color. Food Res. 3(4):429-38. 1938 .
} 
of excessive sulfur dioxide, errors in titration of the must or wine or both, and sampling errors.

The variable relation of the Balling degree of the musts and the alcohol content of the wines indicates that there is no exact relation between the two, even for musts crushed, pressed, and fermented under conditions as uniform as those used in these experiments. The failure to find a uniform Balling/alcohol ratio is caused by several factors. The original Balling is only an approximate density measurement, since the sample is taken from the freshly crushed grapes. Because of differences in degree of crushing between varieties and between the same variety in different seasons or regions, the amount of freerun juice from the crushed grapes will vary. Uniformity in the Balling-alcohol ratio cannot, therefore, be expected.

Tasting Procedure.-Since the purpose of the tasting was to evaluate the varieties of grapes, the scoring was based on the merits and defects of the wine which originated in the grapes, rather than those which might arise from fermentation or aging practices. The tasting sheet and the descriptive terms used for recording the results of the organoleptic examination are given below :

Appearance.-This refers to the clarity and freedom from sediment; brilliant, clear, dull, and cloudy indicate increasing opaqueness; maximum score 10.

Color.-Hue and amount of color must be appropriate to the type of wine; white wines vary from straw, colorless, yellow, gold, to amber and may have green tint; red wines vary from pink to medium and dark red and may have violet or brown tints; maximum score 10 .

Odors.-For off smells such as oxidized and hydrogen sulfide, subtract points; the aroma varied from varietal to distinct or simply vinous; bouquet developed in aged wines; delicate, agreeable, clean, fruity, aromatic, cooked, rancio, and flowery were other terms used; maximum score 15 .

Volatile acidity.-When the volatile acidity was not the result of any varietal defect the maximum number of points (10) were usually given.

Total acidity.-Wines which lack acidity taste flat and unpalatable; those with too much taste green, unripe, or acidulous; different types of wines require high or medium acidity and the score varies accordingly; maximum score 10 .

Dryness.-When the residual sugar of dry table wines is the result of excessive sugar in the grapes, points may be subtracted; sweet dessert types which lack sugar owing to a deficiency in the musts taste thin and points may be subtracted; maximum score 8.

$B o d y$.- The nonsugar solids chiefly influence the texture; white, dry table wines have extract contents lower than red table wines; watery and thin refer to wines lacking extract; rich, heavy, and robust indicate high extract contents; maximum score 6.

Taste.-Only those tastes originating in the grape were noted; these include fruity, fresh, bitter, green, stemmy, moldy, raisin, and alcoholic; maximum score 15.

Smoothness and astringency.-These terms are more or less reciprocal and must be appropriate for the type of wine; astringency was chiefly noted in red wines and varied from low to high tannin (below 0.11 to 0.30 per cent tannin) ; smooth, soft, rounded, slightly rough, rough and harsh were indicated for the smoothness; maximum points 10.

General quality.-The proper conformity of the constituents for each type of wine make them taste balanced or harmonious; unbalanced and unharmonious indicate the opposite; wines with simple and uncomplex flavors are usually obvious and lack character or finesse; the response to aging is also important; maximum score 8.

On the basis of the total score four classes may be established for the different qualities of wines : wines scoring 86 to 100 are from the best varieties after proper aging; those scoring from 78 to 85 are wines of above-average quality and in the text are called quality wines; when the score ranged from 70 to 77 the wines were without particular defect, lacked character, would not respond 
to aging, and in the text they are called standard or bulk-quality wines; and wines below 70 had some serious defect. Either table or dessert wines which would markedly improve in quality with aging were considered as quality wines. Common wines are those which because of some inadequacy of the variety do not improve with aging.

Classification.-It was very difficult to classify wines according to type. Hilgard's tasting record apparently had no independent classification of types, but relied almost solely on the known district of origin of the variety in Europe. This method appeared somewhat disadvantageous, since it set up a priori considerations as to what the quality should be; further, it interposed a conscious or subconscious comparison with wines produced abroad, which would certainly not be judicious. In general in the present study the wines have been tasted blind-that is, without previous identification of variety or of place of origin. For such a tasting, some classification of types was needed. The system used for table wines ${ }^{28}$ was as follows :

Dry red wines with varietal character.-Distinguishable varietal types such as Zinfandel, Cabernet, Barbera, Muscat, Fresia, native Americans, and the like.

Dry red wines without distinctive flavor.-Five empirical types were set up: "red table" for wines of medium body and color, medium or higher acidity, and bottling quality; "high hill" for full-bodied wines with high color and some astringeney; "red standard" for sound, ordinary wines not of bottling character; "red ordinary" for wines with some defect; and "pink" (or rosé) for wines of medium or low body, medium or higher, acidity, and a light pink color.

Dry white wines with varietal character.-These include varietal types such as Riesling, Muscat, Semillon, Sauvignon blanc, Traminer, Chardonnay, Americans such as Catawba and Delaware, and others.

Dry white wines without distinctive character.-Three empirical types were set up: "white table" for wines with sufficient character for bottling; "white standard" for sound ordinary wines not of bottling quality; and "white ordinary" for wines with some defect.

Natural sweet white or red wines.-These include both wines with a distinguishable varietal character such as Semillon, Muscat, and Sauvignon blane and wines without a distinetive varietal flavor.

\section{The system used for dessert or aperitif wines was as follows :}

Dry white.-Wines with a rancio or cooked flavor (California sherry type).

Sweet red.-Wines with a distinguishable varietal character such as red muscatels, and Zinfandel and wines without distinct flavors.

Sweet white.-This includes wines with a varietal flavor such as muscatel and very sweet nondistinctive wines of the Angelica type as well as sweet wines with a rancio flavor.

Although not impractical, this system is not proposed for commercial use; but for experimental tasting it had the merit of freeing the tasters from any preconceived ideals regarding types and quality. A simplified tasting card was used to record the pertinent data after the system had been worked out. ${ }^{30}$

${ }^{28}$ For a more complete discussion of these types of wine and their commercial classification see: Amerine, M. A., and M. A. Joslyn. Commercial production of table wines. California Agr. Exp. Sta. Bul.' 639:1-143. 1940.

${ }^{29}$ For a more complete discussion of these types of wine and their commercial classification see: Joslyn, M. A., and M. A. Amerine. Commercial production of dessert wines. California Agr. Exp. Sta. Bul. 651:1-186. 1941.

${ }_{30}$ The authors are indebted to their colleagues for assistance during 1936 to 1938 . Mr. E. H. Twight was also a member of the staff during most of this period, and his counsel was helpful. 


\section{INFLUENCE OF ENVIRONMENTAL CONDITIONS}

The interrelation of environment and variety is revealed in every recognized type of wine. The relative importance of each as a factor in the production of wines of high quality is debatable, with many salient points on either side. Generally speaking, and because each outstanding table wine type takes its character primarily from a single variety, one is inclined to attribute the principal difference between wine types to the variety used rather than to the region of production. Environment limits grape growing to definite regions on the surface of the earth. It likewise, just as definitely, limits the adaptation of individual varieties to certain areas within these regions. It is this environmental-varietal interrelation that furnishes the bases for distinct wine types in most European countries. The significance of variety in European types indicates the great importance of choosing grapes adapted to the particular environment. The fact that the variety or varieties grown in certain European regions are so perfectly adapted to these regions has made it possible for the wines produced there to establish a worldwide reputation for quality.

\section{INFLUENCE OF CLIMATE}

The experience and research of the European vintners and enologists also afford a fairly definite indication of what climate does to grapes. Climate influences the rates of change in the constituents during development and the composition of the grapes at maturity. Under relatively cool conditions ripening proceeds slowly, and this is favorable for producing dry table wines of quality. These conditions foster the retention of a high degree of acidity, a low $\mathrm{pH}$, and good color (see tables 1 and 2). With most table-wine varieties they bring the aroma and flavoring constituents of the grapes and the precursors of the aroma and flavoring substances of the wines to their highest degree of perfection in the mature fruit. The combination of specific environments with the qualities of the White Riesling, the Pinot noir, the Cabernet Sauvignon, or the like, has made possible the great table wines of the world. If, on the contrary, the varieties lack special character, the most favorable climatic conditions will not make possible the production of quality wines. The table wines of these varieties will be improved because of a better balance of the sugar, acid, tannin, and flavor of the grapes at maturity ; but they will still lack the special qualities such as aroma, bouquet, and freshness that are characteristic of high-quality wines.

Effect on Aroma.-Under warm climatic conditions the aromatic qualities of the grapes lose some of their delicacy and richness, and the other constituents of the fruit are less well balanced; hence the table wines, even of the best varieties, cannot compare with those of the cooler regions. In the very hot regions where growth and ripening changes proceed with great rapidity, the aroma of most dry-wine varieties is harsh and coarse, and the other components are so poorly balanced that usually only common dry table wines can be made.

Condition for Dessert Wines.-The abundance of heat in some regions, which makes them poorly suited to dry wines, makes them ideal for dessert wines such as port, muscatel, and sherry. With abundant heat the varieties 
especially suited to the production of such wines attain their most perfect development. Large summations of heat, especially just before and during ripening, favor a high ratio of sugar to acid in the fruit; and the effect of the heat on the aroma is less objectionable than with dry wine.

Application of Climatic Data.-When accompanied by proper vinification and aging, the variety, through its inherent characteristics such as aroma and

TABLE 1

Influence of Regional Conditions on the Composition of Grapes Picked at Approximately the Same Stage of Maturity

\begin{tabular}{|c|c|c|c|c|c|c|c|c|c|}
\hline \multirow{2}{*}{ Variety } & \multicolumn{3}{|c|}{ Original Balling degree } & \multicolumn{3}{|c|}{$\begin{array}{l}\text { Per cent total acid } \\
\quad \text { (as tartaric) }\end{array}$} & \multicolumn{3}{|c|}{$\mathrm{pH}$} \\
\hline & Fresno & Davis & $\begin{array}{l}\text { Bonny } \\
\text { Doon }\end{array}$ & Fresno & Davis & $\begin{array}{l}\text { Bonny } \\
\text { Doon }\end{array}$ & Fresno & Davis & $\begin{array}{l}\text { Bonny } \\
\text { Doon }\end{array}$ \\
\hline Alicante Bouschet....... & $\ldots$ & 19.9 & 19.1 & $\ldots$ & 0.63 & 1.29 & $\ldots$ & 3.63 & 2.95 \\
\hline Burger................ & $\cdots$ & 17.8 & 17.6 & $\cdots$ & .55 & 0.81 & . & 3.46 & 3.15 \\
\hline Cabernet Sauvignon.... & 22.9 & 22.4 & 20.7 & 0.65 & .67 & 1.10 & 3.48 & 3.63 & 3.41 \\
\hline Sauvignon vert.......... & 24.2 & 24.3 & 22.4 & .44 & .57 & 0.57 & 3.67 & 3.81 & 3.28 \\
\hline Semillon......... & 21.0 & 18.1 & 24.1 & .41 & .55 & 0.69 & 3.42 & 3.36 & 3.07 \\
\hline Zinfandel..... & 21.0 & 22.8 & 24.7 & 0.55 & 0.55 & 1.16 & 3.51 & 3.58 & 3.14 \\
\hline
\end{tabular}

TABLE 2

Influence of Regional Conditions on the Color of Grapes*

\begin{tabular}{|c|c|c|c|c|c|}
\hline \multirow[b]{2}{*}{ Variety } & \multicolumn{5}{|c|}{ Average color valuet (by vino-colorimeter) in various regions } \\
\hline & $\begin{array}{l}\text { Delano, } \\
\text { Fresno }\end{array}$ & $\begin{array}{c}\text { Lodi, } \\
\text { Guasti, } \\
\text { Davis }\end{array}$ & $\begin{array}{c}\text { Livermore } \\
\text { Valley, } \\
\text { Asti, } \\
\text { Ukiah }\end{array}$ & $\begin{array}{c}\text { Napa } \\
\text { Valley, } \\
\text { Santa Clara } \\
\text { Valley }\end{array}$ & $\begin{array}{c}\text { South } \\
\text { Sonoma } \\
\text { County, } \\
\text { Santa Cruz } \\
\text { Mts. }\end{array}$ \\
\hline 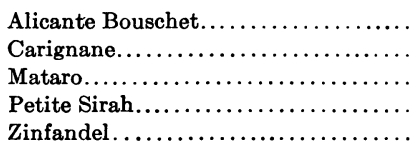 & $\begin{array}{r}54 \\
89 \\
500 \\
57 \\
147\end{array}$ & $\begin{array}{r}47 \\
82 \\
286 \\
50 \\
91\end{array}$ & $\begin{array}{r}37 \\
70 \\
200 \\
45 \\
75\end{array}$ & $\begin{array}{l}28 \\
48 \\
73 \\
28 \\
65\end{array}$ & $\begin{array}{l}17 \\
40 \\
62 \\
20 \\
20\end{array}$ \\
\hline
\end{tabular}

* Data from: Winkler, A. J., and M. A. Amerine. Color in California wines. II Factors influencing color. Food Research 3 (4):439-47. 1939.

$t$ The color value is based on the direct reading so that intensity increases as the figures'decrease.

flavoring constituents, determines the type of wine to be produced; whereas the regional conditions, by influencing the sugar-acid ratio, the total acidity, and the tannin content, determine the quality within the type.

To evaluate the influence of environment many varieties have been collected from all the principal grape-growing regions of California. In order to reduce the size of tables and to differentiate among the recommendations, the grape districts of the state have been grouped into five climatic regions. This grouping was based upon temperature differences or more specifically upon the summation of heat as degree-days above $50^{\circ} \mathrm{F}$ for the period April to October inclusive. (For definition of degree-days see footnote in table 4.) The summa- 
tions for the regions are: I, less than 2,500 degree-days; II, 2,501 to 3,000 degree-days ; III, 3,001 to 3,500 degree-days; IV, 3,501 to 4,000 degree-days ; and $V, 4,001$ or more degree-days. The localities in each region from which one or more samples have been collected were as follows :

Region I: Napa and Oakville in Napa County; Hollister and San Juan Bautista in San Benito County; Woodside in San Mateo County; Mission San Jose in Alameda County; Saratoga in Santa Clara County; Bonny Doon and Vinehill districts in Santa Cruz County; and Guerneville, Santa Rosa, and Sonoma in Sonoma County.

Region II: Soledad in Monterey County; Rutherford, St. Helena, and Spring Mountain in Napa County; Santa Barbara in Santa Barbara County; Almaden Vineyard, Evergreen, Guadalupe district, and Los Gatos in Santa Clara County; and Glen Ellen in Sonoma County.

TABLE 3

Influence of Season on the Composition of Must and Wine; Averages from All Regions*

\begin{tabular}{|c|c|c|c|c|c|c|c|c|c|c|}
\hline \multirow{3}{*}{ Variety } & \multirow{2}{*}{\multicolumn{2}{|c|}{$\begin{array}{l}\text { Average date } \\
\text { of harvesting }\end{array}$}} & \multirow{2}{*}{\multicolumn{2}{|c|}{$\begin{array}{l}\text { Balling degree } \\
\text { of the must }\end{array}$}} & \multicolumn{6}{|c|}{ Wine } \\
\hline & & & & & \multicolumn{2}{|c|}{$\begin{array}{l}\text { Percent } \\
\text { alcohol, } \\
\text { by volume }\end{array}$} & \multicolumn{2}{|c|}{$\begin{array}{l}\text { Per cent } \\
\text { total acid }\end{array}$} & \multicolumn{2}{|c|}{$\begin{array}{l}\text { Color value } \dagger \\
\text { (by vino- } \\
\text { colorimeter) }\end{array}$} \\
\hline & 1935 & 1936 & 1935 & $1936 \ddagger$ & 1935 & $1936 \ddagger$ & 1935 & 1936 & 1935 & 1936 \\
\hline Alicante Bouschet.. & Oct. 1 & Sept. 23 & 21.7 & 22.9 & 10.9 & 12.3 & 0.61 & 0.57 & 64 & 63 \\
\hline Burger.......... & Sept. 30 & Sept. 19 & 19.8 & 19.5 & 9.6 & 11.0 & .66 & .55 & $\ldots$ & .. \\
\hline Carignane... & Sept. 30 & Sept. 19 & 22.3 & 23.3 & 10.9 & 12.4 & .70 & .50 & 27 & 22 \\
\hline Palomino........ & Sept. 24 & Sept. 30 & 21.5 & 22.9 & 11.0 & 12.5 & .38 & .36 & .. & .. \\
\hline Petite Sirah... & Sept. 28 & Sept. 22 & 23.2 & 25.6 & 11.3 & 13.9 & .67 & .56 & 77 & $\ddot{59}$ \\
\hline Zinfandel....... & Oct. 1 & Sept. 19 & 24.7 & 23.9 & 12.8 & 13.5 & .71 & .58 & 31 & 19 \\
\hline $\begin{array}{c}\text { Average of } 240 \\
\text { varieties..... }\end{array}$ & Sept. 30 & Sept. 21 & 22.1 & 23.0 & 11.0 & 12.2 & 0.61 & 0.50 & 39 & 33 \\
\hline
\end{tabular}

* Data from: Winkler, A. J., and M. A. Amerine. What climate does-the relation of weather to the composition of grapes and wine. The Wine Review 5 (6): 9-11; (7): 9-11, 16. 1937.

$\dagger$ For color value see footnote to table 2.

$\ddagger$ The apparent discrepancies in the figures for Balling degree and alcohol in 1936 are the result of raisining in the samples.

Region III: Livermore and Pleasanton in Alameda County; Calpella, Ukiah, and Hop land in Mendocino County; Calistoga in Napa County; Alpine in San Diego County; Templeton in San Luis Obispo County; Loma Prieta in Santa Cruz County; and Alexander Valley, Asti, and Cloverdale in Sonoma County.

Region IV: Guasti in San Bernardino County; Escondido in San Diego County; Acampo, Escalon, Lockeford, Lodi, and Manteca in San Joaquin County; Cordelia in Solano County; Ceres, Hughson, and Vernalis in Stanislaus County; Ojai in Ventura County; and Davis in Yolo County.

Region V: Fresno and Sanger in Fresno County; Madera in Madera County; Arena and Livingston in Merced County; and Trocha in Tulare County.

Some of the locations are, as might be expected, on or near the borderline between regions.

\section{INFLUENCE OF SEASONAL CONDITIONS}

There is also a seasonal influence that is more or less marked according to the locality of the producing region in the temperate zone. Wines of best quality are usually produced in the hot years of the coolest regions. In the warmer locations the cool years produce the higher-quality wines. Greater and more frequent deviations from the optimum conditions required for maturing 


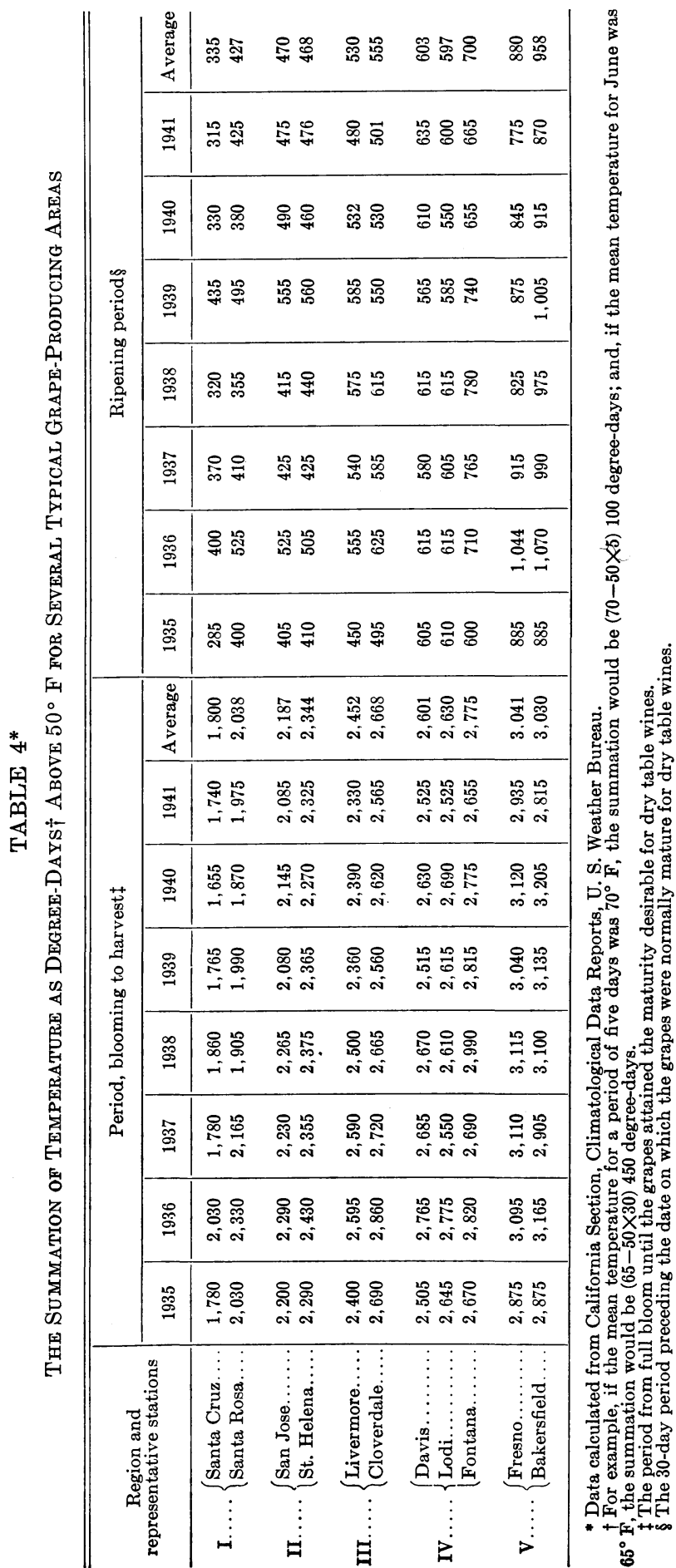


of the fruit occur in the coolest regions. For this reason, and because California's present grape acreage is all in the warmer part of the geographic zone adapted to grape production, some producers believe that every year is a "vintage year" in California. If this term simply designates years in which the grapes attain full maturity, such belief is correct. By general usage abroad, however, the term designates instead the years of outstanding quality. To say that the wines of all years are outstanding or superior or even to say that the wines of all years are of equal quality in California is far from the truth.

The figures of table 3 indicate the magnitude of the influence of seasonal conditions. They show that the total acidity and the color were lower in the warmer year-1936. The slightly higher Balling degree of the 1936 fruit does not account for the lower average total acid content; and the color normally increases with an increase in maturity.

These figures deal only with substances that may be readily determined. Experience and tastings indicate, however, that other substances are also affected by changes in the seasons to a recognizable but unknown extent.

\section{INFLUENCE OF OTHER FACTORS}

Climate includes many factors such as wind, rain, humidity, and temperature. Of these, apparently, temperature is the most important single factor in grape and wine production. It is measured fairly readily, though in actual practice not too accurately. Although climate in general and its influence on the quality of wines are of interest, more complete records are available for the differences in temperature between the seasons of the various regions in California than for the other factors; hence temperature will be used not only to explain further the data of table 3 , but also to show the considerable annual variation between the years, from 1935 to 1941, for a number of locations in the state. Table 4 shows the summation of heat above $50^{\circ} \mathrm{F}$ for two periods in the development of the fruit in each of these years.

\section{FACTORS INFLUENCING THE SELECTION OF THE BEST VARIETY}

In the final evaluation of a grape variety the first consideration must be the use to which the grape is to be put. No variety that produces wines lacking in character can be recommended for the production of quality wines. For bulk wines adequate consideration should be given to the basic essentials of composition and character; then, in addition, sufficient emphasis must be placed on the production factors. The final selection is thus based on two factors: yield, and quality of the product.

Production.-Although the necessity of adequate production is self-evident, it becomes less important as the quality increases. Certain poorly yielding varieties continue, for example, to be widely planted throughout the world because they produce outstanding wines-notably the Cabernet Sauvignon. The amount of crop produced also has a marked influence on the composition of the grapes. In years of light crop or, in general, with vines that have a small number of clusters, the sugar content is greater than normal, and the total acidity is reduced. This, of course, influences the character and type of wine.

High-producing varieties should not be planted in districts where only low 
production is possible, nor should low-producing varieties be planted in rich soils; no variety will make a fine wine in such locations. Heavy producers, however, are essential in making cheap bulk-quality wine.

A quality grape variety results from a complex of several production factors. The condition of the grapes at harvest is very important. Varieties which easily become moldy, sunburned, rotten, or which insects attack, are more difficult to pick and to deliver to the winery in a satisfactory condition. Such grapes either contribute undesirable spoilage organisms to the musts or give off-tastes to the wine. These varieties, if black grapes, cannot be used for producing white wine. Diseased fruit is also sometimes high in oxidizing enzymes that discolor the white musts and wines. Yield and the soundness of the fruit must both be considered from the production point of view.

Composition.-The chemical composition of the musts is also very important. The sugar/acid relation may apparently take any one of four forms, although for a given variety this is influenced somewhat by amount of crop and various environmental conditions. These four forms are : low sugar with low acid; low sugar with high acid; medium sugar with medium to high acid; and high sugar with low acid. The status of this relation will largely determine whether or not the grape is to be used for table wine or for dessert- or appetizer-wine production. The dry table wines, for example, require grapes of fairly low $\mathrm{pH}$ (3.0 to 3.4 ), high acidity ( 0.6 to 0.9 per cent), and a moderate sugar content $\left(19^{\circ}\right.$ to $23^{\circ}$ Balling). The sweet table wines and the dessert and appetizer wines, on the other hand, must be of a higher $\mathrm{pH}$ (3.3 to 3.7), medium acidity ( 0.4 to 0.6 per cent), and more generous sugar content $\left(23^{\circ}\right.$ to $29^{\circ}$ Balling).

The Balling-acid ratio has also been shown ${ }^{\mathrm{s1}}$ to be of utility in classifying the varieties of wine grapes within a given region. In region IV those with ratios below 28.6, 31.4, and 34.3 at $20^{\circ}, 22^{\circ}$, and $24^{\circ}$ Balling are typical dry table-wine grapes. Varieties with ratios exceeding these figures at the Balling degrees given are typical dessert-wine grapes. Some varieties have a ratio below 28.6 at $20^{\circ}$ Balling, but exceed 31.4 and 34.3 at $22^{\circ}$ and $24^{\circ}$ Balling. These latter should be grown in a cooler location for table wines and a warmer location for dessert wines. About 100 varieties have been tested by this system for Davis conditions. The procedure in making this type of study involves periodic sampling throughout the ripening period. The results are referred to, for region IV conditions, under the varieties being tested.

The importance of a low $\mathrm{pH}$ in fermentations of must intended for table wines is well known. The utility of detailed studies of the acids in ripening grapes for differentiating wine-grape varieties has been demonstrated. ${ }^{83}$

Other composition factors are also important. The presence or absence of anthocyanin pigment will determine whether a red wine may be produced. Numerous varieties that have anthocyanin pigments only in the skins may be used, however, for white wines. There appear to be several classes of white wine-grape varieties as far as the color of wine is concerned. Color may, how-

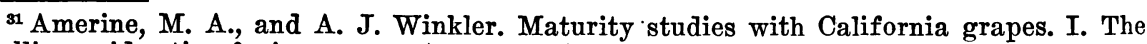
Balling-acid ratio of wine grapes. Amer. Soc. Hort. Sci. Proc. 38:379-87. 1940.

${ }^{32}$ See citation in footnote 28, p. 502.

${ }^{33}$ Amerine, M. A., and A. J. Winkler. Maturity studies with California grapes. II. The titratable acidity, $\mathrm{pH}$, and organic acid content. Amer. Soc. Hort. Sci. Proc. 40:313-24. 1942. 
ever, be influenced to a considerable extent by the $\mathrm{pH}$ and oxidation-reduction potential of the fermenting must and the resulting wine. The general distinction appears to be between the varieties such as Burger, Folle blanche, and certain Rieslings with only a small amount of yellow pigment in their skin and the well-colored varieties such as Semillon and Muscat Canelli.

The tannin content of red varieties is also important. The varieties, with typical examples, may be divided as follows : high color with low tannin (Saint Macaire); high color with high tannin (Salvador); low color with low tannin (Mission and Grenache); and low color with high tannin (Grignolino and Troia de Barletta). The other composition factors such as inherent flavor and the flavor produced in wine making have already been discussed.

Time of Maturation.-In cool regions early-ripening varieties are necessary in order to have the fruit ripen properly. With the possible exception of the coolest portion of region I, early-ripening varieties are not essential in California. Early varieties in most regions of the state are at a disadvantage for two reasons. First, they ripen during the hottest period of the year, and their Balling-acid ratio is unduly increased. Second, unless the grower is particularly careful, the grapes will become overripe before the winery is ready to receive them. Furthermore, because the grapes ripen in the hottest part of the year, they become overripe very rapidly. The only possible advantages of such varieties are to prolong the picking season in very large vineyards and to provide high sugar concentration in cool, unfavorable years. The latter is a minor consideration in this state. Varieties such as Chasselas doré, Meunier, and Red Traminer are seldom useful because of their very early ripening.

Late-ripening varieties, on the other hand, are at a distinct disadvantage in regions I and II, where they fail to mature in cool seasons. In regions III, IV, and $V$ they deserve more attention. Their late ripening enables them to escape the severe heat of September. The climate is hot enough, however, so that they mature normally. Since most of the very large vineyards are located in regions IV and V, the planting of such varieties will help to prolong the picking season without permitting the grapes to become overmature. Varieties such as Mission, Tinta Madeira, Raboso Piave, and perhaps Fogaruna should receive more attention because of their late period of ripening.

Blends. - The varieties recommended for planting in the various climatic conditions of the state are given in the sections which follow. In early listings in California mixed plantings were recommended. In the present report the recommendations are to keep varieties segregated, to facilitate harvesting and utilization. A given vineyardist in region I may wish to plant one or all of the varieties listed on page 533. In each of the regions varieties are recommended for making quality red or white wines or for making standard red or white wines. The individual grower must determine which type of wine he wishes to produce, or how much of each, and make his selections accordingly.

Some will wish to plant a number of varieties so that several types of wine may be produced or with the idea of blending. Blending may be considered either from the standpoint of the varieties of grapes or of the types of wines. Many useful varieties of grapes are deficient in one or more necessary substances and even varieties which are ordinarily sufficiently well balanced for producing a satisfactory wine will, under some environmental conditions, fail 
to attain their normal composition. Deficiencies in color, sugar, or acid content are common examples of this. In addition, certain types of wine require a particularly nice "balance" which is not of ten achieved from any single variety of grape. Securing the exact balance in a Champagne stock is an example of this. In either case, blending is a desirable and useful procedure. But blending is not a cure-all, and its indiscriminate use will lower the average quality

TABLE 5

Relative Value of Red Varieties for Table and Dessert Wines

\begin{tabular}{|c|c|c|c|c|}
\hline Variety & $\begin{array}{l}\text { Relative } \\
\text { value for } \\
\text { table wine }\end{array}$ & $\begin{array}{c}\text { Relative } \\
\text { value for } \\
\text { dessert wine }\end{array}$ & $\begin{array}{c}\text { Relative } \\
\text { productivity }\end{array}$ & Type of pruning* \\
\hline Aleatico $\ldots \ldots \ldots \ldots \ldots \ldots \ldots \ldots$ & 52 & 73 & Medium & Spur \\
\hline Alicante Bouschet................ & 40 & 40 & High & Spur \\
\hline Barbera.......................... & 78 & . & High medium & Spur \\
\hline Black Malvoisie .................... & . & 71 & High & Spur \\
\hline 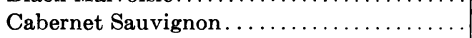 & 98 & . & Low & Cane and spur \\
\hline Carignane & 57 & 56 & High & Spur \\
\hline 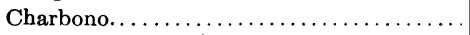 & 59 & . & High medium & Spur \\
\hline Gamay............................. & 70 & .. & Low medium & Spur \\
\hline Grand noir. . & 46 & 61 & High & Spur \\
\hline$\ldots \ldots \ldots \ldots \ldots \ldots$ & 82 & 77 & High & Spur \\
\hline Grignolino........................... & 79 & . & Medium & Spur \\
\hline 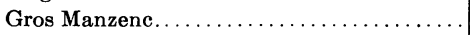 & 72 & . & Low medium & Spur \\
\hline 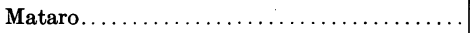 & 47 & 61 & High & Spur \\
\hline Mission $\ldots \ldots \ldots \ldots \ldots \ldots \ldots \ldots \ldots$ & . & 79 & High & Spur \\
\hline Mondeuse $\ldots \ldots \ldots \ldots \ldots \ldots \ldots \ldots$ & 67 & . & High & Spur \\
\hline Nebbiolo........ & 68 & . & Low medium & Spur \\
\hline Pagadebito....... & 49 & 45 & Medium & Spur \\
\hline Petit Bouschet..... & 46 & 61 & Medium & Spur \\
\hline$\ldots \ldots \ldots \ldots \ldots \ldots \ldots$ & 71 & 67 & High medium & Long Spur \\
\hline 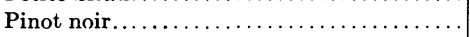 & 92 & . & Low & Short cane and spur \\
\hline Pinot Saint George...................... & 51 & . & Medium & Spur \\
\hline 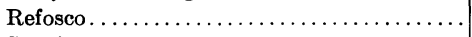 & 65 & 67 & High medium & Spur \\
\hline Sangioveto......................... & 68 & . & Medium & Spur \\
\hline Saint Macaire.$\ldots \ldots \ldots \ldots \ldots \ldots \ldots \ldots \ldots$ & 65 & .. & High medium & Spur \\
\hline$\ldots \ldots \ldots \ldots \ldots \ldots \ldots$ & 69 & .. & Medium & Cane and spur \\
\hline Tinta Madeira .......................... & . & 81 & High medium & Spur \\
\hline Trousseau............................ & .. & 77 & High & Spur \\
\hline$\ldots \ldots \ldots \ldots \ldots \ldots \ldots$ & 58 & 57 & High & Spur \\
\hline Zinfandel......... & 67 & 73 & High medium & Spur \\
\hline
\end{tabular}

* Where cane and spur pruning is mentioned, see the system of pruning indicated for Cabernet Sauvignon, page 553 .

of the products of the winery. Varieties which possess no particular merit and which are markedly deficient or overabundant in color or acid had better be discarded, no matter what their production, rather than to try to rectify them with special grapes and special vinification procedures. This is especially true for the ordinary varieties of grapes when acceptable substitutes exist. Likewise, it would frequently be better to leave varietal wine types undiluted and age them longer than to dilute them beyond recognition in order to achieve an early maturity.

Relative Value of Varieties.-The two primary objects of this investigation, to date, have been concerned with the influence of region and variety on the quality of the wines produced. The relative importance of the region is definitely shown by tables 8 to 25 . Similar information for the varieties is indi- 
cated, though not so directly, by the statement regarding the samples from a single region and year at the right of the tables.

The use of numerical equivalents for the relative values of the different varieties makes direct comparisons possible and lends emphasis to their worth for wine production. Such values can be derived directly from the tasting scores of the wines of each variety, since all wines were scored on the same

TABLE 6

Relative Value of White Varieties for Table and Dessert Wines

\begin{tabular}{|c|c|c|c|c|}
\hline Variety & $\begin{array}{l}\text { Relative } \\
\text { value for } \\
\text { table wine }\end{array}$ & $\begin{array}{l}\text { Relative } \\
\text { value for } \\
\text { dessert wine }\end{array}$ & $\begin{array}{c}\text { Relative } \\
\text { productivity }\end{array}$ & Type of pruning* \\
\hline Burger. . & 61 & .. & High & Spur \\
\hline Catarratto..... & 72 & . & High medium & Spur \\
\hline Chardonnay $\ldots \ldots \ldots \ldots \ldots \ldots \ldots \ldots \ldots$ & 92 & .. & Low & Cane and spur \\
\hline Chasselas doré $\ldots \ldots \ldots \ldots \ldots \ldots \ldots \ldots \ldots \ldots$ & 52 & $\begin{array}{l}\cdots \\
.\end{array}$ & Low medium & Spur \\
\hline Clairette blanche ..................... & 61 & $\cdots$ & High & Spur \\
\hline Feher Szagos....................... & . & $\ddot{57}$ & High & Spur \\
\hline Folle blanche.......... & 69 & . & Medium & Spur \\
\hline French Colombard $\ldots \ldots \ldots \ldots \ldots \ldots \ldots \ldots$ & 67 & . & High & Spur \\
\hline Gray Riesling $\ldots \ldots \ldots \ldots \ldots \ldots \ldots \ldots \ldots$ & 47 & 76 & High & Spur \\
\hline Green Hungarian . . . . . . . . . . . . . . . . & 51 & . & High & Spur \\
\hline Inzolia & 47 & 68 & High & Spur \\
\hline Palomino $\ldots \ldots \ldots \ldots \ldots \ldots \ldots \ldots \ldots \ldots$ & 48 & 82 & High & Spur \\
\hline Pinot blanc.... & 83 & . & Low & Spur \\
\hline Peverella........ & 77 & . & High & Spur \\
\hline Red Traminer.. & 81 & . & Low & Cane and spur \\
\hline Roussette...... & 57 & . & Medium & Spur \\
\hline Sauvignon blanc. . & 78 & . & Low medium & Cane and spur \\
\hline Sauvignon vert.... & 48 & 61 & Medium & Spur \\
\hline Semillon........ & 85 & . & Medium & Spur \\
\hline Saint Emilion........... & 67 & .. & High medium & Spur \\
\hline Sylvaner $\ldots \ldots \ldots \ldots \ldots \ldots \ldots \ldots \ldots \ldots$ & 85 & . & Low medium & Spur \\
\hline 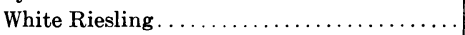 & 88 & $\cdots$ & Low & Cane and spur \\
\hline Muscat of Alexandria.................. & 41 & 67 & High & Spur \\
\hline Muscat Canelli......................... & 68 & 82 & Low medium & Spur \\
\hline Muscat Hamburg. . . . . . . . . . . . . . . . . . & 52 & 67 & High & Spur \\
\hline Malvasia bianca. & 56 & 73 & Medium & Spur \\
\hline Orange Muscat.. & 67 & 77 & High & Spur \\
\hline
\end{tabular}

* Where cane and spur pruning is mentioned, see the system of pruning indicated for Cabernet Sauvignon, page 553 .

basis and by the same individuals. To do this the average score for each was reduced to a common basis. A value of 40 was arbitrarily assigned to the wines of Alicante Bouschet, which regularly received a low score, and then the numerical equivalents for the other varieties were obtained by using the differences between the average scores of their wines and the score of the wines of Alicante Bouschet and multiplying this by five to secure a proper spread. Any other variety could have been used as a basis for the comparisons as long as an appropriate value was assigned, but the Alicante Bouschet was chosen because it is generally grown and well known. Values for the varieties now grown to a considerable extent as well as the varieties that are recommended for planting are shown in tables 5 and 6 . The relative values for the different varieties shown in these two tables are for the region or regions to which the varieties are best adapted for the production of either table or dessert wines. 


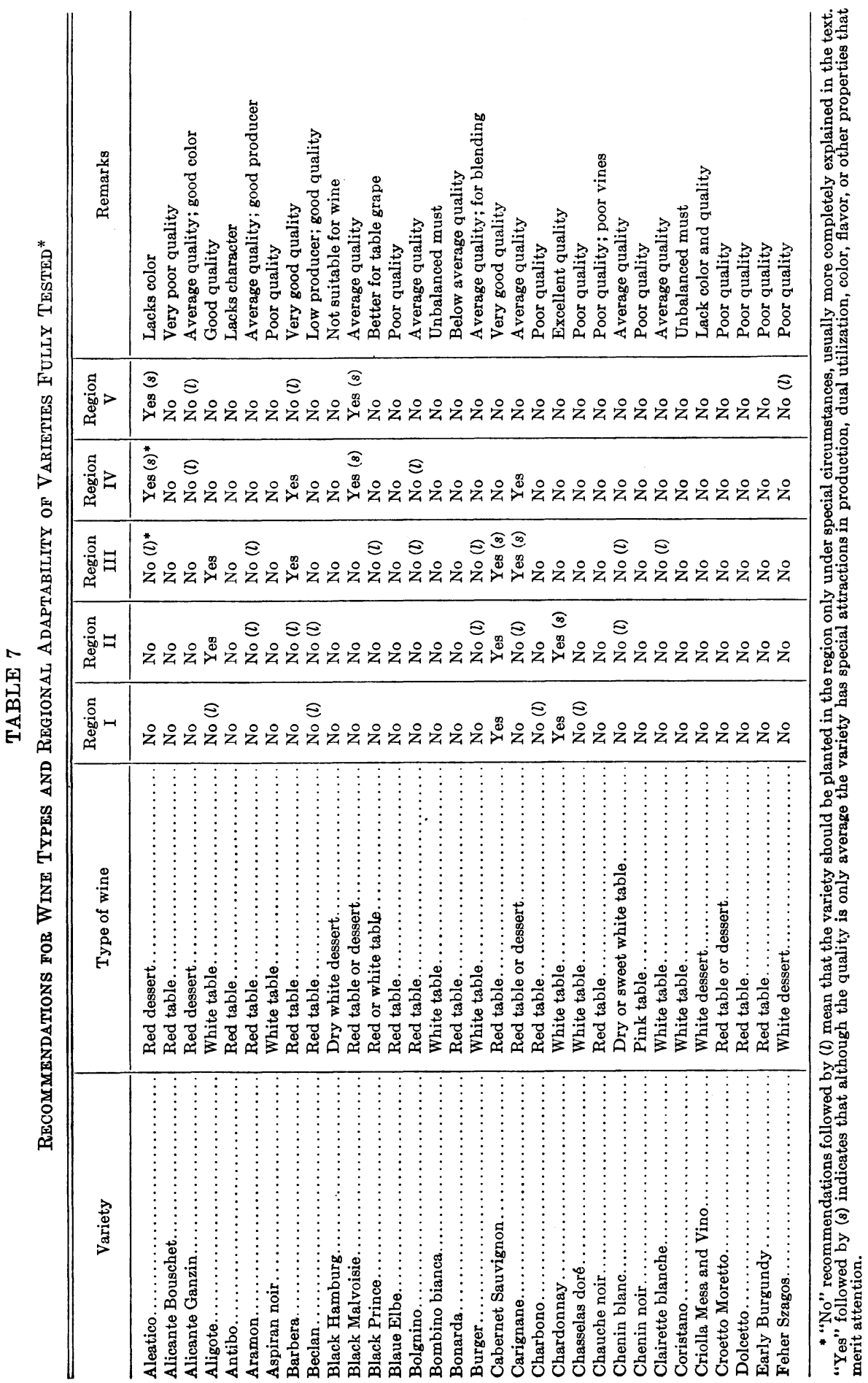




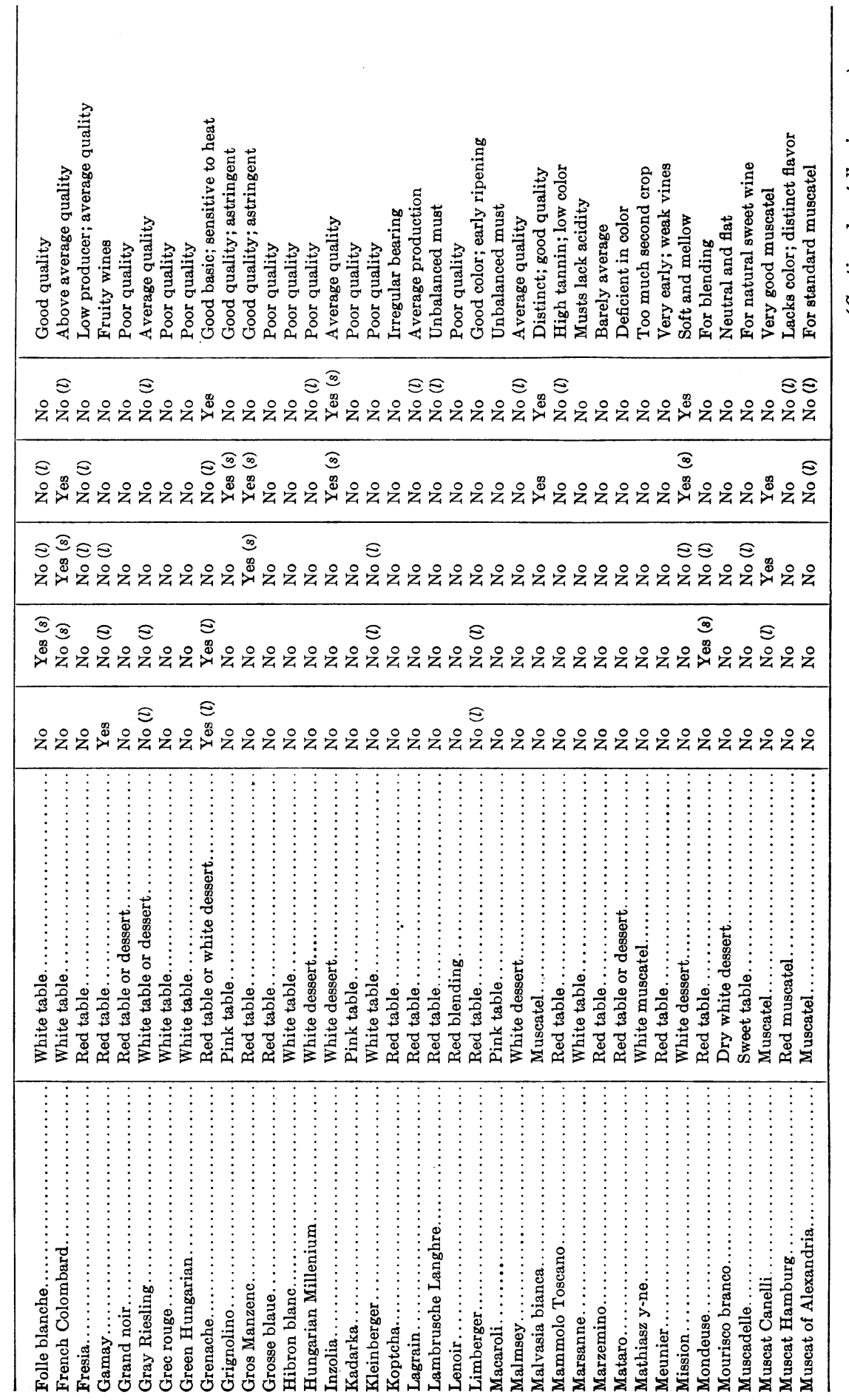




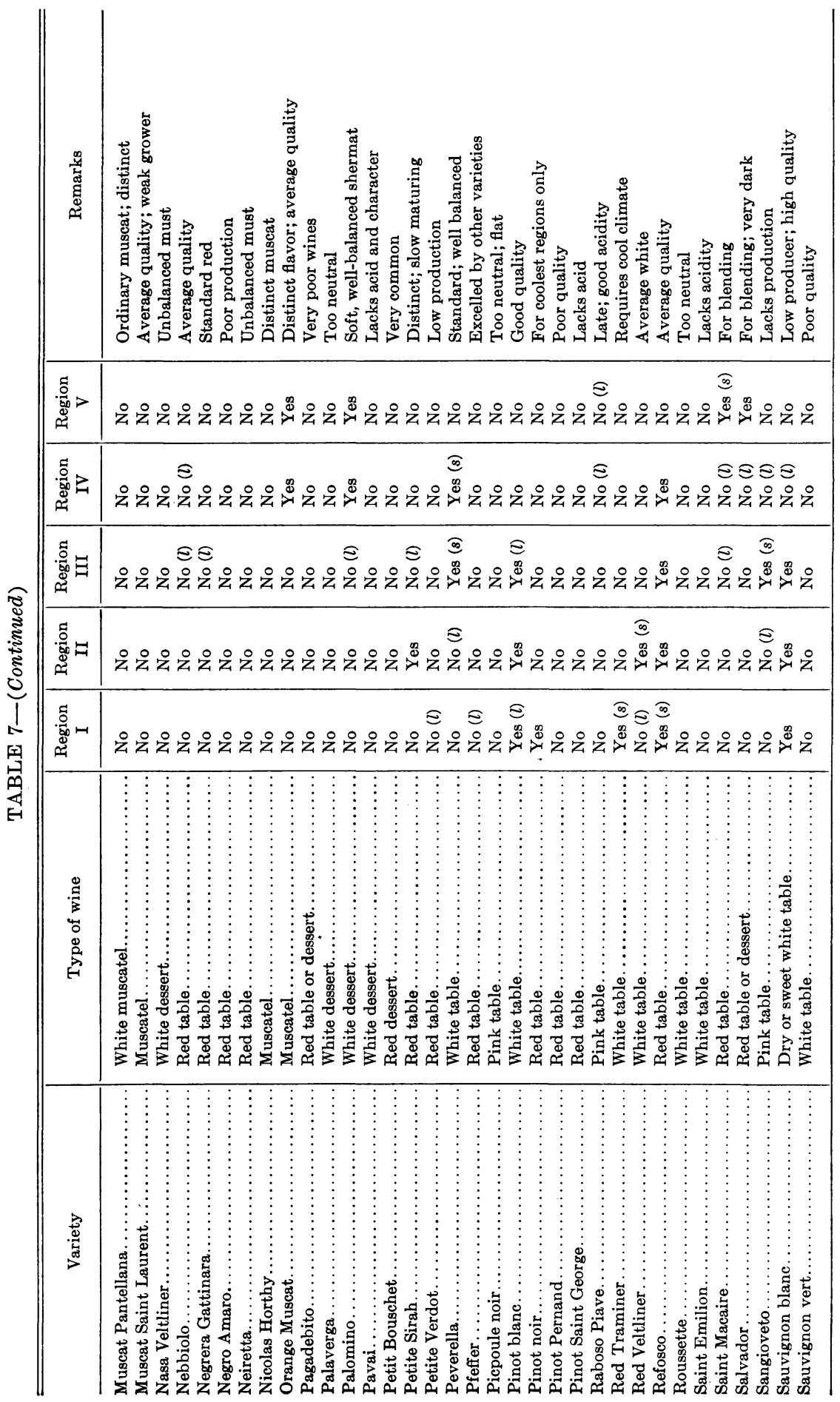




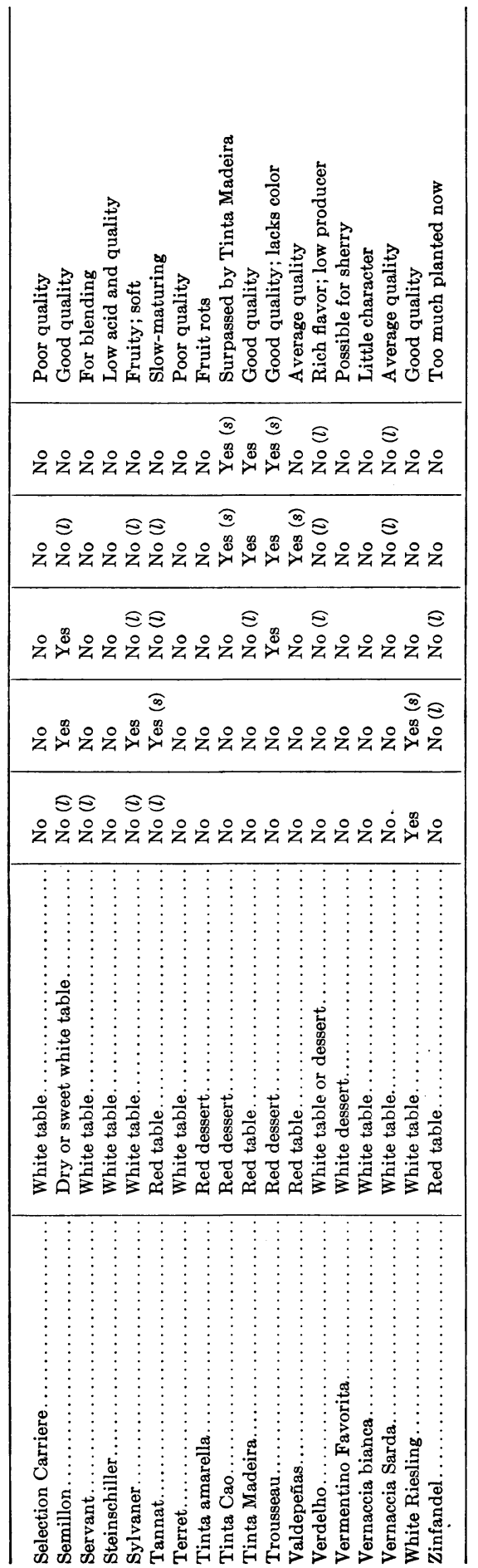




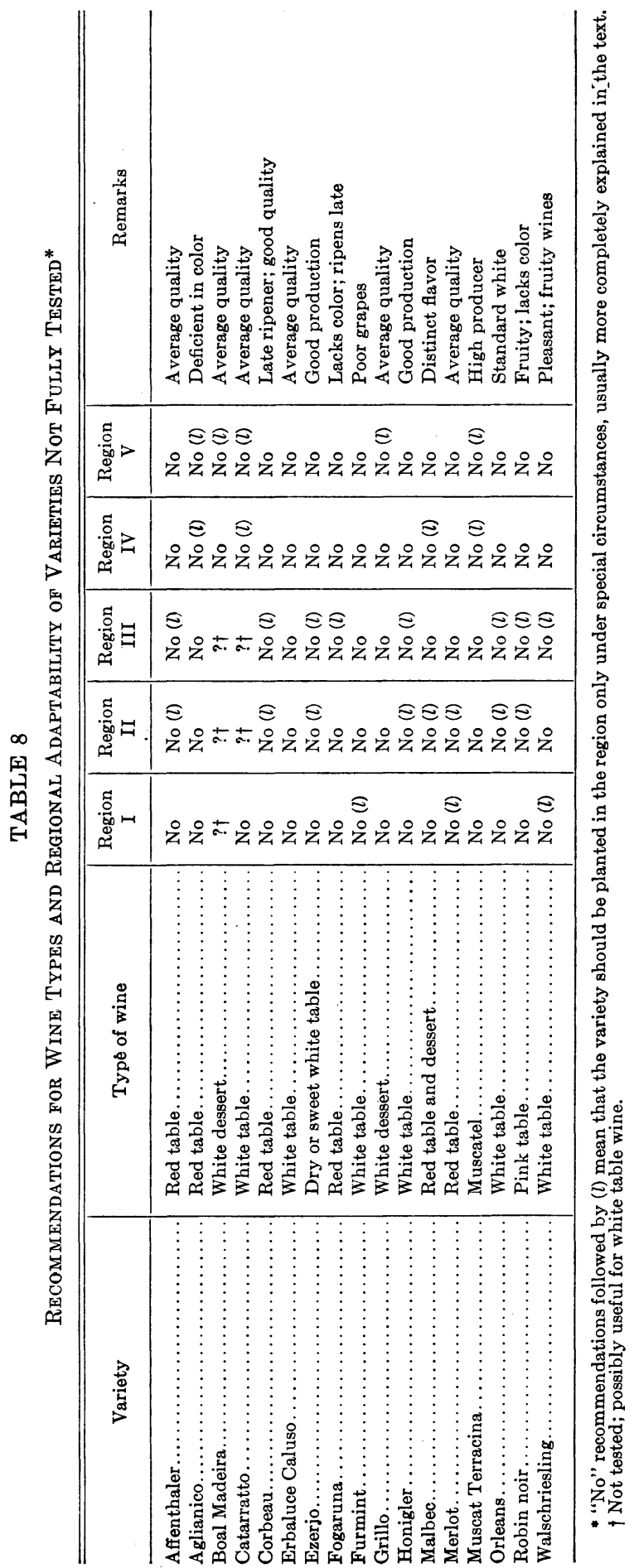


It must be remembered that these are relative values. As more information becomes available they will no doubt change, but the changes probably will be of small magnitude, arising primarily from the collection of grapes from better or poorer environmental conditions than those of the present samples. These figures will still serve as a guide for the selection and evaluation of varieties both for planting and for purchase. As they now stand, they clearly indicate one of the principal fallacies in the industry of today, namely, its failure to make sufficient price differential in the purchase of grapes of different varieties.

As stated above, the relative values for the varieties are for the region or regions to which they are best adapted. This is the only means by which the real value of the varieties for wine production can be approached. In general, the wines of a variety that possesses a high value in a cool region will lose in relative value more rapidly as it is grown in warmer and warmer areas than its productivity increases in these regions. This is well illustrated by Pinot noir, Petite Sirah, White Riesling, and others. Likewise, a variety adapted to region $\mathrm{V}$, where its table wines possess a low value, will lose in productivity, as it is grown in cooler and cooler regions, more rapidly than the relative value of its wines increases.

The relative values of varieties for wine production are further influenced by their fruiting habit and productivity. The fruiting habit of a variety may necessitate special pruning systems, and its productivity is next in importance to the quality of the wines it produces. Therefore, the recommended system of pruning for each variety, and its relative productivity, were added to tables 5 and 6.

Table 7 summarizes the varietal recommendations concerning varieties fully tested for their regional adaptation and suitability for the recognized types of wine. Table 8 gives data for varieties not fully tested. Reference to the description of each variety which follows, together with the data in tables 9 to 23 , will explain the selections more adequately.

\section{RECOMMENDED VARIETIES ${ }^{34}$}

Only varieties which produce the best wine of their type, whether standard or quality red or white table or red or white dessert wines, are recommended. For varieties which cannot be unqualifiedly recommended see page 562 .

\section{VARIETIES FOR REGION I}

Region I contains few fertile soils which are, or may well be, planted to vines. As a rule only hillside slopes of very moderate fertility are available for grapes (fig. 1). Heavy-bearing varieties should not be planted, since their production cannot compete with that of warmer and more fertile districts. In general, white varieties should be preferred to red.

(Text continued on page 533)

${ }^{34}$ The varieties collected and here listed have been in all cases, as nearly as can be determined, the same as those grown under these names in the variety collection of the University Farm at Davis. Probably not all have been correctly identified. Changes in the nomenclature of some varieties may be made, and the correct identification may be obtained by referring to later publications of this station or by writing to the Division of Viticulture, College of Agriculture, Davis. In the capitalization of variety names the authors have followed the style used in the ampelographies of Europe. 


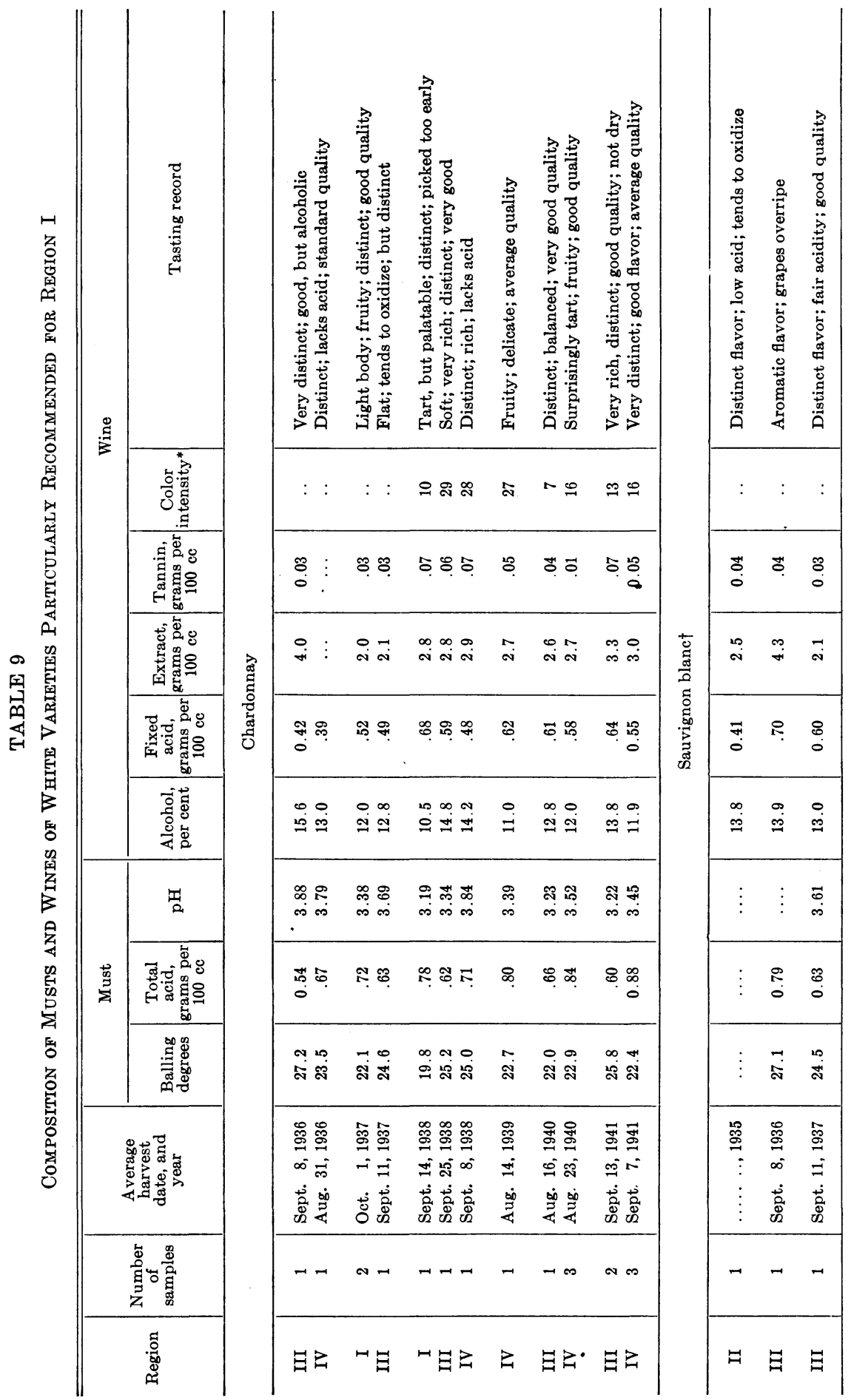




\begin{tabular}{|c|c|c|c|c|c|c|c|c|c|c|c|}
\hline 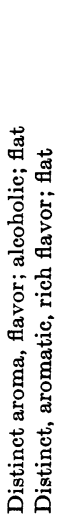 & 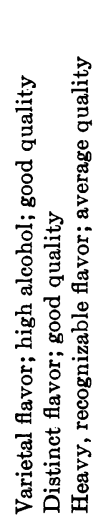 & 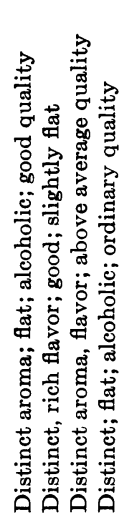 & 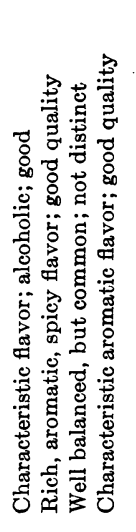 & \multirow{13}{*}{ 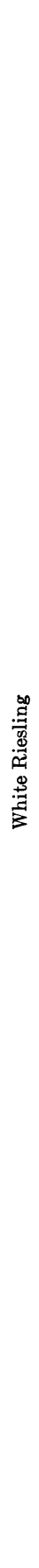 } & 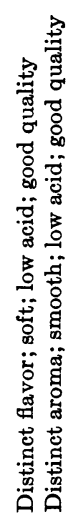 & 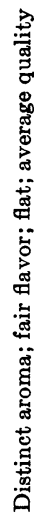 & 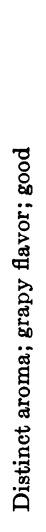 & 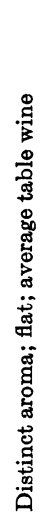 & 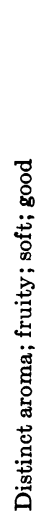 & 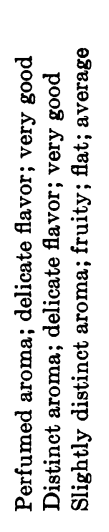 & 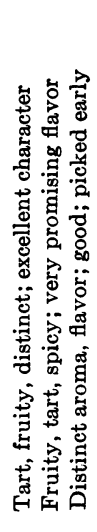 \\
\hline$\stackrel{N}{\infty} \infty$ & む゙きみ & $\Re \stackrel{\infty}{\infty} \stackrel{\infty}{\sim}$ & م & & $::$ & $:$ & : & $\approx$ & $\vec{a}$ & 209 & $\infty=0$ \\
\hline 웅 & 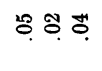 & 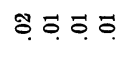 & 웅 $8 \%$ & & $\ddot{0}$ & \% & $\%$ & 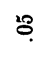 & 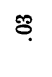 & 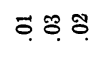 & 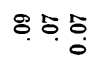 \\
\hline$\vec{a} \underset{\sim}{a}$ & $\stackrel{0}{\sim} \stackrel{0}{-i}$ & 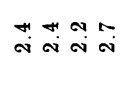 & 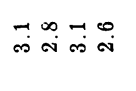 & & $\vec{a} \underset{i}{0}$ & $\stackrel{\circ}{i}$ & $\vec{a}$ & $\stackrel{\infty}{i}$ & $\stackrel{\infty}{i}$ & ๙̃. & 華 \\
\hline भ̆ के & 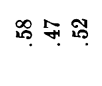 & 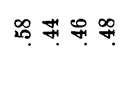 & 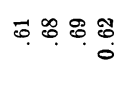 & & $\underset{0}{0}$ & "艹 & $\Re$ & $\Re$ & \& & 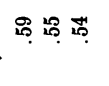 & 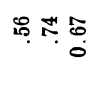 \\
\hline 蕰 & 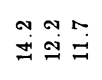 & 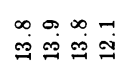 & 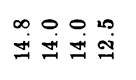 & & $\exists \stackrel{0}{=}$ & $\ddot{\infty}$ & $\stackrel{+}{\Xi}$ & $\stackrel{9}{=}$ & $\stackrel{\sim}{\cong}$ & 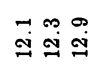 & 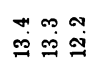 \\
\hline $\begin{array}{l}\infty \\
\substack{\infty \\
\infty} \\
\infty\end{array}$ & 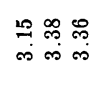 & 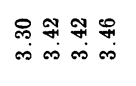 & 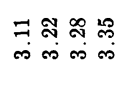 & & & $\underset{+i}{\Delta}$ & $\underset{\infty}{F}$ & $\underset{\infty}{\infty}$ & $\stackrel{2}{\infty}$ & 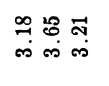 & 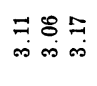 \\
\hline স্ণ & 꿈우용. & 추 8 的 & 우 $\stackrel{0}{0} \underset{0}{\infty} \stackrel{R}{R}$ & & $:_{\stackrel{\circ}{0}}$ & I! & $E$ & ஜุ & $?$ & ำ & ஜำ \\
\hline 象。 & 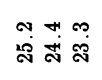 & 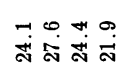 & 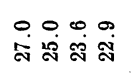 & & : & $\stackrel{\leftrightarrow}{\mathscr{\infty}}$ & สิ่ & 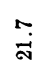 & $\ddot{\circ}$ & 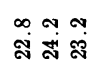 & ڤุ \\
\hline 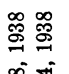 & 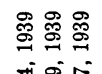 & 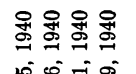 & 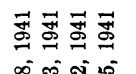 & & 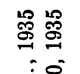 & 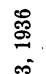 & $\begin{array}{l}\hat{\mathscr{g}} \\
\stackrel{\sigma}{\sigma}\end{array}$ & $\frac{\infty}{\mathscr{\Phi}}$ & $\underset{\mathscr{g}}{\stackrel{\mathscr{g}}{=}}$ & 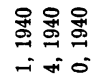 & 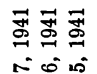 \\
\hline ثं & 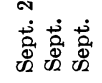 & 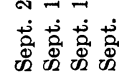 & 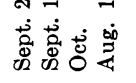 & & 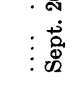 & 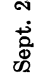 & ठ் & $\dot{\Xi}$ & 我 & 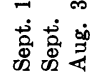 & 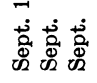 \\
\hline$\rightarrow-1$ & $\neg \neg N$ & $\neg \infty \infty$ & - & & $-\infty$ & N & + & $\omega$ & N & $\rightarrow r$ & 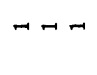 \\
\hline 可 & ま刍 & w & 曰ヨ & & 日曰 & B & $Z$ & $Z$ & $Z$ & 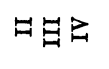 & Z \\
\hline
\end{tabular}




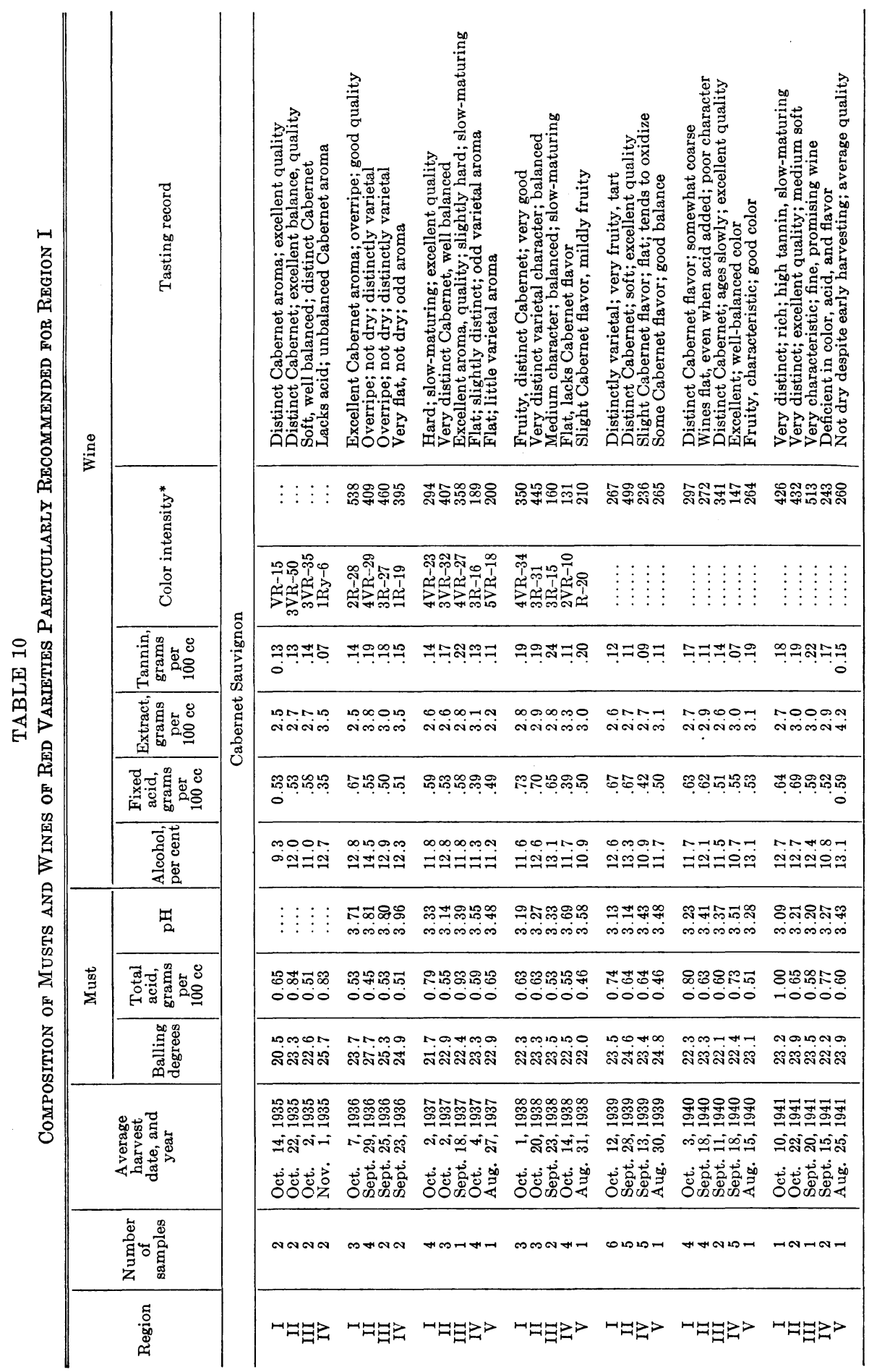




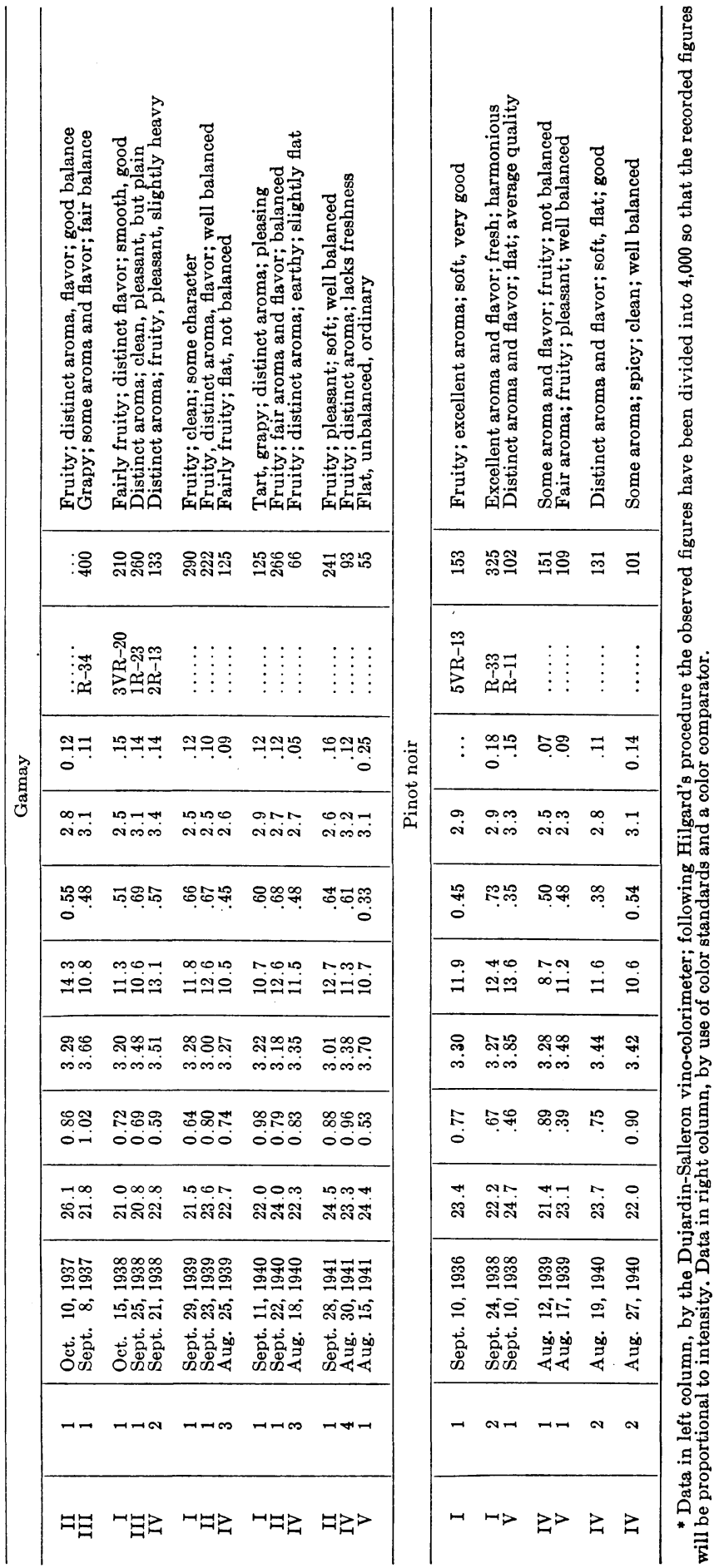




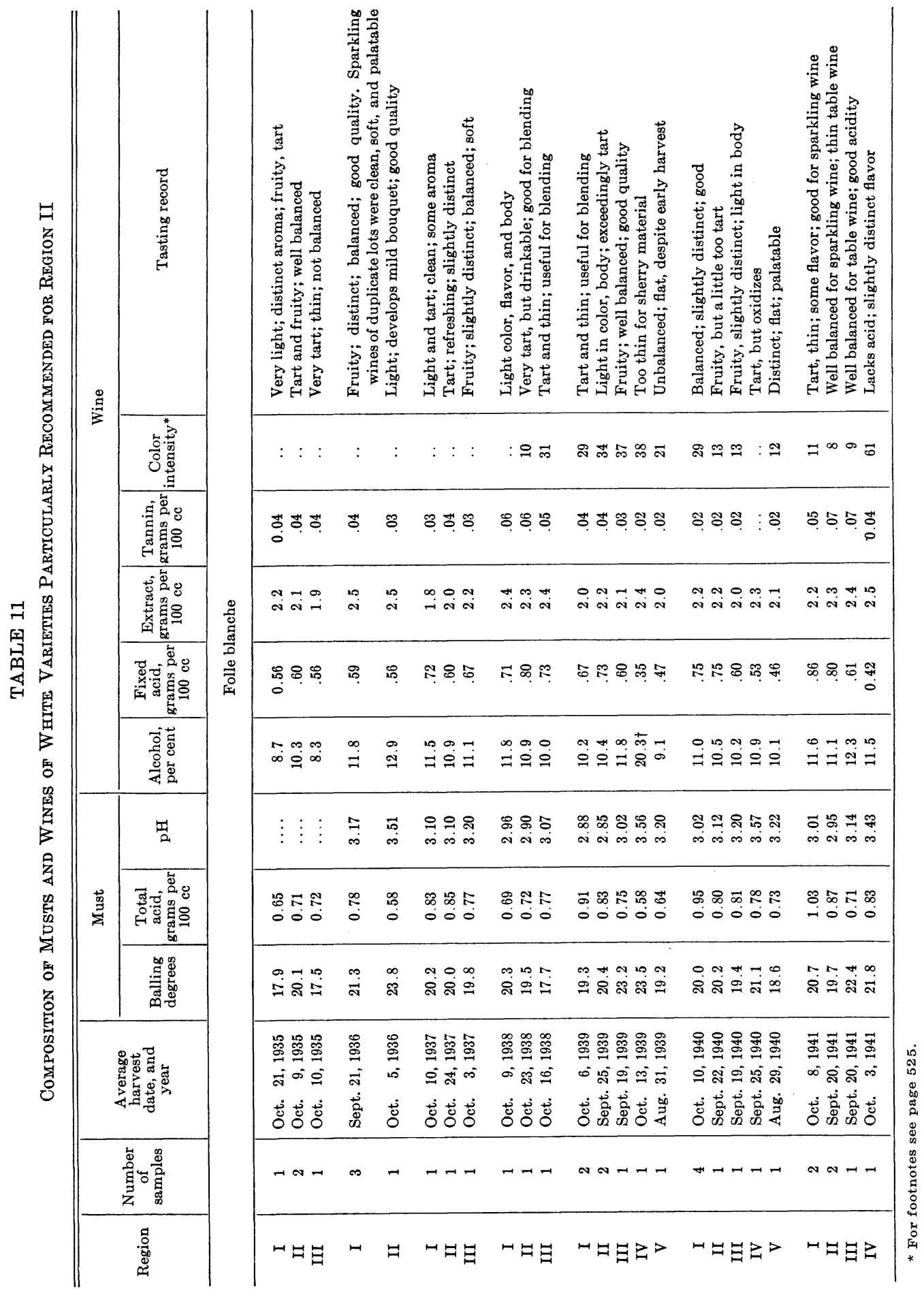




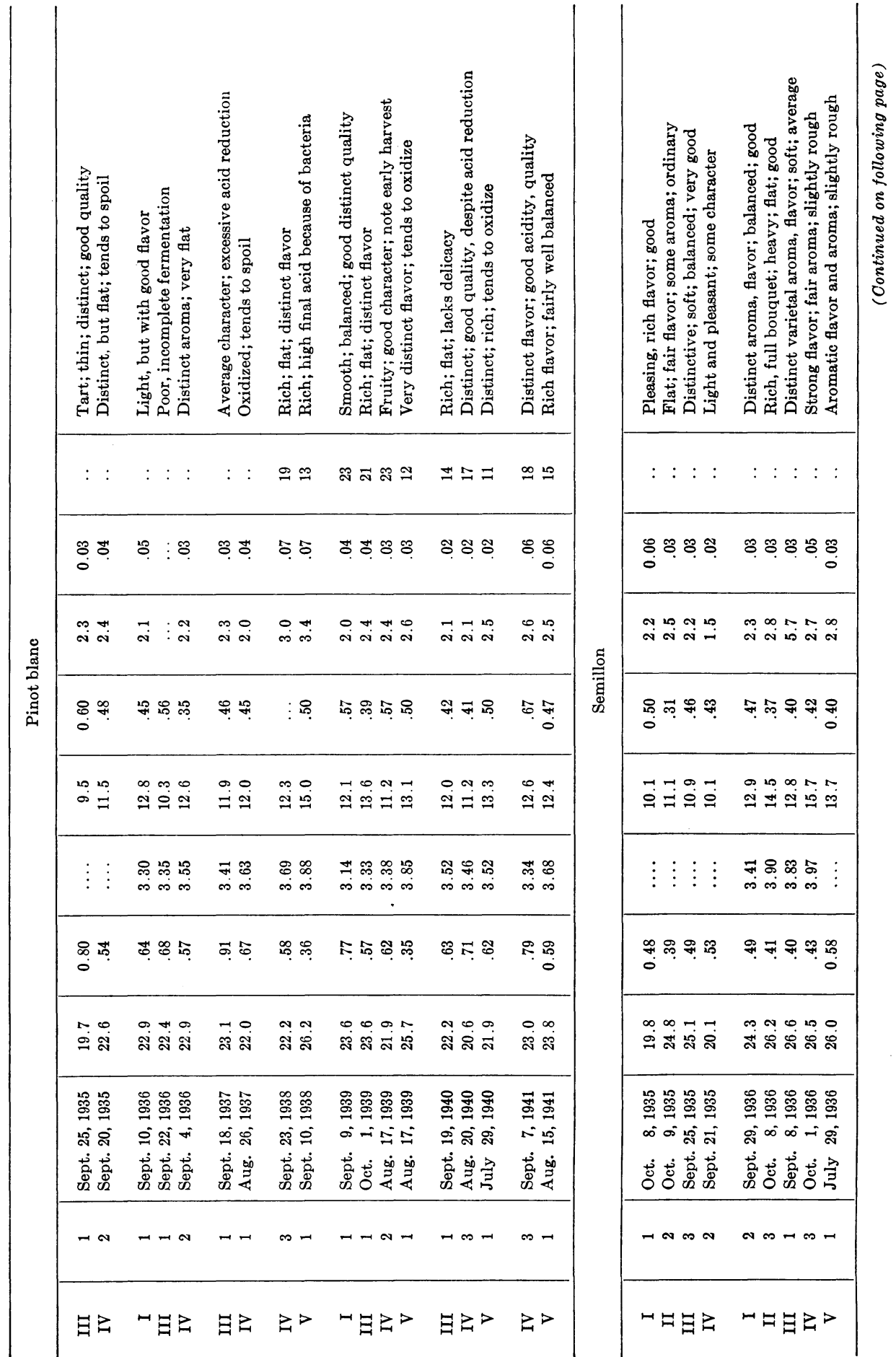




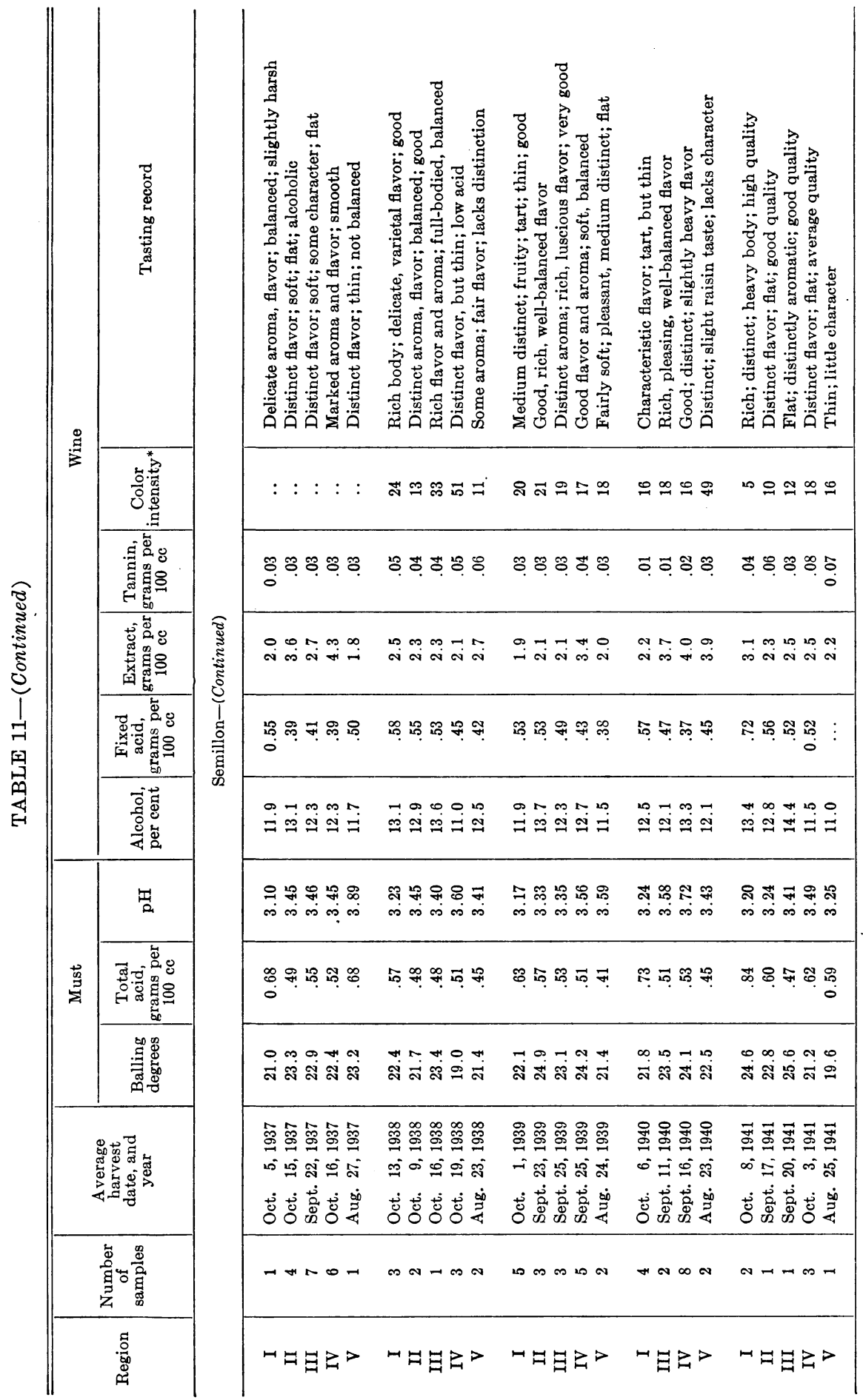




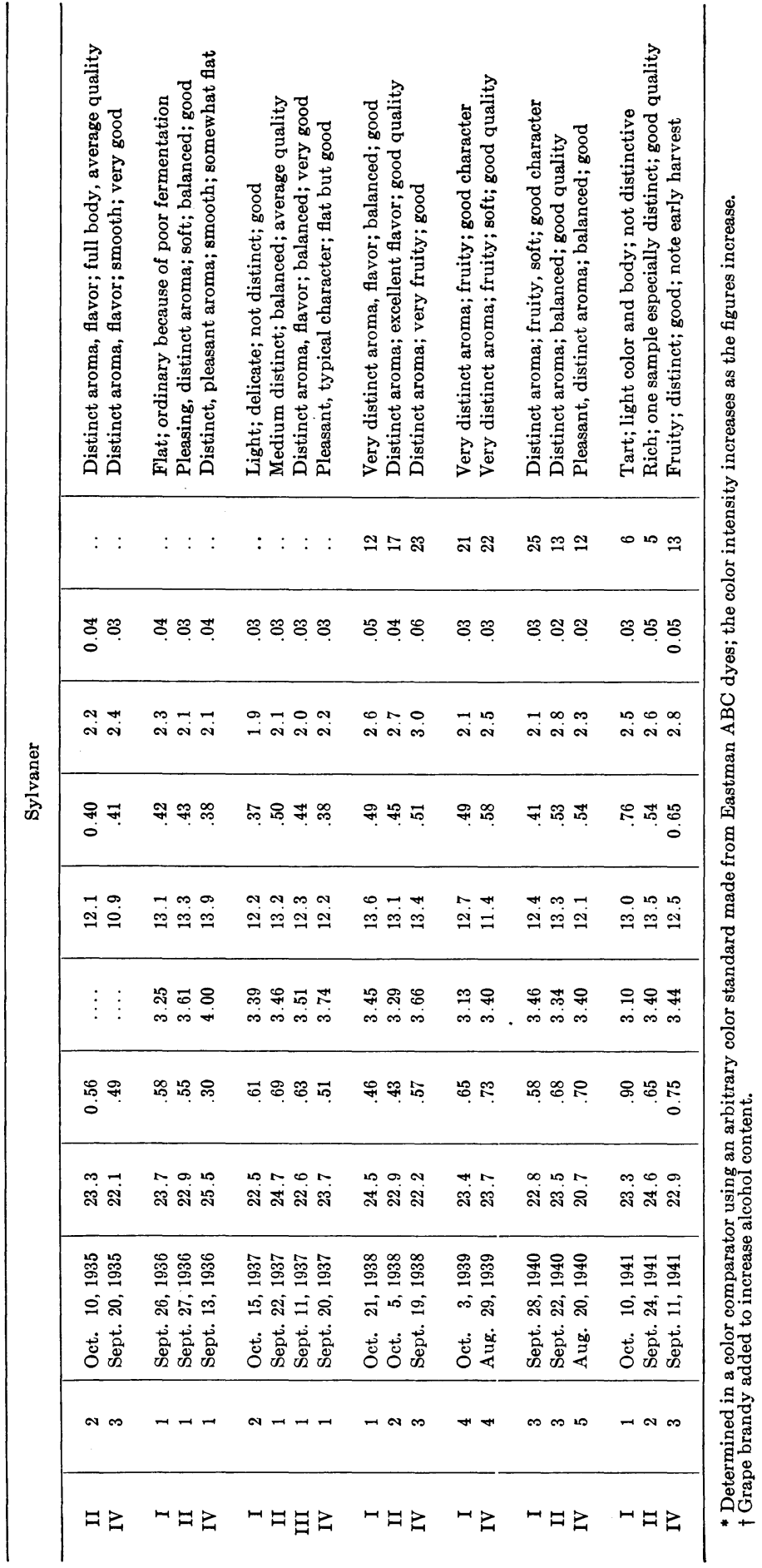




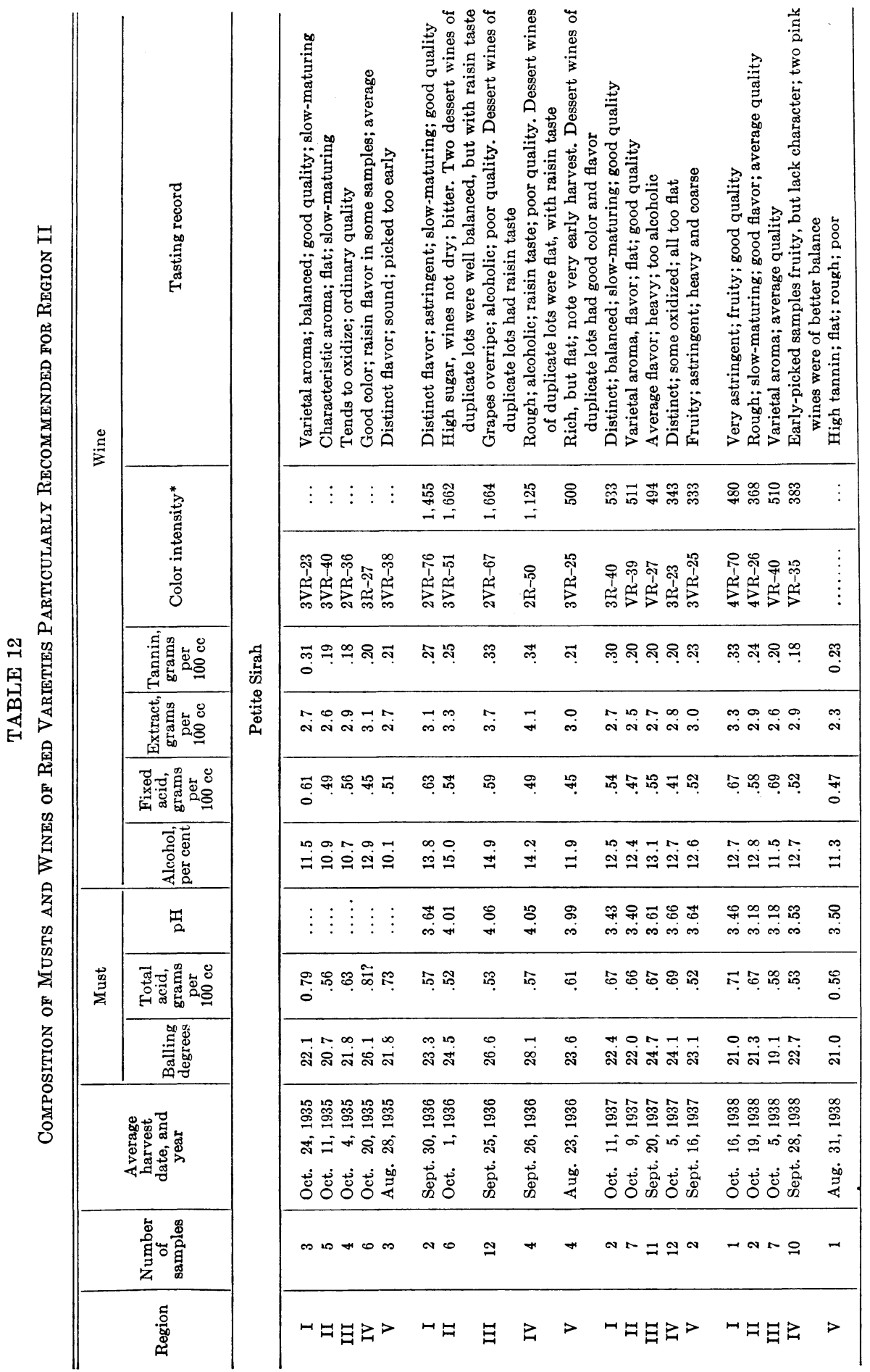




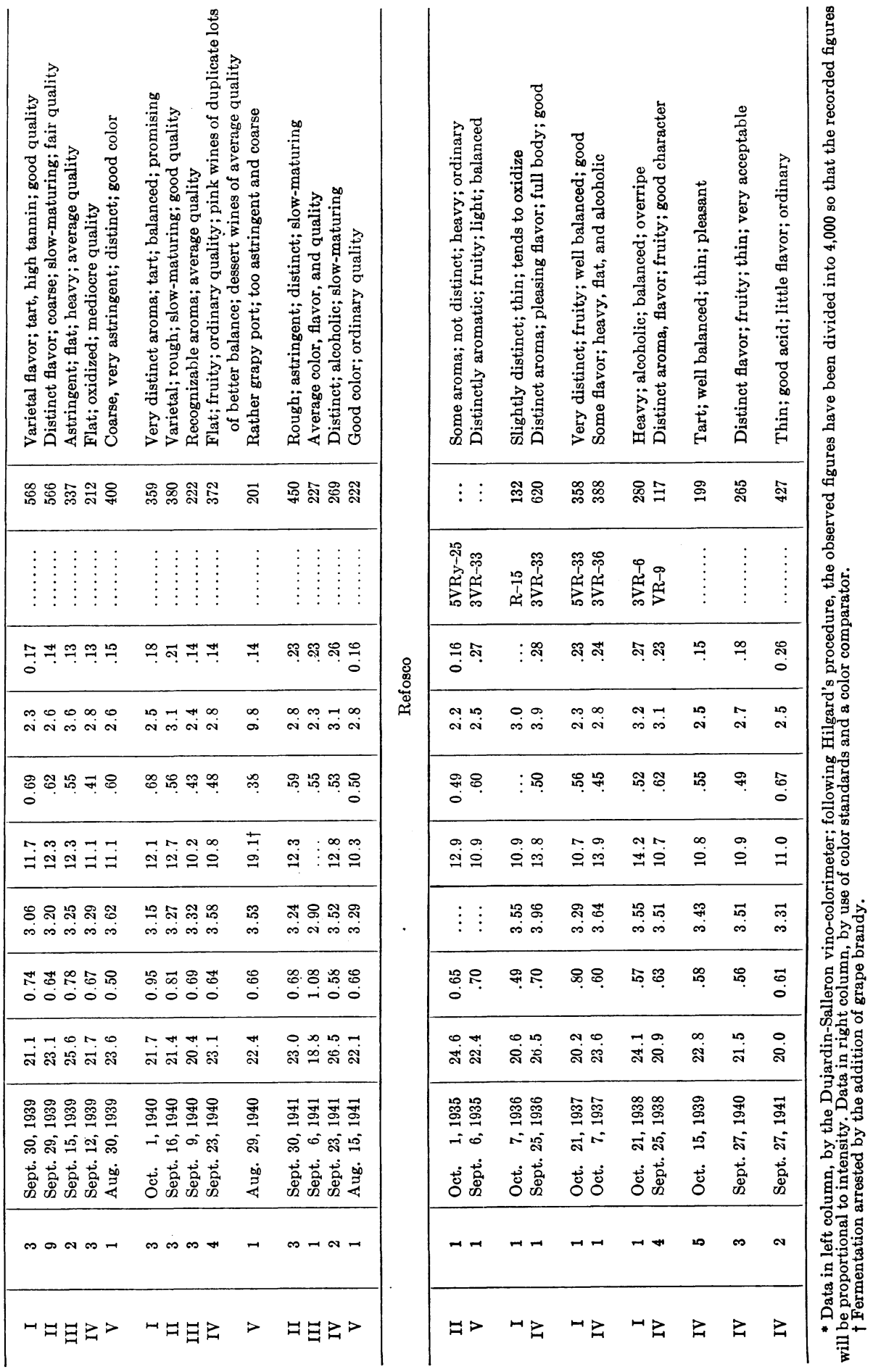




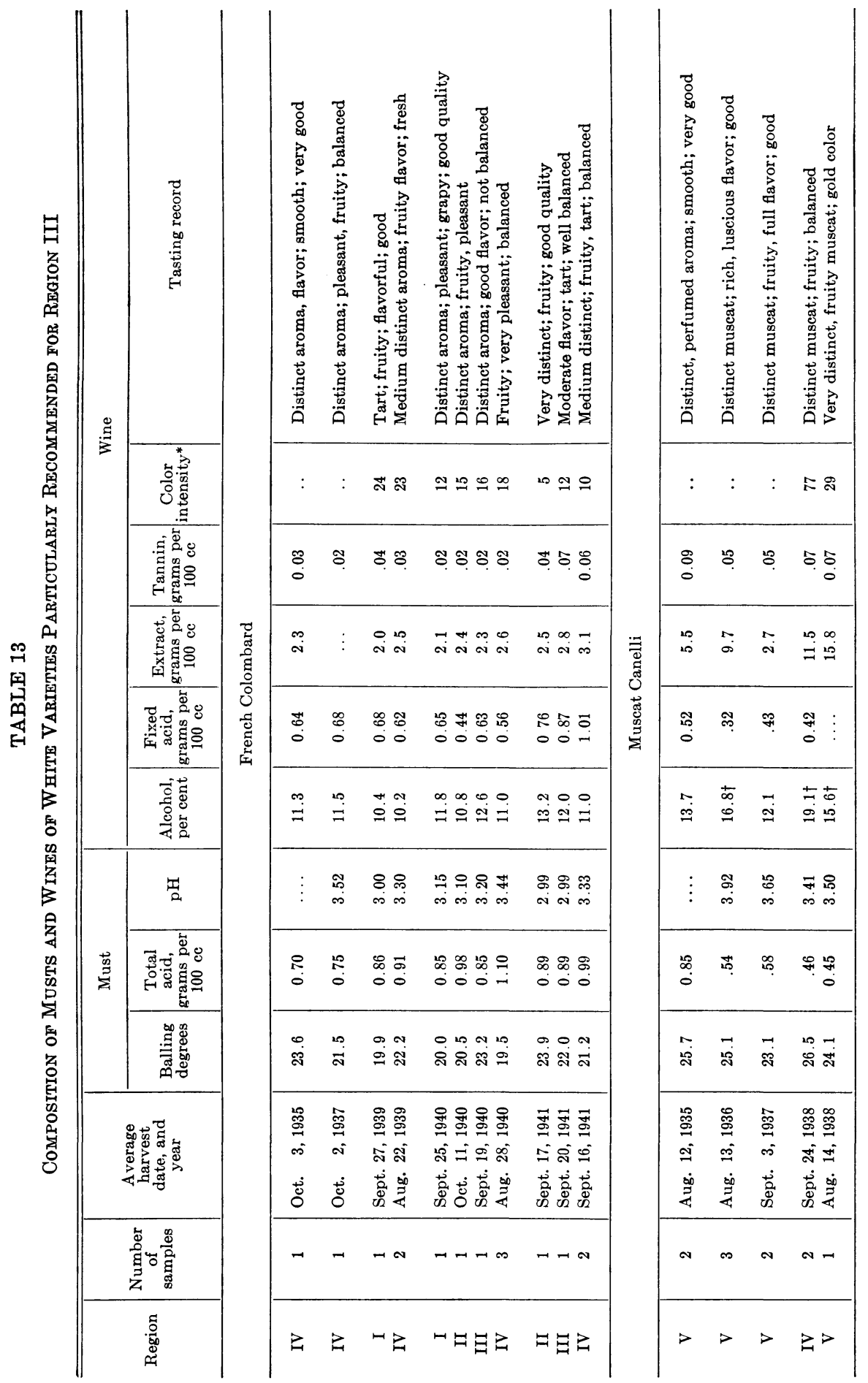




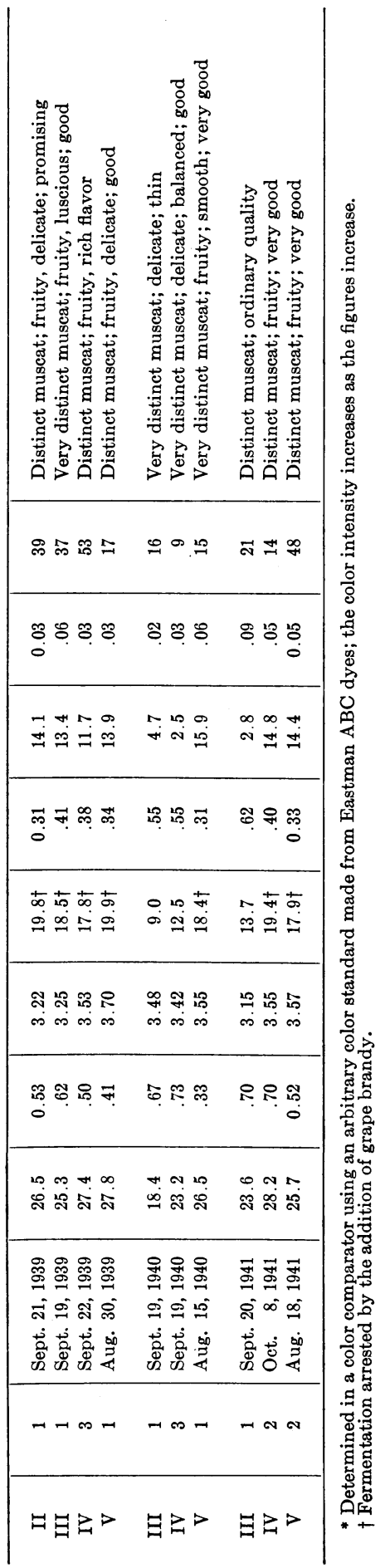




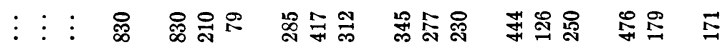

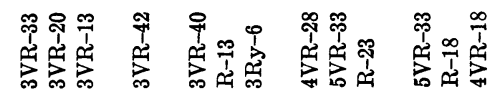

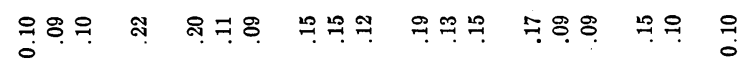

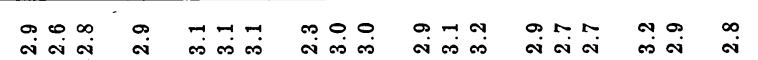

$\operatorname{los}$

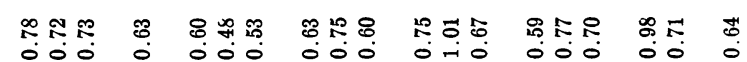

no.

号怘品 莳

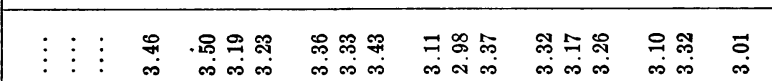

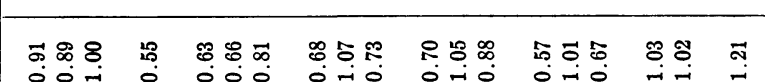

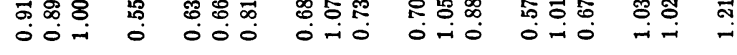

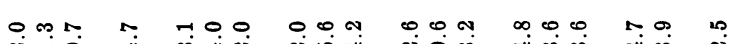

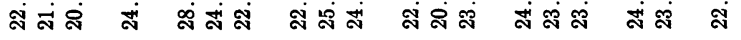

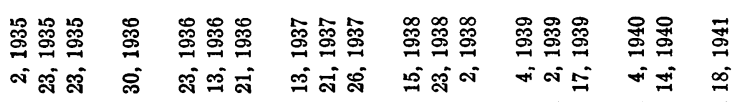

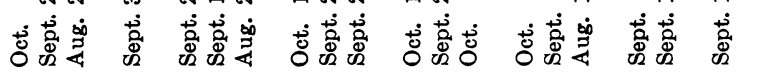

舟

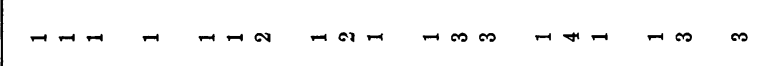

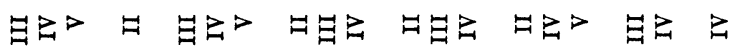




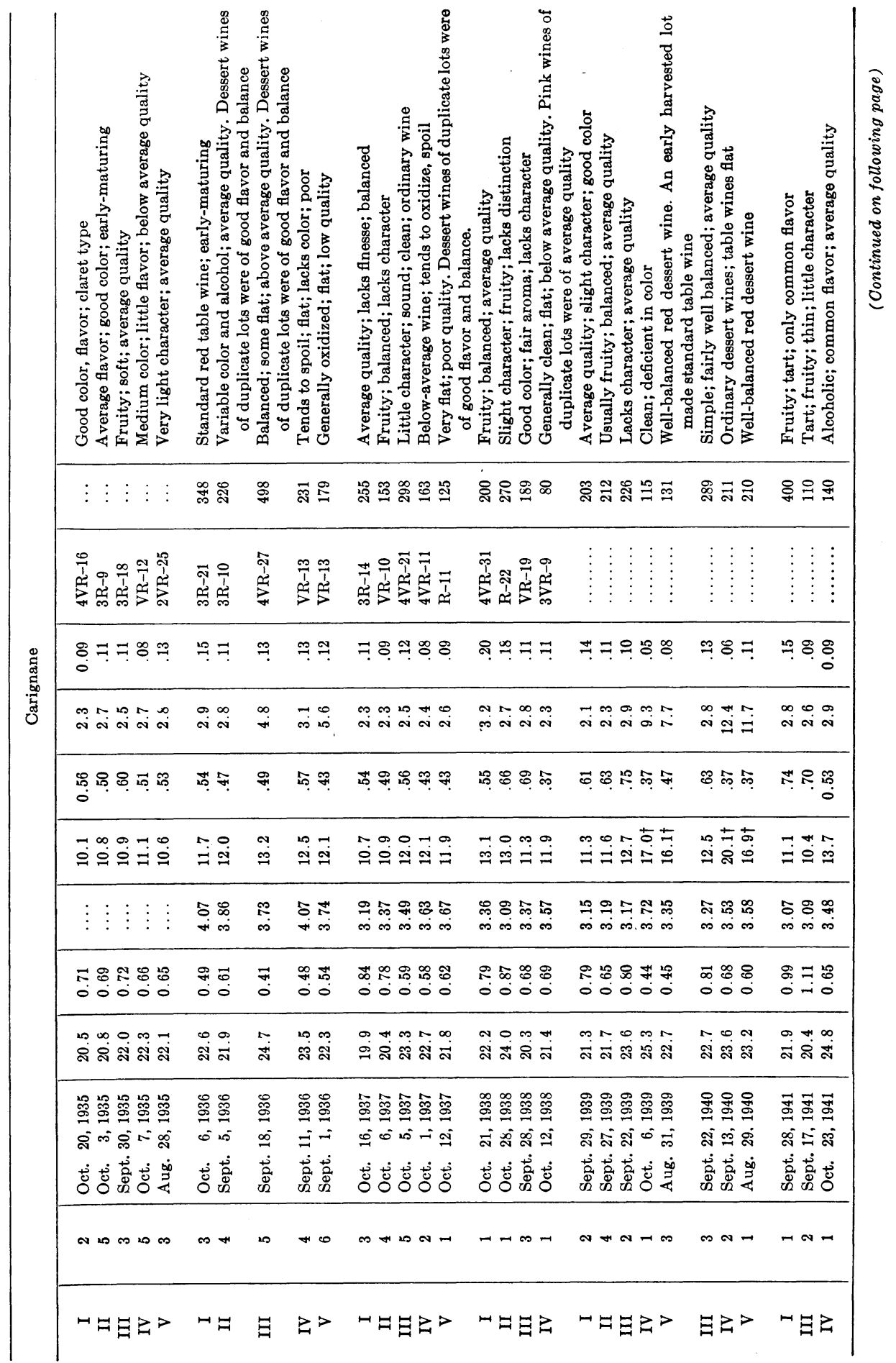




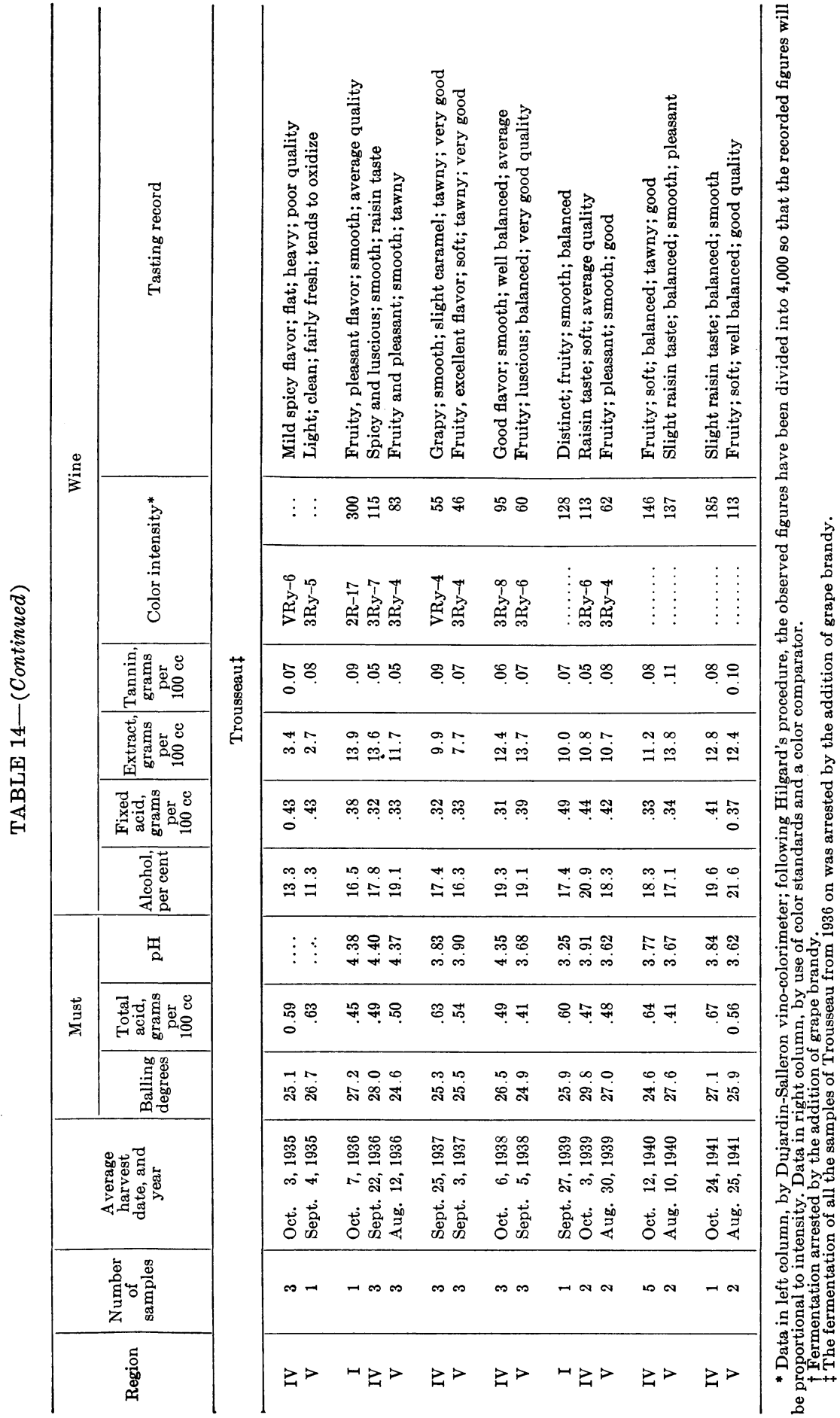


White Varieties.-Recommended white varieties for high-quality dry table wines are White Riesling, Chardonnay, and Sauvignon blanc, the first two being the most desirable. Red Traminer is useful but should be planted only in the very coolest locations for producing an aromatic wine. Sylvaner is not recommended for this region, since it is so susceptible to mildew in foggy locations. Varieties such as Burger and Folle blanche should be avoided, since they will not ripen. Table 9 gives analyses of the recommended varieties.

Red Varieties.-Recommended red varieties for high-quality table wines are Cabernet Sauvignon and Pinot noir; and for standard or blending table wines are Gamay and Grenache.

Table 10 gives analyses of musts and wines of these varieties collected from the various regions, except for the Grenache (table 17).

\section{VARIETIES FOR REGION II}

In region II may be found both valley-floor vineyards and hillside vineyards. The former should produce most of the standard red and white table wines of California; the less productive hillside vineyards, though unable to compete for standard wines, can nevertheless produce fine wines.

White Varieties.-Recommended white varieties for high-quality dry table wines are Pinot blane, White Riesling, and Sauvignon blanc (usually for natural sweet wine); and for standard, special, or blending dry table wines are Semillon (for dry or natural sweet wine), Sylvaner, and Folle blanche. Red Veltliner is useful but less desirable.

Table 11 gives analyses of musts and wines of the recommended varieties collected from this and the other regions except for the White Riesling and Sauvignon blanc (see table 9).

Red Varieties.-The recommended red variety for high-quality table wines is Cabernet Sauvignon.

Recommended red varieties for standard, special, or blending wines are Grenache, Petite Sirah, and Refosco. Also possible but less desirable are Mondeuse and Tannat.

Table 12 gives the analyses of musts and wines of the recommended varieties from various regions except for Cabernet Sauvignon (table 10) and Grenache (table 17).

\section{VARIETIES FOR REGION III}

The warm conditions of region III favor the production of grapes of greater sugar content without too much sunburning and too little acidity, which may occur in still warmer regions. Most of the vineyards are on fairly flat land, but some of the soils are rocky and of low productivity. The better-quality natural sweet wines come from the latter soils. It is a mistake to hope for $d r y$ wines of the finest quality in this region, even on the less fertile soils, since betterbalanced wines of this quality can be had in regions I and II. However, excellent natural sweet wines should be produced. Good standard whites and reds also can be produced on the more fertile soils. Trousseau, though not particularly recommended on account of the cost of production, will produce very good red dessert wines in this region.

White Varieties.-Recommended white varieties for natural sweet wines are Semillon, Sauvignon blanc, and Muscat Canelli (by itself). Not ordinarily recommended are Chenin blanc and Muscadelle (by itself). 


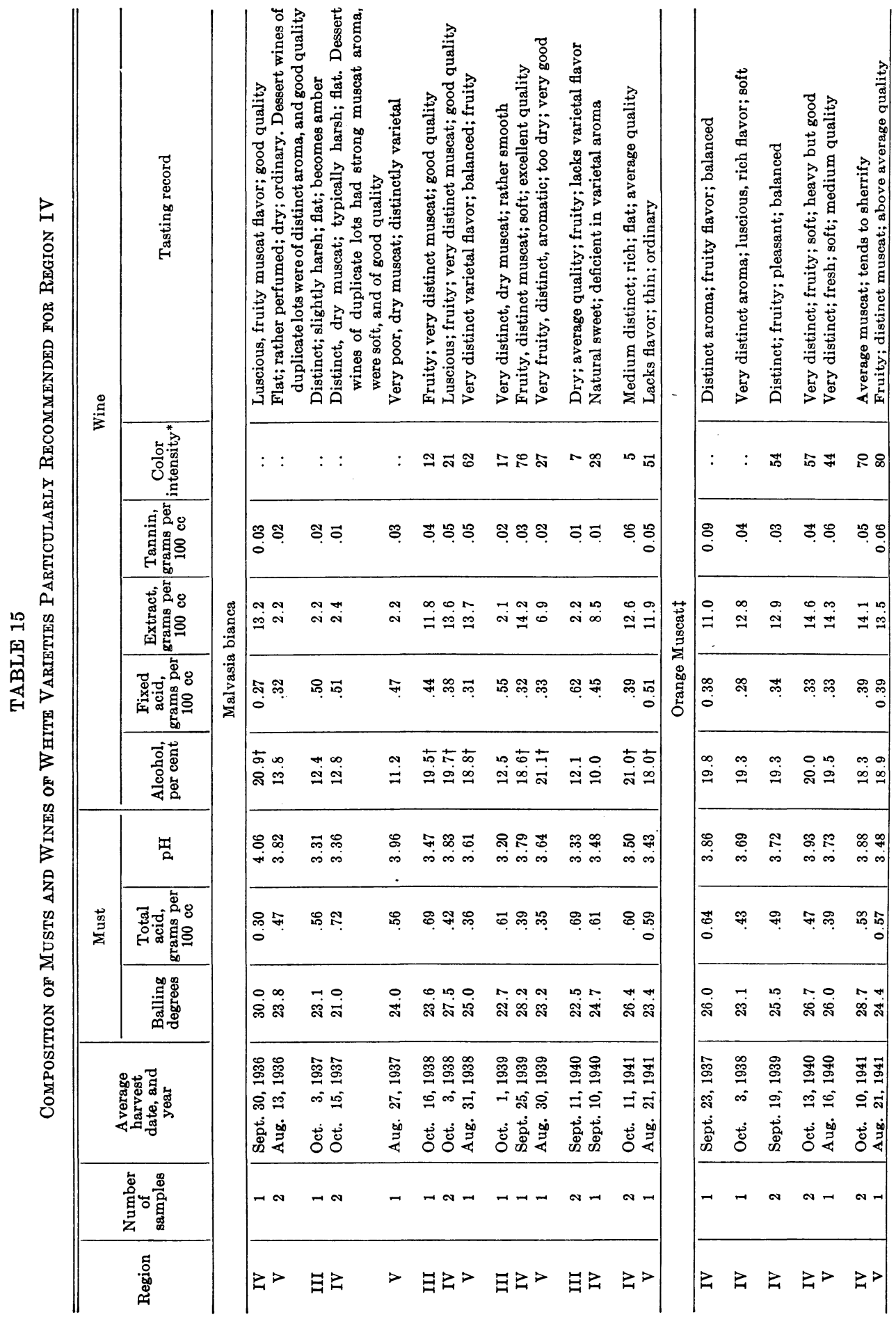




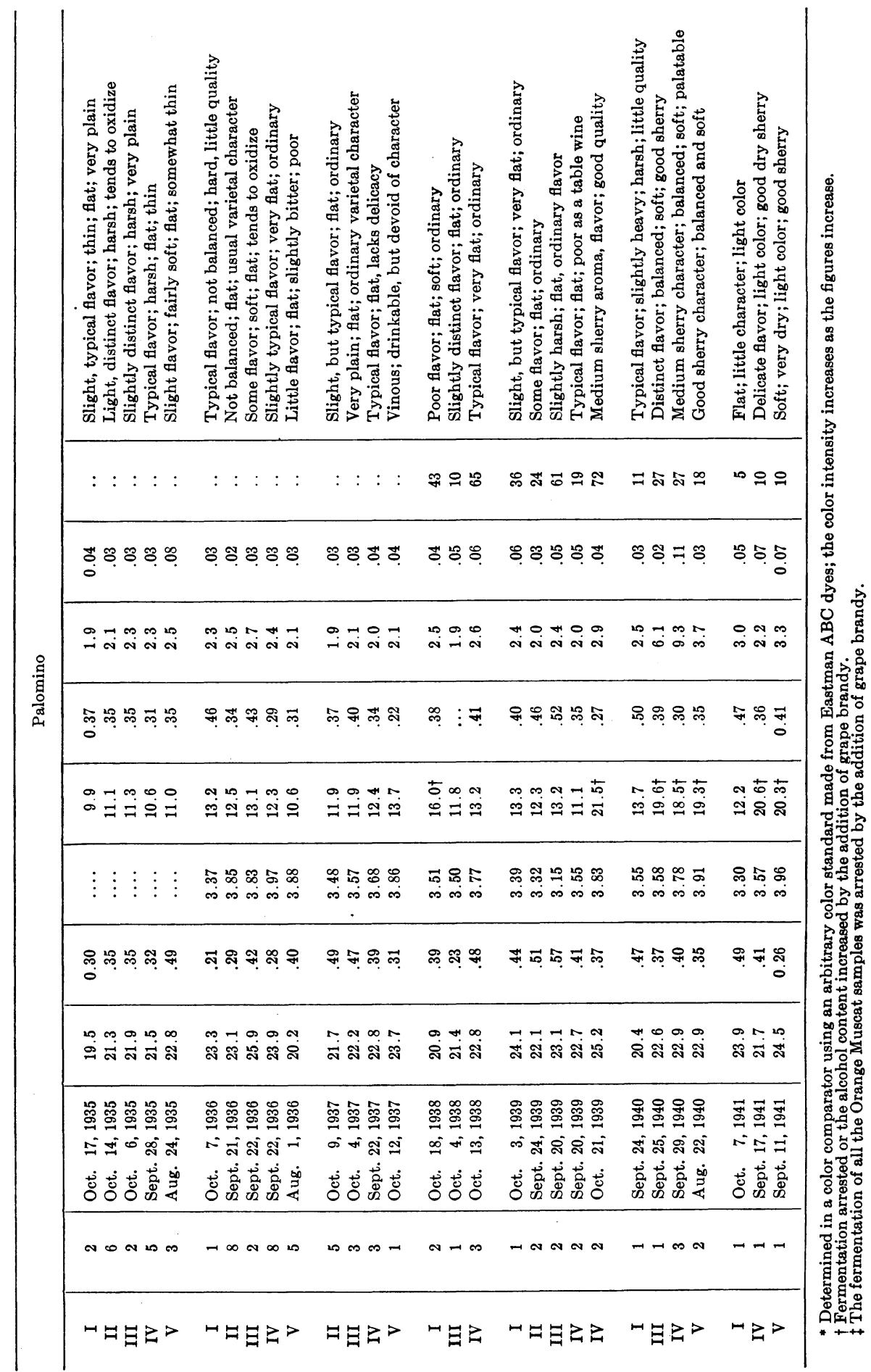




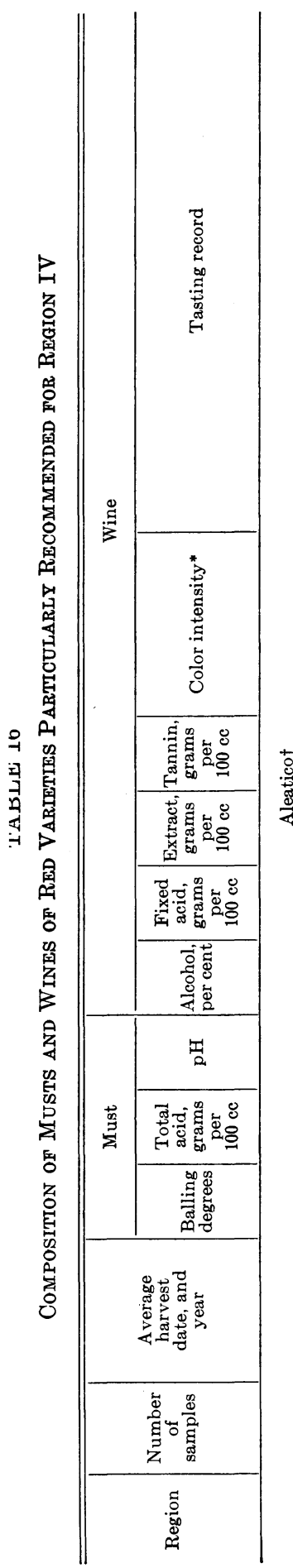

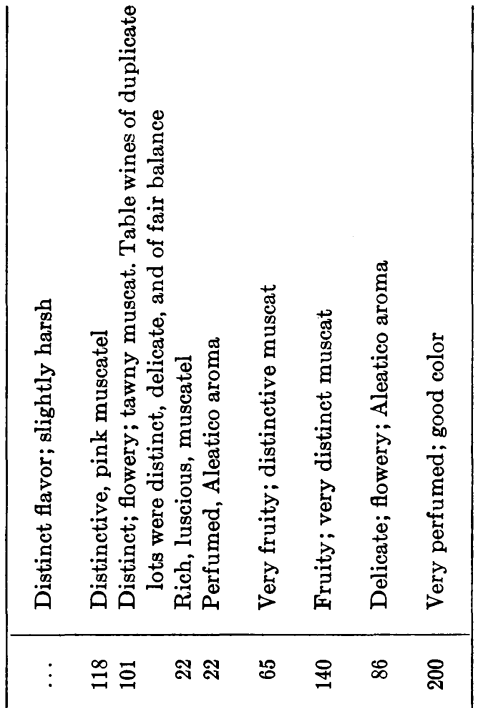

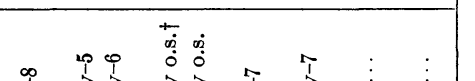

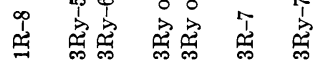

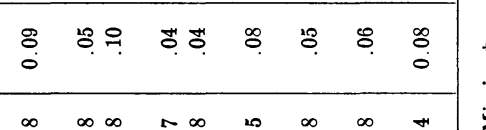

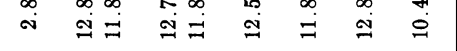

\begin{tabular}{|c|c|c|c|c|c|c|c|}
\hline 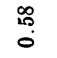 & 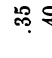 & & & $\mathscr{H}$ & \& & 유 & \& \\
\hline
\end{tabular}

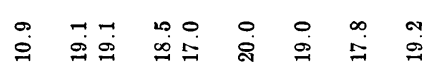

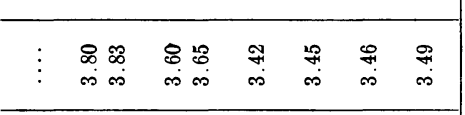

舫

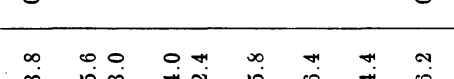

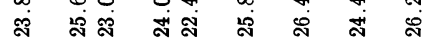

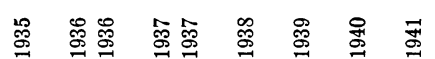

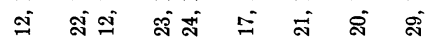

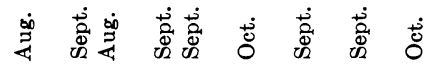

A ผ

$P B D B Z Z B$

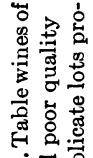

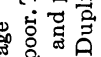

在

西完解

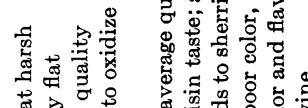

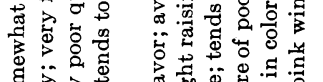

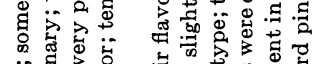

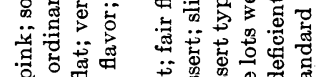

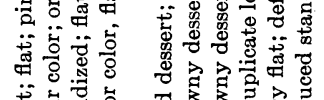

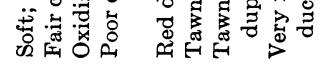

$\vdots \vdots \vdots \quad \cong \quad$

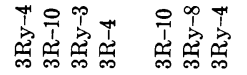

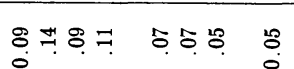

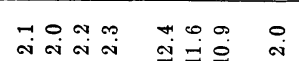

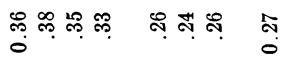

ח ח

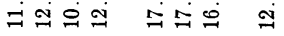

$\vdots \vdots \vdots \vdots$ 㔖

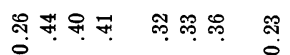

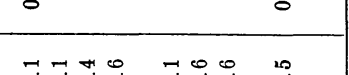

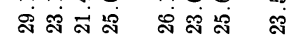

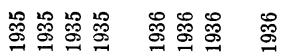

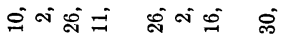

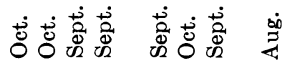

\begin{tabular}{|c|c|c|}
\hline$\neg-\infty N$ & $\rightarrow-\infty$ & N \\
\hline ・EZ〉 & 曰ヨ己 & $>$ \\
\hline
\end{tabular}




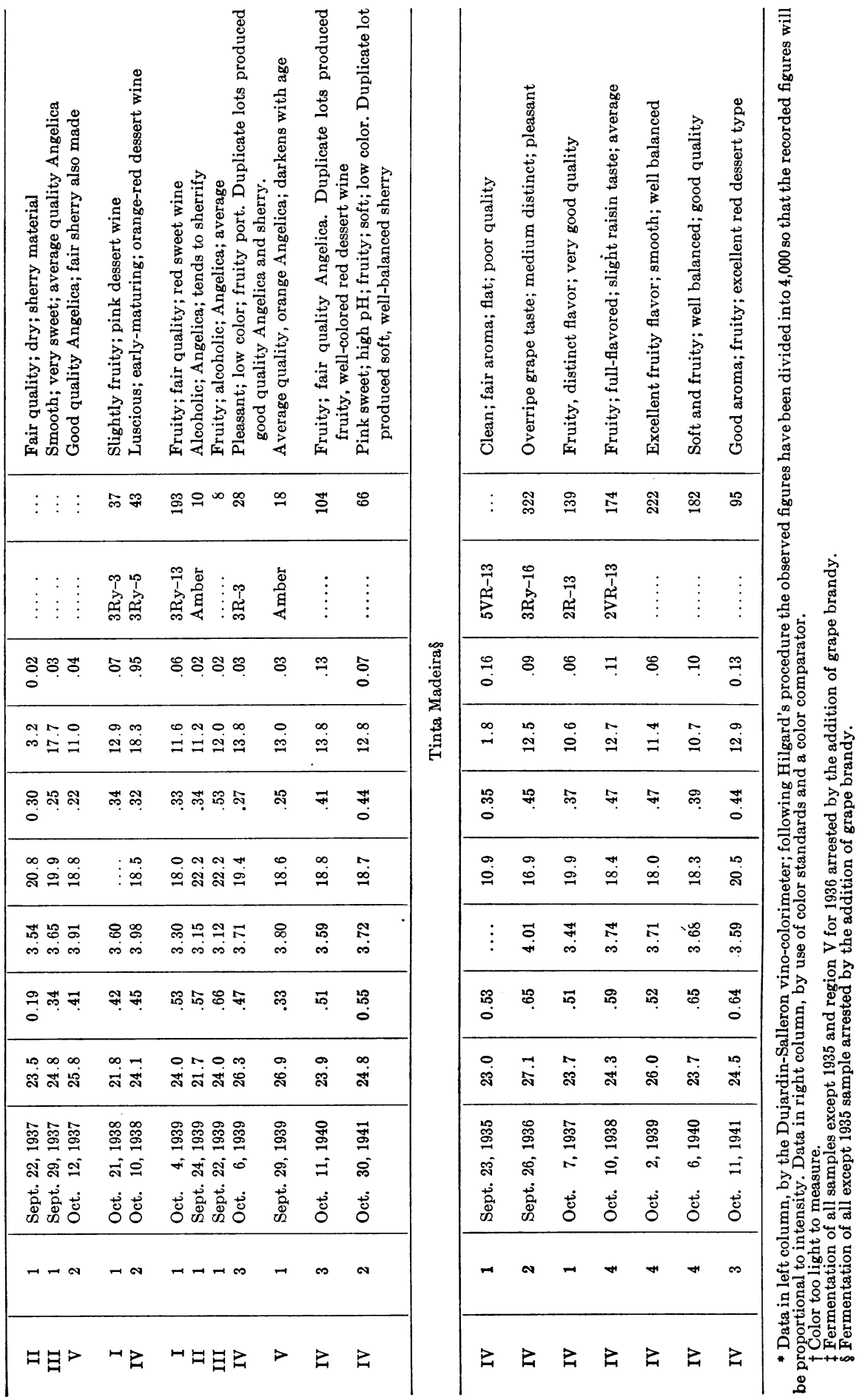




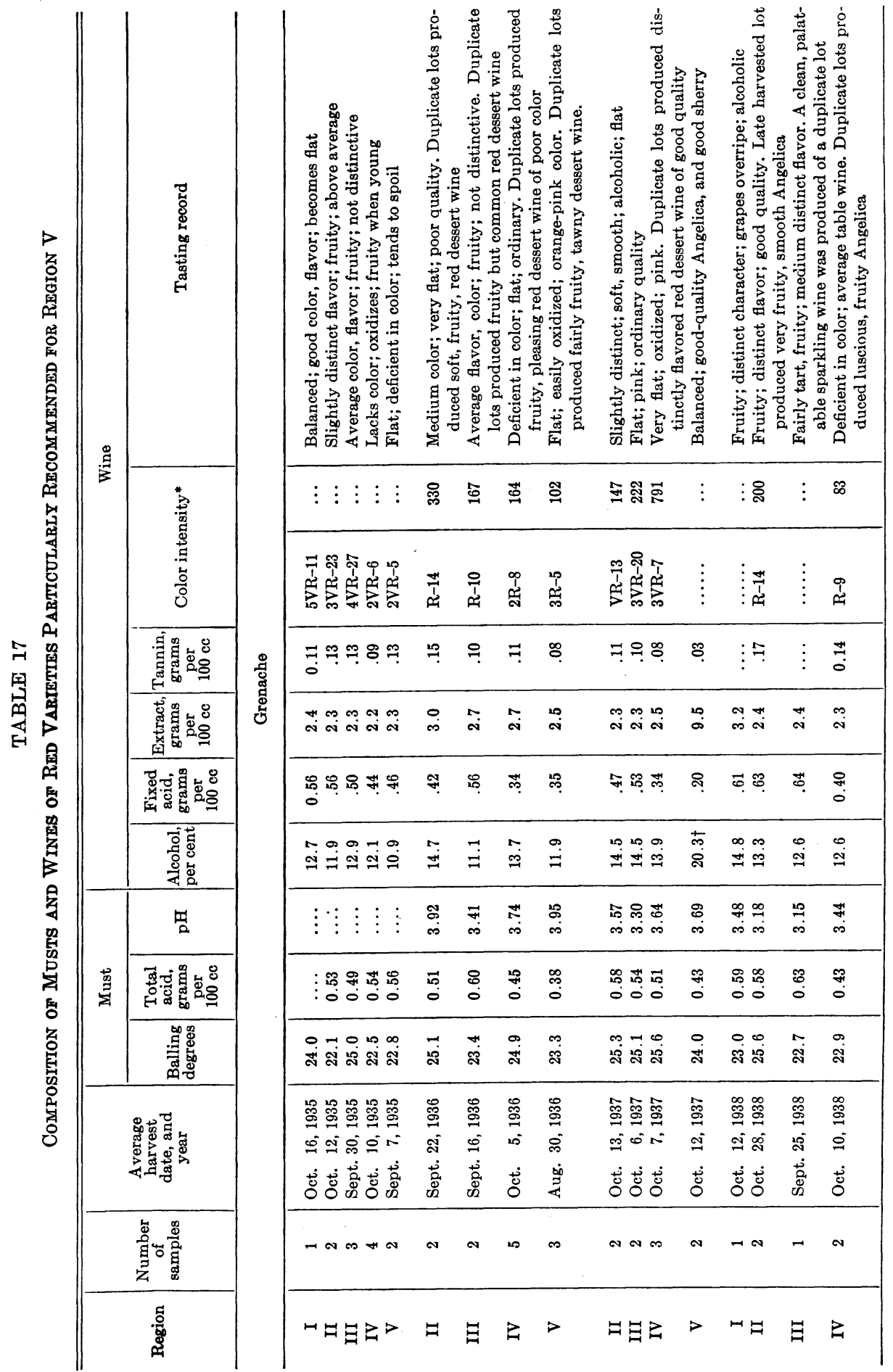




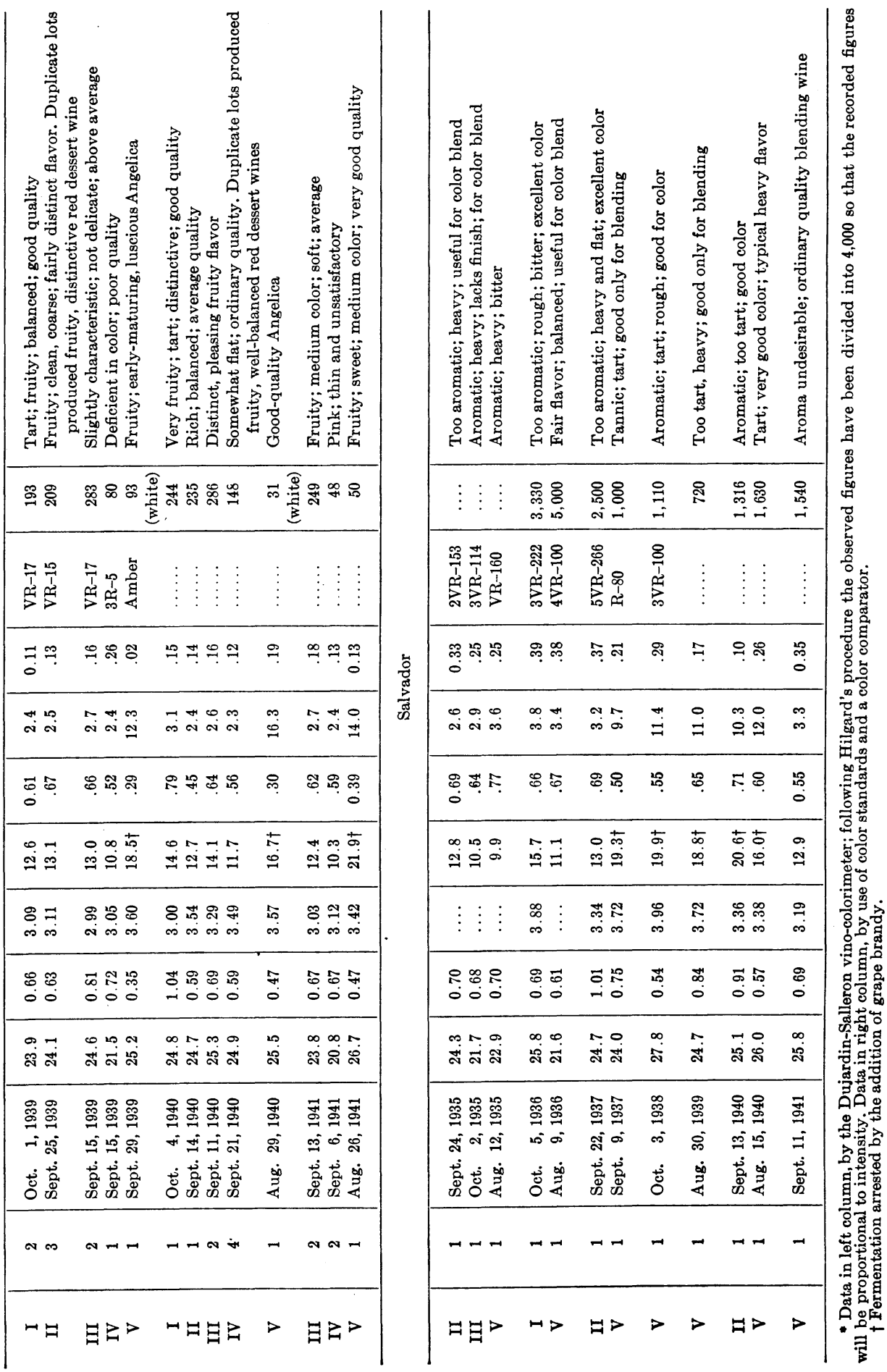


Recommended white varieties for standard, special, or blending wines are French Colombard and Pinot blanc. Also possible but not ordinarily recommended are the Folle blanche and Peverella.

Table 13 gives the analyses of musts and wines of the recommended white varieties from various regions of California except for Sauvignon blanc and Semillon. (See tables 9 and 11.)

Red Varieties.-Recommended red varieties for standard, special, or blending table wines are Barbera, Carignane, and Refosco. Also possible but less desirable are Gros Manzenc and Sangioveto.

The recommended red variety, if a red dessert wine is to be produced in this region, is Trousseau.

Table 14 gives the analyses of musts and wines of the recommended red varieties except for Refosco. (See table 12.)

\section{VARIETIES FOR REGION IV}

The soils of region IV are usually fertile. Most vineyards there are irrigated and are capable of producing large crops. Certain vineyards of the foothills on the sides of the Sacramento and San Joaquin valleys fall, however, into this climatic zone. It is questionable whether these low-producing vineyards should be planted to grapes at all, since they cannot compete successfully with the fertile, irrigated valley soils. Bioletti ${ }^{35}$ summarized the recommendations for these foothill regions in the report for 1895-96 and 1896-97. The lack of production and the temperature conditions prevent the production of highquality table wines or of cheap blending wines. That superior dessert wines might be produced was a possibility in his opinion.

Although natural sweet wines are possible here, in warm years the suitable grapes will become sunburned and raisined. White dessert wines can be produced, however, as well as good red dessert wines. The standard white and red table wines from this district are fairly satisfactory if produced from highacid varieties.

White Varieties.-The recommended white variety for standard-quality table wine is the French Colombard. Peverella is also possible. (See p. 543 and 574.)

Recommended varieties for muscatels include Malvasia bianca, Muscat Canelli, and Orange Muscat.

Recommended varieties for white dessert wines are Mission, Palomino, and Verdelho.

Table 15 gives analyses of musts and wines of the recommended white varieties from various regions, except for the Muscat Canelli and French Colombard (table 13) and for Mission, a red variety (table 16).

Red Varieties.-The recommended red variety for standard table wine is Barbera. Also possible but less desirable are Grignolino (for pink wines) and Gros Manzenc.

Recommended red varieties for bulk-quality table wines are Carignane and Refosco. Valdepeñas is useful but has certain deficiencies.

Recommended red varieties for dessert wines are Tinta Madeira and Trousseau. The Tinta Cao is nearly as good and may sometimes be planted in place of the Trousseau. The Aleatico is recommended for muscatel.

\footnotetext{
${ }^{35}$ See citation in footnote 17, p. 496.
} 
Table 16 gives analyses of musts and wines of the recommended red varieties from various regions of California, except for the Barbera, Carignane, Refoseo, and Trousseau, for which see table 14.

\section{VARIETIES FOR REGION V}

Region $\mathrm{V}$ is the hottest section where wine grapes are grown in the state. It is likewise the most uniformly fertile. Except for a few vineyards near Redding, and some in the lower foothills, the district is entirely in the highly productive, irrigated central valleys. Bulk-quality red table wines can be produced from the higher acid varieties, but white table wines should not be attempted on account of the warm storage conditions and the necessity for maintaining a high sulfur dioxide content in order to keep the color suffciently light. Region IV vineyards are better adapted for producing bulk red table wines; region III white table wines. Very good white and red dessert wines can be produced.

White Varieties.-Recommended varieties for muscatels are Malvasia bianca and Orange Muscat. The Muscat Canelli is a possibility, but it is a weak grower under these conditions and the fruit frequently sunburns badly.

Recommended varieties for white dessert wines are Palomino, Mission, and Grenache. Analyses of Malvasia bianca, Orange Muscat, and Palomino, have been given in table 15. The analyses of the musts and wines of the Mission are given in table 16 and those of Grenache in table 17.

Red Varieties.-Recommended varieties for red dessert wines are Trousseau (although preferably planted in III and IV) and Tinta Madeira (table 16). Tinta Cao is also practicable. Black Malvoisie may be useful because of possible dual use as a shipping grape, but is not recommended.

A recommended variety for special or blending wines is Salvador. Analyses of its musts and wines are given in table 17.

\section{NOTES ON RECOMMENDED WHITE VARIETIES}

Chardonnay.-The Chardonnay is supposed to be a white variation of the Pinot noir, which it resembles in several respects. The young shoots, tendrils, and leaf stalks are of almost identical coloring-bright, glossy green, and reddish-brown on the exposed side. The hairy coating on various parts of the two varieties is also similar in character and amount. This is the variety from which are produced the famous white Burgundy wines of France.

Chardonnay differs from the Pinot blane, a variety with which it is often confused, in both fruit and vegetative characters. It shows considerable color on the shoots and other parts, as indicated above, whereas Pinot blanc lacks conspicuous color except at the nodes. The hairy coating on the Pinot blanc leaves, too, is much heavier, persisting on the underside of the mature leaves as tufts of matted hairs, while the underside of the Chardonnay leaves are glossy green, with only an occasional long hair. In many leaves of Chardonnay the two lower primary veins are naked or tend to be naked from their attachment on the petiole to their first branch along the side next to the petiolar sinus. In the Pinot blanc a marginal strip of leaf tissue covers these primary veins, as in most varieties. Pinot blane clusters are small, conical, and compact, while Chardonnay are small, conical-cylindrical, and loose to well filled. The Chardonnay ripens a week to 10 days earlier than Pinot blanc. 
The Chardonnay, a vigorous grower, is only a moderate producer. During the early years in the vineyard its vines are less productive than the Pinot blanc; but as they increase in size and develop a large bearing surface, they are equally or more productive. The unfavorable bearing habit can be largely corrected by the pruning system discussed for Cabernet Sauvignon (p. 553).

The clusters of Chardonnay, as indicated above, are loose to well filled. The berries are small and firm, with a thick, tough skin. They are resistant to unfavorable weather conditions and handling injuries, but the juice yield is only moderate.

When harvested at normal maturity for the production of dry table wines, the musts were well balanced. They retained a favorable acid content, and the $\mathrm{pH}$ of those from regions I and III was relatively low.

The Chardonnay wines from properly matured fruit of regions I and III were excellent-distinctive in aroma and flavor, rich, smooth, well balanced, superb in finish. They revealed most of the properties of this variety to excellent advantage. They developed normally and cleared rapidly. After attaining maturity, they kept very well.

The Chardonnay wines of region IV, though still distinct in aroma and flav.or, were less harmonious, somewhat flat, and lacking in finish. These were only average table wines.

This grape is well adapted to regions I and II. There it will set well and at maturity will possess the rich, pronounced flavor and other properties of the variety. Good wines have been produced of it in region III; though great care is necessary to time the harvest in order to secure the qualities at their best without permitting the acid to drop too low or the $\mathrm{pH}$ to go too high. Nowhere, in fact, should the Chardonnay be planted by any one not prepared for great effort in its production, harvesting, vinification, and aging.

It should not be planted in regions IV and $V$ as it does not produce suffciently good wines to compete with more productive sorts.

Folle blanche.-Until the advent of the phylloxera the Folle blanche was the principal grape of the Charantes region of France. Its use in brandy making is well known.

Wherever the Folle blanche has been grown in California it has produced well. The vines are vigorous, their short thick canes remaining upright. The clusters are medium-large, short-conical, and compactly set with mediumsized, round berries. The leaves are dull green and five-lobed, with cobwebby tomentium below and a few long hairs above. The fruit matures without rotting in dry years, but is unfortunately susceptible to bunch rot in humid regions or seasons. The grapes are easily crushed, and the juice yield is satisfactory.

Regardless of the region, the musts and wines of this variety have been well supplied with acid, almost without exception. As a result, the wines have a tartness all too uncommon in California wines. Generally they have been light, fruity, pleasant, soft, very clean and refreshing, but with only a mild distinctiveness. Their quality has been average to good, but never outstanding. Their slight distinctiveness, together with their tartness, freshness, and freedom from objectionable properties, is their principal value. When the grapes are grown in a suitable location, the product may be aged into a table wine 
well above average. It is also a good stock for California white sparkling wine, or in blending may lend acidity and freshness to wines of more quality and character but less acidity.

Wetmore and the California Viticultural Commission ${ }^{38}$ were much impressed with the possibility of Folle blanche wine for beverage brandy. The grapes tested, however, came from region II or III. Although there is only a limited amount of data regarding the brandy, plantings in region IV or V do not seem a happy choice. Even so, the brandy will surely be better than that of neutral very low-acid varieties.

Folle blanche is recommended for regions II and III. It may be planted in I for blending wines only. Small plantings for beverage brandy tests are recommended for regions I, II, and III.

French Colombard.- This variety was introduced to California viticulture by Mr. George West. Apparently its European connections were not established at that time, so it was known as West's Prolific in the rather wide distribution it attained, especially in region IV, prior to the adoption of national Prohibition. Since its fruit did not meet the shipping requirements of the dry era, all of these early plantings were either grafted to other varieties or uprooted.

Late in the Prohibition period this variety was discovered as occasional mixes in a black-wine-grape vineyard in the Lodi area. Its European identity was still unknown, so when Mr. L. K. Marshall, who recognized its promise, reintroduced the variety, he named it Winkler. Recently it was shown that this variety is the French Colombard. This name identifies the variety as of great importance in France for the production of brandy, especially in the Cognac region, and gives some indication of what might be expected of it in California.

The yines of this variety are very vigorous and productive. At Davis it has outyielded Green Hungarian and has almost equaled Burger. Its clusters are medium-large, long-conical, well filled with medium-sized, short-oval berries. The fruit ripens about midseason and has regularly reached the crusher in good condition.

In order to better portray the place of this interesting variety, the results of twenty-two lots of wine produced by Hilgard ${ }^{37}$ will be utilized along with those of the present investigations. Hilgard produced lots of wine as follows : nine from region II, six from region IV, and seven from region $V$.

This variety has been outstanding in retaining a high degree of acidity at full maturity in the warmer regions. Its $\mathrm{pH}$ has been very low. The general balance of its musts has fitted them unusually well for producing dry table wines in region IV. These wines have been distinct in aroma, fairly full and pleasing in flavor, tart, refreshing, and well balanced. Their finish, too, has been rather good. For this area of production, they have shown exceptional balance and quality. Although not so full and harmonious as the Pinots or the Sylvaner, they have ranked well above the average as table wines.

There was little difference in the balance of the musts of the French Colom-

${ }^{38}$ Wetmore, C. J. Grapes suitable for fine brandy. p. 12-14. In: Brandy distillation. Appendix A to the Biennial Report of the Board of State Viticultural Commissioners for 1891-92. 125 p. California State Printing Office, Sacramento, Calif. 1892.

${ }^{37}$ See citation in footnote 16, p. 496. 
bard grown in the different regions. Though the wines of the cooler regions were a bit lighter and slightly more delicate, the difference was minimal when compared with that of most of the other varieties. The wines of the French Colombard do not show up so well by comparison with the better varieties in the cooler regions as they do in region IV.

These wines have fermented unusually well and have been singularly free of difficulties while aging. They have matured relatively rapidly, and kept well.

In region IV French Colombard will be of value in its own right for producing standard-quality table wines as well as for blending to improve the balance of the products of other more highly flavored but flatter varieties. Its wines are too tart and do not possess sufficient finish to compete with those of the better varieties adapted to regions I and II. Although the French Colombard is adapted to region III, further tests should be made to determine its relative value here and its possibilities in region $V$. It is not recommended for dry table wines in regions I and II. Its possibilities for beverage brandy production are being tested.

Malvasia bianca.-Malvasia bianca is a muscat-flavored variety, ripening in midseason. At Davis it has been a moderate producer. When overcropped, however, it does not ripen till very late in the season. The clusters are large, closely set with medium to large berries. The skin is fairly thick, and the grapes remain on the vines in good condition until late. Unlike the Muscat of Alexandria, the fruit matures evenly and does not raisin while ripening, although sunburn may occur. The grapes are easily crushed, and the juice yield is good. The flavor is a distinct but delicate muscat.

This variety has been tested in regions III, IV, and V. The musts have more acidity than those of Muscat of Alexandria, although in regions IV and V they are usually too deficient for dry or natural sweet table wines. The samples from region III, however, appear well balanced and might serve for the latter purpose. Unfortunately, the flavor is like that of the other muscat varieties: the dry wines are rather harsh, but seem to be more fruity and to have a cleaner fermentation.

The dessert wines appear more promising, since they are uniformly distinct. in muscat aroma, have no raisin or overripe grape taste, and possess a fruity, well-balanced character.

Hilgard tested this variety and found it to have a rich delicate muscat flavor. Although Bioletti did not recommend it, he did not recommend any muscat-flavored variety; so his omission is not significant. (Bioletti did mention the Muscat of Alexandria for the production of raisins; and for the San Joaquin Valley foothills he regards ${ }^{38}$ Malvasia bianca as being "very suitable for the production of a delicate sweet muscat.")

The Malvasia bianca is recommended only in regions IV and $V$, where it will produce white muscatel. Plantings should be restricted in view of the competition of the present large acreage of Muscat of Alexandria, and also because the demand for muscat-flavored varieties may very well not be maintained if a more critical dessert-wine market develops in America. Small plantings, destined to supplement present acreages, would nevertheless be desirable, since the wine is above average in quality. The present recommenda-

${ }^{38}$ See citation in footnote 17, p. 496. 
tion for muscatel is to plant Malvasia bianca or Orange Museat and Muscat Canelli. The latter variety, though not a good producer, has the most desirable flavor. The flavor of the Malvasia bianca is good, and its yields are regular. Muscat Canelli.-Muscat Canelli is probably the same as Muscat de Frontignon. Under these two names it has won renown abroad as the variety from which are produced the Asti Spumanti wines of Italy and the best-known French muscatels.

The vines are only average in vigor and moderate in productivity. The planting distances should be reduced. The clusters are medium-large, longconical, and well filled with medium-large berries. The juice yield is average or slightly above. The berries withstand raisining much better than those of the Muscat of Alexandria and are also more resistant to handling injuries. They ripen before the latter variety, however, and if left on the vines until midseason will raisin badly.

Consistently, the musts and wines of the Muscat Canelli have had more acid than those of the Muscat of Alexandria. This property alone has improved its wines. Although improvement in cleanness of fermentation is perhaps most important, the flavor is also better. Its wines do not have the marked harshness found in those of the Muscat of Alexandria.

The dry wines of this variety have been only average, but still they have been among the best of this type. While young they have been rich in the muscat aroma, and this property was retained in considerable quantity into the second and sometimes the third and fourth years. In addition, these wines have been full flavored, fairly smooth, and fairly well balanced.

The dessert wines have been heavily perfumed, richly flavored, luscious, smooth, well balanced, good to excellent in quality for the type. For these wines the Muscat Canelli ranks among the best of the many muscat varieties.

This variety has produced wines of good to very good quality in regions II, III, IV, and V. It is best adapted to III and IV, where it attains full maturity every year and its aroma and flavor are at their best.

In region $V$ the fruit is somewhat subject to sunburn, since the vines are not vigorous and their growth is not dense. In cool seasons in region II the fruit may not ripen completely. This variety should be considered only because of its potentialities for quality sweet wines. Either natural sweet or dessert wines may be produced from it. Sweet sparkling wines with a muscat flavor have not had sufficient popularity to warrant extensive plantings of this variety.

Orange Muscat.-The Orange Muscat, a recent introduction, is both vigorous and productive. The clusters are medium-large; the berries irregular, varying from large to very small. The irregularity in size is of little importance for wine production, though somewhat undesirable in table grapes. The skin is thick, and the berries rather hard. The grapes are only moderately easy to crush, and the juice yield is below average. The grapes ripen evenly and normally, reach the crusher in a very clean condition, free of rot and, compared to other muscat varieties, relatively free of sunburn and raisining.

The wines are rich in muscat aroma, with a full, soft, luscious, and distinctive muscat character. In this respect it is among the strongest and most pleasant of the muscats. In regions IV and $V$ these wines have been more delicate and better finished than those from Muscat of Alexandria. They are 
not equal to Muscat Canelli, and are somewhat different in character from it. The aroma is more flowery than that of the other white muscat varieties.

The Orange Muscat should find a place for itself, especially in region IV, and in region $\mathrm{V}$ when the purpose of planting a muscat is solely for wine production. (See p. 574 for further comments on muscat-flavored wines.) It is more productive than Muscat Canelli and does not suffer the sunburn of the latter. It will not regularly ripen in the cooler regions.

Palomino.-Its great vigor and productivity have made the Palomino a favorite white variety with many California growers. The clusters are very large, with round to "vertically flattened" (oblate) berries. The skin is thick and moderately tough. Pressure between thumb and finger reveals the rubbery texture. Because of its open cluster structure, its thick, tough skin, and the firm texture of its pulp, this variety is relatively resistant to unfavorable weather, though mildew may cause some damage. The tough skin and firm texture, however, impede satisfactory crushing; and the juice yields are much below average.

The dry table wines from the Palomino grapes of all regions have, without exception, been disappointing. Their flavor has a typical harsh character, which in the dry wines is especially coarse and unpleasant. Even in the coolest locations the acid content of the mature fruit is deficient for producing a balanced table wine. This deficiency has caused most of the wines to be flat and easily oxidized.

The composition of the must indicates the suitability of ripe Palomino for dessert wines. Regularly, except when overcropped, it attains a high percentage of sugar; and it never contains more than moderate amounts of acid. Appropriate wines from regions III, IV, and V, when baked or treated with film yeast, have produced good to very good sherries-well balanced, soft, pleasant, and typical in flavor and aroma according to the method of production.

On the basis of its vigor and productiveness the Palomino, under the erroneous name of Napa Golden Chasselas, has been widely planted in coastal counties. Since, however, the dry wines of this variety have never possessed more than ordinary quality, it should not be planted in regions I and II. Furthermore, the plantings already located there should be converted to better dry white table wine grapes.

For sherry in regions IV and V, no single variety equals the Palomino. It responds more favorably to baking than any of the other varieties tested. Its greatest value is in the production of dry, delicate, lighter sherries; yet the sweet heavy types profit by generous percentages of Palomino.

Pinot blanc.-The Pinot blanc is grown extensively in certain sections of France. From it the Chablis wines derive their characteristic properties. (For comparison with Chardonnay, see p. 541.)

The vines are somewhat below average in vigor, and moderately productive. The clusters are small, conical, compactly set with small, round, firm berries. The skin is fairly tough. Because of the compactness this variety is not very resistant to unfavorable weather conditions. Rains or foggy, damp weather may cause rot. It resists handling injuries very well.

The musts of normally matured fruit from regions I and III were not particularly well balanced for table-wine production. They have tended to be 
somewhat low in acid and high in $\mathrm{pH}$. The musts from regions IV and $\mathrm{V}$ have been too low in acid and too high in $\mathrm{pH}$, except when the fruit was picked very early.

The Pinot blanc wines from regions I and III were distinct in aroma and flavor, smooth, fairly well balanced, of good finish. The quality was good. Most of the varietal characteristics except acidity were well displayed. The wines cleared normally and kept well.

The wines from regions IV and V made from this variety were generally unsatisfactory. Though of good aroma and flavor, they were flat and only fairly well balanced, with a marked tendency to oxidize. The deficiency in acidity was their main defect. Earlier harvesting that retained a higher per cent of acidity improved the quality of wines of region IV considerably, but still they were only average.

The Pinot blanc is adapted to the warmer parts of region I and to region II. In areas where it will not mature until very late, the loss from rot will be excessive. In the warmer areas, such as region III, the acid content will tend to be low at normal maturity.

- This variety is not adapted to regions IV and V. Here the quality will not be high enough to offset the relatively low yields.

Sauvignon blanc.-The Sauvignon blane is a rather poor producer unless pruned long. The small clusters are closely set with medium-sized oval berries, which have a moderately tender skin and should therefore reach the winery as soon as possible after harvesting. The small-sized clusters and the small crops make this grape expensive to harvest as well as to grow. The flavor is usually distinct and aromatic. The juice yield is average.

Because of its low production, the Sauvignon blane should be considered only for the best-quality wines. It has been tested in all the regions of California. It ripens fairly early and if harvested by midseason retains a fair degree of acidity. The distinctive flavor is carried over and even increased in the wine, whether the grapes are produced in the coolest or the warmest region. If harvested before full maturity, however, the fruit has a much less distinctive flavor. Irrespective of the year and the region there seems always to be an overabundance of sugar. The better-quality wines came from regions I and II, although very good wines were produced in III. The distinct aromatic flavor is so strong that in some regions and years it may have to be blended with a more neutral-flavored variety to achieve consumer acceptance. It should not, however, be diluted too much. The possibility of using Sauvignon blane for natural sweet wines should be more widely investigated, particularly in warm seasons and in region III. The high degree of sugar achieved without undue raisining makes it suited for this type of wine.

The Sauvignon blane is recommended in regions I, II, and III for producing quality wines either by itself or by blending. In addition, in region III it is recommended as a constituent of natural sweet wines. This agrees in general with Hilgard and Bioletti, who recognized its high quality.

Semillon.-The Semillon is the most important grape of the Sauternes region in France, where its fruit accounts for about 75 per cent of the production. The wines of the Graves also contain a large percentage of this grape, from which they derive their fullness. 
Semillon vines are above the average in vigor and productivity. The clusters are medium-large, conical, compact, and often winged. The berries are medium-sized, round, yellow-green, with a rather tender skin. In poor soils or dry years they are smaller. Very ripe grapes have a slight pinkish tinge-not sufficient, however, to color the must. If the vines are overcropped, the Semillon does not ripen properly and may even shrivel before reaching $20^{\circ}$ Balling. For this reason it should seldom be cane-pruned. It must be handled with care and without delay. Fruit of advanced maturity is very susceptible to rain damage. Small cracks occur in which molds grow rapidly, especially the harmful Penicillium.

In general the musts are better suited for natural sweet rather than dry table wines. Their acidity is too low for the latter except in the cooler seasons of region I. Then, too, the character and flavor are more pleasing in a wine that retains some sugar. Dry wines produced from Semillon, even in the cooler regions, are frequently heavy, slightly harsh, and somewhat unharmonious.

The wines from regions II and III were characterized by a balance of their properties that places them among the superior wines of our state. Some had a smoothness, body, flavor, and richness of aroma that the Semillon alone can give and then only when planted in an ideal environment. Allowing for the absence of the complement to the aroma and flavor resulting from the Botrytis cinerea abroad, as we must do under our very dry autumns, these wines were gratifyingly typical of this variety. Only those that retained an appreciable amount of sugar reached this high quality. In these regions the acidity was regularly too low for balanced dry table wines.

In region IV the natural sweet wines of the Semillon do not equal those of regions II and III in delicacy and balance. They were regularly somewhat heavy, their aroma and flavor were stronger, but less delicate, and the acid was lower. Nevertheless, many showed real quality and were among the best wines of this area.

In region $\mathrm{V}$ the wines were generally heavy, coarse, and flat. Raisining was a serious problem.

The Semillon cannot be recommended for region I. There the wines are only average or slightly better than àverage. The vines are susceptible to mildew, and their fruit will rot badly in years of early rainfall. Production is relatively low and irregular.

This variety comes into its own on the appropriate soils of regions II and III. Time may tend to indicate special locations, though many of the differences now supposed to exist arise more definitely from the handling of vines and fruit and from vinification than from the local areas of production. The reputation of the Semillon from the rocky soils of the Livermore Valley is, however, probably based on a real difference in quality: these wines are said to be more aromatic than those produced at similar temperatures in the Napa Valley. Since the poor and rocky soils of Livermore do not support such a large vegetation and cropping as the rich mid-valley alluvial soils of the Napa Valley, the Livermore vines seldom overcrop and consequently attain a high degree of sugar. Possibly also the average berry is smaller, with a greater relation of surface to volume; the skin contains more of the aroma-producing substances. In these regions there is sufficient heat to mature the crop, yet not 
enough heat to cause serious difficulties in harvesting and handling. Here the production is good for the variety, and mildew can be controlled in all seasons.

Although less well adapted to region IV than to regions II and III, the Semillon under suitable cultural operations, timely harvesting, and prompt and proper vinification procedures will produce a very acceptable natural sweet table wine in this environment. The individuals and firms interested in producing a good natural sweet table wine in this region may well consider the Semillon. It will produce good crops; and unless unsound and raisined fruit is permitted to enter the crusher, the product will be creditable.

The Semillon is not adapted to region V; here it tends to sunburn, and considerable raisining occurs.

Sylvaner.-The Sylvaner ranks second among the varieties of central Europe, where it produces above-average wines under a range of conditions. In our state it is sometimes erroneously called Franken Riesling.

The vines, of medium vigor, are productive. Its almost entire, medium-sized, round, yellow-green, hairless leaves are an aid in identification. The clusters are small to medium, cylindrical, compact, and usually winged. The berries, small-medium, round, dark bluish-green to yellow-green, show prominent corky dots. Although the skin is relatively thick, it is tender and requires careful handling. Early rains may cause considerable rot. Prompt moving from the vines to the crusher is very important. The grapes crush easily, and the juice yield is satisfactory.

Sylvaner commences growth somewhat later than most varieties in spring. This fact may reduce the frost hazard. Still, the fruit matures relatively early. It is rather susceptible to mildew.

The musts have shown unusual uniformity of composition in the different regions from which fruit was obtained. The failure to show a higher degree of acidity in the cooler locations was due, no doubt, to a more advanced stage of maturity of the fruit in these regions at the time it was harvested; but the variety is one of restricted acidity at best. In general, the must was somewhat low in acid for the production of superior wines. This defect can be overcome somewhat by more careful timing of the harvest. (See table 11 for must composition for 1939, 1940, and 1941.)

The wines from regions I and II possessed a very delicate and distinct varietal aroma and flavor. Although fuller and less delicate in these respects, the wines of regions III and IV were still typical of the variety. In fact, the loss in quality and richness with increasing heat of the producing region was less marked in Sylvaner than in most of the other good varieties. Under the best conditions these wines revealed the potentialities of the variety. Many of the lots have run remarkably true to type. This finding was not entirely unexpected for the Sylvaner; of the better varieties of central Europe, it has proved to be the best adapted to warm locations.

Although the Sylvaner produces rich, delicately flavored, well-balanced wines in region I, it cannot be recommended for planting there. Under the prevailing climatic conditions the vines will be very susceptible to mildew, and the fruit will rot badly in years of early rains. In protected locations of limited area, however, the mildew may perhaps not be such a handicap.

The Sylvaner is very well adapted to region II and the cooler parts of III. 
Under the conditions of these areas it can potentially produce with regularity its best California wines, provided it is harvested at the proper time. Mildew can be controlled effectively, and in most years the fruit will be mature before the earliest rain. The heavy soils of the more coastal valley floors are not best, however, for Sylvaner. In these soils it overcrops and has considerable bunch rot, particularly in cool, humid seasons.

In the warmer parts of region III and in region IV the quality of the wine, although good in many seasons, will not be sufficiently high and uniform to offset the lower yields and reduced acidity. The Sylvaner may succeed in special locations when the producer utilizes it to best advantage. In general, however, the more productive sorts such as Semillon and Folle blanche should be chosen for region III and the bulk sorts for IV.

Sylvaner has no place in region $\mathrm{V}$.

White Riesling.-The White Riesling is among the most famous white wine varieties. Its product, the Riesling wines of Germany, has a reputation equal to that of the Sauternes and White Burgundies of France and the Tokays of Hungary. It is grown only on a limited scale in California, where it has usually been called Johannisberger Riesling. This appears to be a serious misnomer, since there is no such variety abroad and since it breaks the direct ties with the famous products of the White Riesling in Germany.

The vines, above average in vigor, are about average in production. Because of the size of the clusters the vines should be cane-pruned as directed for Cabernet Sauvignon (see p. 553) if full crops are to be produced. The clusters are small, cylindrical, winged, well-filled to compactly set with small, round, greenish-yellow berries. Since the skin is fairly thick and moderately tough, the berries resist rains and unfavorable weather. They also resist handling injuries, but should be crushed without delay if the rich, delicate aroma is to be carried over into the wine without impairment.

The distribution in Europe indicates that White Riesling is well adapted to a cool climate. This is supported by the results of this study. In no California region from which this variety was obtained was the must sufficiently well balanced for an outstanding wine. The usual deficiencies were those attending insufficient acidity.

The fruit of region II, however, has had a relatively favorable acid content. Its products were distinct in aroma and pleasant in flavor, soft, and of good quality. They did not possess, however, the balance, richness, or delicacy of the best Riesling wines.

The wines from regions III and IV possessed the properties of the variety, but the proportions were even less harmonious than for region II. Aroma and flavor were poorer, and the acidity was definitely low. Despite these deficiencies, these wines were rated as average to good. This fact speaks well for the unusual potentialities of White Riesling for producing quality wines. It is not, however, an indication of adaptation to the environment. The results to date indicate that White Riesling should be grown in the coolest areas of our present grape-producing regions. This statement agrees with Professor Hilgard's findings and with pre-Prohibition experience. The variety should produce superior wines in region I, where the product retains in marked degree the qualities that have made it famous in Europe. 
Further tests should be undertaken to establish the relative merits of the cooler regions and to find localities where these wines approach the highest quality attainable by the variety.

White Riesling produces fairly well in region II; but its wines, although above average, lack the balance, finish, and character that may be expected. It could be recommended only for the cooler locations in this region. Significantly, Bioletti in 1907 failed to recommend it for California. His recommendations for the coast counties were presumably for regions II and III.

Neither its productivity nor the quality of its wine commend the White Riesling for regions III and IV or for warmer localities, where the product at best will be only good table wine. The warmer the region the poorer are the wines. Other varieties such as the Semillon and Sauvignon blanc should supplant it in region III.

\section{NOTES ON RECOMMENDED RED VARIETIES}

Aleatico.- In Italy this variety is used for natural sweet wines of the vino santo type. Sometimes in Tuscany the grapes are hung on strings and allowed to partially dry in order to secure a very high concentration of sugar. The clusters are rather long and above medium in size. The grapes are round, of medium size, and have a distinct muscat flavor. They ripen in midseason and will raisin if left on the vines after maturity.

The Balling-acid ratios of the musts average over 44, indicating that they are well suited for dessert wines. Except in a single 1935 sample the total acid content is medium or low. The degree Balling was seldom high, largely because of the exceptionally early picking that was practiced. Harvesting and picking present no particular problems. The grapes, being fairly easily bruised, must be picked carefully. They stem without difficulty, and all of the berries are easy to crush. Despite the low total acid content, no difficulty was experienced in the fermentations. Grapes from irrigated vineyards, however, may have considerable rot.

All but two of the samples were utilized for the production of dessert wines. The total acids show a marked reduction following fermentation and the addition of grape brandy, which is natural but seems more pronounced than in some other varieties. The tannin content of the two dry samples was low, and that of the sweet wines was very much reduced. The color content likewise was very deficient compared to commercial types of red sweet dessert wines. During aging the color becomes more of an amber than a red, and in one case a completely amber wine was produced from this variety.

The tasting record indicates that the dry red muscats in general are unsatisfactory, characteristically harsh in taste. No such objection was noticed in the sweet wines. Although typically aromatic like a muscat, the wine has a perfumed character not found in other muscat varieties.

The Aleatico is not suited for dry muscat-flavored wines in the warmer districts of California and presumably will also not be sufficiently well balanced when grown in the cooler districts to produce a natural sweet wine. Hilgard, however, reports good acidity from grapes in region II; and further tests should be made in II and III. Its place is mainly for a sweet table, or sweet dessert wine in regions IV, V, and possibly III. The most serious defect is 
poor color; dessert wines of this variety are too light in color. Natural sweet wines of low color content may, however, be satisfactorily produced; and the product may be blended to produce full-colored wines. Blending is not recommended, since the typical perfumed aroma, a principal merit of the variety, would be diluted by the practice. Small plantings are recommended in regions IV and V for those with a market for a distinctively flavored red muscatel. Biolett ${ }^{30}$ recommended the Aleatico for making a good red muscatel in the San Joaquin Valley.

Barbera.-The Barbera is known the worla over because of the Italian wines of that name. Besides showing a pronounced varietal character these wines have usually - not altogether to their credit-been characteristically Italian. The roughness and gassiness of the Barbera made abroad are not, however, necessary features of its wines.

The Barbera is well above average in vigor and produces moderately well. According to Hilgard it produced about 5 tons per acre at Tulare on sandy soil. Vineyards observed in recent years have been more variable in production. Some old vineyards on poor soils have had a very small production. The vines leaf out relatively late, and show fair resistance to mildew.

The clusters are large-medium, conico-cylindrical, well filled with long-oval, large-medium, firm, black berries. Since the skin is thick and relatively tough, the fruit usually reaches the crusher in good condition. The juice yields are good. If left on the vines until late in the season, the grapes shrivel and smaller yields are obtained.

The musts have consistently shown a relatively high acidity. The degree of acidity appeared to be affected less by maturity and by region of production than in most varieties. One lot from region III at $28^{\circ}$ and another at $25.6^{\circ}$ Balling still contained 0.63 and 1.07 per cent, respectively, of acid, and a sample at $22.0^{\circ}$ Balling from region $\mathrm{V}$ contained 0.81 per cent.

As in their native country, the Barbera wines of California have been robust and somewhat heavy. The extract has varied from 2.6 to 3.2 , with little to no sugar present.

As a rule the wines have been distinctive in aroma and flavor, fruity, medium to high in acidity, average to good in character, full-bodied, and usually good in color and finish. (Since the identity of the grapes of region II is questionable, their wine will not be considered.) The wines of this variety in region III have been the most balanced in character. In the warmer regions (IV, and more particularly V), the wines were less delicate, somewhat poorer balanced, heavier, and generally lower in quality. In the latter regions the color was sometimes deficient. None of the wines have been above normal in tannin content, all being lower than most of the other well-known Italian varieties in this respect.

Because of their general character of heavy body, high acidity, and at least average tannin content the wines of Barbera require aging and greatly profit by it. After reaching full development they maintain their characteristics and quality under favorable storage conditions.

The Barbera will not ripen normally year after year in region I, and even when it does mature it will be excessively acid. The same would be true to a

\footnotetext{
${ }^{39}$ See citation in footnote 17, p. 496.
} 
degree in region II and in all but the warmer parts of region III. In III and IV the variety offers real promise. Here it is productive, ripens well, produces a good to superior wine of pronounced varietal character, and is one of a few varieties that possess relatively high acidity when fully mature. It is among the best varieties tested for the production of average- and above-averagequality dry table wines in region $\mathrm{V}$, but its planting is less well indicated for that region than for III and IV.

Cabernet Sauvignon.-The Cabernet wines of the world take their name from the two very closely allied varieties, the Cabernet franc and the Cabernet Sauvignon. These possess a specific color, a distinctive flavor, and a particularly intense aroma. In a favorable environment they transmit their qualities so that the wine is very distinctive. They-in particular the Cabernet Sauvignon-have given the clarets of France the character and qualities that make them one of the two most esteemed of all red wines.

The Cabernet Sauvignon is among the most vigorous of vines. With proper pruning, it is a moderate bearer. During the early life of the vines, canes should be retained in addition to spurs. After the vines attain considerable size (in eight to twelve years), spurs alone may provide sufficient bearing surface. Since the clusters are medium-small, a large number must be grown for approximately normal crops. With proper pruning the crop was increased over the spur-pruned vines by $10.3,5.3$, and 0.0 pounds to a vine, respectively, in the fourth, sixth, and eighth years at Davis. By the eighth year the vines spur-pruned from the start were so large that their bearing surface could produce full crops. From then on, the production of the spur-pruned and combined spur- and cane-pruned vines has been about equal. If the cane pruning is to be stopped after eight or ten years, the spurs must be developed along with the canes to give the vines spread and bearing surface. As the vines become larger, the canes are reduced in number or length or both as more and more fruit is produced on the spurs.

Although the system described above is the most economical for handling varieties with small clusters, no supports being required after eight or ten years, these vines can be cane-pruned throughout their life. Several successful vineyards of this variety in regions II and III are cane-pruned.

The clusters are medium to small, long-conical, loosely filled with small, round, tough-skinned, black berries that adhere firmly to the pedicels. Because of these latter properties the fruit withstands unfavorable weather with very little spoilage. It is not so readily crushed as most of the other less resistant sorts. If the grapes become overripe there may be considerable difficulty in securing adequate crushing.

The Cabernet Sauvignon grapes grown in regions I, II, and III prove well suited for table wines of superior quality. When this fruit was harvested at proper maturity the wines were distinctive in aroma, full flavored, soft, well balanced, excellent in quality. As a rule they have been genuinely typical of this variety at its best. They possessed sufficient natural acidity, normal tannin content, and good color. Earlier criticism that the Cabernet wines of California are excessively tannic should have been directed at the methods of vinification and not at the variety.

These wines require aging in the wood to permit them to mellow down and 
to change the undue aromatic pungency of their youth to the pronounced but highly esteemed character of the mature Cabernet. Aging alone achieves the ultimate superb balance that distinguishes these wines. The Cabernets from suitable environments in California are no exception; they profit greatly by aging. Once matured properly, they keep unusually well.

When the grapes in regions II and III were permitted to become overripe, the acid was much reduced; the wines were less well balanced. They became heavy table wines with character and flavor, and above-average quality. A Cabernet Sauvignon of $24^{\circ}$ Balling in these latter regions is usually overripe.

The grapes of this variety from regions IV and V do not produce a satisfactory table wine. The wines have consistently been deficient in acid, and therefore flat, lacking in freshness, and not delicate in aroma. They are, for the most part, only heavy wines of ordinary quality. Occasionally, in cool seasons, they have approached the true character and deserved a rating of good.

The Cabernet Sauvignon ranks first in the production of high-quality red table wines in California. When quality alone is considered in the planning of new plantings of red varieties, the Cabernet Sauvignon usually heads the list for regions I, II, and III.

Its wines will not bear dilution without some loss of character. To be called Cabernet a wine should, on the basis of these investigations, contain 75 per cent or more of Cabernet Sauvignon grapes. The practice of permitting the variety to get overripe and then diluting its must with some other variety of low sugar content is not recommended.

Since the Cabernet Sauvignon will not produce a distinguished wine in regions IV and $\mathrm{V}$, it should not be planted there.

Carignane.-In the early work of the University in enology, thirty-three wines were produced of Carignane grapes from a number of locations. The results were somewhat discordant. In several favorable areas these wines were good, but in most localities they were only fair to poor. Best results were obtained on the well-drained soils in parts of the Santa Clara and upper Russian River valleys. In 1907, however, Bioletti omitted the Carignane from his recommendations. Nevertheless, the variety has been very widely planted.

The popularity of this variety has been stimulated by its great vigor and productivity. Its very upright habit of growth, which simplifies the training, has also been a factor. The most serious weakness is susceptibility to mildew : usually it requires one to several more sulfur dustings than most of the other varieties, and failure to control the mildew may result in considerable loss in crop.

The Carignane cluster is medium to large, conical, sometimes shouldered, well filled with medium-sized, oval, thick-skinned, black berries. The fruit is firm and ships well-a quality at least partly responsible for the planting of about 20,000 acres in the period 1920 to 1930 . The fruit is crushed without difficulty.

Carignane in regions I and II is usually fairly well balanced for table wines. In warm seasons the acid content may be low, and the color deficient. On the whole, however, the products have been sound, fruity, well-balanced table wines of good-average quality. They are pleasant, though not one could be considered to be a quality wine. They have developed rather rapidly and, 
under the experimental storage conditions, have cleared very satisfactorily and in a minimum of time. Once mature they have kept only moderately well. The wines of region III have been very similar to those described above, but lower in acidity. This latter condition has influenced their balance and slightly reduced their general quality.

In the interior the Carignane is only fairly well suited for table wines. The products of region IV have been of only fair balance, medium or lower color, little flavor, low acidity, and average quality. They have suffered much from lack of freshness. They are here only bulk wines. In region $\mathrm{V}$ there is a further loss in quality; the wines are definitely flat.

The dessert wines from regions IV and $\mathrm{V}$ have been only ordinary to average, without the softness or mellowness expected in this type.

On the basis of its productivity and the average to lower quality, the Carignane is primarily suited only for bulk table wines. Even its best products have little character and will profit little from aging once they are stable.

Although some of the best Carignane wines have been produced in region I, the variety cannot be recommended there, primarily because of difficulty and expense in controlling mildew, but also because the crops would be light. In regions II and III it does well on the fertile soils of the valley floors. Even here the control of mildew will be difficult in cooler years and damp locations. It seems only wise to use the better locations and exposures of these districts for varieties more resistant to mildew and able to produce superior wines. It is, however, useful in the warmer and more fertile portions of region III.

Although its wines are not the best, Carignane is well adapted to the rich soils of region IV, where it comes into its own for large crops and sound common wines. In this region, if necessary, its grapes can be used for either table or dessert wine. It is poorly suited to region $\mathrm{V}$.

Gamay. ${ }^{40}$ - The Gamay is widely distributed in France. It is the principal variety of the Beaujolais region, and a lesser variety in Burgundy and other areas. There, it is moderately vigorous and productive. Quantitatively it surpasses the Pinot noir, but qualitatively it does not compare so favorably.

The clusters are of medium size, short-conical, compactly set with smallmedium sized, short-oval berries. A thin skin makes the grapes susceptible to handling injuries and to raisining.

The fruit from regions I, II, IIl, and IV yielded a very well-balanced must for dry table wines. The acidity has been ample, and the $\mathrm{pH}$ much below the average. The color, however, is low, frequently only equaling that of a wellcolored pink or rosé wine. The one lot from region $\mathrm{V}$ was rather over-mature. Its acid content was too low, its $\mathrm{pH}$ high, and its quality injured by raisining.

The wines from regions I and II have been distinct in aroma and flavor, well balanced, delicate, refreshing, and well finished. They were decidedly distinctive and above average in quality. They did not, however, possess the delicacy, richness, and finish of Pinot noir and Cabernet Sauvignon wines from the same areas. Even in these cool areas the color of Gamay is deficient for a wellcolored normal red wine. Its lightness harmonizes well, however, with the other qualities-namely, liveliness, delicate flavor, and fruitiness.

\footnotetext{
${ }^{40}$ The variety referred to here is the Gamay Beaujolais. This is the principal variety of the Gamay group now grown in California.
} 
The Gamay wines of regions III and IV were well balanced and well supplied with aroma and flavor, and have been less tart, although still light and refreshing. In cool years they have been pleasant and very acceptable, but in warm seasons they have tended to be heavy and flat-just common wine.

The product of region V was very ordinary. Since the variety is early, it ripens here in the intense heat of August, so that its acid content is low and raisining will be a difficult problem each year.

The Gamay is well adapted to regions I and II, where it will produce a light, delicate, refreshing wine above the average in quality. With particular care in timing the harvest, it may yield a very acceptable product in region III. The value of the wines is in their sprightliness, delicacy, and lightness. Unless provisions are available to preserve these, the variety should not be grown. It is not recommended for region IV or $\mathrm{V}$.

Grenache.-The Grenache has been grown rather extensively in California. It is very vigorous and in most localities yields heavily. The vines cover their fruit well; in the cooler locations, in fact, heavy coverage with not-too-high resistance makes the variety more susceptible to mildew. It is rather resistant to the grape leafhopper, and in a measure to red spider.

The leaves are almost entire, yellow-green, and without hairs. The clusters are large, short pyramidal, with a very thick stem, and well filled to compact. The berries are small medium, round, and reddish-black. The juice yield is good.

Because of the very general distribution in California, samples were obtained from all regions-in many instances more than one sample from the same region.

After studying numerous lots of table wine produced from Grenache, it appears that the variety is not usually suitable for this type of wine. This was more strikingly true of the warmer regions; not one table wine of even ordinary quality was produced from these grapes in regions IV and V. The wines of III have been of average and above-average quality in only two out of six years. These wines have been lacking principally in acidity and character, have suffered from too much alcohol, and tended to become oxidized in flavor and color.

In the coolest regions the table wines of Grenache have not been consistently good. They have frequently been lacking in acidity, heavy, only mildly distinctive, and low in color. Hilgard, ${ }^{41}$ noting the deficiency of color in Grenache, gave Carignane a better rank because of it. Nevertheless, the wines of region I for 1938, 1939, and 1940 and those of region II for 1937, 1938, and 1939 indicate real possibilities for pink or light-red wines. Further studies, with a more accurate timing of the harvest, should reveal locations where good to very good pink wines can be produced of this variety year after year.

The many lots of dessert wines from Grenache, have, on the whole, been very satisfactory. The Angelicas have been fruity, luscious, delicate, fullbodied, and rich, while the red sweet wines of the port type, have been fruity, distinctive, and well balanced, though somewhat lacking in color.

Judging from the analysis and observation on the Grenache, its possibilities for pink wine should be tested further in regions I and II, and it is certainly a

\footnotetext{
${ }^{41}$ See citation in footnote 16, p. 496.
} 
good variety for Angelica, red sweet, and perhaps sherry. Its fruit will be well suited for these latter types in regions IV and $V$ and the warmer parts of III. It is recommended for commercial planting only in these latter regions.

The present findings differ from Hilgard's : he states that Grenache cannot be recommended for any location yet tried, although he made wines of its grapes from Fresno, Tulare, Cupertino, and Livermore. Bioletti likewise failed to recommend it in 1907 and speaks of it as a common variety not to be planted in the coast counties. On the other hand, the present recommendations are supported by the uses to which Grenache is put in its home country, France. There the Tavel, the best known of all pink (rosé) wines, derives its character from the Grenache; and Banyuls, a rancio-flavored sweet wine of the south of France, is also a product of it.

Mission.-The Mission was the first grape of Vitis vinifera lineage planted in California. ${ }^{42}$ In the beginning of wine production, dry wines were the primary product. It was, no doubt, the holdover impression from the poor dry wines of the Mission in early days and the limited tests of only five of his own that led Hilgard to state: ${ }^{43}$ "There is little to be said in favor of our old, rejected friend, the Mission, except that it may still be useful in some localities as an ingredient of sherries. Its total lack of character and low acid render it unfit for any other purpose than blending where a neutral ingredient is desired."

Possibly Hilgard was unaware that the Mission variety has always been associated with the production of Angelica and that well before 1900 it had gained considerable reputation as the source of this wine. Lachman ${ }^{44}$ attests to this as follows: "The Mission grape which was no doubt transplanted to this country by the padres, was found to adapt itself to our soil and climatic conditions. ... The Angelica made from this grape has never been excelled by wine produced from any other variety ..."

The Mission grows vigorously and produces large crops. Its clusters are large, irregular-pyramidal in shape, loosely set with medium-sized, round, crisp, brownish-red berries.

The table wines produced have been almost complete failures, low in acidity and lacking in distinctiveness. They have been flat, lacking in flavor, deficient in color, and sometimes harsh. As regards these types, Hilgard's conclusions are correct - the variety should not be planted.

The possibilities of Mission for dessert wines, on the contrary, show promise for certain types. On the whole, its dessert wines have possessed average or better quality, though some have been difficult to keep. They have been smooth, full-bodied, delicately flavored, fruity, and fairly well balanced. Certain Angelicas have been luscious, mellow, golden, and very good. The dry sherries have been smooth, delicate, and pleasing.

Only one well-colored red dessert wine was obtained from the Missionfrom grapes of Escondido in region IV. The other wines of this type have been pink to tawny. Aside from their deficiency in color, the red sweet wines had a mild but distinct aroma and flavor. Apparently they require special care to prevent oxidization and to retain as much acidity as possible.

${ }^{42}$ See citation for Leggett in footnote 6, p. 494.

${ }^{43}$ See citation in footnote 16, p. 496 .

${ }^{44}$ Lachman, Henry. A monograph on the manufacture of wines in California. U. S. Dept. Agr., Bur. Chem. Bul. 72 (Pt. 2) :25-40. 1903. 
These observations upon the dessert wines of Mission not only confirm the earlier opinions regarding its value for Angelica, but also show its use for sherry and occasionally for red sweet wine. Its deficient color can be corrected by judicious blending without spoiling its soft mellowness.

The Mission is well adapted to regions IV, V, and possibly to III. In V its acidity may tend to be too low. It is recommended for dessert wines in these regions.

Petite Sirah.-The Petite Sirah is widely grown in California, and samples have been secured from every district. The grapes are highly susceptible to changes in climatic conditions. In the extremely warm year of 1936 the Petite Sirah was a complete failure in every district, the grapes raisining very early in the season and the resulting wines being alcoholic, flat, and coarse. In very cool seasons the heavily loaded vines in fertile soils of regions I and II will fail to ripen.

The Petite Sirah is a variety of good production and vigorous growth. When young its clusters are somewhat entangled in the canes, and considerable damage may be done them during harvest. It rots very quickly after early rains and, as indicated above, raisins easily in hot, sunny weather.

Usually, except in very hot years, the grapes can be harvested sufficiently early. (Region V samples were harvested in August.) The resulting wines, however, though of sufficient alcoholic content for table purposes, may be somewhat green tasting. If harvested later, the musts from this region are high in $\mathrm{pH}$, and there is some difficulty in obtaining a clean fermentation. The experiments with dessert wine from Petite Sirah, though not extensive, suffciently indicate that the variety is too high in tannin for this type of wine and accordingly makes a slow-maturing product. This is not a final objection to the use of the variety for this purpose, since some slow-maturing red dessert wines finally reach very good quality.

The adaptation of Petite Sirah in California indicates that it should be planted only in regions at least as cool as region III. Apparently it always matures its fruit under the coolest California conditions, unless overcropped, and its best table wines are regularly produced in these regions. The quality in region I has been uniformly above average, and a few samples have been outstanding.

These best wines are less aromatic than distinctively flavored varieties such as Cabernet Sauvignon, but they do have a characteristic aroma and flavor and, when properly vinified and matured, are recognizable. This flavor is not, however, typical of Burgundy wines of France, and the desirability of using Petite Sirah for making all Burgundy-type wines in this state is not yet indicated by commercial experiments.

In regions II and III standard red table wines have been produced in all but the hottest years, and the variety seems to have a permanent place as a heavy-bodied, red table wine.

The present recommendation is that no further plantings of Petite Sirah be made in regions IV and V; that plantings in III and usually in II be confined to those areas capable of, and to those producers who wish only to secure, an average-quality, heavy-bodied, red table wine. Plantings in region I should be restricted because the variety matures slowly, but may be made by those 
willing to produce a moderately distinctive, above-average, slow-maturing red table wine.

Pinot noir.-The Pinot noir is the variety from which are made the Burgundy wines of France. It is widely planted in Europe, but only under the climatic and soil conditions of the Côte-d'Or have its red wines attained perfection.

The vines are somewhat below average in vigor. With long pruning they bear moderate crops. The clusters are small-medium, cylindrical, often winged, and well filled with small, short-oval berries. The skin is fairly thick, but not too resistant to water loss. The fruit matures very early.

The wines of Pinot noir from region I have been excellent in aroma and flavor, fruity, soft, very harmonious, superb in finish. They have revealed much of the true character of the variety when grown in a favorable environment. In short, they were among the outstanding quality wines produced in these investigations.

These wines fermented without difficulty and have aged normally but somewhat slowly. They have kept well. On the whole they were well colored.

The wines from regions IV and $\mathrm{V}$ were much commoner in quality. Although they possessed a fairly distinct aroma and flavor, they were unharmonious and often flat. Many were tainted with an overripe grape or raisin taste. They also aged more rapidly, tending to turn brown. Their poorer keeping quality was no doubt directly chargeable to the condition of the fruit at crushing and not to the variety. The color content was only approximately that of pink or rosé wines.

On the basis of these and past tests, the Pinot noir can be recommended for table wines in region I. With proper handling, vinification, and aging in this area the product will be of outstanding quality. The fruit is, however, very delicate, requiring unusual care in handling. The possibilities can be realized only by those willing to become specialists. The tendency of the young wines to become oxidized and flat requires that they be kept cool and out of the air as much as possible.

In the warmer regions (particularly in III, IV, and V) the Pinot noir will fail. Its fruit will ripen under the severe conditions of summer, long before most wineries are ready to operate. Under these conditions the mature fruit will be poorly balanced, and raisining will occur. The quality will be poor at best, and sound wines can ordinarily be produced only by blending.

Refosco.-The vines of the Refosco are vigorous, though not so strong as Carignane. It is a moderately productive variety. The fruit resists mildew but, as a result of the long internodes of the canes and the open character of the foliage, is subject to sunburn in the hot interior valleys. The vines produce well with spur pruning. During development of the vines the spurs should be left with more buds to compensate for their limited number and to spread the fruit.

The clusters are long and medium-large. The main stem of the cluster and its branches are strong, with berries firmly attached. The firm flesh is inclosed in a rather tender but thick skin. The combination of firm flesh, thick skin, and open-cluster structure has made the fruit fairly resistant to unfavorable weather conditions or light early rains. Ripening comes in late midseason. 
The juice yield has been good. The fermentations have gone well and to completion, except when the fruit was much overripe. The wines from regions I and II were average in alcohol, with medium body, excellent color, pleasing aroma and bouquet, and sufficient acid. They were well supplied with tannin, but not enough to make them rough or to prolong unduly the aging period. In region IV the wines were somewhat heavier and fuller, but still balanced as regards their principal constituents. The wine from region $V$ was very acceptable as a standard table wine. It may have benefited by the cool season of 1935 , but Hilgard's and Bioletti's results support the very wide range of the adaptation. In all the regions, the table wine of Refosco surpassed Carignane in both balance and character.

The place for the Refosco, if grown in regions I to III, would be on the fertile flat soils. Here it will produce wines that are distinctive and well balanced. Although not great, they will be superior to Carignane, Mataro, and Mondeuse, and far better than Alicante Bouschet, Petit Bouschet, Grand noir, and similar varieties that now occupy much of this land. In region IV Refosco should interest those who wish to specialize in something well above average. Bioletti also recommended it for this region. It is not advised for region $\mathrm{V}$ as a table-wine variety.

Salvador.-Salvador, a hybrid of Vitis Rupestris and Vitis vinifera, is of interest because of its intense color. Its vines are of low to medium vigor, but very productive for their size. The clusters are small, slender, well filled with medium-small round berries. The pigment is present only in the skin, except in very ripe fruit, where there may be some diffusion into the pulp.

As shown by the figures of table 17 the Salvador musts and wines contain abundant acid and tremendous amounts of tannin and color. The American parent also gave this variety an aromatic flavor, somewhat objectionable in its wines.

The table wines of Salvador have been distinctly aromatic, heavy, rough, and intensely colored. With time they mellow down, though they remain too deeply colored.

With the addition of brandy, as in the production of dessert wines, the principal properties of these wines are diluted. They are, nevertheless, still very rich in tannin, the aromatic flavor, and color.

The primary, if not the only, merit of the wines is their blending value to correct deficiencies in color. For this they can be used in moderation without noticeably injuring the wines into which they are blended. If they are used too freely, the ill effects of the excessive acidity and of the aromatic flavor may more than offset the improvement in color. In general, a blend of 2 to 5 per cent should add sufficient color.

The Salvador has done well wherever it has been grown. Naturally, the color is more intense in the cool regions. In view of this fact, the relatively small amounts required, and the better success that can be had when the blender makes and understands his wines, it would appear only logical that this variety be grown only by the wineries utilizing it, regardless of their location. Since lack of color is seldom a problem in region I, II, and III, plantings there are not recommended. Vintners in regions IV and V who have difficulty in securing sufficient color for their red dessert wines might consider small 
plantings of Salvador. A better procedure, however, would be gradually to plant larger acreages of varieties such as the Tinta Madeira, which are naturally well balanced in coloring matter.

Tinta Madeira.-This variety derives its name from two sources: Tinta from its color properties, and Madeira from the island. It is much more important in the Alto Douro Valley of Portugal, however, than in Madeira.

The vines are vigorous and somewhat more productive than those of Tinta amarella or Tinta Cao. To obtain full crops regularly, the vines should be pruned moderately long. The clusters are medium-sized, conical, shouldered, usually well filled. The berries are medium-sized, long-oval, black, with a thick but tender skin. Of the varieties of Portugal tested, the fruit of this and the Tinta Cao has regularly reached the crusher in the best condition.

The musts from region IV were poorly balanced for dry wines; the few table wines made of this variety were decidedly ordinary. Hilgard's observations, based on fruit collected from region II, agree with these findings.

At maturity the Tinta Madeira retains more acid than the other port varieties. This adds to its fullness of flavor. To date its wine has been the smoothest and best balanced of the red dessert wines produced in region IV.

The dessert wines have aged fairly rapidly. Though the young wines have been slightly astringent, this property has not retarded their mellowing ; they have regularly developed a high degree of smoothness. The slightly higher acidity and moderate tannin content have improved the keeping quality.

This variety is not recommended for dry table wines. For red dessert wines it is among the best and is recommended for regions IV and V. It is a pity that a larger acreage has not been planted in the San Joaquin Valley. This is, however, a delicately flavored quality sort; and to bring its potentialities to full development it must be handled carefully. Rough handling and attempts at aging in very large tanks will almost surely result in disappointment. In region $\mathrm{V}$ care must be exercised in harvest to avoid raisining. In region III this variety may have some value, but further tests will be necessary.

Trousseau.-The Trousseau is grown extensively in the Jura region of France and, according to $\mathrm{Olmo}{ }^{45}$ is the same as Bastardo, a prominent variety of the Alto Douro Valley, Portugal, where it is among the four varieties most extensively planted for the production of port.

The vines are vigorous and productive. The canes are semierect, with short internodes and many short laterals. This habit of growth gives the vines a leafy appearance and protects the fruit from sunburn. On the other hand, the dense coating of leaves favors mildew when sulfuring is neglected.

The clusters are medium-sized, almost cylindrical, usually winged, and compact. The berries are small, medium, oval, reddish-black, with a thick but tender skin. The variety matures early. When mature fruit is permitted to hang on the vines, raisining may set in promptly, especially on old vines.

For dry table wines the Trousseau has failed completely. This agrees with Hilgard, ${ }^{46}$ who stated: "For a dry red wine . . . it is quite useless, lacking sufficient color, acid, or tannin." In addition these wines have been lifeless and very subject to deterioration during aging and storage.

${ }^{45}$ Olmo, H. P. Le Trousseau et le Bastardo. Revue de Viticulture 87:174-75. 1937.

${ }^{46}$ See citation in footnote 16, p. 496. 
The low acidity, low tannin, and moderate sugar content of the musts make for mellow, soft, dessert wines. These properties, along with the somewhat spicy, fruity flavor, make up the character and high quality of such wines. These wines develop an oxidized taste very rapidly if the casks are not kept full.

The dessert wines are deficient in color. This, however, is characteristic of several other good port varieties as well. Most of the Trousseau dessert wines had a tawny color. Lack of color can be corrected by blending in a small percentage of some darker wine. Unfortunately the present large commercial demands are for the darker ports.

This variety cannot be recommended for dry table wines anywhere in our state, but can produce red dessert wines above the average in quality. Its limitations should be considered before planting. In region $\mathrm{V}$ and in the warmer part of region IV the fruit ripens very early, usually before the wineries are ready; hence it raisins and does not yield a quality product. In the coastal regions, where it ripens under cooler conditions, the fruit will be caught by rains in some years. The result will be the development of rot in the compact clusters.

Trousseau is adapted to regions III, IV, and V. Throughout these regions it will ripen before the usual autumn rains. With prompt harvesting and moderate care in handling, the crop will reach the crusher in sound condition. Even in these areas, Trousseau should be planted only by those able to give special care to its harvest, and perform extra work in bringing its wines to full development. It is a variety for the vintner who wishes to specialize-not for the mass producer. The Tinta Madeira and Tinta Cao will produce very good ports and do not have the viticultural handicaps of the Trousseau.

\section{VARIETIES THAT CAN BE ONLY LIMITEDLY RECOMMENDED}

Numerous varieties cannot be wholly recommended. The reasons differ from variety to variety. The most common reason is simply that other varieties excel them under most conditions for their particular type and quality of wine. Under particular conditions, some of these grapes have given good results in California and abroad. The mere fact that a variety can produce good wine does not, however, prove that others will not excel it if adequately tested. Furthermore, some varieties have succeeded under special, restricted conditions that can seldom be duplicated satisfactorily. This is true of certain varieties that have found a place in local and minor regions of European viticulture over a long period. The taste created for such varieties as Nebbiolo and Chenin blane will insure their continued propagation. But to plant them here and expect their wines to compete with better ones is risky. Perhaps, as the California industry expands and greater attention is paid to particular flavors, some may find a local but permanent place.

Other varieties listed here have special qualities of production, possible dual utilization for wine and shipping, disease resistance, period of ripening, and the like. Where one or more of these factors must be specially considered, some variety in this group may prove useful.

Because of another factor, the present plantings, Zinfandel is included in this group. The Zinfandel has a permanent place in California for a distinc- 
tive type of wine, but it is already the most extensively planted red-wine-grape variety, and only occasionally will its new plantings be as profitable as those of the varieties listed in previous sections. All the varieties listed here have one or more defects, and one should plant them only after considering their handicaps.

\section{WHITE VARIETIES OF LIMITED RECOMMENDATION}

Under this head are included blending varieties, Burger and Servant; varieties having a muscat flavor, Muscadelle and Muscat of Alexandria; table or natural sweet wine varieties, Aligote, Chenin blanc, Gray Riesling, Peverella, and Vernaccia Sarda; and dessert wine varieties, Inzolia and Verdelho. These have a wide range of climatic adaptation, some being suited to the cooler regions and others to the warmer. Table 18 gives the analyses of musts and wines of these varieties.

Aligote.-This variety is used for standard white wines in the Burgundy district of France. In California it appears to be capable of somewhat better results. Apparently no previous tests have been made.

The Aligote is of average vigor, productive, and ripens its fruit in midseason. The fruit is clean and reaches the crusher in good condition. The juice yield is average.

The musts were well above average in composition. Its wines have uniformly been clean and of average or higher quality. The flavor has been mildly rich and distinct, the color excellent, and the keeping good.

The Aligote will produce standard and better white wines in regions II and III. In I and in IV it will also produce average wine in most years. Under further testing more restricted areas may appear specially desirable. It should find a definite place in regions II and III.

Burger.-Burger is among the most extensively grown white wine varieties of California. The source of this variety is uncertain, but it is probably of rather minor importance abroad or its identity would have been determined.

The vines are of only moderate vigor, but will bear immense crops on fertile soils and good crops wherever grapes will grow. The vines are hardy and require spur pruning. They should be opened up as fast as possible in their development in order to separate the clusters.

The clusters are very large, irregular to conical-shouldered, generally very compact. The berries are of large-medium size, round, very juicy, waxy-yellow, without any particular flavor. The skin, easily broken, renders the fruit very susceptible to handling injuries in harvesting and to damage by early rains.

Except in region I the acid content has been only average, with many lots running low-this despite the relatively low to very low Balling degree of most lots. Although not a high-acid sort, Burger would probably possess a better balance, as regards sugar and acid, if not permitted to overbear. Often these vines are so heavily loaded that the fruit must be left on them for weeks after the normal time of harvesting in order to secure the minimum amount of sugar. Meanwhile the acid continues to decrease. This condition is most serious in the warmer regions, where the acid is normally lower and where it is depressed more rapidly because of the higher temperatures.

The wines from region I were very light in color and body, tart, and fruity, 


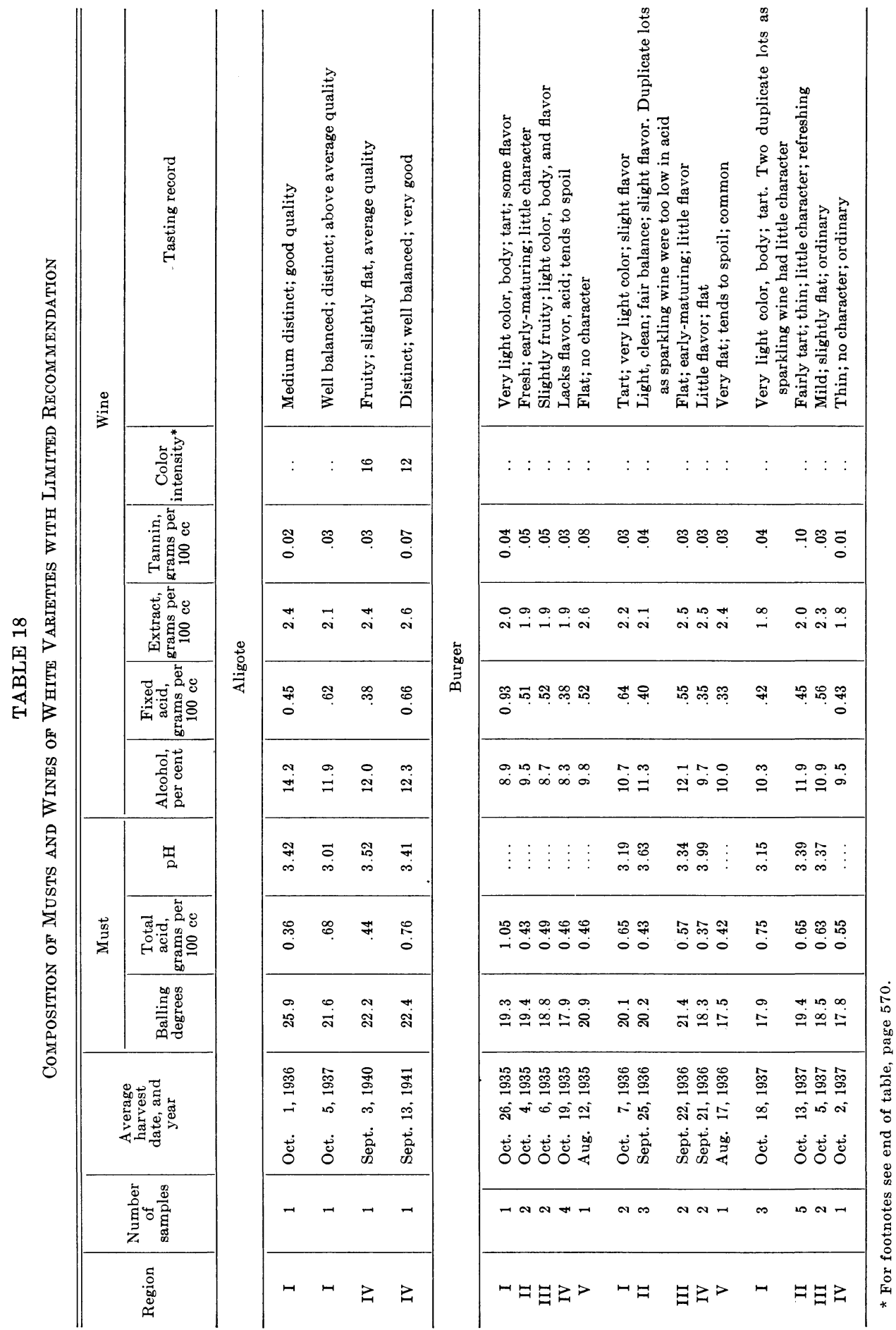


Feb., 1944] Amerine-Winkler: Composition and Quality of Musts and Wines

565

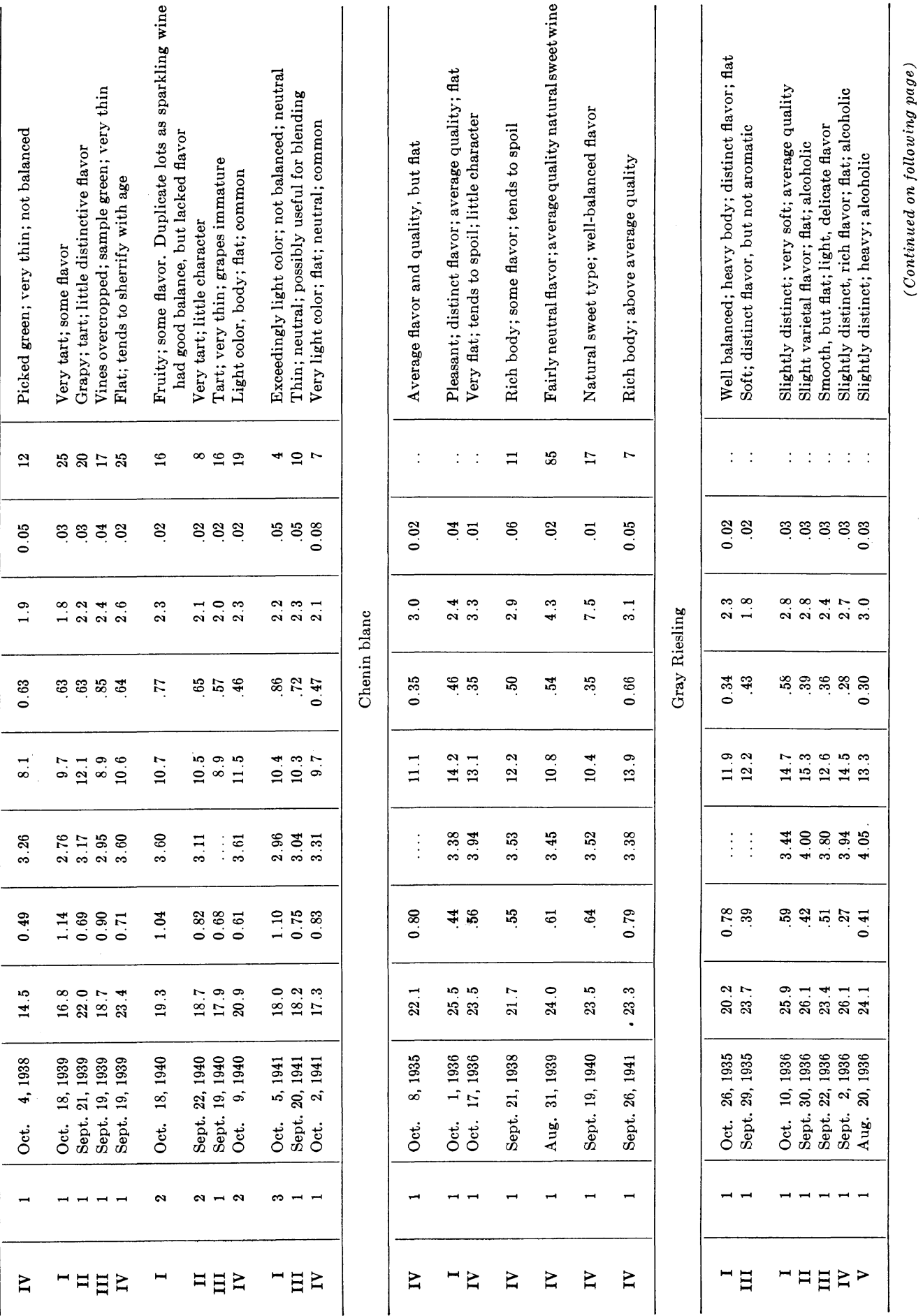




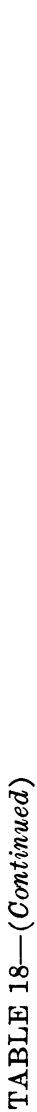

$\stackrel{0}{3}$

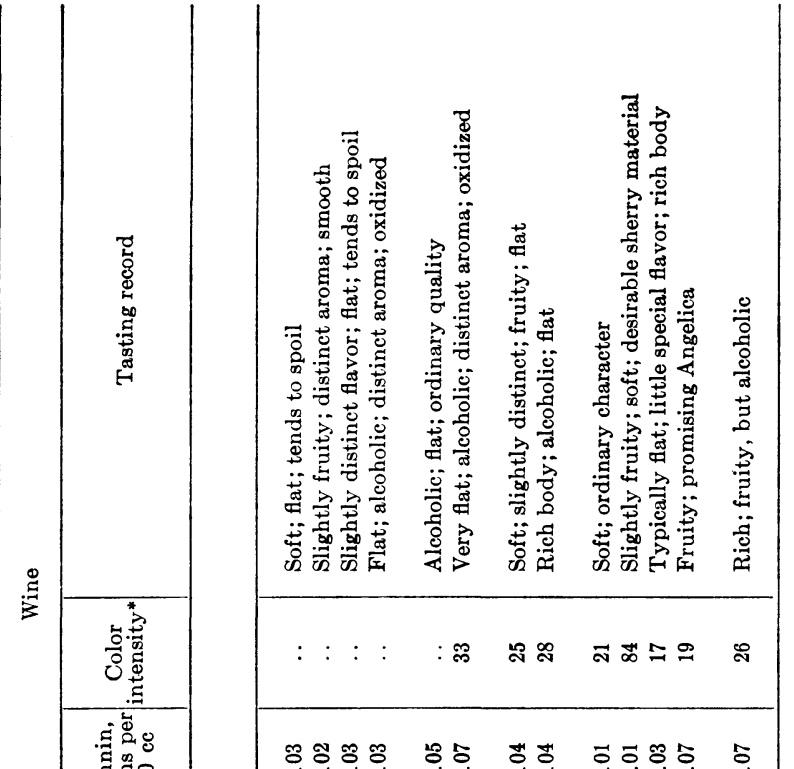

है

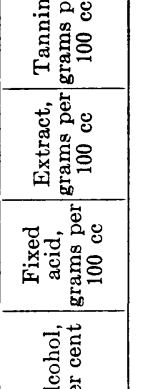

窝

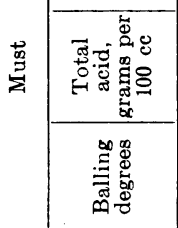

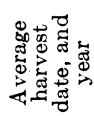

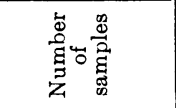

范

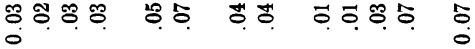

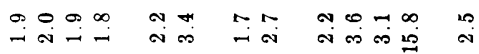

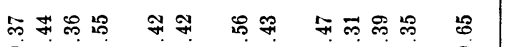

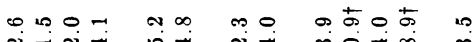

エコささ

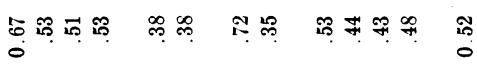

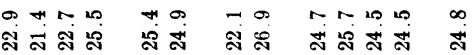

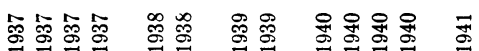

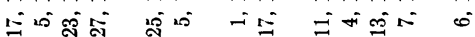

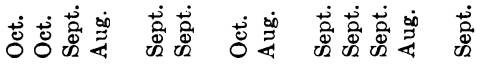

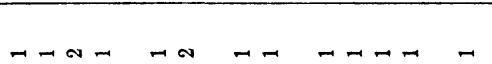

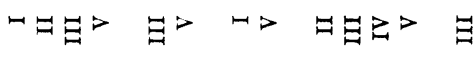

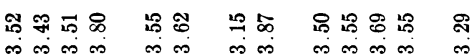

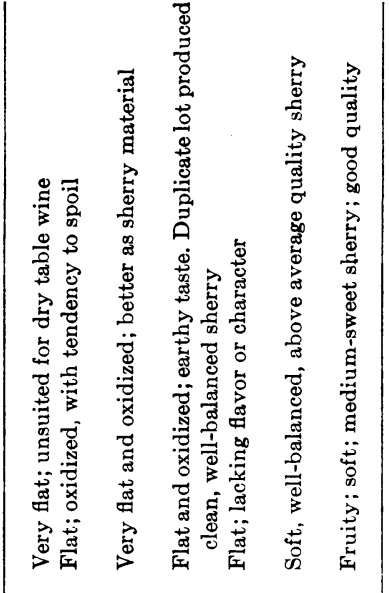

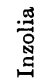

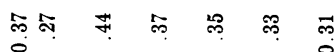

0,000000

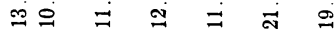

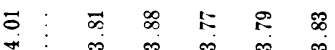

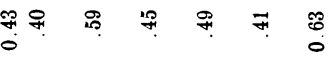

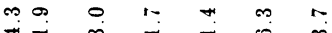

गี

兽

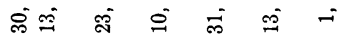

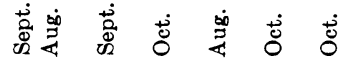

\begin{tabular}{|c|c|c|c|c|}
\hline$-\sigma$ & - & - & - & $\infty$ \\
\hline$\nexists>$ & $\geq$ & $z$ & $>$ & Z \\
\hline
\end{tabular}




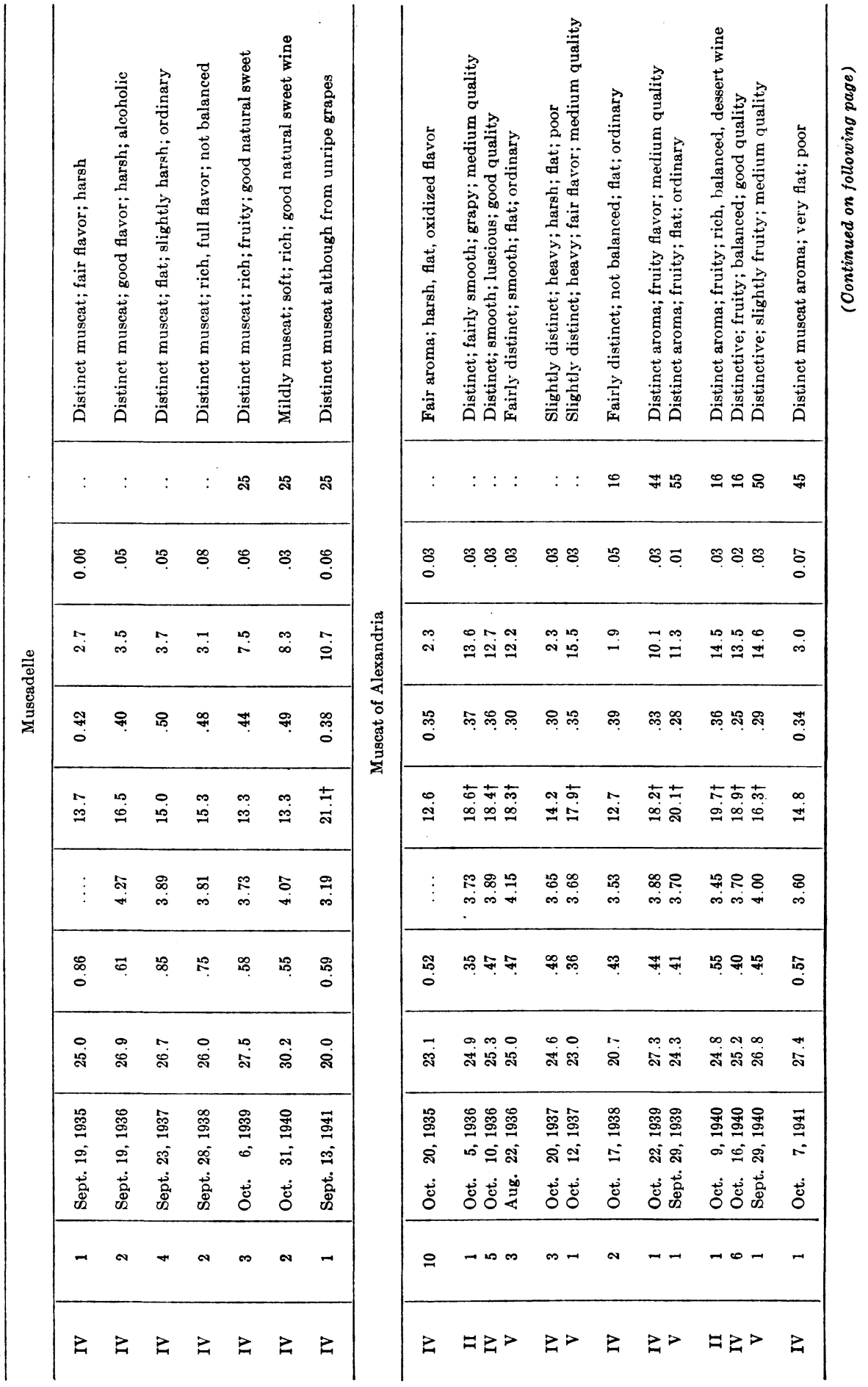




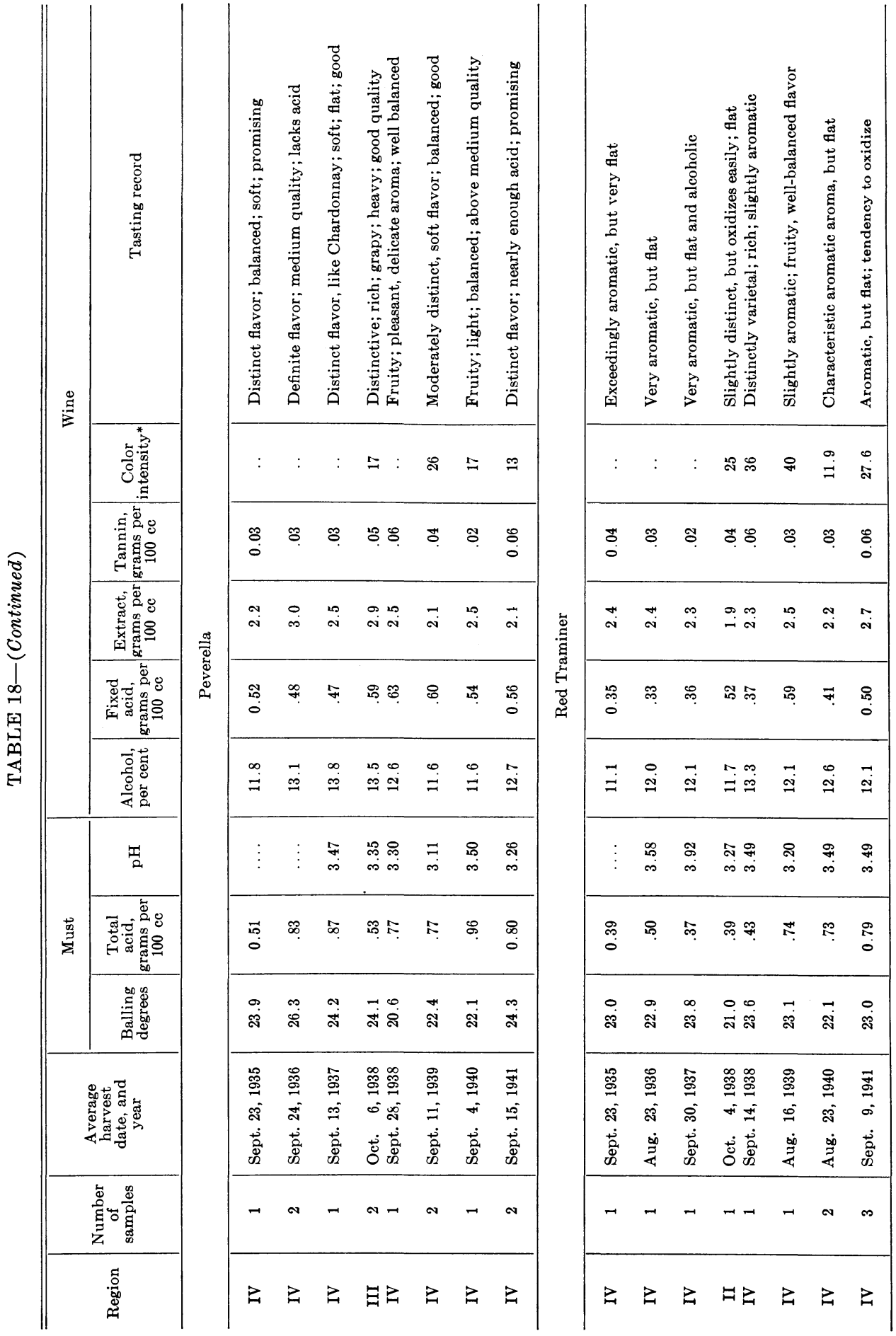




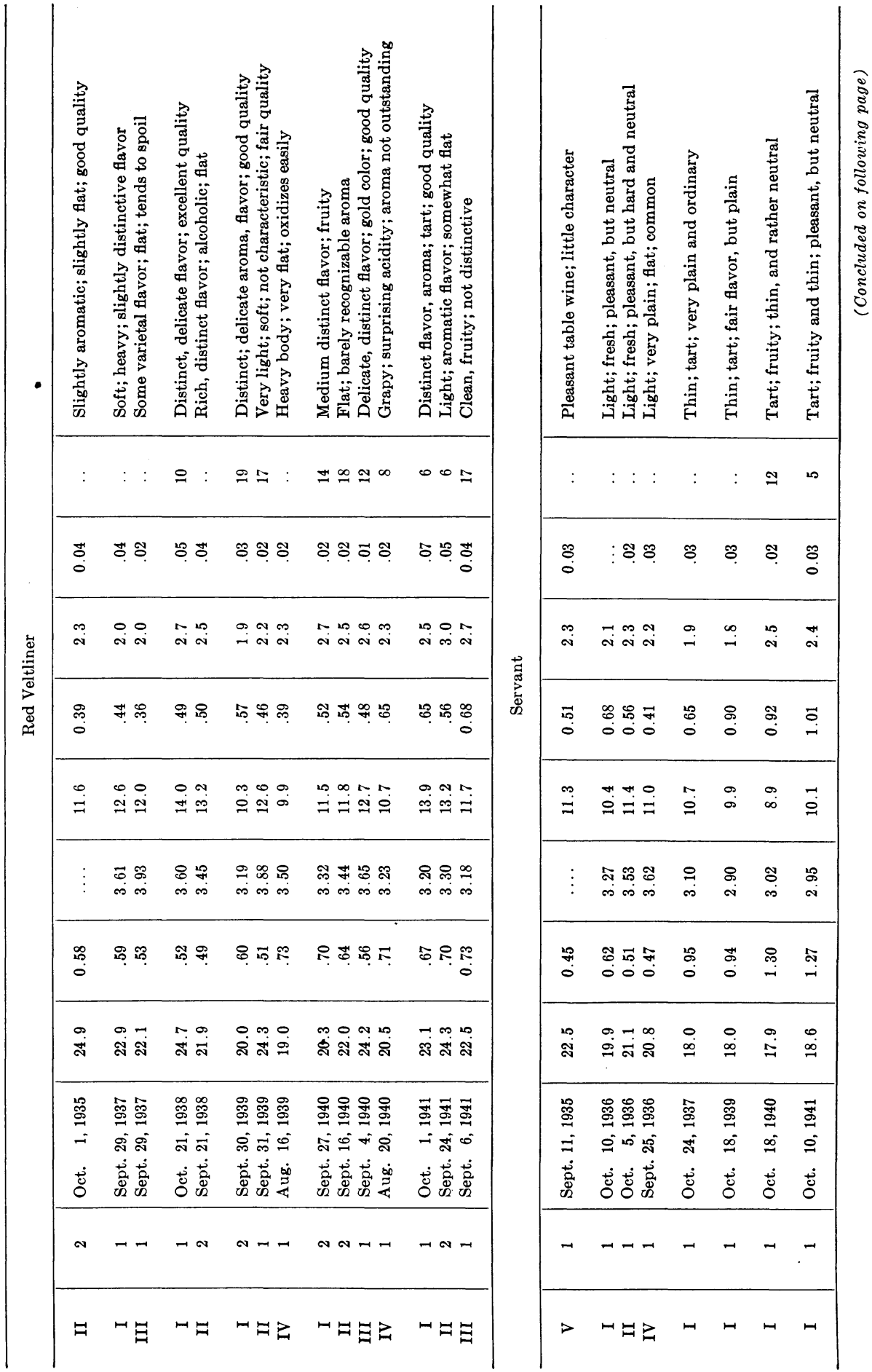




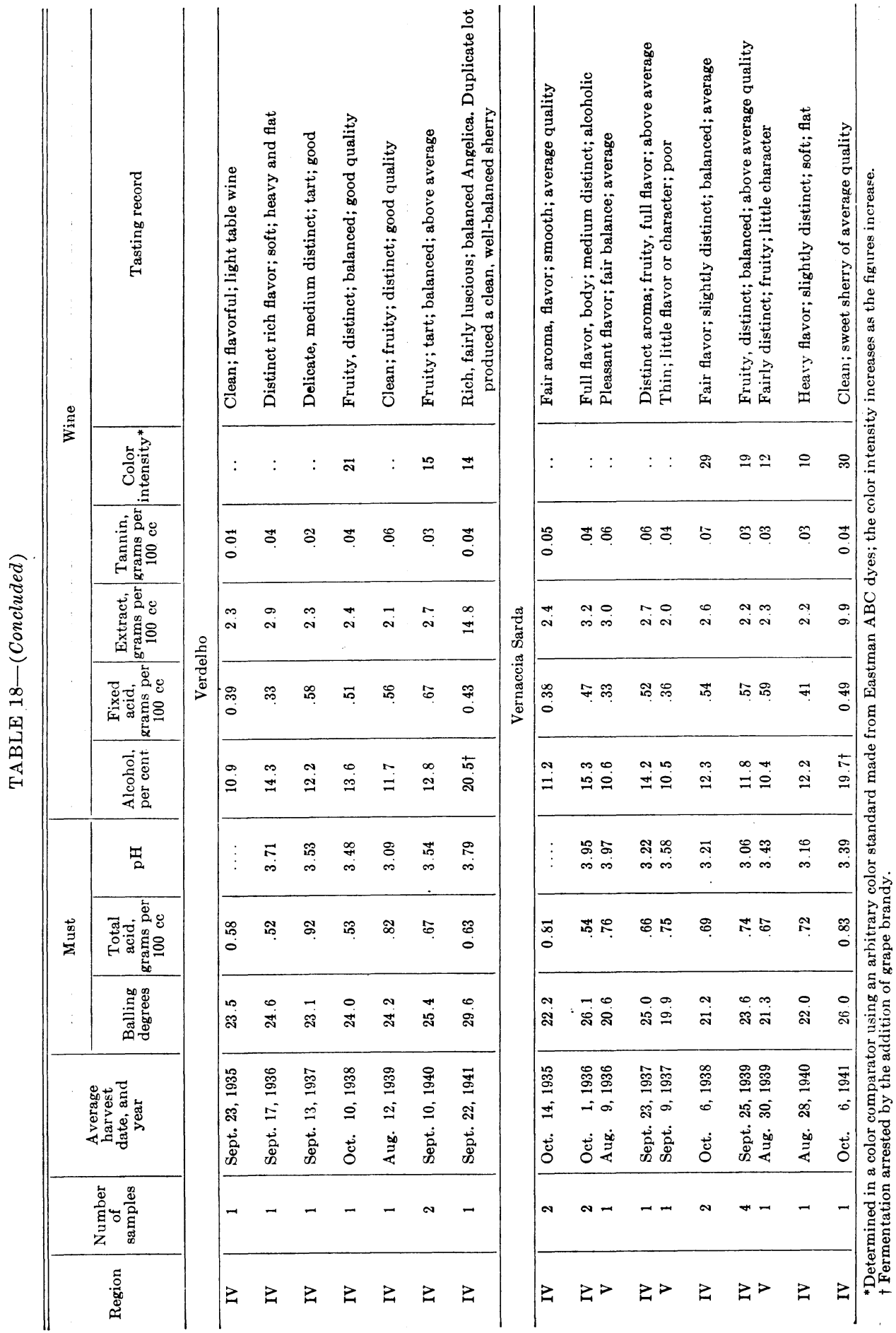


with some flavor. Although pleasant and refreshing, they had little substance or character. Sparkling wines produced from some of these lots by the bottle fermentation method, were fair to well balanced, but lacked flavor.

In region II the Burger reaches its best development year after year. The grapes mature every year and except in the occasional hot years possess a fair balance of sugar and acid. The wines were light, clean, tart, fruity, fairly well balanced, with some flavor and distinctiveness. They have matured early into palatable, refreshing wines of average quality. In the bottle they have developed a pleasing but slight bouquet.

In the cool years those of region III were pleasant and refreshing; but in warm years like 1936 they were flat and very ordinary. The lots from region III for 1939 and 1940 were too immature, because of overcropping, to produce balanced wines.

All the wines of regions IV and V were flat, lacked flavor, and tended to spoil.

The Burger has been considered to be preëminently a blending wine. The results support this finding within certain limits. Unblended, the wines lack flavor and character. In this form they can be considered only as neutral and thin though sometimes pleasant wines. Their neutrality or plainness, on the other hand, fits them for blending where the purpose is to reduce body, alcohol, flavor, and aroma. In warm years they have been used for equalizing the fermentation of high-sugar grapes. They can add little or nothing except lightness, the only property or component in which they have been outstanding. For use in blending the source should be limited to region II, and possibly III; the products of IV and V have proved unsuitable.

The Burger will not regularly mature in region I. Here it is also very subject to bunch rot in the years of early rainfall. In region II and in the cooler parts of III it will produce a light, pleasant, refreshing wine of ordinary character. These wines may, in addition, have considerable value for blending. The results in regions IV and V do not justify further plantings there. The use of these wines for blending is being overdone, to the detriment of some otherwise quite good wines.

Chenin blanc.-The Chenin blane is the principal white variety of Anjou and Tourraine, France, where it produces dry and natural sweet table wines as well as sparkling (mousseux) wines. Although now found in several vineyards in California (often incorrectly as Pinot de la Loire and White Zinfandel), it was apparently not tested by either Hilgard or Bioletti.

The vines are vigorous and productive. The clusters are long, conical, winged, compact; the stem is very long and tough; the berries are mediumsized, oval, with tough skins. The fruit resists handling injuries and rot except in humid regions where, when overcropped, it develops considerable bunch rot. It is crushed without difficulty, and the juice yield is good.

At Davis it has produced table wines of slight flavor, full body, medium-tolow acidity, and average quality. These wines have tended to be heavy and lacking in freshness.

The table wine from region I was pleasant, distinctly flavored, heavy but not badly balanced, and good in quality. Even for this region it lacked in acidity; but 1936 was a season favoring low acid. 
To date, the natural sweet wine has been the better product. It was well balanced in its several components, though not particularly distinctive. This better showing as a natural sweet wine is not surprising, since the product in France more often than not retains a quantity of sugar. The wines of this type are not equal, however, to those of the Semillon, at least in the districts in which it is now grown.

On the basis of the results to date, it appears that Chenin blanc will, in the proper environment, produce standard table wines and that its quality is relatively the same here as abroad. It cannot compare with the quality, character, and finish of Pinot blanc, Chardonnay, and Semillon.

The variety may, because of its productivity, find a place on the fertile valley soils of regions II and III. In the cooler years and with early rainfall it will suffer from excessive bunch rot. It has no place in regions IV and V.

Gray Riesling.- - It is most unfortunate that this variety has become established in California under this name, for it possesses none of the genuine aromatic qualities of the true Riesling. It has a mildly spicy flavor, but nothing more.

Gray Riesling is a strong, vigorous grower. During the development years it should be pruned long to insure full crops. Once the vines are well established, long spurs may suffice. The clusters are small, conical, shouldered, compact; the berries medium-sized, oval, and greenish-pink to brown. Since the fruit is very firm and difficult to crush, the juice yield is small.

The variety is rather susceptible to mildew, but otherwise reaches the winery in good condition except when early rain causes rot.

The table wines from regions I, II, and III were slightly distinct in aroma and flavor, soft, fairly well to well balanced, ordinary to good in quality. None of them reveal possibilities of anything more than sound, clean table wines. Their primary weakness was a deficiency in acid.

The table wines from regions IV and V were full-bodied and lifeless. Even though more timely harvesting would have improved them, they would still have remained unbalanced and flat.

Dessert wines of the Gray Riesling have shown promise for both sherry and Angelica. In these types the balance has been good, and the softness and mildly spicy flavor are desirable.

The results indicate that the Gray Riesling can produce clean, standard table wines on the more fertile soils of regions I and II and the cooler parts of region III ; but at present no plantings are recommended. The wine is too soft and undistinguished to compete with the better varieties. It should not be planted for table-wine production in regions IV and V. Here it produces good to very good dessert wines, but its production may be a limiting factor. Since other varieties are already known to be useful, it is not recommended. Should a demand for a "natural" white port develop, plantings in regions IV and V should be considered.

Inzolia.-The Inzolia is not suitable for dry table wine, being very low in acid at even a moderate sugar content. Because it ripens slowly, not attaining high sugar except late in the season under the best conditions, it is likewise not suitable for Angelica and therefore seems useful only for sherry material.

The grapes reach the winery in very good condition even after early fall 
rains. Their texture is very firm, crushing is somewhat difficult, and the juice yield is low. All the table wines produced between 1936 and 1938 were flat and lacking in character, and in some cases showed deterioration shortly after they were prepared. The sherry material and sherries made during 1938 to 1940 were, on the contrary, well balanced, and acquired good sherry character after moderate baking.

The variety could be recommended only for regions IV and V. Until, however, further tests demonstrate a higher quality in the sherries, Inzolia is not recommended even there, since Palomino is available. If plantings of any other variety are contemplated for sherry production, the Inzolia is suggested.

Muscadelle.-The vines of the Muscadelle are vigorous, with slender semiupright canes. Production has in some instances been disappointing, apparently because of improper pruning rather than variety, and usually only with young vines of limited development. At Davis five-year-old vines that were spur-pruned produced only 18 pounds apiece, whereas cane-pruned vines produced 27 pounds. Two years later the production under the same pruning treatments was 25.7 and 27.3 respectively. There has been no difference since. As is shown by the vine growth, as well as by the composition of the fruit, the retention of some canes during the first six or seven years has been highly beneficial. The variety is moderately resistant to mildew. Since it leafs out late as compared with many varieties, it may escape spring frosts in some locations.

Since the clusters are small, 3 to 6 inches long, loose and slender, harvesting costs are somewhat above the average. The skin is thick and tough, and the berries are very firmly attached to the pedicels. These qualities greatly increase the resistance to rot and mechanical injuries : the fruit can be left on the vines until very ripe, and the large amount of foliage prevents sunburn or raisining. The pulp is soft and yields only a moderate amount of juice. The free-run juice is very thick, and clarification of the must is therefore difficult.

The dry wines from region IV have been very rich in the muscat component, but usually heavy, alcoholic, and not too well balanced. In general they have been harsh, lacking in life, and poorly finished. The natural sweet wines have been much better balanced for the type and seem to indicate the place for the variety. In these the sugar appears.to mask the harshness, and the other components become quite harmonious. Even so the wines do not equal those of Muscat Canelli or Orange Muscat.

In region III the variety may have a limited place for blending in the production of natural sweet wines. Here and in region II it may resist unfavorable spring and fall weather conditions somewhat better than the other muscat varieties. Elsewhere other varieties of more pronounced aroma, better general balance, lower harvesting costs, or greater productivity will be preferable.

Muscat of Alexandria.-Only of late has the Muscat of Alexandria been used on a large scale as a wine grape in California, although occasionally used in Spain for wine. It is preëminently a raisin grape and, as such, has made a place for itself both here and abroad, particularly in the Malaga district of Spain.

The clusters are long and loosely set with large berries of nonuniform size, usually obovoid. The fruit ripens in mideason unless the vines are overcropped. As the foliage is not dense, much sunburning or raisining may occur 
if the fruit is left on the vines too long. The proper period for harvesting depends on the size of the crop and the amount of the second crop. Much undue raisining is permitted to occur because the grower harvests the light-cropped vines at the same time as the very heavily laden vines, which may contain much second crop. To be sure, the muscat flavor does not adequately develop until the grapes are yellow. On the other hand, the flavor of wines from overripe, raisined grapes is flat and raisiny, while the color is too dark. The ideal picking arrangement would be to separate the green from the ripe fruit at picking time and to use the green grapes for grape brandy to be used in arresting the fermentation of muscatel wines.

The dry table wines from Muscat of Alexandria have been a failure-harsh, poorly balanced, flat, and only poor to ordinary. Although the young wines have had a pronounced aroma, this has been practically lost by the time they were mature. The variety does not contain sufficient acid for dry wines, and its characteristic harshness is unleashed in this type. By adding large amounts of acid and fermenting at low temperatures one can produce a palatable dry muscat wine. Even so, the wines lack in fruitiness and are rather coarse.

Dessert wines have been more promising--fairly smooth, well balanced, fruity, and good in quality. The characteristic varietal harshness is usually sufficiently covered by the sugar in this type to pass unnoticed. The flavor, however, is not the best. Hilgard" wrote, "Though the Muscat flavor is in such high repute for 'vins de liqueur' in Europe, it seems somewhat discredited in California. This is doubtless due to the use of the Muscat of Alexandria, which is much inferior to the Muscatel [sic Muscat Canelli] for this purpose." In the dessert wines the muscat aroma is preserved much better, so that the wellmade wines are rich in this property at full maturity.

Generally, the dessert wines from Muscat of Alexandria have not equalled those from Muscat Canelli or Malvasia bianca.

Muscat of Alexandria is well adapted for producing raisin and table grapes and bulk dessert or muscatel wines in the San Joaquin Valley (region V). In the southern California areas of region IV this variety attains its highest quality, particularly around Escondido. Except for the latter location, in which other varieties have not been tested, its dessert wines are surpassed by those of Muscat Canelli and Orange Muscat. Where facilities are available and where the very best muscatels are esired, these other varieties should be preferred to it. The post-Prohibition demand for cheap muscatel wine may be only transitory. At any rate, the wisdom of producing large quantities of very sweet, easily recognizable, aromatic wine from muscat grapes is questionable. Judging from the enological experience of Italy and France, there is a place for high-quality muscat-flavored dessert wines. These can be better produced by using the better muscat varieties mentioned above.

Muscat of Alexandria is a moderate grower on rich soils, but is not successful on very sandy soils. Its production is governed by its vigor. It is somewhat more productive than Muscat Canelli on the same soils, but it has been equalled in production by Orange Muscat wherever the two have been compared.

Peverella.-Peverella is a variety of the southern Tyrol. Its value was not recognized by Hilgard, who obtained only ordinary wine from it. Bioletti,

${ }^{47}$ See citation in footnote 16, p. 496. 
however, recommended it for the coast counties, and he also found it to produce standard wines under warmer conditions.

Its clusters are large, conical, and closely set with medium-large, firm, shortoval berries. The fruit matures in good condition. The berries are easily crushed, and the juice yield is slightly above average. On fertile soils the vines are vigorous and productive.

Most samples of must from region IV have had a good acid content; none have been very high, but neither have those of low acidity been very low. As a result the wines have been fairly well to well balanced. They have been distinct in flavor, fruity, soft, rich, full-bodied, and medium to good in quality.

The Peverella should be a good variety for the cooler parts of region IV and perhaps will reach its best quality in III. Here it will have sufficient acid in most years and will ripen its fruit. In region $\mathrm{V}$ it will be just another variety because of insufficient acidity, while in I and possibly II the fruit may fail to mature. Peverella is recommendable for planting in region III and probably IV for standard white table wines.

Red Traminer.-This variety is well known but of limited importance in Europe, where it is frequently called the Gewürz Traminer. It has small, nearly entire leaves. The clusters are likewise small. The berries, almost round, are closely set in the elusters. The skin is rather thick and russet or pink late in the season. The grapes ripen early and in region IV will raisin if left on the vines too long after maturity; but they reach the crusher in good condition because the skin is so thick. The juice yield is below average. Unless the fruit is pressed immediately after crushing, the musts and wines will have too much color.

In region IV, if left until September, the fruit becomes too low in acidity. Even in August the $\mathrm{pH}$ is too high for the best table wines. Unfortunately it has not been tested sufficiently under the cooler conditions of regions I, II, and III to predict accurately its performance. Hilgard tested it in several locations in the Santa Clara Valley, probably in region II. He reported very low acidity, but this was probably because of lateness in harvesting his samples.

Although very low in acidity and a poor producer, Red Traminer was recommended for the coastal counties by Bioletti in 1907. The reason is obvious. The grapes and wines have a very distinctive aromatic flavor even in region IV. Every sample produced has been aromatic. This almost muscat type of flavor has brought the variety into general use in Alsace in France. The flavor is not associated with a harsh, bitter after-taste, as in the usual dry muscat. Although it can definitely be stated that the Red Traminer should not be planted in regions III, IV, and V, a final report for regions I and II cannot now be made. Comparing the available data, however, it is recommended for trial plantings only in the cooler parts of region I.

Red Veltliner.-This late-ripening variety produces well. The clusters are large and winged. The berries, small and oval, are closely set. Lateness of ripening and compactness of cluster may result in some rot during early rainfall. The juice yield is average.

This variety is planted in several locations in regions I, II, and III. The musts have had only an average amount of acid even when the harvest was too early. The best wines came from region I, especially. San Benito County. Re- 
gions II and III produced wines variable in quality, but not consistently distinctive in flavor. Only two wines were produced from region IV. Of these, one was flat and heavy; the other of good acidity, but only ordinary flavor.

Hilgard tested a Green Veltliner, which he did not recommend. Bioletti, though familiar with the variety, failed to mention it. Not a single outstanding wine has been produced from it, though some were very sound, clean, and palatable. Red Veltliner is recommended for standard wines in region II.

Servant.-Because of its large berries the Servant has generally been considered a table grape. It is a vigorous grower and prolific bearer wherever it has been planted. The very large clusters are well filled with thick-skinned berries. The fruit withstands unfavorable weather conditions very well, better than practically any other variety.

In regions IV and V the Servant matures with a Balling-acid ratio adapting it for table use ; but there it is poorly suited for table wines, being far too low in acid at $20^{\circ}$ Balling. Besides, its wine is deficient in flavor.

In the north coastal areas, on the contrary, its Balling-acid ratio adapts it for dry table wines. Here it produces a light, pleasant wine; but with little aroma or flavor. The musts are easily fermented, and the wine matures rapidly. It is too light to keep for a long time, but for blending with heavy-bodied alcoholic wines is equal to Burger. Several tests using wines of this variety from region I as a part or all of a sparkling wine base have given clean-tasting, neutral wines. Folle blanche from the same district, however, gave more flavorful wines for this purpose, as did other varieties as well.

The Servant can never be considered as producing more than a blending wine. Its products in region I and II will possess more acid at the same alcohol content than those of Burger, but neither variety has sufficient alcohol. Its fruit, too, is not so subject to rot as Burger. Under a few cool conditions of region I, therefore, it may replace the latter for blending wines.

It cannot be recommended for the production of Servant wines as such.

Verdelho.-The Verdelho is cultivated extensively on the island of Madeira. In California it has been planted very little. Its vines are above average in vigor. If clusters alone counted, it would be very productive; but the clusters are small. Longer pruning will increase the yields. The clusters are short to medium, conical, usually with one or more shoulders. The berries are small, long oval, their light green becoming yellowish at maturity. This variety matures its fruit early. The firm berries and loose clusters make the fruit resistant to bad weather.

Its dry wines from region IV have possessed a pleasing, rich, fruity aroma and flavor and have been sufficiently well balanced and finished to indicate merit. The wine of the hot season of 1936 was heavy and too low in acidity. The variety should be tested further, especially in region IV, for sherry. The present results with Angelica and sherry have been very promising and appear to agree closely with the earlier findings of this station. Hilgard stated $:^{48}$ "It acquires a marked and delicate 'rancio' very quickly and easily, and its full aroma and high quality make it very valuable as an addition in the making of sweet wines." Its fruit ripens regularly without undue raisining-a valuable characteristic in a dessert-wine grape.

${ }^{48}$ Full citation given in footnote 16, p. 496. 
The Verdelho will add quality to the white dessert wines of region IV. As elsewhere, however, the cost of harvesting the small clusters must be considered. For this reason and because of its low production, its place here is questionable. It may find its best use for blending purposes to add quality to thin sherries and Angelicas.

Because of its earliness, Verdelho is not so well adapted to region $\mathrm{V}$ as to region IV.

Vernaccia Sarda.-The Vernaccia Sarda is a vigorous grower and heavy producer. Its clusters are large, long-conical, shouldered, well filled to compact; the berries are medium-sized, round, and very dark green, with a medium-thick, tough skin. It matures in late midseason.

At normal maturity the fruit in region IV yielded a must of moderately suitable balance for dry table wines. The neutral character of this grape makes its wines, as might be expected, only average. They were mildly distinct, fruity, and full-bodied, typical of the standard table wines produced under such conditions.

Even the must of fruit grown in region $V$ retained a fair acidity. The dry wines, however, were of somewhat poorer balance than in region IV. Their flavor was less pleasing, and they lacked finish. All these wines displayed a tendency to oxidize, ullage requiring special attention in their development.

To date, the sherries have been only average. Although well rounded and full-bodied as dry wines, the sherries have not been too harmonious. With further aging they may show improvement.

In region IV the Vernaccia Sarda produces a table wine of about average quality. There it will merit consideration only for bulk wines. Because of a higher degree of acidity and a mildly distinct aroma and flavor it will, under most conditions, produce better white table wines than Green Hungarian, Palomino, or Burger.

Although not particularly well adapted to region V, Vernaccia produced some fair dry white table wines. Its use here should depend on the demand for common bulk dry white wines. In general it offers most promise as a blend in the production of sherry. It is not now recommended for planting in California.

\section{RED VARIETIES OF LIMITED RECOMMENDATION}

Most of the varieties listed here are suitable for red table wines in one or more regions. All have, however, one or more defects which limit their usefulness. These include Aramon, Beclan, Bolgnino, Charbono, Fresia, Grignolino, Gros Manzenc, Lagrain, Mammolo Toscano, Meunier, Mondeuse, Nebbiolo, Negrara Gattinara, Raboso Piave, Saint Macaire, Sangioveto, Tannat, Valdepeñas, and Zinfandel.

Also listed is a variety that produces blending wine, Alicante Ganzin; two dessert-wine varieties, Black Malvoisie and Tinta Cao ; and a muscat-flavored variety, Muscat Hamburg. The analyses of musts and wines of these varieties for various regions are given in table 19.

Alicante Ganzin.- - The Alicante Ganzin is a hybrid of the Alicante Bouschet and Aramon $\times$ Rupestris Ganzin. This indicates some American blood and the source of the abundant color; its juice is intensely red at maturity. The cross has also endowed the variety with some resistance to mildew. Its 


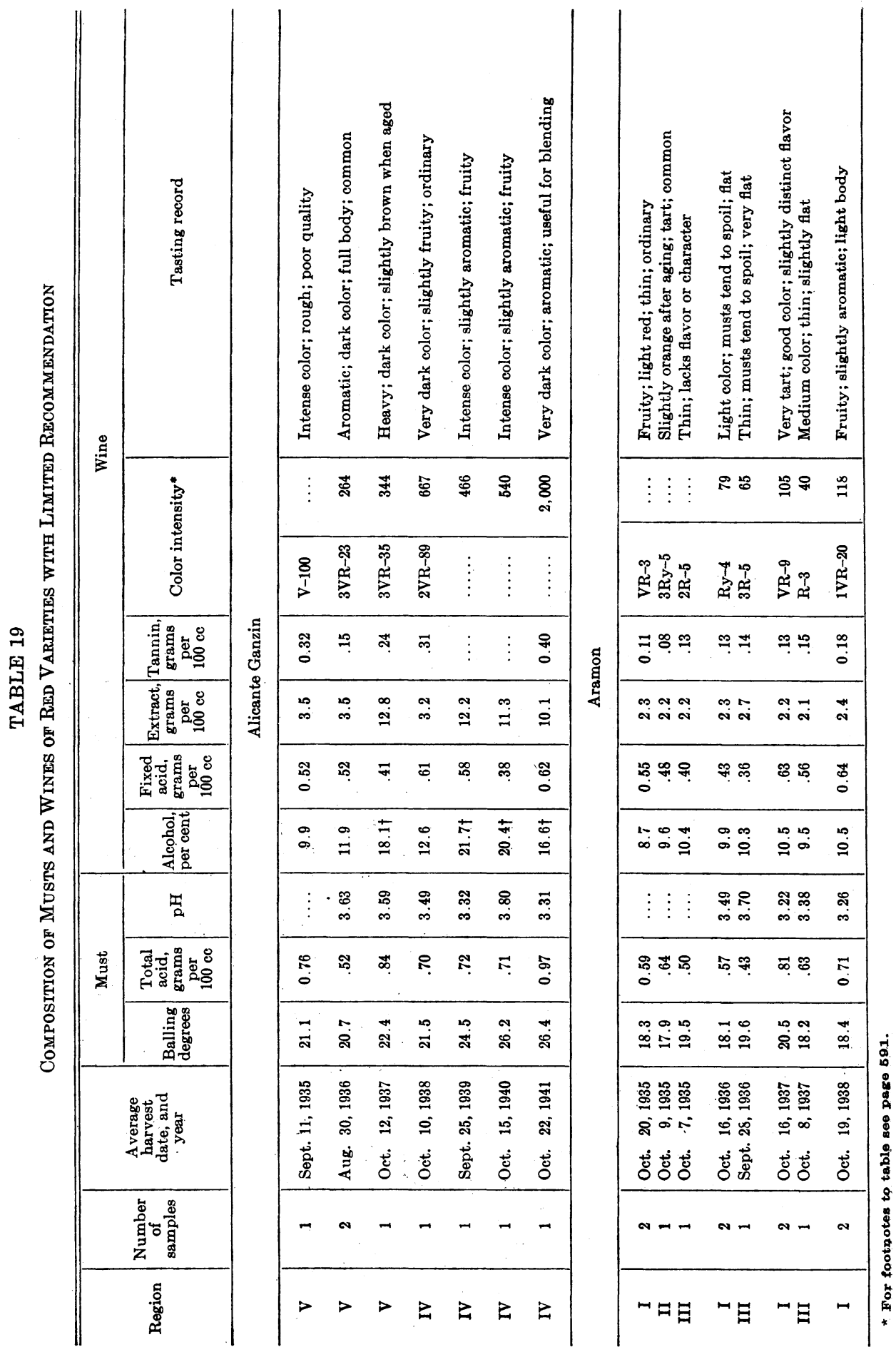




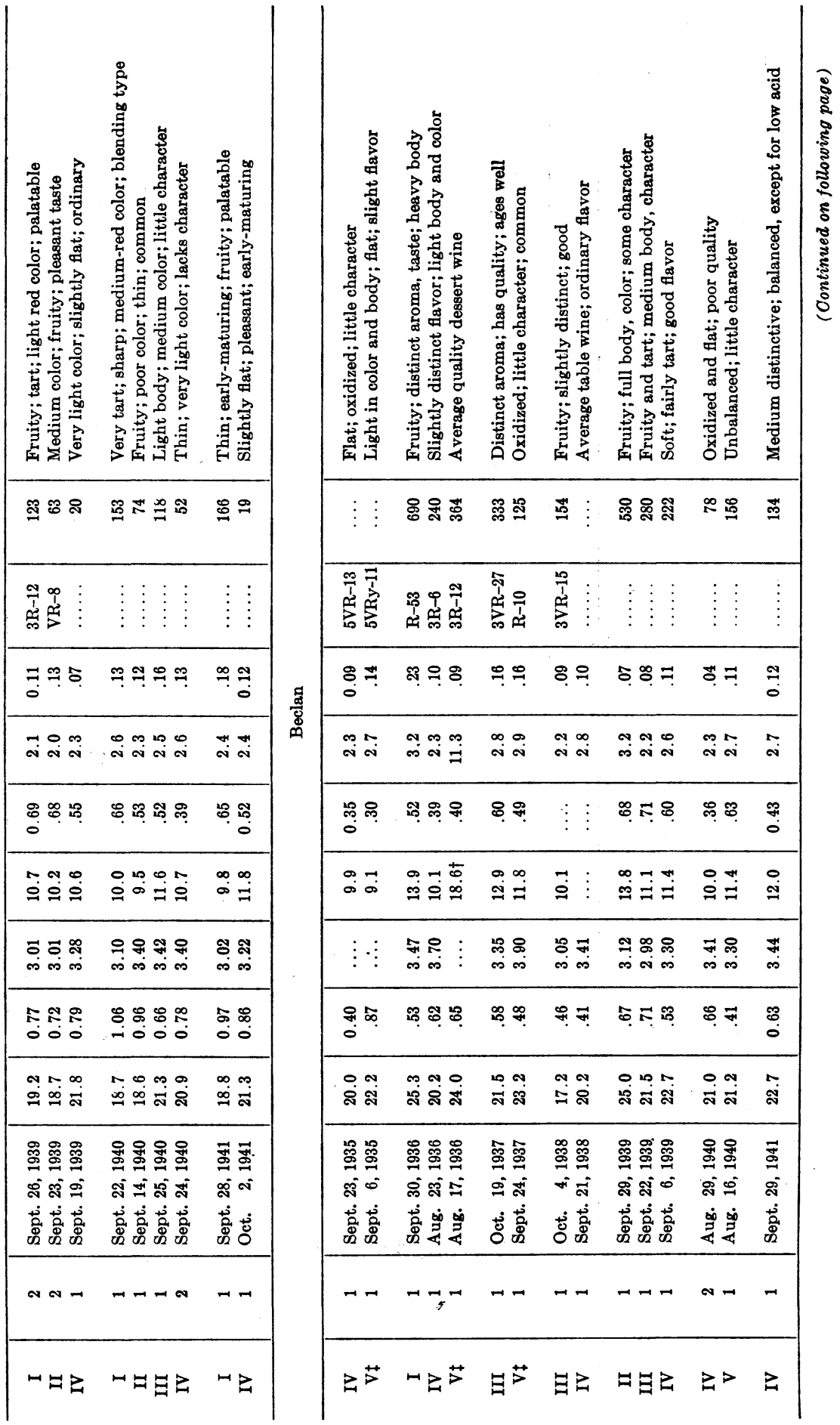




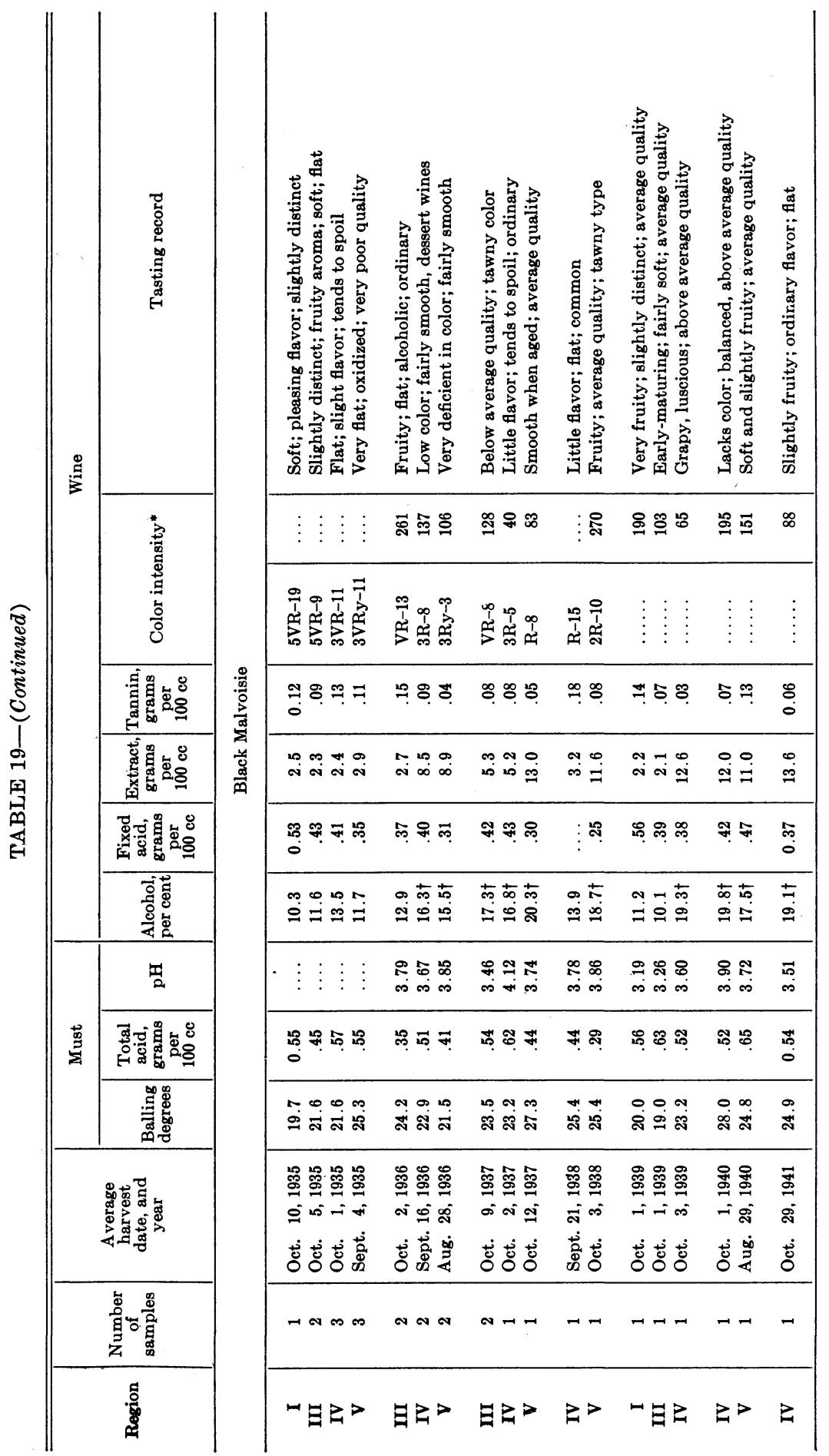




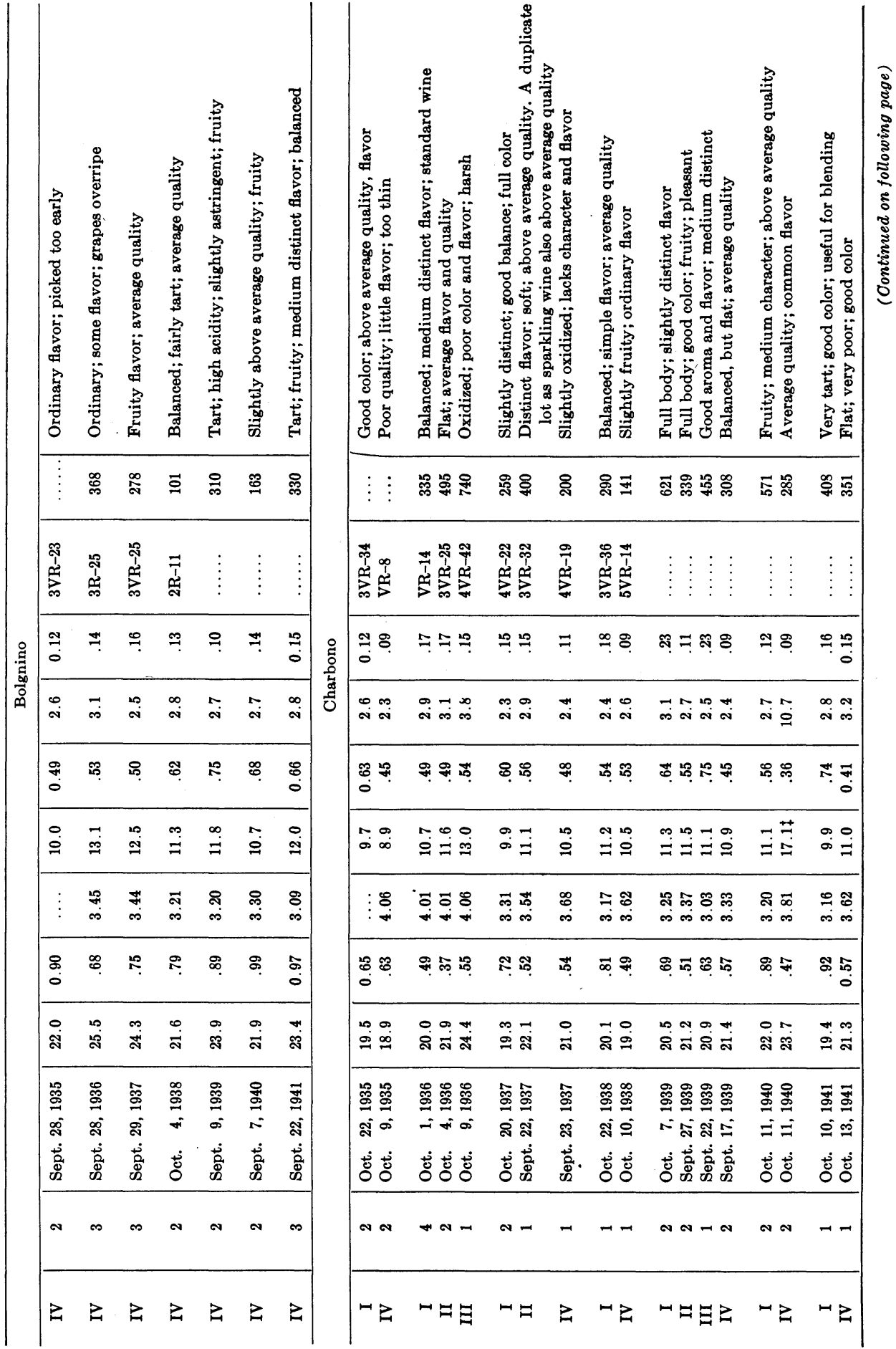




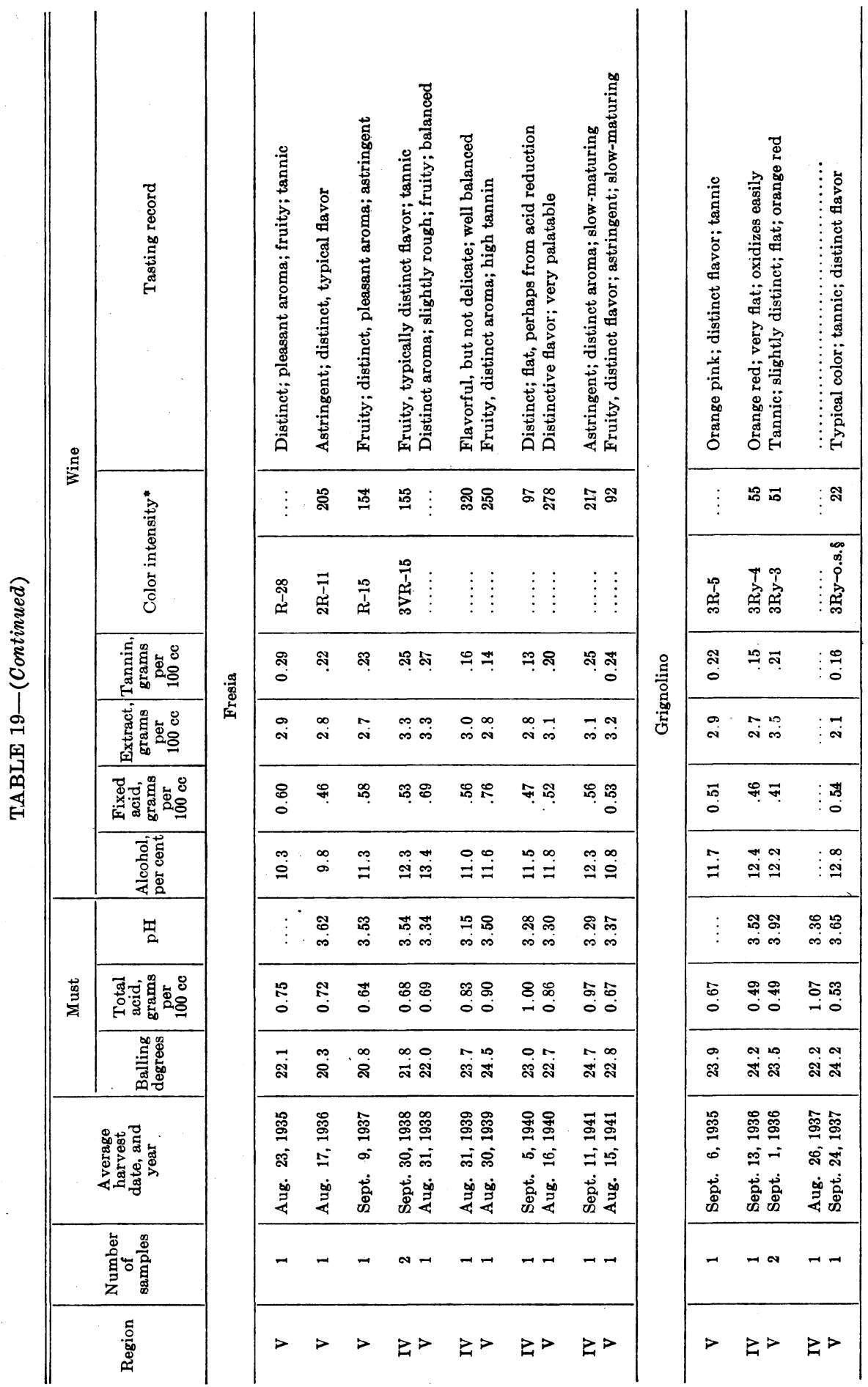




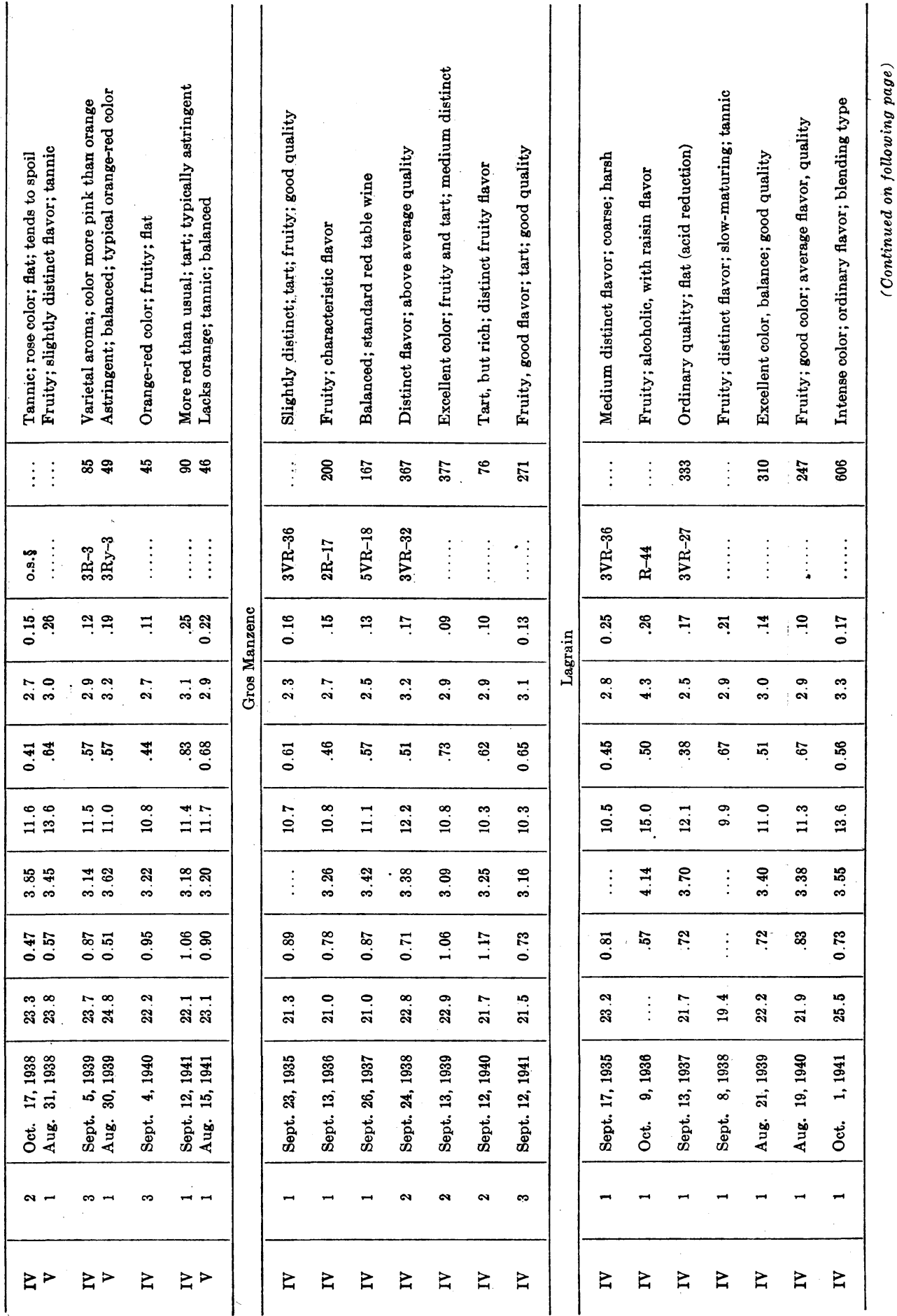




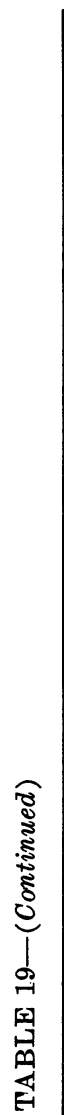

$\stackrel{8}{3}$
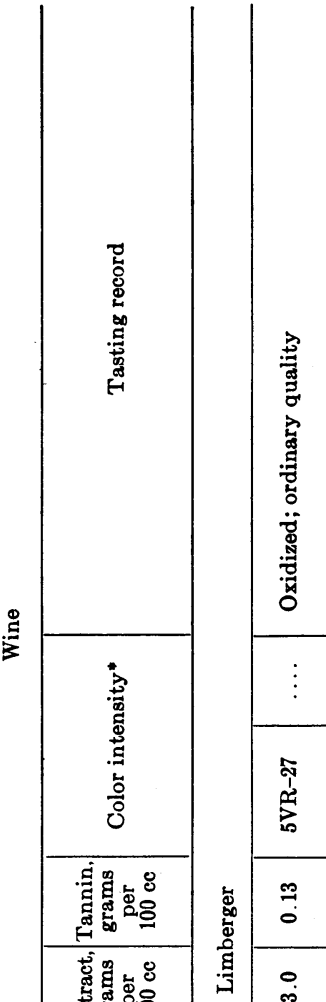

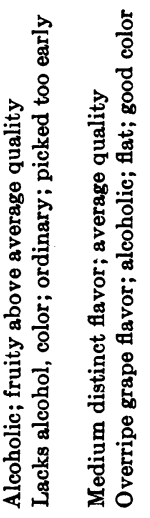

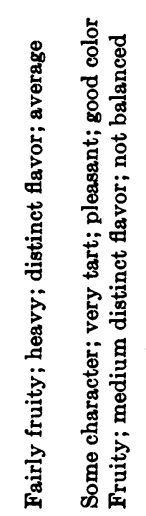

은 우
蜜

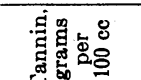

ثี艹

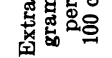

कृत्:

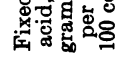

क용

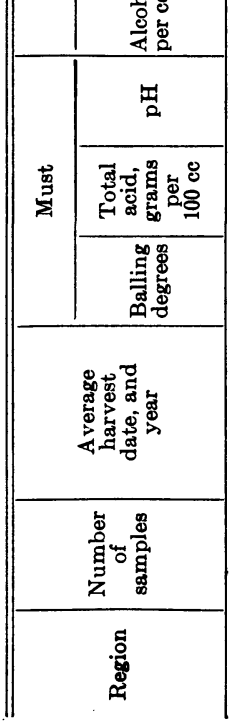

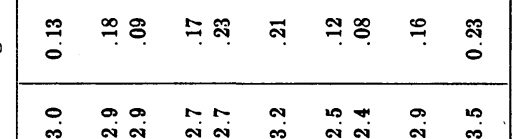

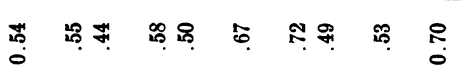

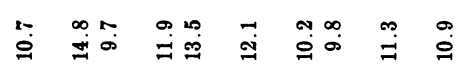

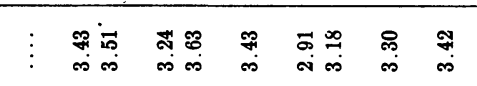

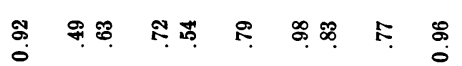

ง คน ค ค

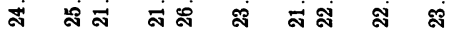

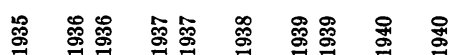

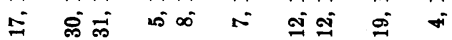

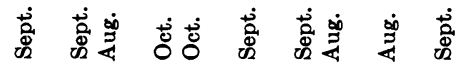

\begin{tabular}{|c|c|c|c|c|c|}
\hline- & $\rightarrow \rightarrow$ & $\rightarrow-1$ & - & $\rightarrow-$ & - \\
\hline$Z$ & $r z$ & ${ }^{H} Z$ & $Z$ & $r Z$ & $B$ \\
\hline
\end{tabular}

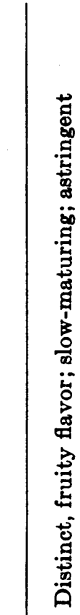

1 年

훙

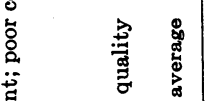

흉

.

(

$+$

哥

a

营

要

ส

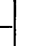

(1) 甉

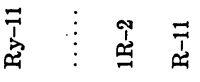

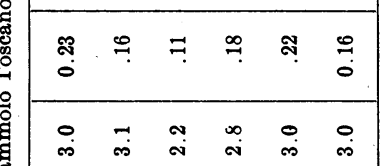

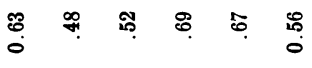

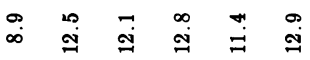

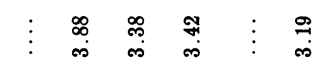

か

$00-000$

๙ุ

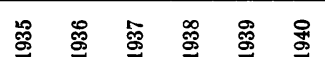

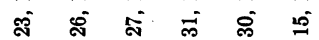

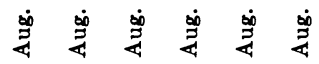

$--\rightarrow---$

$>>>>>$ 


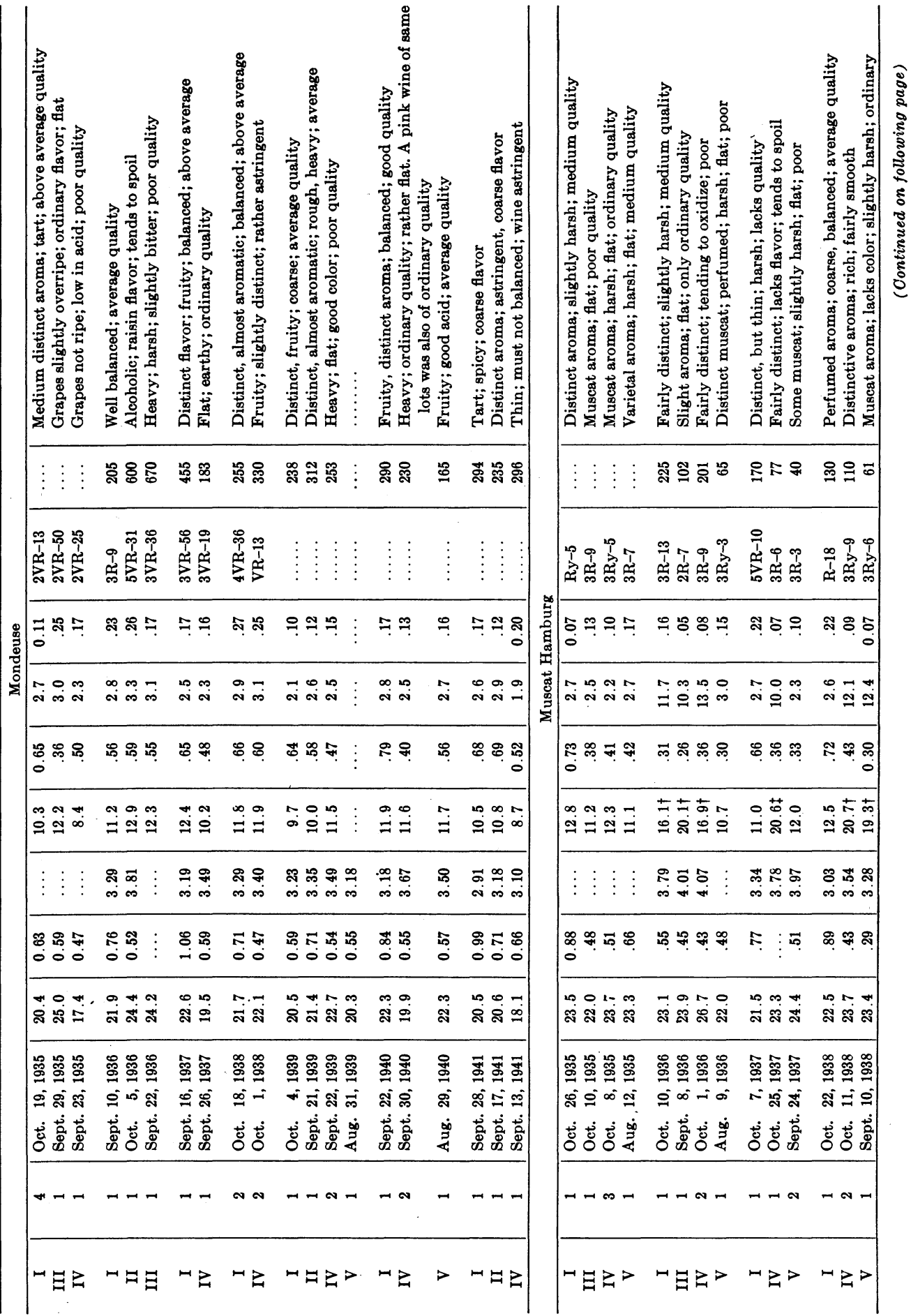




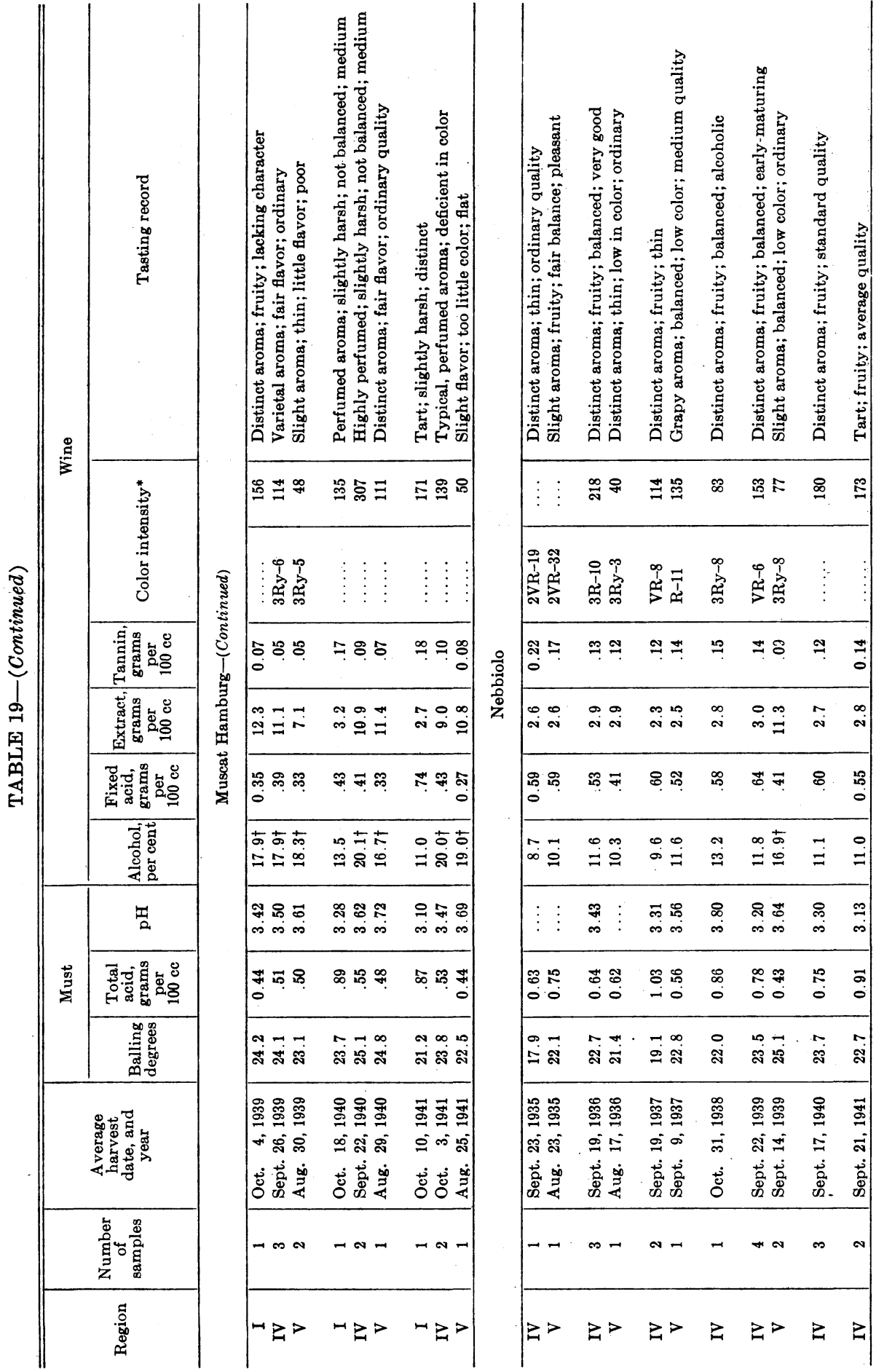




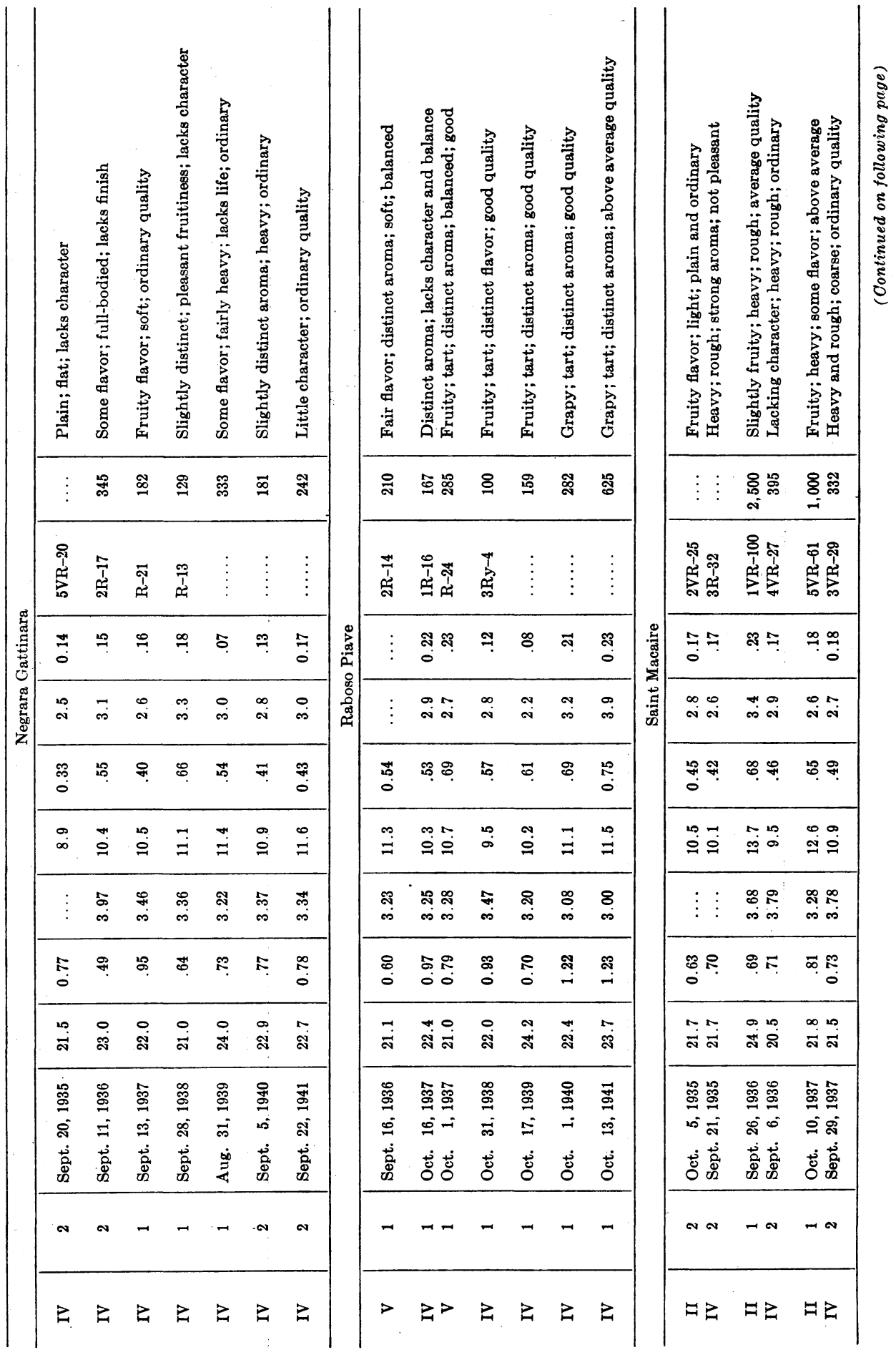




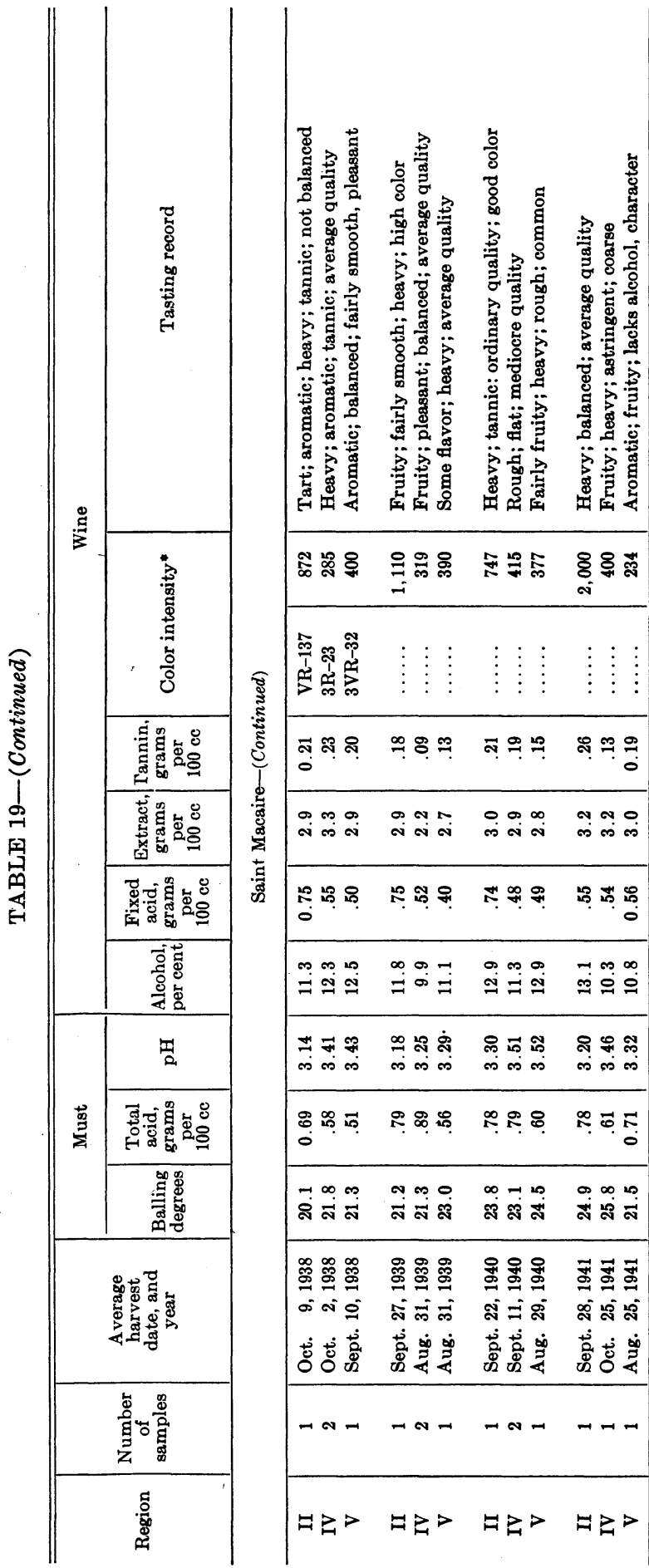

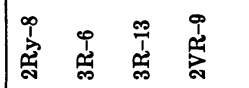

\begin{tabular}{|c|c|c|c|c|c|c|}
\hline 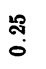 & $=$ & $=$ & สุ & $=$ & $\stackrel{2}{?}$ & $\stackrel{7}{\circ}$ \\
\hline$\underset{\sim}{\stackrel{\infty}{\sim}}$ & $\stackrel{\circ}{\ddot{\infty}}$ & $\stackrel{\circ}{i}$ & $\vec{\infty}$ & $\vec{\infty}$ & $\ddot{\infty}$ & $\ddot{\infty}$ \\
\hline$\stackrel{\text { Pُ }}{0}$ & 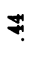 & $\stackrel{\infty}{+!}$ & $\$$ & ㄴํ & เด & ஜ̊ \\
\hline$\ddot{g}$ & $\Xi$ & $\stackrel{\infty}{\mathfrak{I}}$ & $\stackrel{\circ}{\stackrel{\Theta}{j}}$ & $\stackrel{\infty}{g}$ & $\stackrel{\infty}{=}$ & $\stackrel{\infty}{=}$ \\
\hline$\vdots$ & $\begin{array}{l}\varnothing \\
\text { i. }\end{array}$ & 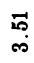 & $\underset{\infty}{\stackrel{N}{*}}$ & $\underset{\infty}{\stackrel{9}{t}}$ & 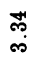 & 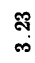 \\
\hline $\begin{array}{c}\infty \\
0 \\
0\end{array}$ & \%ั. & $\begin{array}{l}\overrightarrow{0} \\
0\end{array}$ & $\underset{\circ}{\delta}$ & ลิ & $\exists$ & $\stackrel{8}{\circ}$ \\
\hline $\overrightarrow{\underset{\Im}{~}}$ & 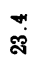 & $\overrightarrow{\text { iे }}$ & $\stackrel{\circ}{\not}$ & هُ & $\begin{array}{l}\infty \\
\text { జ̇ }\end{array}$ & İ \\
\hline 吕 & ஜ̊ & 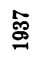 & 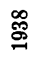 & 嵒 & 尽 & 灾 \\
\hline ๙ิ & $\overline{=}$ & $\therefore$ & $\therefore$ & ๑ั & 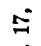 & เิ่ \\
\hline 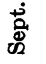 & $\begin{array}{l}\text { 䒼 } \\
\text { on }\end{array}$ & $\dot{0}$ & $\dot{8}$ & $\begin{array}{l}\text { 莒 } \\
\text { कृ }\end{array}$ & $\begin{array}{l}\text { 莒 } \\
\text { की }\end{array}$ & $\begin{array}{l}\text { 总 } \\
\text { की }\end{array}$ \\
\hline- & N & N & N & N & $\infty$ & - \\
\hline$>$ & $Z$ & $>$ & 传 & $\sim$ & 二 & 2 \\
\hline
\end{tabular}




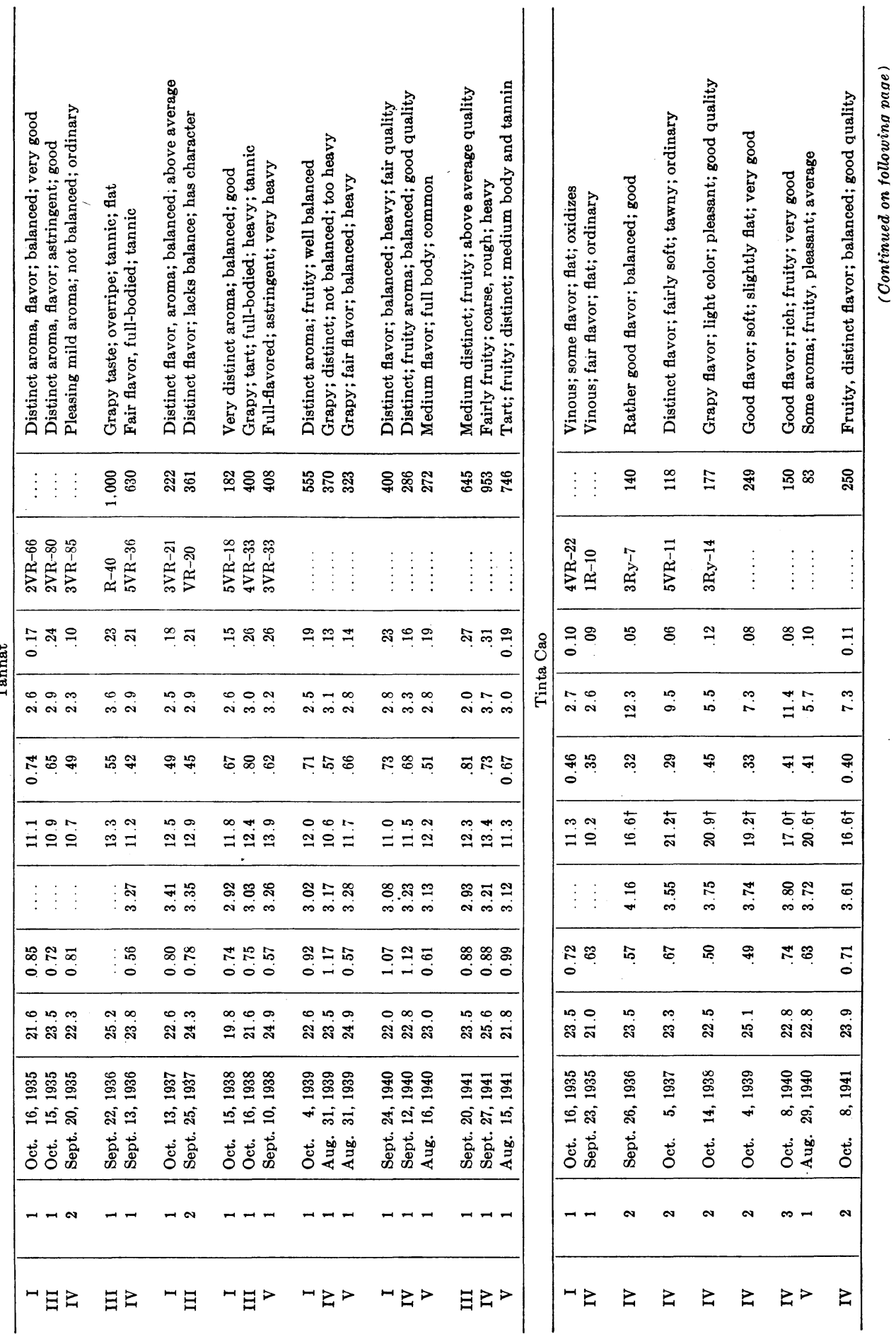




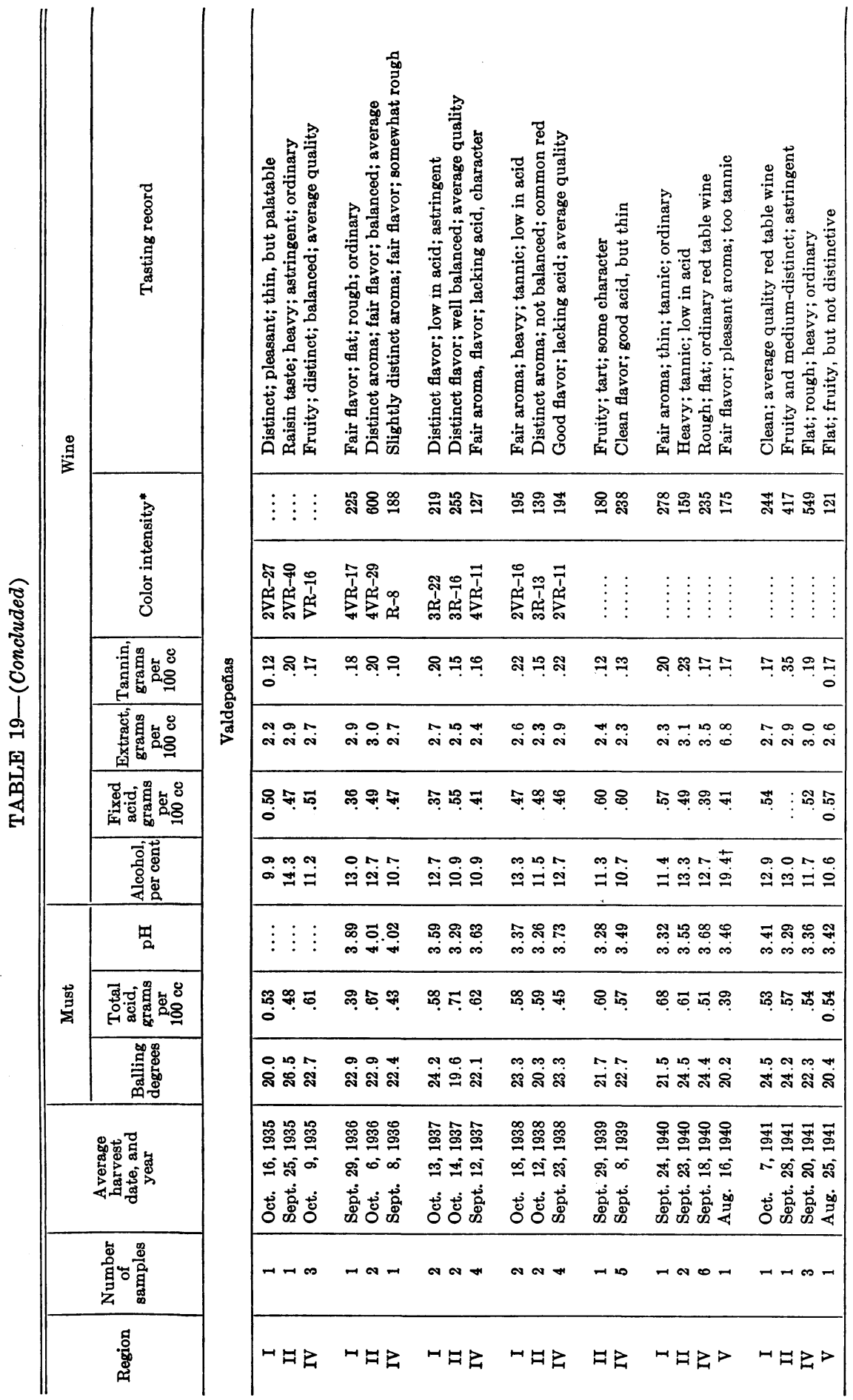




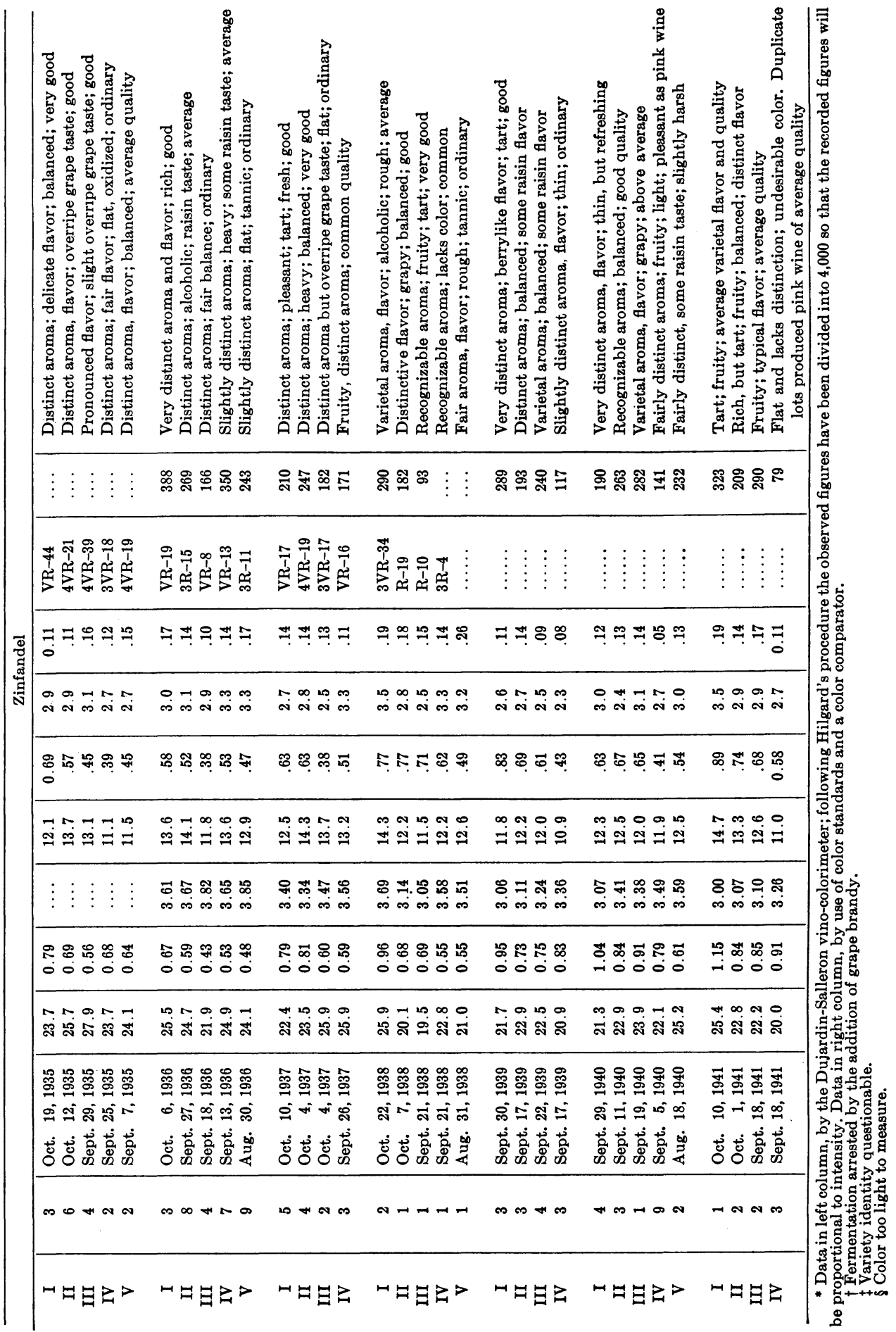


slight resistance to phylloxera is not sufficient to survive these organisms when conditions favor them.

The vines are moderately vigorous and productive; the clusters mediumsized, long-conical, shouldered to winged, and well filled with medium-sized short-oval, thick-skinned, black berries. Ordinarily the fruit should reach the crusher in good condition. The grapes are easily crushed, and the juice yield is good.

Except for the very warm season of 1936, the acid content has been good. The $\mathrm{pH}$, nevertheless, has been relatively high.

The primary value is its color. In this property the variety surpasses Alicante Bouschet, but does not equal Salvador. Its wines have possessed abundant color, but its stability as regards both the amount and the hue has not been satisfactory. Although the color has been deposited much more slowly than in Alicante Bouschet wines, it has decreased markedly in time. In several lots the hue has lost attractiveness, and the wines have become somewhat brownish.

The dry wines of Alicante Ganzin, as such, have been heavy, rather tannic, somewhat aromatic, and at best very ordinary. The dessert wines have been of similar character and quality for their type. In both types the wines have been relatively free from objectionable properties.

These wines are valuable solely for blending. For this, their principal merit is their color, a property in which they are inferior to the Salvador, but decidedly superior to products of the other red-juiced grapes. Blends for body and tannin can usually be had from varieties that are desirable for other reasons as well. The Alicante Ganzin is adapted to regions III, IV, and V. In some years its fruit would fail to ripen in regions I and II. Plantings are not recommended.

Aramon.-The Aramon vines are moderately vigorous, and the variety produces unusually well. In southern France it is the predominant variety for light-colored, thin vin ordinaire. Algerian wines of higher alcohol and body are frequently blended with it.

Except in the musts of 1935 and 1936 the original total acid content has been good in the cooler regions. The fixed acid content is by no means, however, so satisfactory, over half of the wines falling below 0.60 per cent in acid. The sugar content is uniformly low. Some difficulties are experienced in harvesting at the proper maturity. The berries are very large and are set rather loosely on a moderate-sized cluster. If clusters are handled roughly they shatter, and if left in the vineyard they rapidly become moldy. The juice yield is particularly large. The fermentations are uniformly good and, with normal precautions, clean.

Hilgard tested 20 samples of Aramon between 1884 and 1894. He considered it useful for blending because of its agreeable fresh taste and its productivity. The wine was noted to be deficient in color and tannin, and was found to mature early. The grapes were sometimes said not to ripen properly, although his analysis shows a fair Balling reading, averaging over $22^{\circ}$ for stations in the Santa Clara Valley.

The wines produced in the present studies are characterized by their low tannin, color, body, and alcohol content, the alcohol being usually below the 
amount desired for dry table wines. If the desirability of producing lowalcohol pink wines in this state should be established, the Aramon is well suited for this purpose. ${ }^{49}$ No wine of quality has yet been obtained from it in any of the tests. All the samples have a distinct fruity, fresh-grape taste. The wines mature very early; in small cooperage, in fact, they are always brilliantly clear and in good condition after the second racking. If carefully prepared they will keep in glass for several years, although the improvement in quality is not commensurate with the aging.

Aramon is therefore suitable for bulk-type pink wines of low alcohol-a type not yet legally permissible in this country. It is also suitable in blending to reduce the color, body, and alcohol of heavy wines. In favored coastal locations, where it attains sufficient sugar yet keeps its acidity, it produces wines of more than bulk quality. A number of these have produced very satisfactory pink and red sparkling wines. At present, however, no further planting can be recommended. Sufficient bulk-quality table wines are produced from existing varieties and in more productive locations than the coastal areas. The variety lacks both color and acid when grown in region IV.

Beclan.-The Beclan has small vines. Hilgard pronounces it well adapted to cool locations and fertile soils and says it produces average crops for such conditions. He must be referring to rather special areas or perhaps to growing conditions somewhat cooler than those now used for this variety. It is highly resistant to mildew.

Beclan clusters are small, cylindrical, winged, and rather compactly set with small, round, firm, black berries. Aside from the smallness of the clusters, the fruit handles well and is crushed without difficulty.

In region I it produced a table wine well above the average in quality, differing but little from the product of region II. The wine from region I, however, was produced in 1936, a very hot season, and that from region II in 1939, an average season ; hence the growing conditions were much the same considering the difference in regions. These wines were fruity, distinct in aroma and flavor, and full-bodied, with some character. They aged rather rapidly, but did not possess sufficient character and finish to be more than good table wines.

The wines of region III were still fairly well balanced, with some aroma and flavor ; but they lacked character and freshness. Those of region IV were generally unbalanced, tending to be flat and to become oxidized. The wine of 1939 , which had a fair acidity, was soft and of good flavor; but it, too, lacked finish.

Some of the samples from region $\mathrm{V}$ did not appear to be typical of the variety. This fact, however, introduces no great difficulty, for the product was entirely unsatisfactory. The table wines were deficient in acidity, body, color, and character, while the dessert wine was just another ordinary red sweet wine.

The Beclan, though a weak grower and a low yielder, produces good table wines in the proper environment. Its low yields will eliminate it from all but the very coolest areas where grapes are now grown. Possibly in the coolest locations its great resistance to mildew will make a place for it. Elsewhere it should not even be considered.

\footnotetext{
${ }^{49}$ Amerine, M. A., and A. J. Winkler. Color in California wines. IV. The production of pink wines. Food Research 6(1):1-14. 1941 .
} 
It is wholly unsuited to regions III, IV, and V on the basis of yield, composition, and quality. Bioletti recommended it for the coast counties only, which is correct if only an average wine is desired. It is said to blend well with the Cabernet and with certain other well-flavored, heavy-bodied varieties such as Tannat.

Black Malvoisie.-The Black Malvoisie is a heavy and regular bearer. Its vines are above average in vigor and thrive on a variety of soils.

Its clusters are large, long-conical, and well filled with large, long-oval, blue-black berries. On account of the shape of the berries it is frequently confused with the Barbera. The latter variety has smaller berries, and the fruit is over twice as high in acid. The skin is fairly thick, though tender; still, this fruit has been used extensively as a table grape. It withstands shipment over short distances, and its handsome appearance and pleasant flavor appeal to some consumers. In the winery it is readily crushed and yields average amounts of juice. If left on the vines until late in the season it shrivels, but rarely sunburns or raisins.

The Black Malvoisie has failed to produce a wholly satisfactory table wine anywhere in the state. It has usually been deficient in color and acidity, but these have been only two of its defects. In region I the table wines have been slightly distinct, fruity, of good flavor, but somewhat thin, and lacking in character. In this region the variety hardly matures its fruit. In the other regions the fruit attains normal maturity; but its table wines have been generally unbalanced, principally through a lack of acidity. They were poorest in region $\mathrm{V}$ and showed some slight improvement in cooler areas, as in going to regions IV and III.

The dessert wines have been smooth, soft, slightly distinct, well balanced, with some character, but usually with a deficiency in color. They have not had very distinct aroma or flavor, but are well balanced for red dessert wines except for their lack of color. Even so, they have surpassed the red sweet wines from other black table grapes. Their quality has not equalled that of the Grenache, the Mission, or the black port-wine varieties such as the Tinta Madeira.

On the basis of these tests the Black Malvoisie is not recommended for planting anywhere in California for wine-making purposes. Its dessert wines are its best products, but other equally or more productive varieties produce superior examples of this type. It produces average-quality table grapes together with a sound red dessert wine, slightly lacking in color. Furthermore, the grapes attain a very high sugar content without undue raisining.

Bolgnino.-The Bolgnino is of moderate vigor and above-average productivity. Its clusters are medium large and conical, compactly set with small, round, reddish-black berries. The fruit matures rather late. Hilgard does not mention Bolgnino until his last report and gives no data for its wines, but. reports at Tulare a must with $24.6^{\circ}$ Balling and 0.48 per cent total acid. It is possible that both he and Bioletti were familiar with it under the name of Nebbiolo Tronero. At any rate, neither variety is recommended in any of their reports.

The experience in the present studies has been restricted to samples from Guasti and from Davis. According to the must analysis in table 19, the acid content is relatively high even in region IV. There is considerable variation in 
the picking dates ; since the grapes are rather sensitive to overripening, it was difficult to pick them at the proper moment. The Balling readings, accordingly, vary. In a hot year such as 1936, the sugar is excessive; in other years adequate. The total acid content shows some unexplained variations; but in the main, the musts themselves are good, as the $\mathrm{pH}$ measurements show. The wines have been tart, fruity, well balanced, with some flavor, of average and better quality. Only in two years has their color been sufficient, the 1940 lot having only enough for a pink wine. On the whole they have tended to be slightly astringent and lacking in finish, but their composition makes them not unpleasing.

The variety can produce good standard table wines in region IV and possibly III. It will probably not ripen normally in regions I and II and will lack color and possibly acid in region $\mathrm{V}$.

Charbono.- The Charbono, a rather weak grower except in very fertile soil, produces only moderate crops. It fruits on old and new wood and has a rather large amount of second crop. The clusters are medium-sized, loosely set with berries larger than the average. It resists mildew even in the coolest locations.

The Charbono ripens rather late, particularly in region I, where it barely reaches $20^{\circ}$ Balling by mid-October. The acidity is good in that region, but below average in all the others. The wines have been of good color, and those from region I have been fruity and agreeably flavored. Even those of region II have been average, though with a tendency to flatness. In regions III and IV Charbono is decidedly not desirable for table wines. In one case it was tested for dessert purposes, but the quality did not justify further trials.

Hilgard ${ }^{50}$ tested it in the warmer districts, where he found it productive and likely to yield an agreeable wine. By Bioletti's time,${ }^{51}$ however, the experience of the station did not justify the planting of this variety anywhere in California. The present results agree with Hilgard's : "It is not a wine to be kept long or used alone ... It is likely to be of use, however, only to those with whom quantity is more looked for than quality." The sole possible recommendation is for planting in the more humid portions of region I for averagequality wines. Under these circumstances its resistance to mildew favors it over the Carignane; but, for the reasons enumerated, average wines probably cannot be economically produced on the marginal lands of the cooler regions.

Fresia.-The Fresia is another variety grown extensively in Piedmont in northern Italy. The vine is only moderately vigorous and requires longer-thanaverage pruning to produce full crops for its size. In Italy it is said to be more productive than the Nebbiolo, which it has replaced in some localities. Here, however, it is not productive in regions IV and V. Hilgard makes the same complaint regarding the warmer localities. It is rather resistant to mildew. The clusters are long, conico-cylindrical, and well filled. The berries are medium-small, almost round, reddish black, with a rather tough skin. The fruit matures in early midseason and tends to shrivel and raisin rather easily if left on the vines after maturation.

Since all the samples came from regions IV and V, it is obvious that the musts are very well supplied with acid. This is also reflected in the sharp red

${ }^{50}$ See citation in footnote 16, p. 496.

51 See citation in footnote 18, p. 496 . 
color and the rather green taste. Otherwise the wines have been fairly well balanced, though somewhat high in tannin, and heavy. The flavor resembles that of the Zinfandel, being markedly fruity and berrylike; but the flavor is coarser, hardly so desirable as the best wines of the latter variety. The distinctive flavor was noted by Hilgard, who thought it possibly too pronounced for general trade popularity. ${ }^{52}$ This may not be a disadvantage under present trade conditions. The use of relatively large amounts of Fresia in region IV would produce fruity and distinctive wines of good acidity, which the consumer would recognize. The quality, though not outstanding, would be recognizable. Because of their relatively high tannin content, these wines sometimes age rather slowly; but, by judicious fining, they can be made salable when young. In Italy they are frequently used within a year or two after production. The high tannin is an advantage in their early self-clarification.

The wines from regions IV and V have been only light red-a disadvantage of the variety. In a cooler location the color would be improved. This, however, would normally involve increased astringency, which would further prolong the aging period.

The wines, though above average, are not good enough to offset the low productivity and lack of vigor. Fresia is not recommended for larger-scale planting anywhere. Its special aroma and flavor, however, might well make it a part of a successful venture for a small winery in the proper location, possibly in some of the warmer coastal valleys. Its omission by Bioletti is significant in view of the varieties that he did recommend for the San Joaquin Valley.

Grignolino.-Wine of pink or light orange-red color is produced from Grignolino grapes in Italy, and immigrants from that country hold it in high esteem. Because of its natural high tannin content it possesses most of the characteristics of red wines. Occasionally the color is more red than orange red.

The vines are moderately vigorous and productive. The clusters are large, long-conical, well filled with medium-sized, round, reddish-black or brown berries. They mature in good condition, but do not withstand early rains. The juice yield is above average.

In the cooler seasons such as 1935, 1937, and 1939, the Grignolino grapes of region IV produced good table wines, and the product of region $V$ was fairly well balanced. In warm years such as 1936 the acidity has been too low. The better wines had a distinctive varietal aroma and flavor, a high tannin content, and a light orange-red color. The high tannin content requires aging in wood for several years and also a heavy fining before bottling.

The Grignolino is a distinctly different wine, appealing greatly to those who like it, but not meeting with general approval. The variety should not be planted unless means and facilities are available to bring the wine to best development and bottle maturity.

According to the figures and observations recorded in table 16, this variety is adapted to region IV and perhaps to III. In region V the acidity has been too low.

Gros Manzenc.-Gros Manzenc is a vigorous grower. To utilize its capacity one should prune it to more buds per spur than usual; but it is not a heavy producer. The clusters are average-sized, long, well filled with medium-small,

${ }^{52}$ See citation in footnote 16, p. 496. 
round, reddish-black berries. The fruit handles well, is crushed readily, and has a good juice yield. The vines are liable to attack by mildew.

Under the environmental conditions of region IV the composition has shown Gros Manzenc to be well suited for table wine. The acid content of the must varied from 0.71 per cent to 1.17 per cent-a very favorable amount for the location. With proper storage conditions a good percentage of the original acid is retained in the aged wines. (See the acid content for 1938, 1939, and 1940.)

The color content of these wines has been ample and of satisfactory hue. Tannin content has been sufficient to lend desirable stability.

These properties, together with a characteristic aroma and flavor, have given the wines distinctiveness, fruitiness, freshness, good color, and good keeping quality. In several respects Gros Manzenc resembles the Barbera wines, but apparently it matures earlier. The wines are above average in quality, particularly in region IV; but so far we have produced no outstanding wine from this variety.

The results to date show Gros Manzenc to be adapted to region IV, and it should do well in III. Here it may find a place for the production of table wines better than those from Carignane, Zinfandel, Petite Sirah, and similar varieties.

Its low production will exclude it from region $\mathrm{V}$, where its quality will not be high enough to offset the smaller crops. In I and II it will be too acid to produce a balanced wine, and Hilgard reports that it failed to ripen at Mission San Jose. Bioletti recommended it for the interior valleys. The present recommendation is that Gros Manzenc will produce standard red table wines in regions III and IV.

Lagrain.-The Lagrain vines are of moderate vigor and productivity. The clusters are easily stemmed, being medium-sized, long, and loosely set with oval; black berries. The thin skin requires moderate care in handling. The juice yield is good.

Table wines of the Lagrain produced at Davis have possessed only moderate amounts of acid. The principal deficiencies, however, have been a rather ordinary flavor and a tendency to be coarse and rough. The very liberal supplies of color and tannin, though of value in themselves, have tended to make the wines heavy and common.

In region IV the Lagrain has been just another variety. In $V$ it would be very deficient in acid; in cooler regions very coarse and tannic. It is not suggested for planting. Although Biolettis recommended it for the San Joaquin Valley, apparently because of the large amount of stable coloring matter, he also noted its low acidity when grown at Tulare. The desirable qualities alone do not warrant planting, especially in view of the heavy ordinary flavor. It would occasionally prove useful in warm districts for blending to balance the color, but is perhaps unnecessary under present trade conditions.

Limberger. - This variety has been collected only in region I and region IV. It has been only an ordinary producer at Davis. The clusters are of moderate size, and the berries very black. The grapes seem moderately resistant to spoilage and have been crushed in good condition. The juice yield has been good.

\footnotetext{
${ }^{53}$ See citation in footnote 17, p. 496.
} 
The Limberger ripens just before midseason and has good acidity. Unless picked at the proper time, however, it will lose much of its initially high acid. Its wines are well colored, and have a fairly coarse but moderately distinctive flavor. Under the climatic conditions of region IV it is not of high enough quality or productivity to warrant planting.

For making average wines in the cooler regions it appears to have a place. It may be used either alone for a standard red wine or in blends to give body and color. Its early ripening will recommend it to growers who desire to spread the picking season over a longer period. It will not, however, make the highest quality wines and should not be planted where the finest are desired.

Further trials should be made, since this variety was not included in the earlier tests and only two regions are represented in the present trials.

Mammolo Toscano.-The Mammolo Toscano matures early and has only moderate or small crops. It has never had a large crop in region $V$, and in two years the crop was very small. Since the vines are probably on their own roots, this scanty output appears to be a varietal weakness. The long clusters are borne on a characteristic and very long stem. The berries are pink and of medium size. The fruit is relatively clean on reaching the winery. It is easily crushed and has a very good juice yield.

Even in region $\mathrm{V}$ the musts have a good acidity, but they will not maintain it if left on the vines until overripe. They ferment cleanly.

The wines are distinctly fruity-apparently a unique varietal trait. Unfortunately they are deficient in coloring material and, strangely enough, high in tannin. To produce a well-balanced wine, therefore, one must age the wines for several years, during which the color becomes less and less satisfactory, taking on an orange hue. The quality, however, is good.

Mammolo Toscano should possibly be tested under cooler conditions than region $\mathrm{V}$, since coolness would increase the amount of coloring material in the skins. In addition, however, the grapes would contain more tannin-decidedly undesirable. In view of the particular aging requirements, the commercial prejudice against light-colored high-tannin wines, and the small production, plantings are not recommended for general California conditions. Small acreages in regions IV and $\mathrm{V}$ for those who desire a distinctive red or pink table wine may be worth while.

Mondeuse.-The Mondeuse is a variety of good productive habits, ripening in midseason. One objection is that it does not ripen when it overbears, as it is prone to do. For this reason it should not be cane-pruned. The clusters are long, and the berries are easily removed by the stemmer. The juice yield is good, and fermentations are usually clean. Because it seldom has too much sugar, it is frequently used to blend with varieties that are overripe.

The musts of this variety are of only moderate acidity, and in regions IV and $\mathrm{V}$ are deficient in acidity for red table wine. The red table wines from regions I and II are well colored, fairly fruity, and distinct in aroma, tending to be almost spicy or aromatic in the cooler years. The flavor may be described as somewhat coarse, obvious, and without finesse. In the warmer regions Mondeuse produces rough, rather heavy, decidedly coarse wines of common quality.

Past usage of this variety has been mainly for blending. Since it lacks qual- 
ity when by itself, this would seem to be the only rational procedure. Hilgard found Mondeuse to be chiefly adapted to region II. Bioletti endorsed it for the coastal counties and considered it useful for the production of standard red wines in the San Joaquin Valley.

It is not recommended except in I and II, and plantings there are advisable only where grapes are required for blending for the production of standard wine. The Mondeuse should not be blended with higher-quality varieties because its own flavor is too pronounced; even with Zinfandel it tends to dilute the varietal flavor of the latter.

Muscat Hamburg. - The Muscat Hamburg is less vigorous than Muscat of Alexandria. The fruit is oval and black. The berries are somewhat smaller than the Alexandria, and the clusters about three-fourths the size. This variety has found some recognition as a table grape, but is not much used for wine.

The composition, except in region I, indicates its usefulness for dessert or natural sweet wines, but not for dry table wines. Some of the wines from region I have been distinctive, with a perfumed aroma and good balance; but they have never been scored above average. The reason is their harshness-a common property of most muscat varieties when not accompanied by sugar.

The table wines from the other regions (III, IV, and V) have in some cases possessed a distinct aroma; but they have usually been harsh, unbalanced, and flat. The color has been very deficient-hardly enough for even a normal pink wine.

The dessert wines have, on the whole, been poorer than those of the Muscat of Alexandria. Muscat Hamburg apparently possesses a stronger muscat aroma than the latter, though the wines have not been consistent in this property. A few have been very good, but many have contained too little of the usual muscat character. The flavor has varied. Obviously, the variety is less readily handled than the Alexandria.

Several natural sweet wines of this variety were well balanced, full, rich, and fairly smooth. These have shown to better advantage than either the dry table or dessert wines. They have been almost as good as those produced by the Aleatico.

This variety may fill a place if dry, red muscat wines are to be produced in regions I or II, which is unlikely. The Muscat Canelli would produce wines of greater smoothness and delicacy in these regions, but they would not be red. It is not recommended for regions III, IV, and V, for there its wines are too low in color and are surpassed by other muscat varieties in flavor although not in aroma. The particular perfumed character may find some utilization in either region IV or V for a pink, or, when aged, a tawny dessert wine, and the possibility for using it as a table grape offers an additional attraction. At present the Aleatico is preferred.

Nebbiolo. ${ }^{54}$ A moderately vigorous variety, the Nebbiolo bears only moderate crops with long-spur pruning. Its clusters are medium-large, slender, and well filled with medium-small berries, which are usually reddish brown around the pedicel. The grapes crush easily and the juice yield is good.

The Nebbiolo is among the oldest and best Italian varieties. In the Pied-

${ }_{54}$ Two Nebbiolos, Nebbiolo bourgu and Nebbiolo fino, are included in this summary. A so-called Nebbiolo Tronero is listed as Bolgnino. 
mont province its finest wines are usually marketed under the name of the locality where the grapes are grown.

The wines from region IV have been entirely successful. Although somewhat sharp and rough when young, they have improved more rapidly than those of the Barbera and Grignolino, and at maturity have been pleasant standard wines. Some of them rank among the best wines from Italian varieties. They portray many of the same qualities for which Nebbiolo is known in Italy.

The grapes have not had so high acidity as the Barbera; but except in 1936, which was very warm, they have had ample. The tannin content, too, has been sufficient without rendering any of the lots excessively astringent. The color content has hardly been sufficient-a disadvantage in region IV.

In region $\mathrm{V}$ the grapes have lacked both acidity and color, and the general quality of the wines has been much reduced. Judging from these results, the Nebbiolo is well adapted to region III and the cooler parts of IV. In areas warmer than Davis the color will regularly be too deficient.

The limited yields restrict Nebbiolo to the production of quality wines only - a fact to be duly considered when plantings are contemplated. Under present conditions the Nebbiolo should probably not be planted in California except in regions III and IV in a limited way by small producers who wish to specialize in a wine of this character.

Negrara Gattinara.-The Negrara Gattinara has been very little known in California, and no previous published results have been found. It ripens in midseason. Its vines are of average vigor and above-average productivity. The clusters are narrow and long, thickly set with small, oval, jet-black berries. The fruit is easily crushed, and the juice yield is good. Mildew may be difficult to control in the less arid regions.

The musts have varied in composition. The acidity was very satisfactory in 1935 and 1937, cool years, but was far too low in the hot season of 1936. The $\mathrm{pH}$, however, has not been excessive.

The dry table wines from region IV have been disappointing. Despite a mild distinctiveness, they have lacked finish and character and have been heavy, with a tendency to be flat and plain. Their color content was sufficient.

The variety is not recommended for general planting. In region III, with very careful harvesting, above-average quality standard red table wines can be produced. Further tests along these lines are indicated.

Raboso Piave.-The Raboso Piave is grown in northeastern Italy. It is a vigorous grower but only a moderate producer with spur pruning. The clusters are medium-large, long-conical, often winged, and rather compactly set with medium-large short-oval berries. The fruit is firm and has reached the crusher in good condition each year. It matures very late, the average picking date being October 15 at Davis.

Its musts from regions IV and V have been very well balanced for dry table wines. Except in the very warm season of 1936, they have retained high acidity with moderate amounts of sugar. Their $\mathrm{pH}$ has been relatively low.

The wines have been distinct in aroma and flavor, refreshing, well balanced, but not definite enough in character and finish to be distinctive. Nevertheless, they have been interesting products for warm regions. They aged rather 
slowly, but were free of handling difficulties, and kept well once they had reached maturity. The color intensity fits the variety better for pink than for red wines.

The Raboso Piave will not mature its fruit regularly in regions I, II, and III. Its only moderate productivity will handicap it in IV and V, but its high acidity may make it useful. Under these special conditions, therefore, it may be valuable in the latter areas.

Saint Macaire.-The Saint Macaire is grown to a very limited extent in one of the regions of lesser importance south and east of Bordeaux, France. It has been distributed rather widely in California. Its total acreage, however, is small, although it was recommended by Bioletti for planting in the interior valleys.

Saint Macaire is only fairly vigorous and moderately productive. Its clusters are medium to large, short-conical, shouldered, and sparsely to moderately well filled with medium-sized, roundish berries. The grapes sunburn in warm locations in the foothills. This is particularly true in dry seasons when the grapes lose their leaves. Otherwise they usually reach the winery in good condition. The grapes are easily crushed and the juice yield is good.

Even in region IV the musts have been fairly well balanced for sugar and acid. They fermented without difficulty to produce heavy, rough, full-bodied wines of about average quality. None of them manifested any marked delicacy, and all lacked smoothness of finish. Their principal value, especially in region II, is their acidity and their intense color. Besides these properties they have a high tannin content.

The wines from region II have in some years shown good balance, fair smoothness, and some character. Those of regions IV and V were also among the better heavy red dry wines of their type produced in these regions. But these latter wines have regularly lacked definiteness and character.

In general the Saint Macaire wines have required long aging, which their quality at maturity does not warrant. As blending wines, however, their acid, color, tannin, and body may have real value in regions IV and V. For blending, this is among the most promising varieties tested in region V. Here, too, its general quality is better than that of the Alicante Bouschet, Grand noir, and Petite Sirah that have been tried in the past. Where better grapes such as Petite Sirah and Tannat are adapted, their wines will be more desirable for blending because of superior quality and distinctive character.

The Saint Macaire may be said not to be adapted to regions I and II. It has produced its best wines in II, but there it has not equalled many other equally productive varieties. In region IV it has been surpassed by several others. It shows promise for blending in region $\mathrm{V}$, where its wines have possessed the best combination of acid, color, tannin, and body of the varieties tested. Still its quality is only average, and because of its poor viticultural characteristics-moderate vigor, average production, and sunburning-only restricted plantings should be made, and these only for blending in standard red wines under region IV and $\mathrm{V}$ conditions.

Sangioveto.- The vines of Sangioveto are moderately productive, somewhat above average in vigor. The clusters are medium-large, slender, well filled with small, oval berries. The fruit is clean, withstands handling well, and vields an 
average amount of juice. The grapes ripen in midseason and have a high acidity. The $\mathrm{pH}$ is moderately low for the climatic conditions of region IV.

On a whole, the table wines produced from Sangioveto in region IV have been well balanced and good. The variety is well supplied with acid, has ample tannin, but lacks color. The wines possess a pronounced berrylike aroma and flavor. In consequence they have been distinctive and fruity, and-for the most part-well balanced. Some samples have lost a large amount of acidity during storage, apparently because of the activity of acid-reducing microorganisms.

The Sangioveto should do well in regions III and IV, but it does not produce sufficiently large crops for economical bulk-wine production. Its wine does not have the finish of the better French varieties, but the distinctive character makes it useful for growers who wish to produce a special type. In region $V$ it will lack acid and color, while in regions I and II it matures too late and with too great an acidity. On account of the restricted amount of color it may have to be blended with varieties of greater color even in regions III and IV. This would conform to the practices of the Tuscany district of Italy. Refosco and Tannat are acceptable for blending.

Tannat.-The Tannat grows vigorously, produces well above average crops, and usually shades its fruit sufficiently. The clusters are medium-large, strongly shouldered, and closely set with medium-sized, short-oval, black berries. Some small green-shot berries are generally present, but these are usually not crushed in wine making.

The wines of Tannat from the north coastal areas-regions I and II-have been of unusual interest-richly endowed with a distinctive aroma, full pleasing flavor, good balance, intense color, and a full body. Their tannin content has been near maximum year after year. In region I these wines were full, well rounded, of considerable character, delicate, and of high quality. Those of region III were somewhat heavier, a bit coarser, much more tannic, and only average in quality.

These wines have matured somewhat slowly; that is, they have tended to retain a degree of roughness and astringency longer than those of most of the better varieties. The intense color persists and retains its desirable hue. Once mature, these wines have kept well. The fact that this quality does not appear to be associated with high alcohol content should be important in itself, since most California table wines suffer in quality from their very high alcohol.

Wines of the Tannat grown in regions IV and V were, as a rule, heavy, somewhat coarse, and less well balanced. Aroma and flavor, too, were less distinctive and pleasing. Here its wines would usually be of value only in blending, for which their high tannin content, good acid, and heavy body fit them well, though unfortunately they add little quality to the blend. Several wines of the warmer areas, for which less mature fruit was used and which were therefore lighter, showed good quality. Care in timing the harvest apparently means better wine. Thus a good product may be secured in region III.

The Tannat is well adapted to cool areas. In areas as warm as region III, especial attention must be given to the time of harvest. It matures in midseason and should be harvested promptly, since its best wines are those of only moderate alcohol content. It will not equal Cabernet Sauvignon under similar 
conditions, but its wines are distinctive and very good in these areas, and it is more productive. The vinification is singularly free of difficulties. It is recommended for region II for the production of standard red table wines.

In regions IV and $\mathrm{V}$, Tannat will not regularly produce a balanced table wine. Its value there would be for blending, which when used appropriately may offer possibilities. With the usual harvesting and vinification procedure, however, the Tannat from these regions will add little other than color, tannin, and body to the blend.

Tinta Cao.-Tinta Cao, though vigorous, is only moderately productive. Its clusters are medium-sized and loose to well filled, with small berries. The fairly tough skin, together with the open clusters, makes it much more resistant to unfavorable weather and rot than most red wine-grape varieties. The vine is relatively resistant to mildew. The juice yield is barely average.

Both the source of the Tinta Cao (the Douro Valley of Portugal) and the composition of its fruit under our conditions indicate its adaptation for dessert wines. When it is used for these types, the wines are above average-well balanced, soft, and pleasant. Their flavor and aroma, though not too definite, are distinctive. The wines of very ripe grapes tend to be somewhat heavy and rough, a fault that can be overcome by earlier harvesting or by blending. The color is pleasing, but rather light for present demands ; some blending may be necessary.

Tinta Cao is not suitable for dry-wine production. Even in our coolest environment, region I, the acid content is too low for table wines. The same is true of the tannin and color content.

The variety is admirably suited to regions IV and V, where it will produce large vines and, if pruned properly, moderately heavy and regular crops. The size of the clusters and the type of pruning required will increase production costs slightly, but the wine is of good quality. It is not, however, recommended above Tinta Madeira, which gives wines of excellent color and equally good flavor and is at present preferred. For red dessert wines the Tinta Cao ranks above such varieties as Carignane and Alicante Bouschet.

Valdepeñas.-The Valdepeñas, introduced from east central Spain, was not included in the variety tests by this station in the 1880's. Several plantings were made, however, in more recent years. Bioletti stated :" ties which the station has tested in the interior valleys, that which combines the largest number of good points as a dry wine grape is the Valdepeñas. The wine made from it has always been satisfactory."

The Valdepeñas ranks with the most vigorous and productive of grape varieties. The clusters are large and irregularly shaped. They vary from longconical, shouldered, to very full or heavy in the middle. The berries also vary, some being very small, the majority medium; many are flattened at the end and are broader than long. The pulp is firm, and the skin is sufficiently tough to resist handling injuries. With normal crops the fruit matures early. The grapes crush easily, and the juice yield is above average. This variety is rather susceptible to mildew and red spider.

The present tests do not completely confirm Bioletti's opinion of the wines. Regularly the musts of well-matured Valdepeñas grapes have been too low in

${ }^{s 5}$ See citation in footnote 17, p. 496. 
acid to produce dry table wine of good balance and quality. Less than 20 per cent of the must samples showed over 0.6 per cent acidity even when the samples of all regions are considered. In fact, the acidity did not show a definite correlation with region of production. This condition was probably an effect of excessive crop in the warmer regions ; if so, it could be corrected.

About all that can be said for this variety is that the products were clean, average-quality, red table wines. In the cooler regions they tended to be fresher, more pleasing in aroma and flavor, whereas in the warmer regions, especially in the warm seasons, they were decidedly flat, heavy, and rough, with hardly enough color. They matured rapidly, without difficulty, and may be considered as typical standard-quality bulk wines.

The red sweet wines of the Valdepeñas have been too astringent for the type. Possibly further tests should be made with dessert wines.

Since this variety will produce only standard table wines in regions I, II, or III, it cannot be recommended. Even on the rich level valley soils the quality of its wines are surpassed by that of other productive sorts. In the past it was supposed to have made outstanding wines in certain coastal locations, but such claims find no support in results reported here. In region IV it may well be considered for bulk wines because of its vigor and productivity.

Zinfandel.-The Zinfandel has attained commercial recognition in California. It was brought in with the earlier importations after the mission period; but when, whence, and by whom remain a mystery.

The vines are not vigorous in the sense of attaining large size. Nevertheless, they are productive. The clusters are large and usually heavily winged. Often the wing may attain such proportions that the two parts are of almost equal size, producing a characteristic double cluster. The berries are medium-large, round to slightly flattened lengthwise, reddish black to black, with a large scarlike area at the apical end. The skin is thick, but not too tough. Although Zinfandel was popular and was shipped extensively during the Prohibition era, its fruit is not particularly resistant to handling injuries.

The fruit ripens unevenly: some berries may be partially raisined while others have not reached maturity. In the warm regions and in most areas in hot years complete raisining occurs in a considerable percentage of the fruit by the time the average Balling reading of the free-run juice of the normal berries in the cluster indicates normal maturity. Since the color is closely correlated with maturing, it, too, is very irregular.

Another defect is the tendency of the clusters to be overcompact. The berries may be so crowded that some are pushed loose from their stems and others are crushed in the final stages of maturity. Thus decay-causing organisms obtain a start. Sometimes the center of a cluster is a rotten mass at harvest time, and the whole cluster has an acetic odor. Once berries break and release their juice it is impossible to control the organisms.

In regions I, II, and III the fruit is, as a rule, well balanced for table wines. It must, of course, be harvested at proper maturity. These wines possessed in marked degree the characteristic fruity, raspberrylike, aromatic flavor.

In regions I and II the wines tended to be somewhat overly tart in the cool years and not too well balanced. Aroma and flavor were rich, delicate, and clean if the grapes reached the crusher in sound condition. 
In the warmer locations of region II and in region III the wines have been uniformly the best balanced, fullest, and most drinkable. They contain most of the richness and delicacy of the aroma and flavor of the cooler regions, and in addition these qualities are fuller and more harmonious. When produced of sound, well-matured, but not overripe or raisined fruit, these table wines were really above average. Even here, at their best, they still lack the finish and character required of the finest wines.

In region IV these wines were less well balanced, had a somewhat less pleasing flavor, and were seldom entirely free of overripe grape or raisin flavors. They were only ordinary to standard.

The table wines from region $\mathrm{V}$ were coarse in aroma and flavor, deficient in acid, harsh, alcoholic, and with a fairly pronounced raisin taste.

Because of its irregular ripening and its tendency to raisin, the fruit of the Zinfandel has usually produced cleaner-tasting pink wines than standard red wines. This was true especially in regions IV and V, but perhaps also in the other regions during hot seasons. These pink wines are fresher, livelier, and cleaner in aroma and flavor because of the much restricted period of fermentation on the skins.

In considering the Zinfandel for planting, one must think not only of its productivity and the readily recognizable characteristics of its wine, but also of its usual condition at harvesting. Only with the greatest care can unsound or raisined grapes be kept out of the fermentation tanks. This difficulty is not of recent origin : Hilgard in 1892, referring to these defects, stated :" $:^{58}$ it is not, therefore, without good cause that its popularity is decreasing, and that sturdier, and on the whole, higher grade varieties are gradually taking its place in the planting of new vineyards." Despite this and other statements on its poor quality, large plantings have continued. Approximately half the present acreage, however, was planted during the Prohibition era, when the quality of a wine was only a secondary consideration. Numerical predominance at present does not indicate merit on a quality basis.

Although its wines in regions I and II are of very acceptable table quality when produced of sound fruit, the Zinfandel cannot be said to be adapted to these areas, except possibly in the warmer parts of II. In some years, the fruit does not mature before the autumn rains, and it is more or less severely attacked by bunch rot in these seasons.

The fruit attains best development on well-drained soils in the warmer locations of region II and in III. Here raisining occurs, but the fruit can usually be harvested before the rains. The Zinfandel is much overplanted at present. Further plantings, if made, should be restricted to regions II and III, and then made only for the production of an average-quality wine.

The Zinfandel should not be used to produce table wine in regions IV and V. Its fruit is badly sunburned, and much raisining usually occurs before the fruit is mature for harvesting. Under irrigation the berries are large, and bunch rot is all too common. In these regions the variety has attained some favor for the production of bulk port. Nevertheless, these wines are usually badly marred by the defects of the fruit at harvesting, and better quality can be obtained from other varieties.

\footnotetext{
${ }^{56}$ See citation in footnote 15, p. 496.
} 


\section{VARIETIES NOT :RECOMMENDED}

Numerous varieties of wine grapes are so devoid of merit that they cannot be recommended anywhere in California under present conditions.

The varieties listed here fail to warrant planting for several reasons. The most common objections are lack of sufficient sugar, acid, or both, poor production, and susceptibility to rot or diseases. Some varieties listed here have flavor, but are so inferior to other closely related varieties in quality or production that they need not be considered. Although such grapes are not recommended, the data and the observations which have brought about their rejection are of great value. This is the only available information about most of them. It accordingly forms the sole basis for sound decisions regarding the utilization of the present stands of these varieties and for their evaluation in the future.

\section{WHITE VARIETIES NOT RECOMMENDED}

White varieties not recommended include Bambino bianca, Clairette blanche, Feher Szagos, Green Hungarian, Hibron blanc, Hungarian Millenium, Kleinberger, Malmsey, Marsanne, Mathiasz y-ne, Mourisco branco, Muscat Pantellana, Muscat Saint Laurent, Nasa Veltliner, Nicolas Horthy, Palaverga, Pavai, Roussette, Saint Emilion, Sauvignon vert, Selection Carriere, Steinschiller, Terret, Vermentino Favorita, and Vernaccia bianca. The analyses of musts and wines of these varieties for various regions are given in table 20.

Bambino bianca.-The Bambino bianca is a vigorous grower and heavy producer. Since it ripens late in the season, it is adapted only to conditions as warm as those of Davis, region IV, or warmer sections.

Its clusters are very large, loosely set with small, round, thin-skinned berries. The grapes do not crush easily, however, and the juice yield is below average. The fruit, despite its late ripening, reaches the crusher in excellent condition.

Although slightly aromatic, its wines, as produced at Davis, were badly balanced, harsh, and of very poor keeping quality. The variety is decidedly not suited for table wines, lacking acidity in region IV and ripening too late for planting in cooler regions. Its undesirable aromatic property, harshness, and plainness of flavor condemn its use for any wines. It is not recommended anywhere in California.

Clairette blanche.- The vines of the Clairette blanche are vigorous and productive in a suitable environment. When the weather is unfavorable at blooming, its clusters may be susceptible to coulure. It produces well only in the warmer districts, and the crop is usually unsatisfactory in region I.

The clusters are medium-large, conical, shouldered, and well filled with medium-sized, oval berries. The fruit is firm and fairly crisp. It withstands handling very well, and the juice yield is good.

Only in region I did the grapes of Clairette blanche contain enough acid for well-balanced table wine. But the fruit matured too late; it was not fully mature by mid-October. As a result, its wine here was of very light though not unpleasant character. It would hardly pass as a well-balanced product. 
The wines of region II were lightly distinct, pleasant, fairly well balanced, and of average quality. Although somewhat lacking in character, they were nevertheless nice, simple wines that should find a place in everyday consumption.

In regions IV and $V$ the wines became softer and fuller in body, but flat, with a tendency to spoil.

In region II these wines were a marked improvement over Green Hungarian and Palomino and might displace these varieties if average white table wines are desired. Unreliable productivity in the cooler regions was noted, however, by Hilgard and Bioletti; and the Clairette blanche is not recommended. It will not mature normally in all years in region I. In regions III, $\mathrm{IV}$, and $\mathrm{V}$ its wines are so generally unsatisfactory that it should not be planted.

Feher Szagos.-The vines of the Feher Szagos are very vigorous and produce large crops. The clusters are large and long-conical, loosely filled with large, long-oval, greenish-yellow berries. The skin is too thin and tender to withstand rough handling. The grapes must be crushed as soon as possible after picking

During periods of high relative humidity or showers shortly before harvesting, many berries may crack at the apical end. In the hotter parts of region $\mathrm{V}$ the cracked berries may dry up ; but in region IV they regularly become infested with rot organisms, and deterioration sets in. If left on the vines too long the grapes begin to shatter badly. The juice yield is good.

As indicated by the acid content of its musts and wines, the Feher Szagos is not suitable for table wines. Every lot has been flat, unbalanced, and deficient in flavor, tending to spoil or become sherrified even if the grapes were from the coolest regions.

For sherry material the variety has shown itself to somewhat better advantage. These wines have been fairly neutral, but smooth, of good character and average quality. They have aged rather rapidly.

Although the sherry types of the Feher Szagos have been smooth, mellow, and average, the usefulness of the variety is very definitely limited by the cracking of its fruit. It should not be planted anywhere except in parts of region V. Even there, in some years, its fruit reaches the crushers in very poor condition. The Palomino surpasses it in all respects except perhaps productivity and rate of aging.

Hilgard was likewise unimpressed with this variety; and Bioletti specifically wrote, "Don't plant . . . Feher Szagos, .. . which makes poor wine."

Green Hungarian.-The Green Hungarian has been popular in regions II, III, and IV because of its great vigor and its productiveness; but the wines are very poor. The vine is singularly free of troubles, but the fruit is rather thin skinned and subject to rot during early rains. The clusters are large, conical, and well filled with medium-large round berries. The fruit is easily crushed, and the juice yield is satisfactory.

This variety can be differentiated from the Palomino on the basis of its upright growth, its round almost entire leaves, and the regular conical shape and greater compactness of the clusters.

(Text continued on page 618)

${ }^{57}$ See citation in footnote 18, p. 496. 


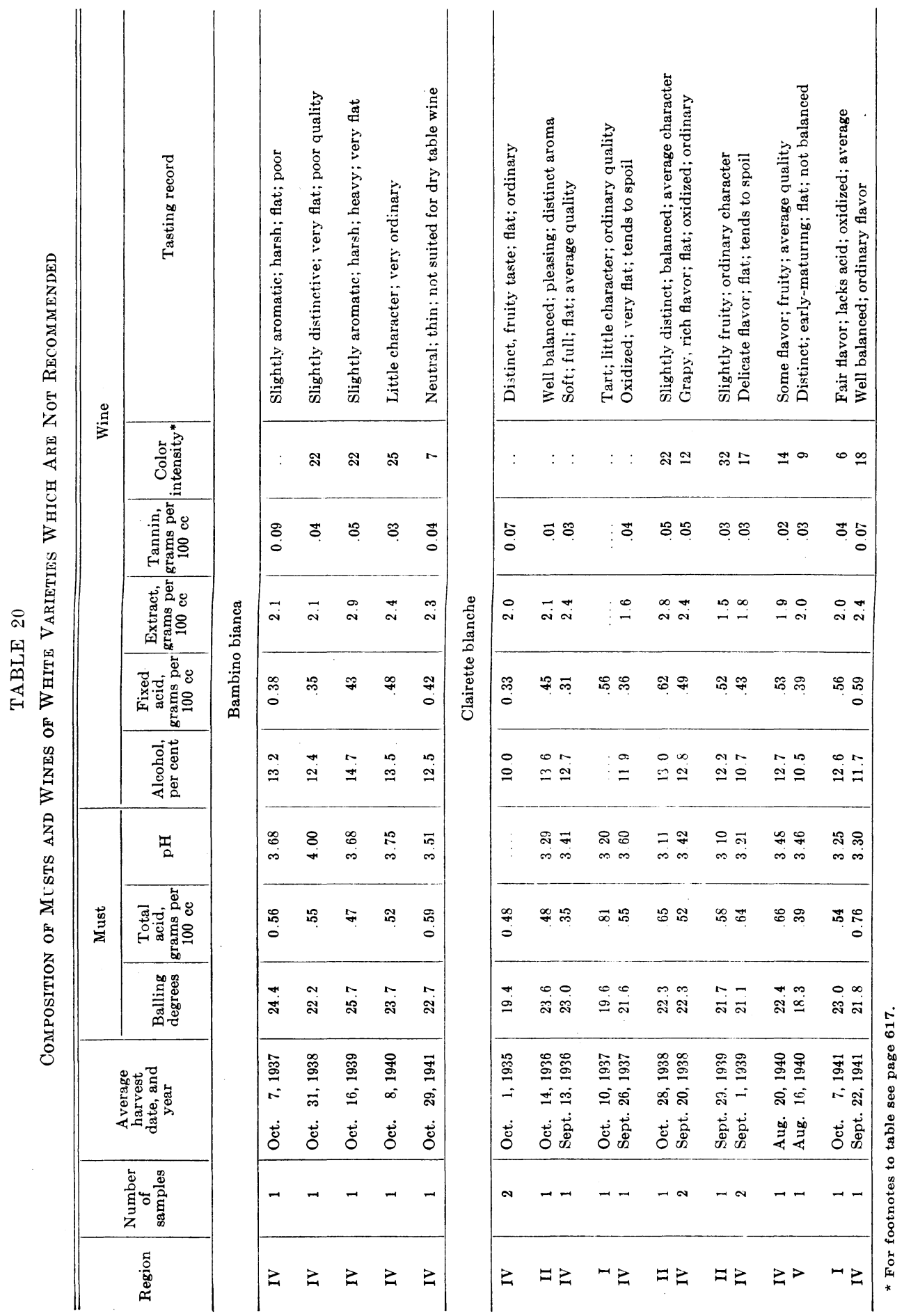




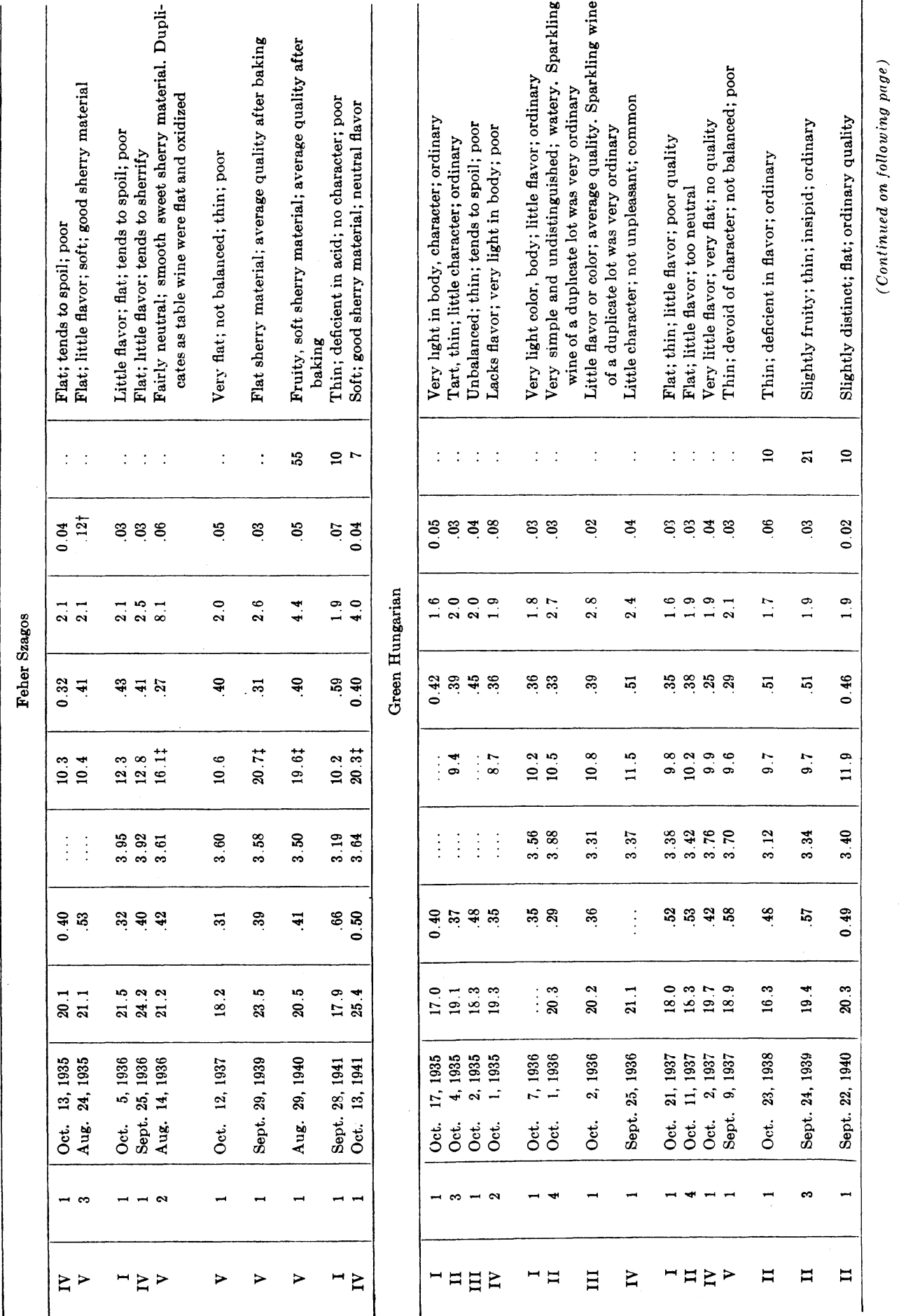




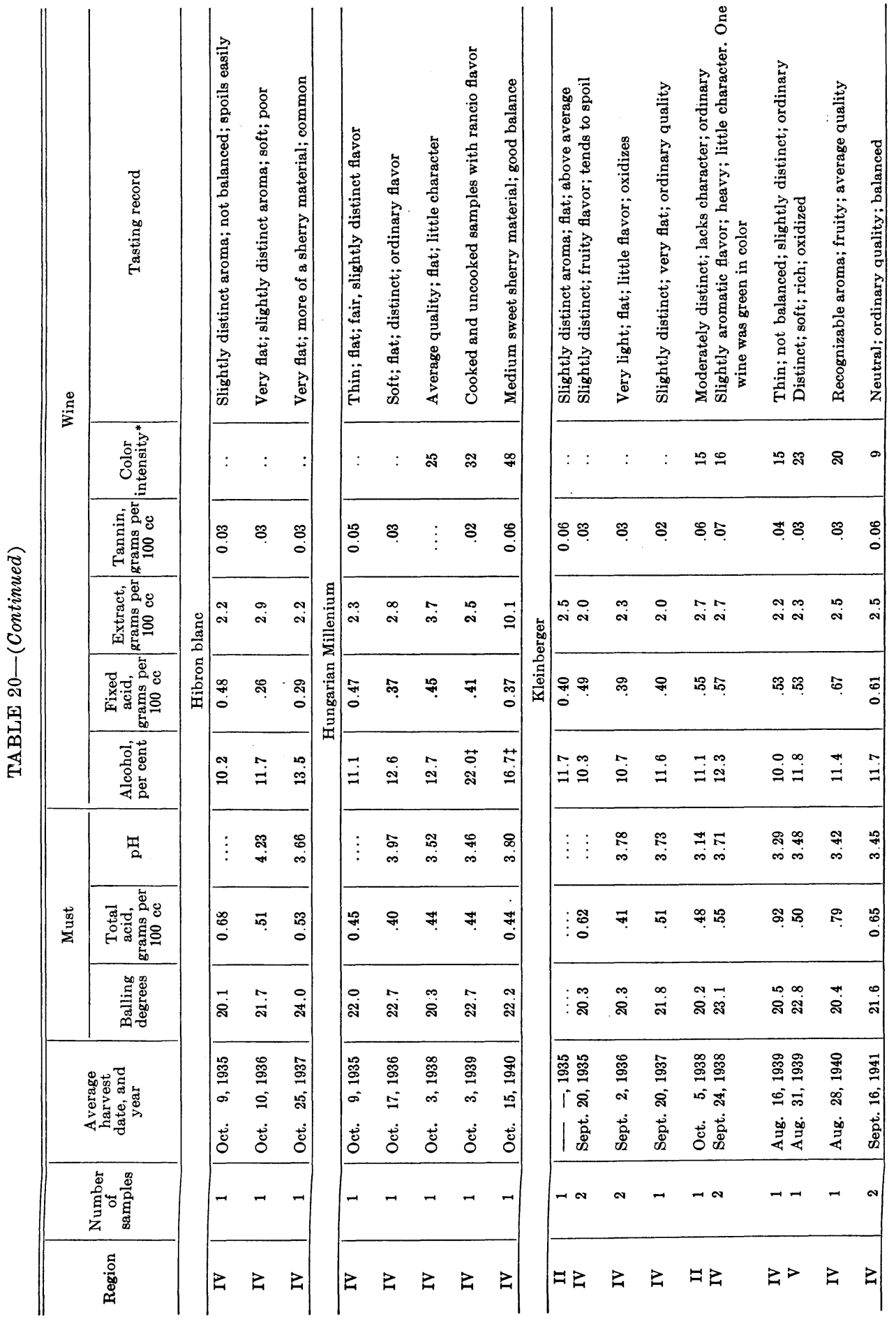




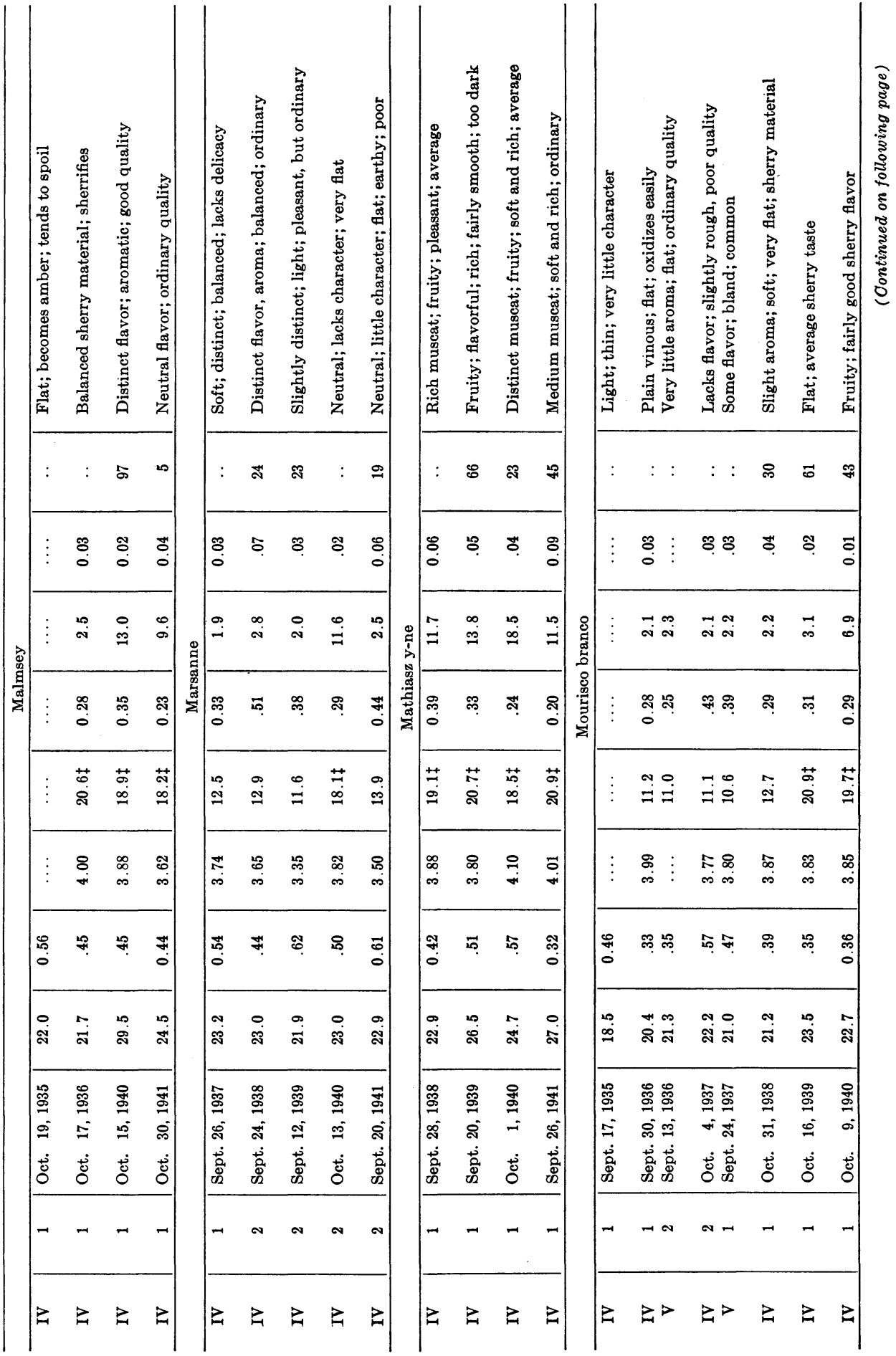




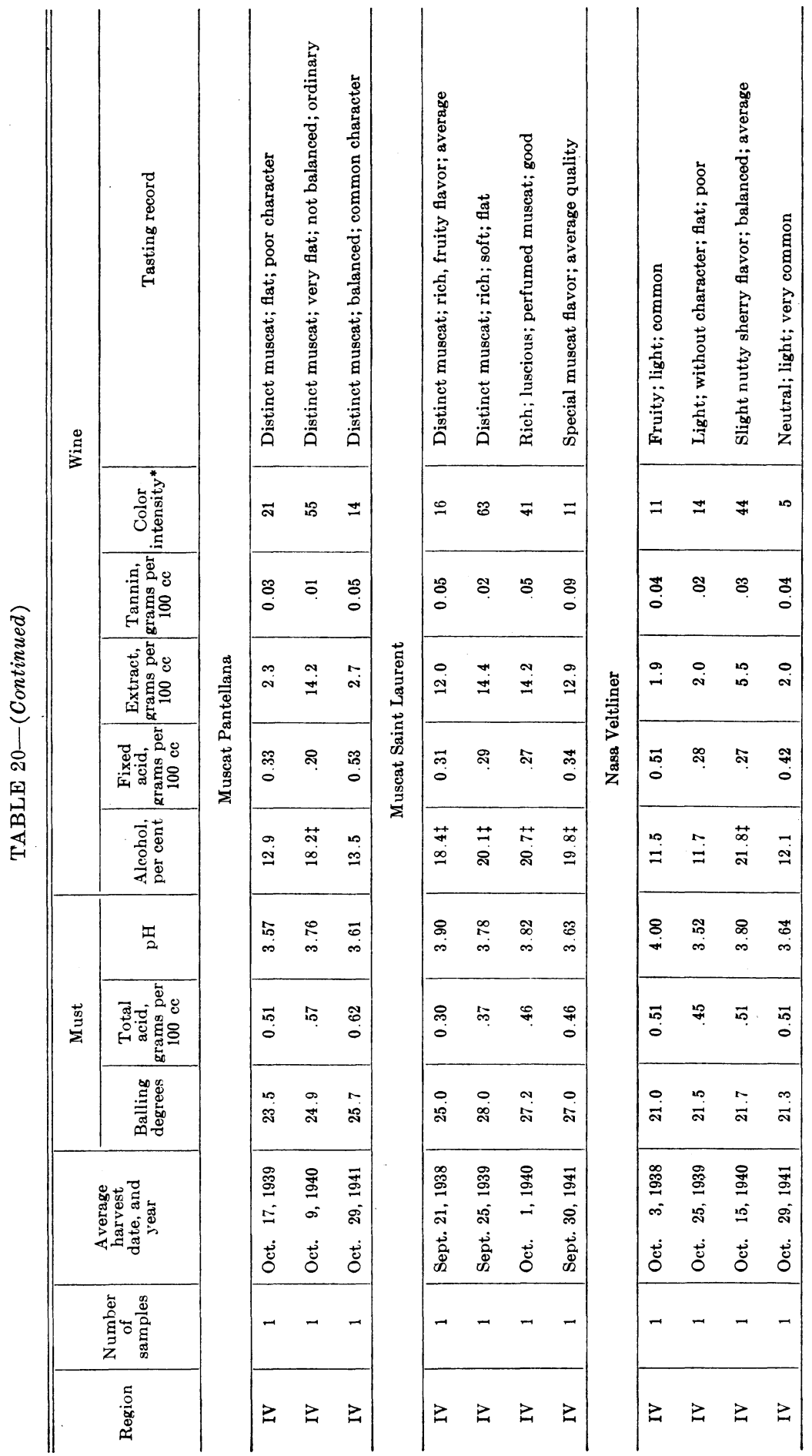




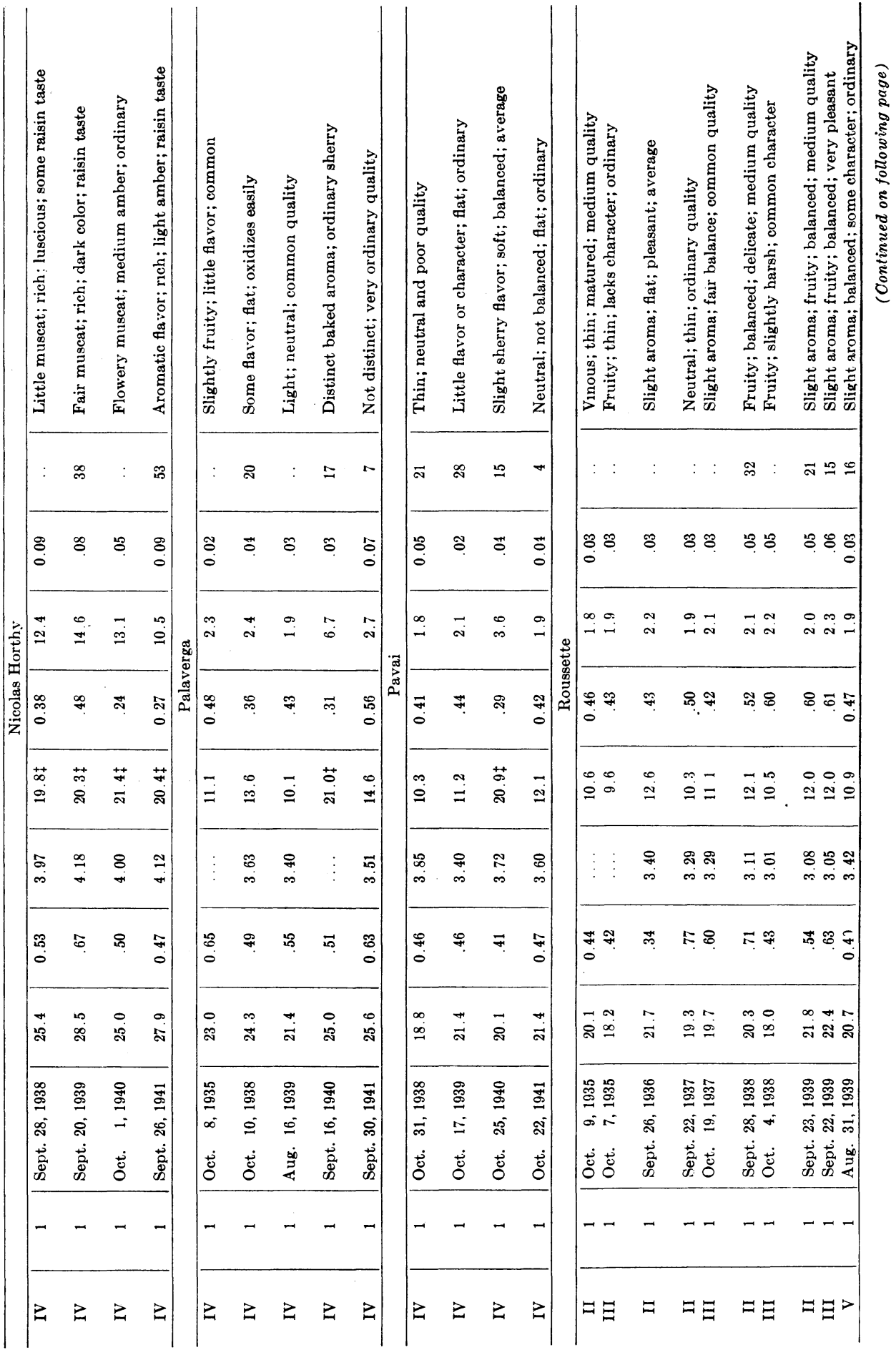




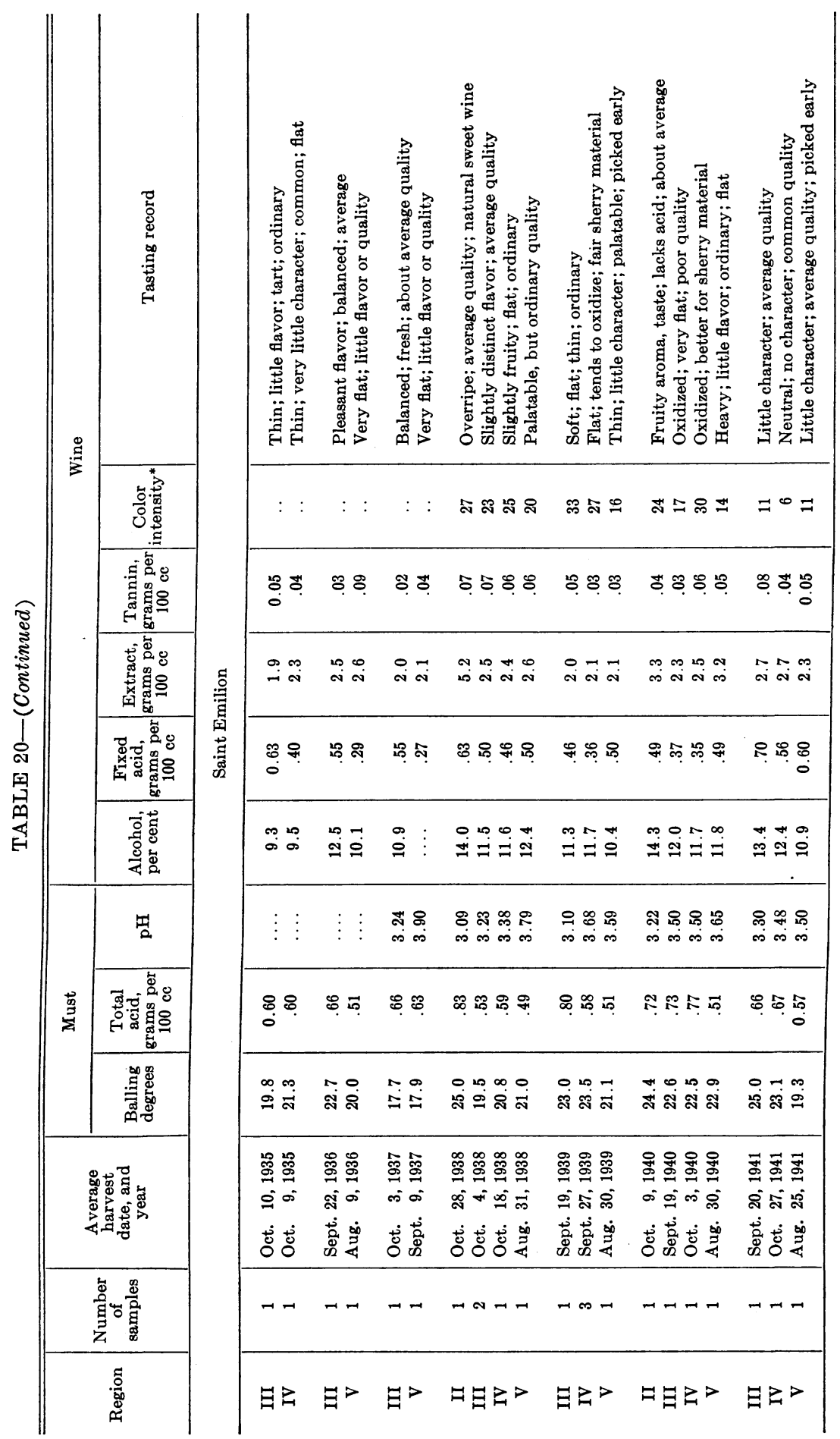



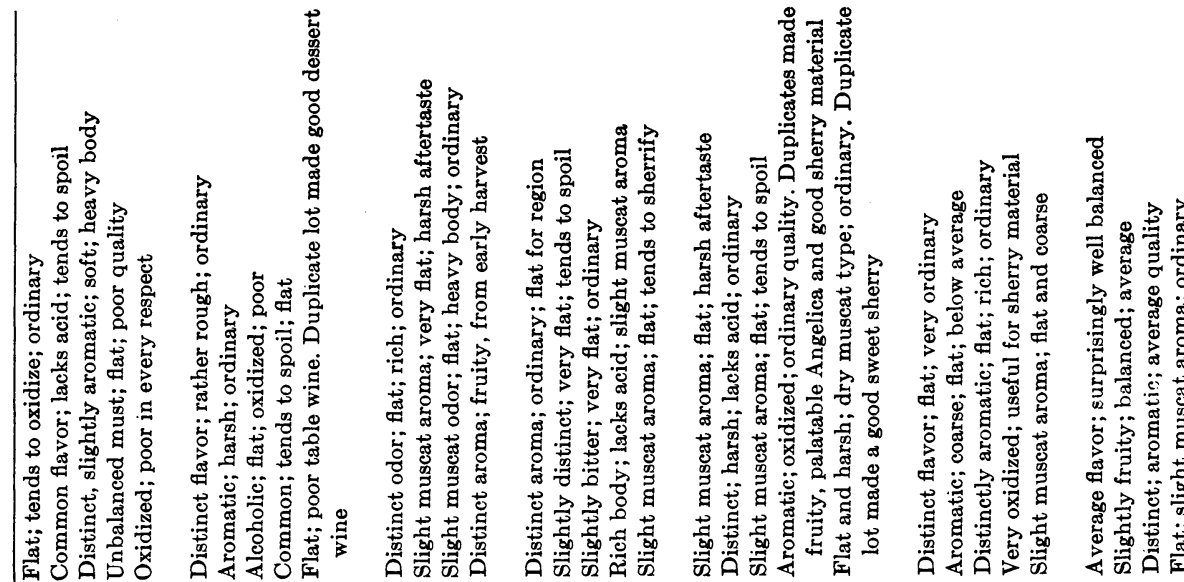

2

오콩ํㅇㅇ ๓

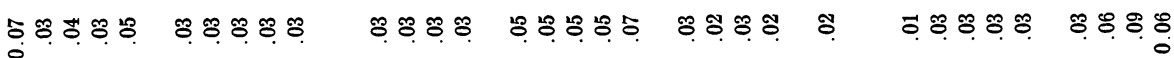

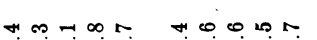

กฺ

이 ๓

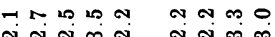

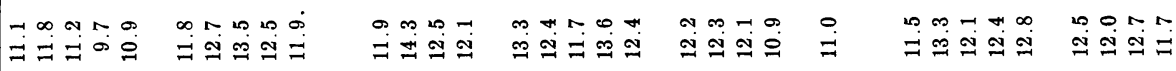

(1)

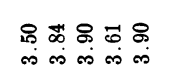

유 ஜ

ผ ๓

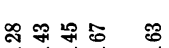

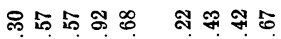

.

0
0
0

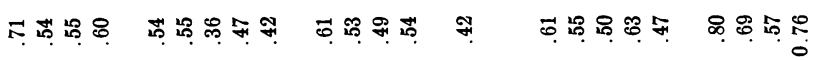

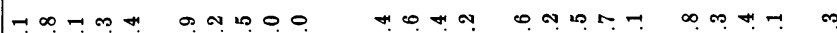

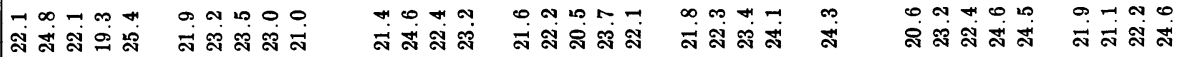

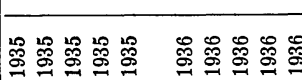

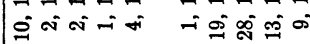

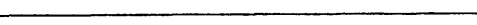

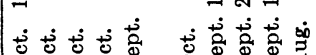

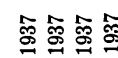

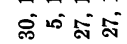

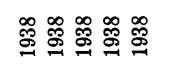

吕哭哭 哭

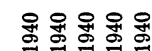

(2)

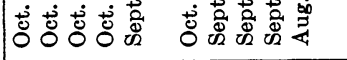

安高咅离

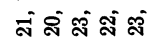

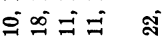

空

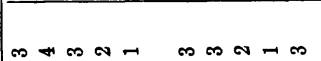

Tha $x$

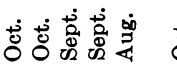

苍茖莒苍

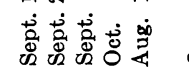

客高紊离 


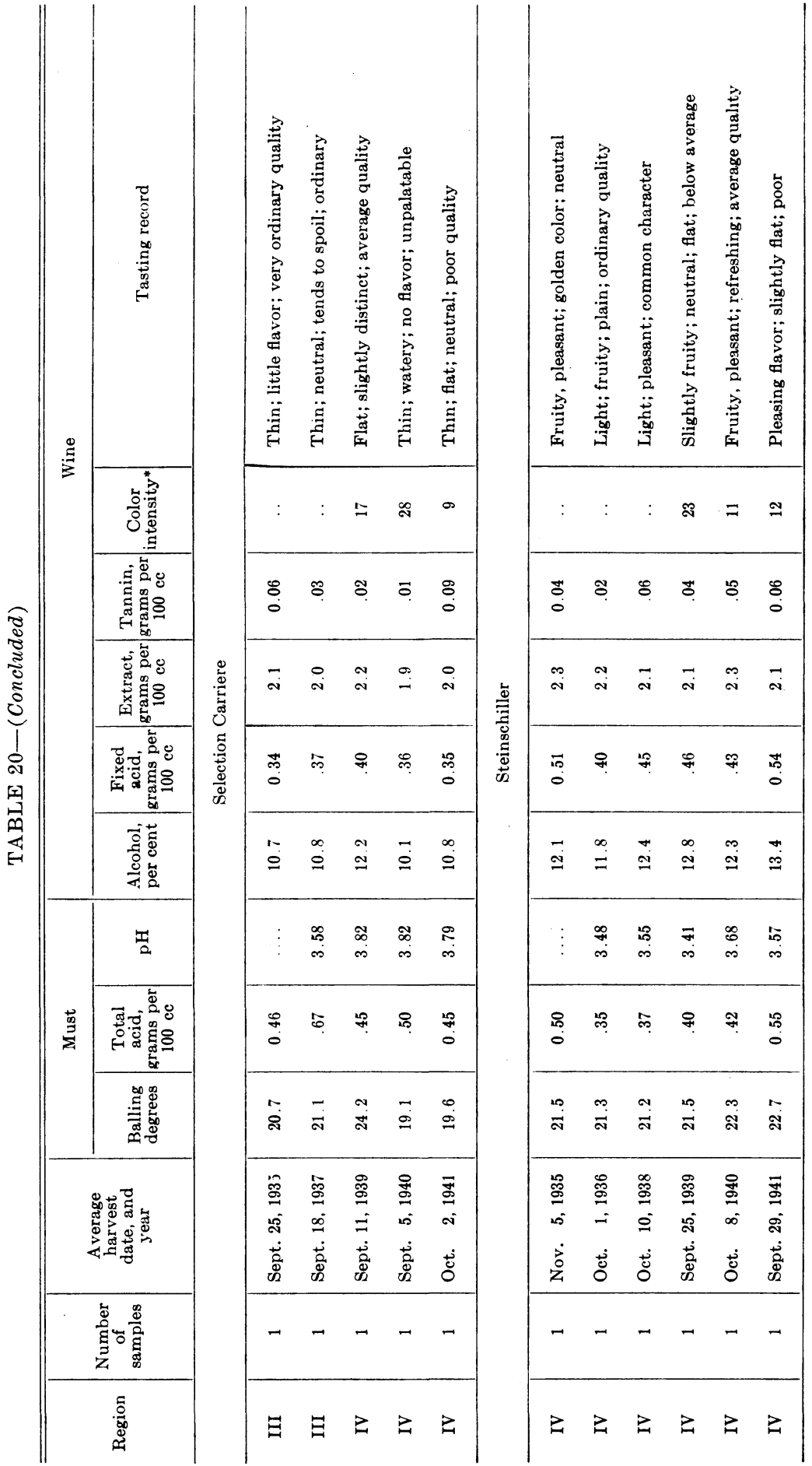




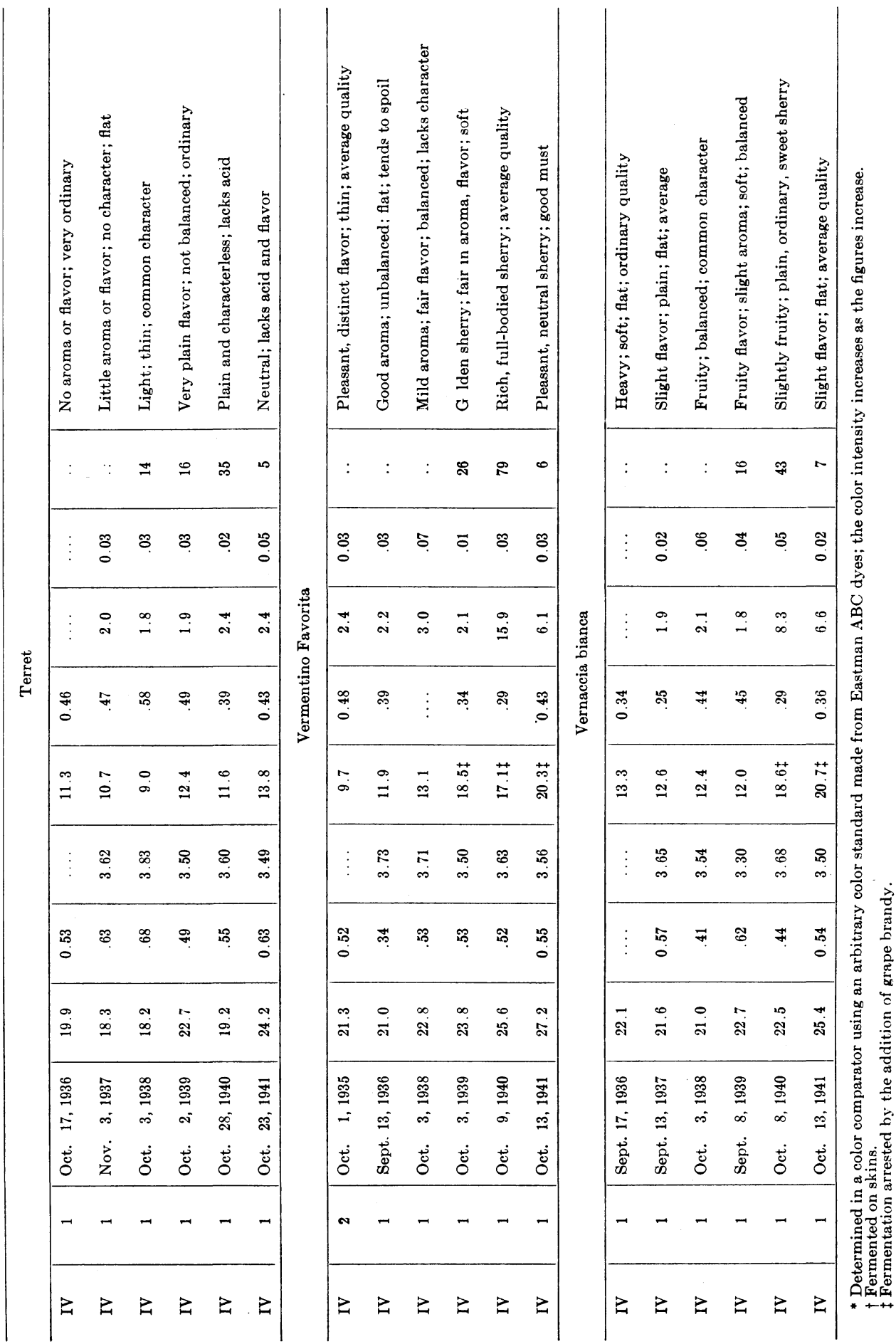


The figures for the Balling degree and acid content of the musts shown in table 20 offer convincing proof that this variety cannot produce a balanced table wine. No sample was fully mature; yet not one contained as much as 0.60 per cent acid, and only four of the fourteen were above 0.50 per cent.

In fact, the variety possesses few desirable qualities. The wines have been thin, flat, lacking in flavor or character, and poor to ordinary in quality.

On the basis of its wines the Green Hungarian cannot be recommended for planting anywhere in the state. This confirms Bioletti's 1907 recommendation. Even in blending, these wines will add only bulk; and they will dilute the possible good properties of wines with which they are blended.

Hibron blanc.-This variety has been tested only in region IV. Its musts have been deficient in acid for white table wine and not sufficiently high in sugar for dessert wine. Although somewhat distinctive in flavor, it is not sufficiently so to be recognizable. The variety is only a moderate producer and, in view of the poor quality of its wine, plantings are not recommended for any California conditions.

Hungarian Millenium.-The Hungarian Millenium is a good producer. It ripens late in the season and generally reaches the winery in good condition. The berries are very firm, and the juice yield is average. Because of the large crop the grapes do not reach a high degree of sugar under region IV conditions. The variety is very low in total acid; and the dry table wines made from it in 1935,1936 , and 1938, although palatable, were unbalanced and mediocre. The sherry material produced in 1939 and 1940 was satisfactory in flavor; but the wines were not of high enough original sugar concentration for producing heavy-bodied sherries.

The Hungarian Millenium is not recommended for California even though the flavor and character are fair for the production of sherry. Conceivably, conditions warmer than those of region IV would increase the sugar concentration sufficiently to make it useful but the acid would be further reduced.

Kleinberger.-The Kleinberger, when grown in regions II, IV, and V, has no promise for making good dry table wine. The grapes tested agree with the description of Hilgard. Apparently it is not a Riesling variety. It is, however, a good producer in this state.

The grapes are very thin-skinned; and under unfavorable climatic conditions, a large portion will rot before ripening. The spoilage in the vineyard is so noticeable that the variety can sometimes be recognized at a distance by the off-smell. The clusters are medium-sized and are very difficult to handle without undue injury.

The juice yield is very good, but fairly large quantities of sulfur dioxide must be used to secure a sound fermentation. Even so, there are large enough amounts of oxidizing enzymes in the spoiled grapes to give the finished wine an amber color. Despite these difficulties the wine has shown a surprisingly uniform distinctive flavor, though not of high enough quality to recommend it greatly. An important objection has been the consistently low acidity of the must and wine.

This grape is not recommended, since other varieties are cleaner and more distinctive. Furthermore, its use for Riesling wine should be discontinued, since the product does not have the proper character or composition. 
Malmsey.-The Malmsey ripens late and has produced excellent crops. The clusters are large, and the oval berries above average in size, rather firm, though the skins are not thick. The juice yield is average. Malmsey is comparatively free from rot during ripening, usually reaching the crusher in excellent condition.

The wines produced from this variety have been too few to give a clear picture of the possibilities. It is entirely unsuitable for dry table wine, having a low acidity, but appears useful for sweet dessert wines. In sherry material its aromatic, almost-muscat flavor would probably be objectionable, although it is traditionally used for sweet Madeiras in the Madeira Islands. The flavor, however, is not a strong muscat and develops only when the grapes are fully ripe.

No plantings are recommended; the variety ripens too late to be considered for localities cooler than region IV. It is obviously the same variety tested by Hilgard, who also found it productive, but of low acidity.

Marsanne.-The Marsanne is a vigorous, moderately productive variety. Its clusters are large, winged, and compactly set with small, round, thin-skinned berries. The fruit is not too resistant to handling injuries and will rot under unfavorable weather conditions. Both the vine and its fruit are rather susceptible to mildew.

The wines have not been successful in region IV. Despite fair aroma and flavor, their general balance has not been good. Some of them equalled or surpassed those of Burger of the same area; others were less good. The variety should possibly be tested further to determine if there are areas to which it is really adapted. Hilgard, however, having tested it in region II, failed to find a district where its acidity was sufficient for table wines. Bioletti ${ }^{\text {ss }}$ must have erred in recommending it for the interior valleys for table wines, since Hilgard had endorsed it for such districts only as a sherry material. In a previous report ${ }^{59}$ Bioletti does not mention the Marsanne in a review of varieties suitable for interior-valley conditions. Aside from lack of distinctiveness, its main defects are low acidity and the high $\mathrm{pH}$ of its musts-common shortcomings of the undistinguished varieties. Marsanne is not recommended for California.

Mathiasz $y$-ne.-The Mathiasz y-ne is a new variety from Hungary. It has a rather unuusal everbearing habit; that is, it produces another crop of clusters whenever new lateral shoots are formed during the growing season. Its first crop may be about ready to mature, the second crop the size of peas, the third crop blooming, while rudimentary forms for the fourth crop are just taking shape. Since each crop requires nourishment, the quality and quantity of the main crop are reduced by competition with the second and later crops. In some seasons the second crop matures; but the third and fourth never mature at Davis. The chief disadvantage of large amounts of second crop lies in the resultant delay in harvesting. If the first crop is left on the vines until the second crop is ripe, the fruit is shriveled and frequently raisined. If the first crop has to be harvested separately, the picking costs are greatly increased.

Another disadvantage is the russet-pigmented thick skin. The grapes must be pressed immediately in order to get a light color ; but by early pressing, the already small juice yield is reduced further, and the amount of muscat flavor extracted from the skins is also restricted.

\footnotetext{
${ }^{58}$ See citation in footnote 18, p. $496 . \quad{ }^{59}$ See citation in footnote 17, p. 496.
} 
The muscatels produced of this variety in region IV have been fairly smooth, rich, and full-bodied. Aroma and flavor, however, have been less pleasing or pronounced than those of several other muscat varieties-for example, Muscat Canelli and Orange Muscat. Although these musts and wines were very low in acid and very high in $\mathrm{pH}$, little difficulty with spoilage was experienced, probably because the grapes were clean and were carefully handled in the winery and because the fermentation was arrested by the addition of grape brandy before deterioration could set in.

In view of its unsatisfactory bearing habit and its commonplace wines, this variety cannot be recommended.

Mourisco branco.-This variety ripens late. It has been an average producer in region IV. The clusters are large and well filled with large, soft, and fleshy berries. The fruit matures in good condition despite its late ripening. The grapes are easily crushed, and the juice yield is above average. The total acid is very low, and the $\mathrm{pH}$ high.

The table wines from regions IV and V have been commonplace, with no properties of particular interest. On the whole they were only vinous in flavor, lacked balance, and tended to oxidize. Their extreme flatness and neutrality is a severe disadvantage.

For sherry production the variety shows up somewhat better. Its wines, treated by the usual California sherry process, reveal a sufficient-to-good sherry flavor, together with acceptable balance. These sherries have been pleasant, with some promise, but have not developed the superior qualities secured from Palomino grapes. The white dessert wines have had little flavor and have been too low in acid even for a sweet wine.

Although resembling in composition and appearance several varieties from the Jerez region of Spain, the product of Mourisco branco as sherry is poor. Its performance to date does not recommend it for planting anywhere, even though Bioletti endorsed it for dessert wines. The present results support its use in the Douro Valley, its region of origin, where it furnishes table fruit. In California it cannot qualify even for this purpose.

Muscat Pantellana.-The Muscat Pantellana, a vigorous grower, has produced large crops at Davis. The clusters and berries are large, the skin thick, the texture hard and crisp. The juice yield is below average for free-run juice. The grapes ripen late and have a mildly aromatic muscat aroma. The musts are of moderate acidity and, for a muscat, of below-average $\mathrm{pH}$.

The wines have not been particularly distinctive. They possessed only a mild aromatic aroma. The dry wines were flat, without character, and decidedly unharmonious, while the muscatels were harsh, with a somewhat undesirable flavor. In general they portray the lack of finish characteristic of the wines from table grapes.

On the basis of results to date, this variety cannot be recommended for wines. Its possibilities as a table grape are receiving consideration.

Muscat Saint Laurent.-The Museat Saint Laurent vines are only average in vigor. Under Davis conditions neither the quality nor quantity of the fruit has equalled that of Muscat Canelli or Orange Muscat. The clusters are small; the berries larger than average. The grapes are thin-skinned and must be handled very carefully. The juice yield is above average. 
The wines, though rich in aroma and flavor, have lacked acidity and balance. The acid content of both the musts and the wines has been very.low. Possibly these have been among the smoothest muscat wines we have produced. Smoothness alone, however, is not all-important.

Since this variety does not equal in quality or production the other welltested and recognized muscats, it is not recommended.

Nasa Veltliner.-The Nasa Veltliner has been tested in region IV. There it is a vigorous-growing, productive, late-ripening variety. Its musts have been of low sugar and acidity; the dry table wines were very neutral, lacking in character, and poorly balanced. They were only plain and ordinary. One sample when baked took on a slight nutty; sherrylike flavor, and was well balanced. Nevertheless, it was only standard dessert wine.

Since its wines have not made a place for it even as a heavy producer, it does not belong in regions IV and V. Further testing would be desirable to determine its possible adaptation to II and III, but there its possibilities are limited by its late maturing. It is not recommended.

Nicolas Horthy.-This is another importation from Hungary, where it is of recent origin. In several respects it resembles the Mathiasz y-ne; the remarks on the disadvantage of the everbearing habit of that variety largely apply here, although to a lesser extent. The grapes when ripe are also russet pigmented. The first crop ripens in midseason. The acidity is low; the $\mathrm{pH}$ uniformly high. The first crop has had a good sugar content.

The wines have possessed a pleasing muscat aroma and have been rich, luscious, and fairly well balanced. They have aged rapidly, but have tended to darken unduly. These have been average muscatels.

The variety is not too vigorous or productive. Its crops have barely equaled Muscat Canelli, which is usually considered a poor producer, and have averaged less than the Mathiasz y-ne under comparable field conditions. The first crop fruit is also very subject to raisining. Largely for this reason, the condition of the fruit arriving at the crusher has never rated above fair. The variety is not recommended.

Palaverga.-The Palaverga is moderately vigorous and productive. It ripens in midseason. Its medium-large clusters are well filled with medium-sized berries. It handles well, is readily crushed, and gives a good juice yield.

In region IV the fruit is poorly adapted for dry table wines, the product tending to be flat, neutral, and decidedly lacking in character. A lot of sherry material that was baked developed a distinct aroma. Still, though clean and delicate, it was only a plain sherry. Further tests should probably be made.

This variety to date has failed to show any promise for wine production. It is mentioned but not tested by Hilgard, and is not endorsed by Bioletti. It cannot be recommended for planting in California. Its only possibility is as a sherry base; but in this regard the wines show too little promise, except in composition.

Pavai.-The Pavai has large clusters and berries and at Davis has been a good producer. Since the skins are thick and the texture is very pulpy, the juice yield is small. The grapes ripen late, but remain in good condition. The musts are very low in acid.

The dry table wines from region IV have been very common-practically 
neutral, with little or no character, and particularly flat. A baked sample possessed a mild sherrylike flavor, was soft, clean, and balanced; but it, too, was only average.

This variety is decidedly not adapted for producing either table or dessert wines in region IV. It would be still poorer in a warmer area, because of its low acidity. It was not promising enough to warrant further testing in cooler regions, where, indeed, it would fail to ripen normally. It is not recommended.

Roussette.-Roussette is a vine well above average in vigor and productivity. The grape ripens late. The clusters are medium, short-conical or pyramidal, and well filled with medium-sized, long-oval fruit. The yellow-green berries usually take on a pinkish blush at maturity. The semiupright and open habit of growth may expose them to the sun; but sunburn has not been a factor in the regions from which grapes were obtained, except in $\mathrm{V}$.

On the whole, the wines have not been unpleasant; but they have possessed little distinctive flavor or character. They might be called bland wines. Some samples were slightly thin, and others were lacking in balance; but these were not serious deficiencies. The light color was retained unusually well.

Since most of the grapes came from regions II and III, the limited acidity of certain samples is noteworthy. Other almost neutral varieties, such as Folle blanche, are much better balanced.

On the basis of these results it is difficult to see where the Roussette might justify a place for itself. It is not productive enough for regions IV and V; and for regions II and III other varieties of equal or greater productivity, which make better wines, should be preferred. Its chief merit is its resistance to disease, but this is insufficient to recommend it for planting. In region $I$ the grapes will probably fail to ripen.

Saint Emilion.-The Saint Emilion (also known as the Trebbiano in Italy and as the Ugni blanc in some parts of France and Algeria) is moderately productive and ripens late. The clusters are large, very long, and characteristically branched at the end of the cluster. The berries are medium-sized and rather soft, with an easily broken skin. They must be transported to the winery very soon after harvesting. When overripe they sometimes have a slight pinkish bloom. The juice yield is high, sometimes almost equaling that of Burger.

This variety has produced only ordinary wines in regions II, III, IV, and V. In IV and V it is always too low in acidity for white table wines; products have frequently been better balanced as sherry material, but are rather thin for this purpose. In regions II and III the variety has occasionally yielded a light, neutral-flavored, early-maturing wine, but also sometimes a flabby, easily oxidized, common product. Because of its neutral character it is better adapted for blending than for producing a wine by itself.

Saint Emilion is not now recommended for California. Its lack of acidity and its neutral character are primarily responsible. Neither Hilgard nor Bioletti was able to recommend it.

Sauvignon vert.-The Sauvignon vert is widely distributed in California. It ripens slightly before midseason and in most locations is a good producer. The clusters are long and rather straggly. The berries are medium-sized, spherical, and accompanied by a large number of shot-berries. The skin is very thin and, as the grape ripens, becomes brownish on the exposed side. The 
grapes are very subject to rot in wet seasons and locations and also to attack by insects. Their quality for crushing is often unsatisfactory.

This variety has been tested throughout California. Irrespective of the region it has been very deficient in acid, the only exception being two of the 1941 samples. This observation confirms the published analysis of Hilgard, who reported an acidity as low as 0.22 .

The wines have had a marked tendency to spoil, owing to the very high $\mathrm{pH}$ of the musts. The flavor is common and lacks softness. The aroma is almost always very distinct, frequently being very aromatic and sometimes even having a muscat quality. Because of the low acidity the wines frequently have a harsh aftertaste.

Of the commonly planted white wine grape varieties of California the Sauvignon vert least deserves a permanent place. Its musts are unbalanced, and its fruit is poor. The wines are undesirable in flavor as well as composition. Several attempts have been made to utilize the variety as a sherry base and as a white sweet wine. It makes a pleasant Angelica type, and its tendency to oxidize suits it fairly well for sherry material. In neither case, however, is it outstanding; other varieties are more useful. The low acidity and the high sugar content suit the variety somewhat better for natural sweet wines, where a slight muscat flavor is somewhat less objectionable than in a dry wine. Semillon and Sauvignon blane are, however, much better for this purpose.

No plantings of Sauvignon vert are recommended for California.

Selection Carriere.-The Selection Carriere is a high-producing variety, ripening late. The medium-large berries are loosely borne on a moderate-sized cluster. The vines, though but fairly vigorous, are comparatively free of diseases. The grapes from regions III and IV were very low in total acid and of only average Balling degree. They were also very high in $\mathrm{pH}$.

The wines have been uniformly neutral, of only moderate alcoholic content and of very low acidity. This variety is therefore devoid of interest. In regions cooler than III it will seldom ripen sufficiently for table wines, and it is too flat and neutral for region III or IV. Its high $\mathrm{pH}$ makes it difficult to ferment and keep. It is not recommended.

Steinschiller.-The Steinschiller is of moderate vigor and productivity. Its grapes ripen very late but resist unfavorable weather unusually well. This fact, however, is of little value in California, for the variety will not ripen here in cool enough regions to retain its acidity. Its vines are markedly resistant to disease.

The clusters are small and rather short. The berries, about medium in size, turn almost russet at maturity. The juice yield is below average.

In the interior it produces only common table wines of little interest. Under these conditions it is very deficient in acid. None of its qualities would justify planting. In region II it will probably ripen too late to produce balanced commercial wines.

Terret.-The Terret is vigorous and productive. Its fruit ripens very late, but remains in good condition until mature. The juice yield is fair. The grapes have some pigment in the skin and must be pressed immediately after crushing.

Wines of the Terret gris and Terret blanc grapes grown in region IV were 
without promise - almost devoid of aroma, flavor, or character, and thin and flat.

In region $\mathrm{V}$ the fruit might attain a higher sugar content, but this would be effected by a reduction in acidity. The Terret will probably not mature in region II or III. It is not recommended.

Vermentino Favorita.-The Vermentino Favorita is distinguished from the Malmsey (Vermentino) by its larger berry size and its less pronounced flavor. Its grapes are fairly small and round, whereas those of the latter are large and oval. The aroma also is more pronounced and possibly more delicate than that of Malmsey. The vines are vigorous, but only moderately productive. The fruit matures relatively late.

The dry wines from region IV have been of only average quality-low in acid, disappointing in aroma and flavor.

The sherries have been much more promising-pleasant, clean, and fullbodied, of good quality.

Vermentino Favorita is not adapted for producing dry wines in region IV. The quality has not been sufficiently high, and the production is low. Although productivity may be improved by longer pruning, the result may be an undue delay in the maturing of an already late-ripening sort. The wines may be of higher quality in the coastal areas; but this point would have to be proved, and the bearing under the cooler conditions determined. In regions I and II the variety would not ripen regularly and uniformly.

Although the extra aroma and flavor of the sherry is very pleasant, Vermentino Favorita cannot be recommended for sherry making in region IV because of its limited production.

Vernaccia bianca.-The Vernaccia bianca was once grown extensively in northern Italy and southern Austria, where it produced bulk wines. Since it starts growth late in spring, Hilgard thought it might be useful for frosty locations. Bioletti does not mention it.

This variety ripens in midseason. At Davis it has produced good crops, maturing in good condition. The clusters are of average size; the berries greenish-white or mottled. In region IV the grapes have reached the crusher in good condition and have given a good juice yield. The musts have been of less than average acidity, and their high $\mathrm{pH}$ reflects this condition.

At Davis the table wines have been flat and plain, lacking in flavor and aroma. They have failed to reveal in sufficiently marked degree any characteristic to indicate that the variety may be improved by a cooler climate. In region IV the dessert wines were lacking in character and flavor-too neutral to be more than ordinary. Vernaccia bianca cannot be recommended.

\section{RED VARIETIES NOT RECOMMENDED}

Red varieties not recommended include Alicante Bouschet, Antibo, Aspiran noir, Black Hamburg, Black Prince (Rose of Peru), Blaue Elbe, Bonarda, Chauche noir, Chenin noir, Coristano, Criolla Mesa, Criolla Vino, Croetto Moretto, Dolcetto, Early Burgundy, Grand noir, Grec rouge, Grosse blaue, Kadarka, Koptcha, Lambrusche Langhre, Lenoir, Macaroli, Marzemino, Mataro, Meunier, Negro Amaro, Neiretta, Pagadebito, Petit Bouschet, Petite 
Verdot, Pfeffer, Picpoule noir, Pinot Pernand, Pinot Saint George, and Tinta amarella. Table 21 gives the analyses of musts and wines of these varieties.

Alicante Bouschet.-The distinctive features of this variety are well known. The leaves, characteristically curved down, are shiny. During the summer and fall they usually turn red. The fruit is black, with a heavy bloom; the juice red. The clusters are medium-large, with the berries set compactly, but not sufficiently so to cause serious breakage. The juice yield is good. Ripening is in midseason, and the vine is a good producer.

The musts in region I are very acid, but the grapes fail to ripen sufficiently. The wine is highly colored. In regions IV and V the fruit fails to retain so much acid, and the wines are frequently flat. The aroma is slightly aromatic, not particularly desirable. The wine is usually rough and somewhat harsh.

The chief attraction has been the highly colored musts, which can be drawn off almost any time after crushing. Unfortunately the color is not stable; almost immediately, it begins to precipitate, a very inconvenient occurrence in bottled wines. Dessert wines stored for years may become tawny through the precipitation of so much color. These wines are very ordinary.

This variety came to be widely planted in California before 1918. It was particularly sought for early in Prohibition because of its shipping qualityit withstood the transcontinental journey better than most wine-grape varieties. Its high coloring-matter content also contributed to the eastern demand, since the color could be "stretched," that is, watered.

Alicante Bouschet is not recommended for California because of low quality and unstable coloring matter.

Antibo.-The Antibo is considered to be primarily a table grape in the Piedmont region of Italy, whence it came to California. At Davis it has been a fair producer, ripening somewhat irregularly, but usually in midseason. The clusters are only medium-sized. The berries are black and larger than the average. They have reached the crusher in good condition.

Though the musts have shown fair acidity from year to year at Davis, the $\mathrm{pH}$ has been relatively high. The dry wines have been flat, harsh, and very plain, with practically no aroma or bouquet and with only mildly vinous flavor.

Because of the almost complete lack of quality factors, little improvement could be secured by growing this variety in a cooler climate than region IV. It should be tested further for possible utilization in region IV for red sweet wine; and in region III and possibly II it might likewise be tried for table wine, though it does not appear promising. It should not be planted commercially in California.

Aspiran noir.-The Aspiran noir vines are fairly vigorous and productive. The clusters are large, conical, shouldered, compactly set with large, oval, firm berries. The fruit matures very late and at Davis, because of its large production, has not ripened properly. The grapes utilized were therefore immature; but, even so, their acid content was low. Because of deficiency in color, the fruit was pressed at once for white wines, which proved to be thin, light, and totally lacking in character.

Although the tests included only two lots, which were rather green, they definitely show that this variety is unworthy of a place in California. 


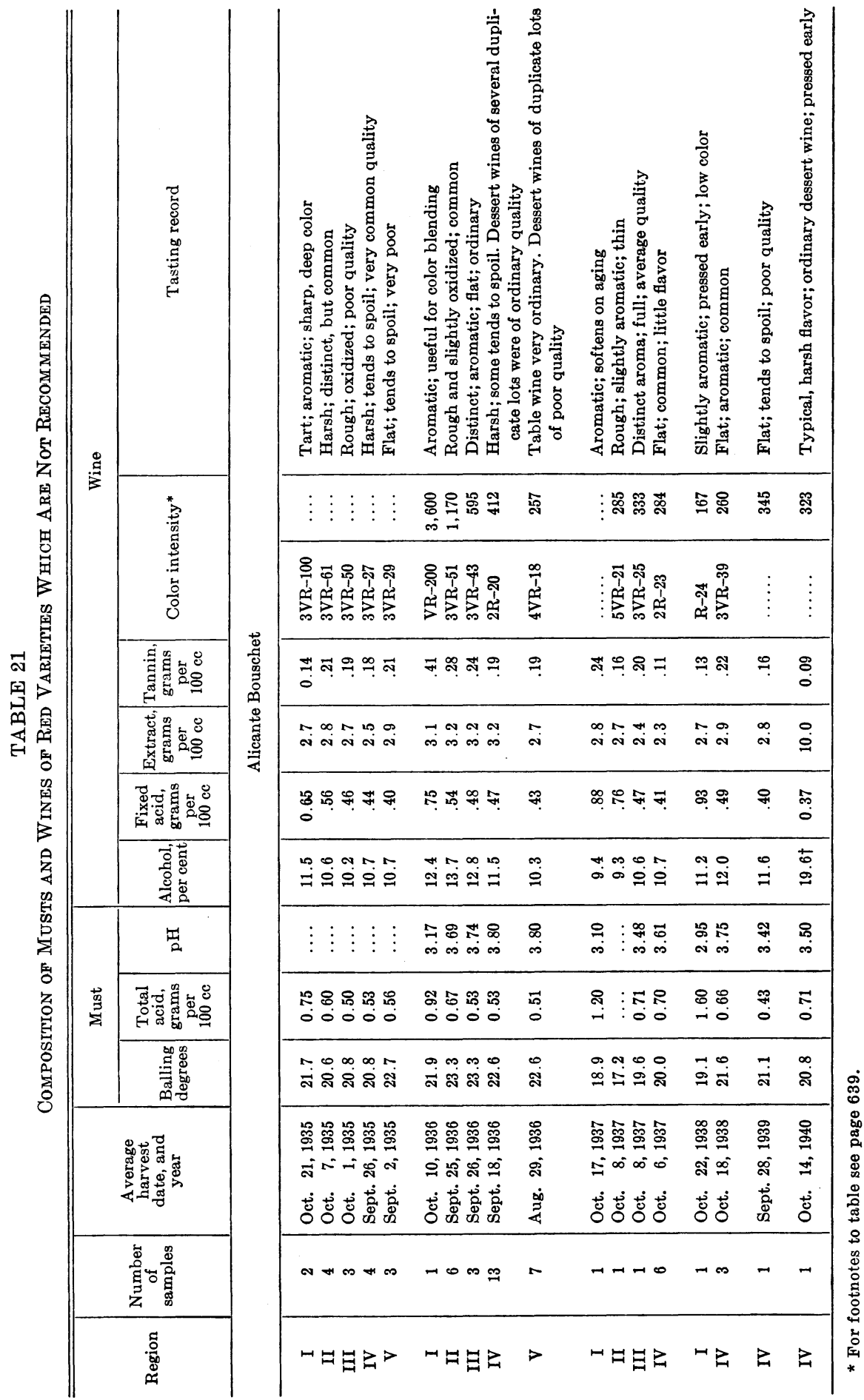




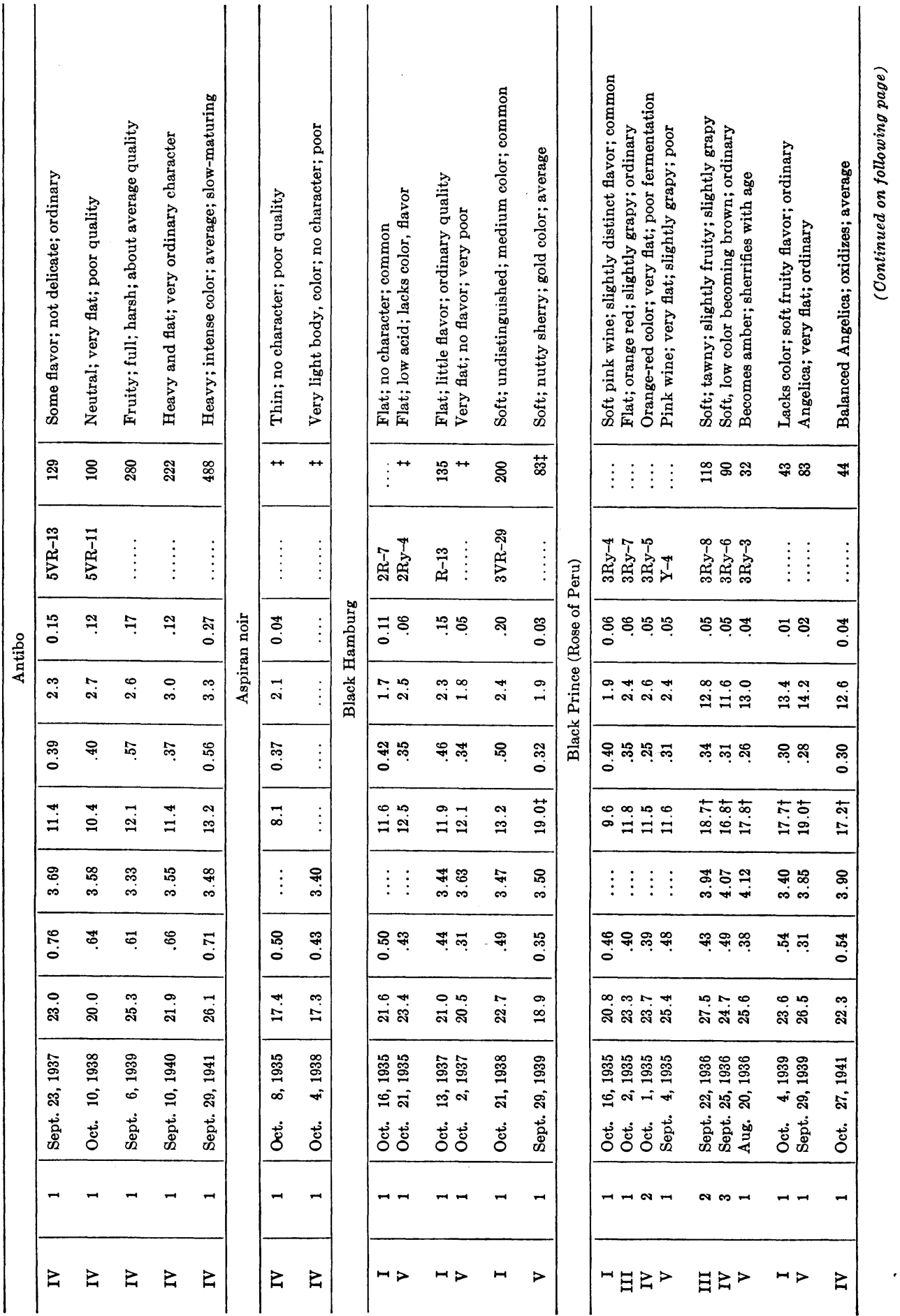




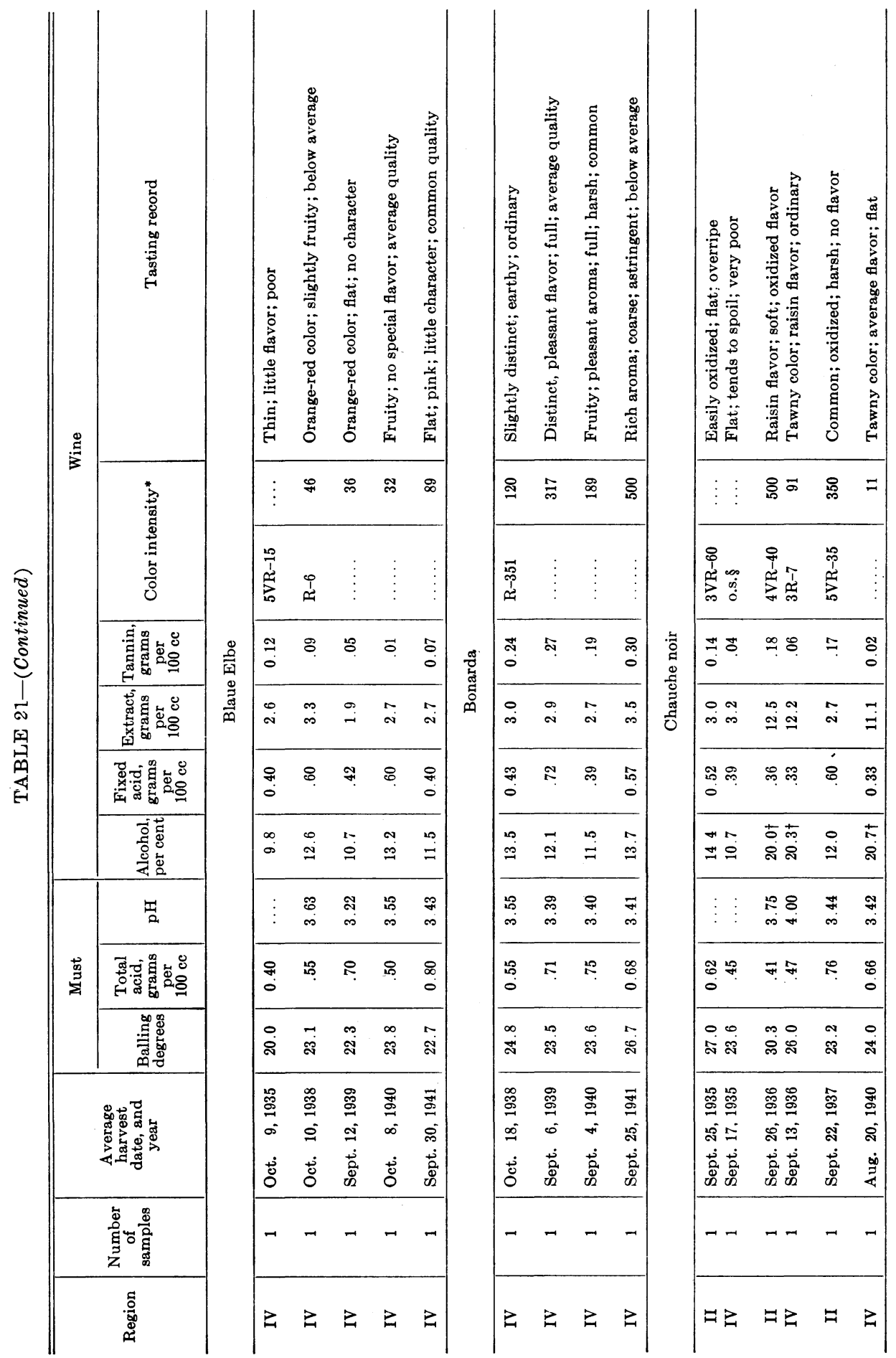




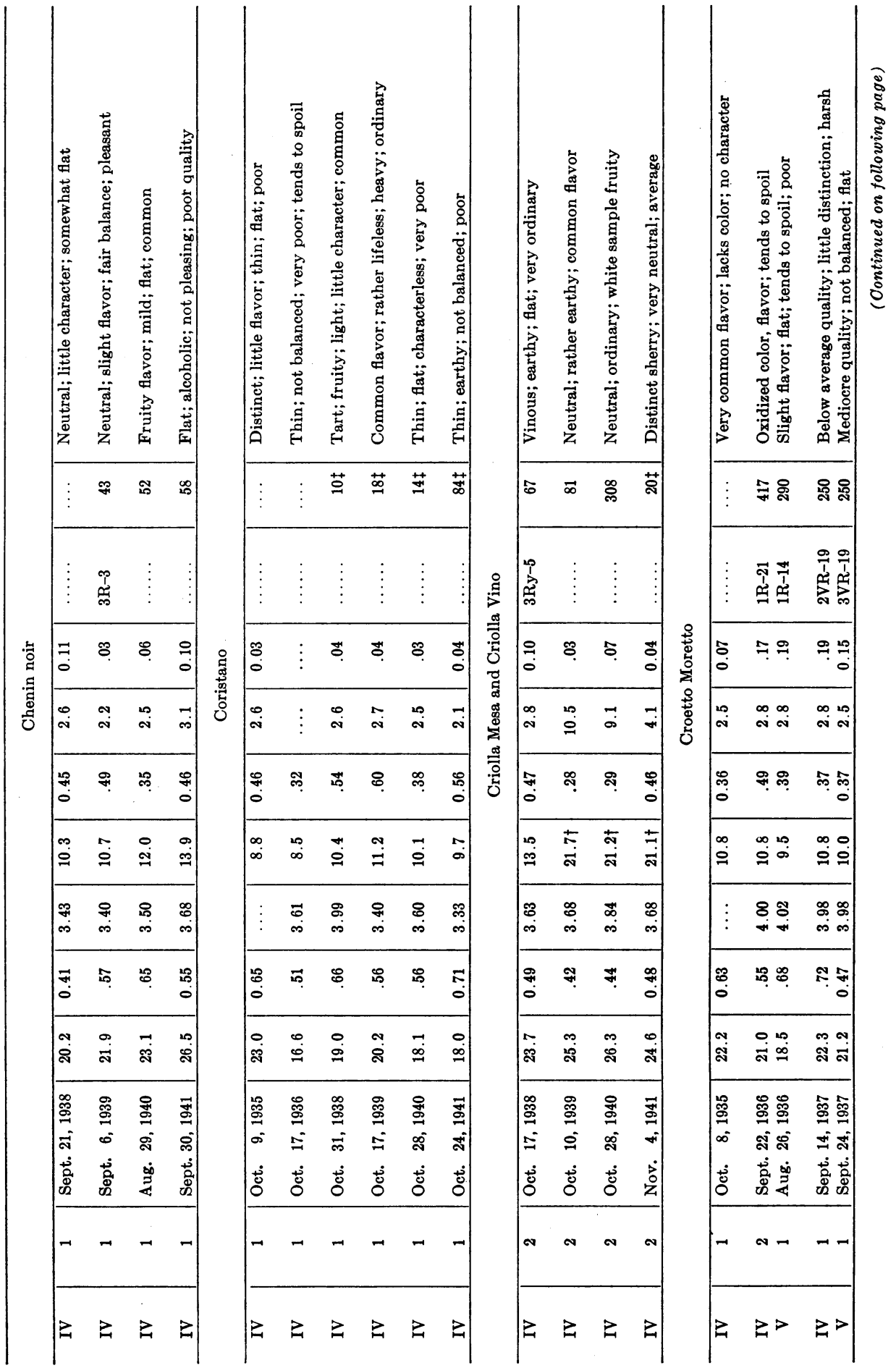




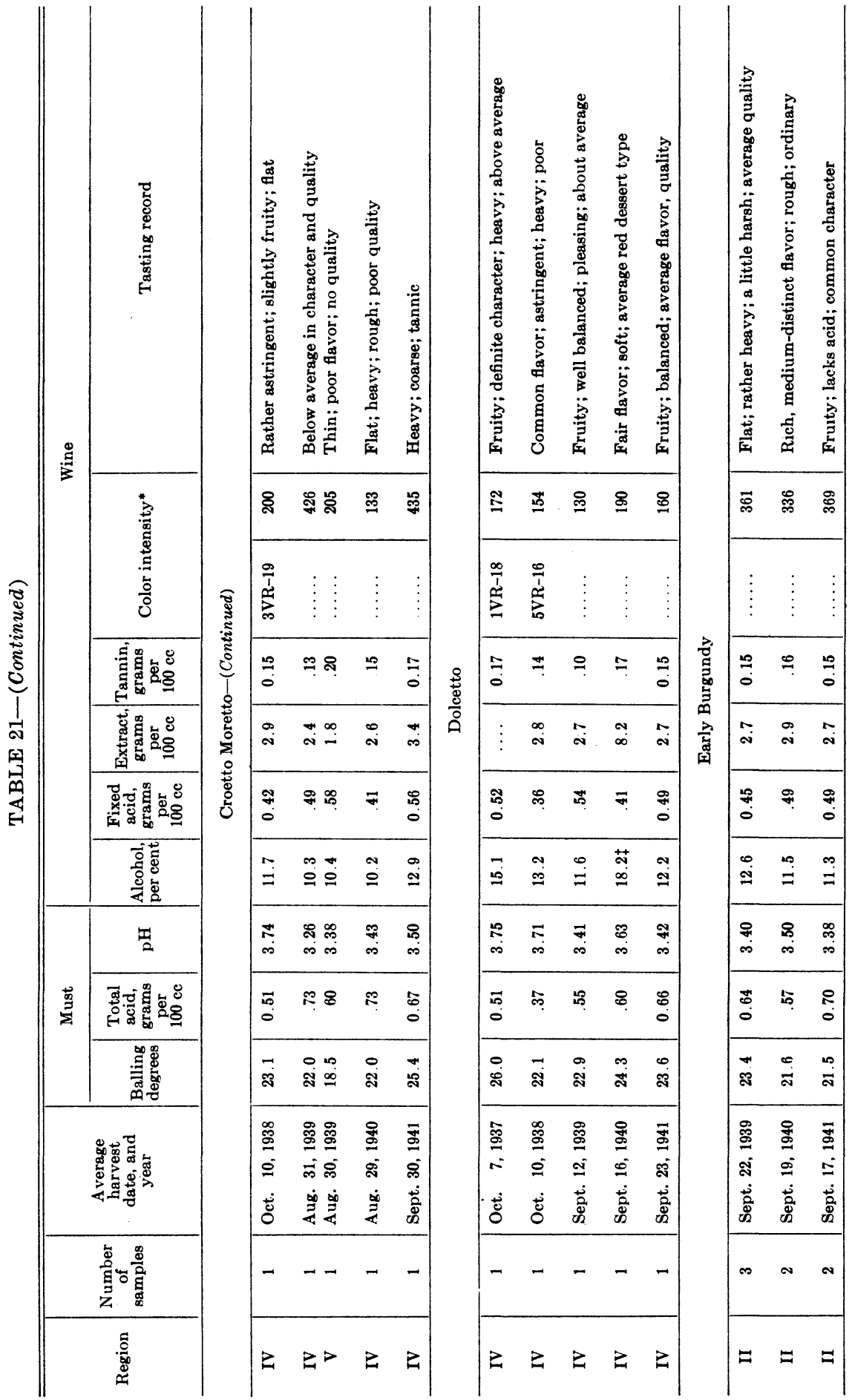




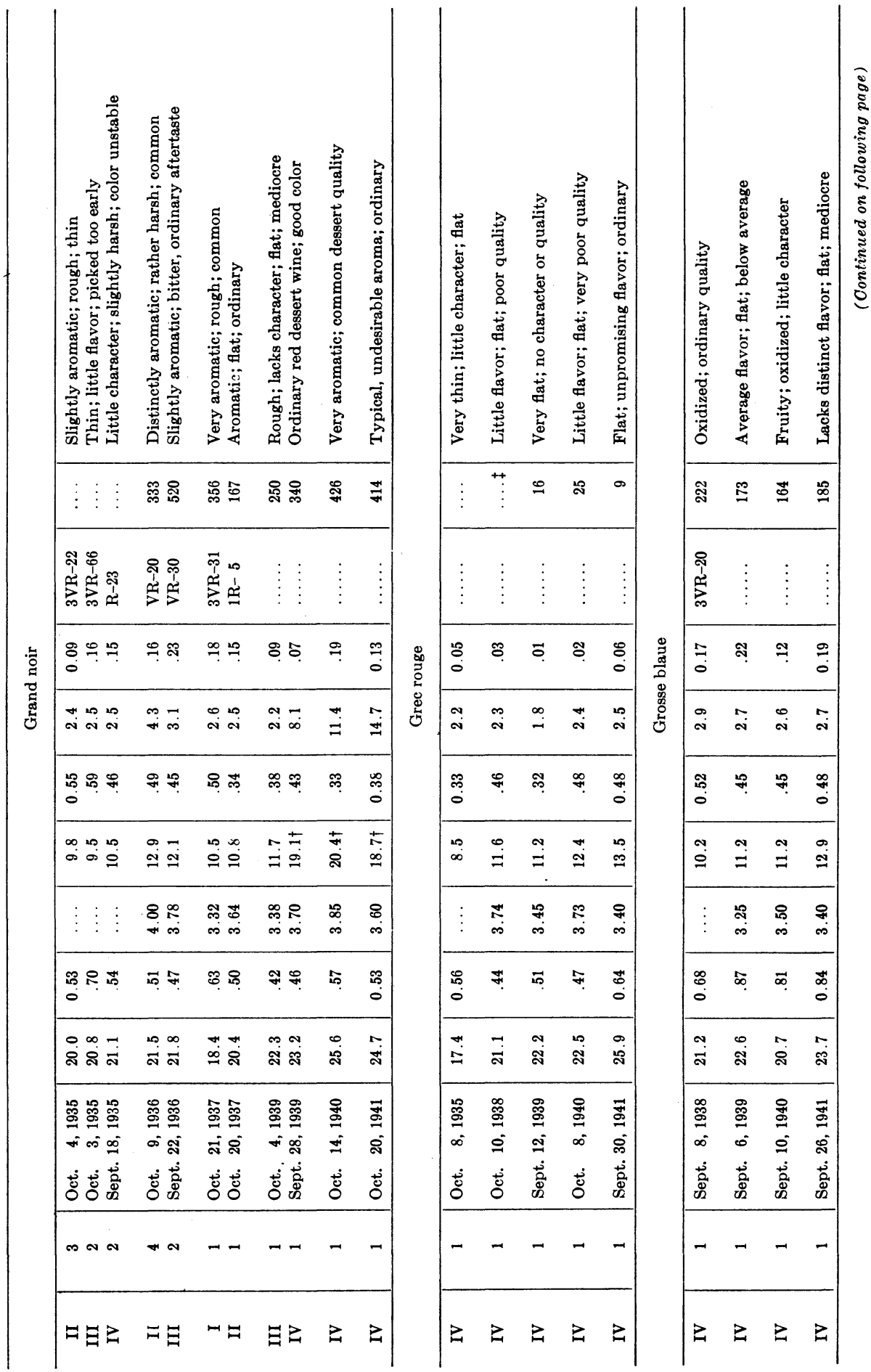




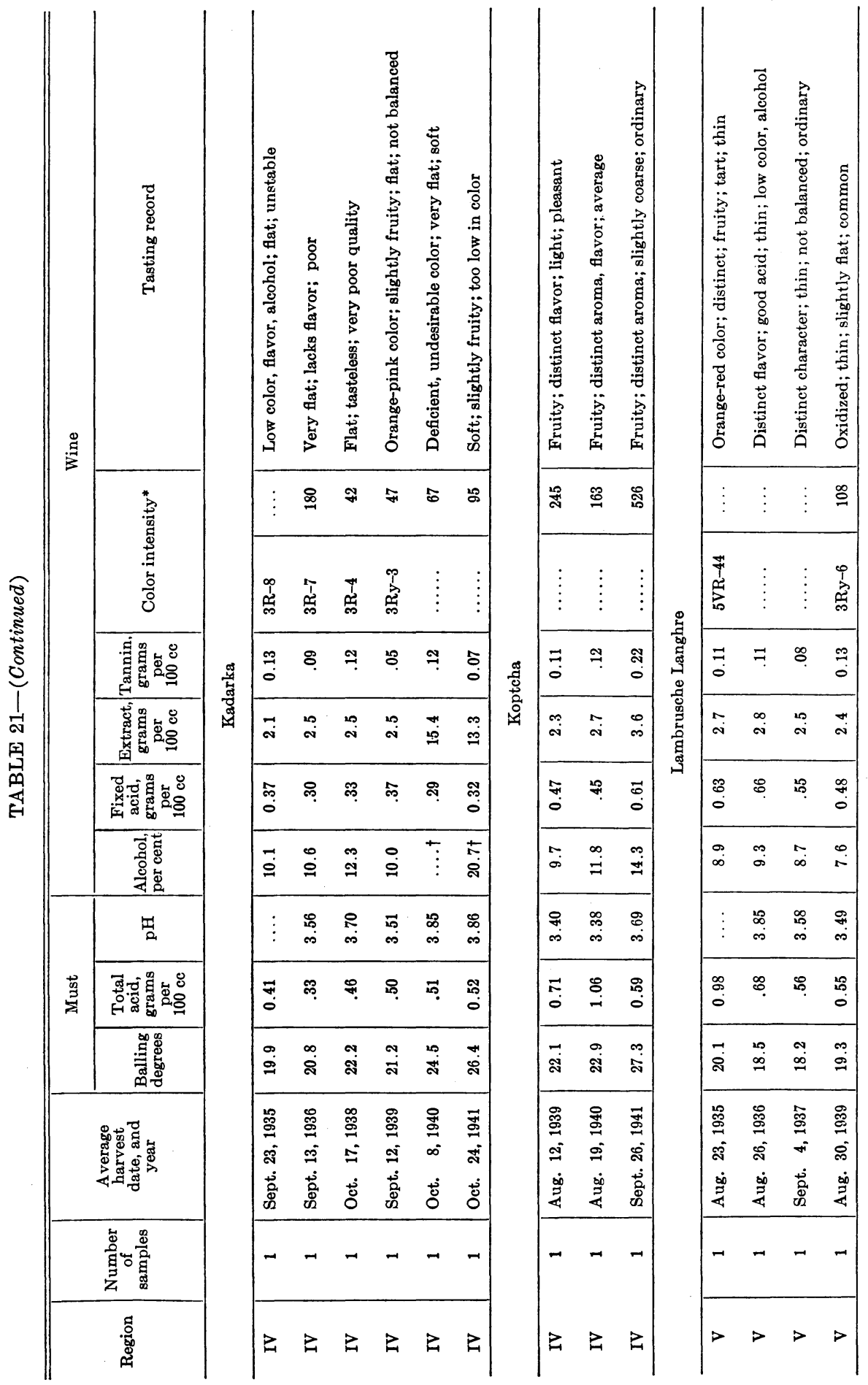




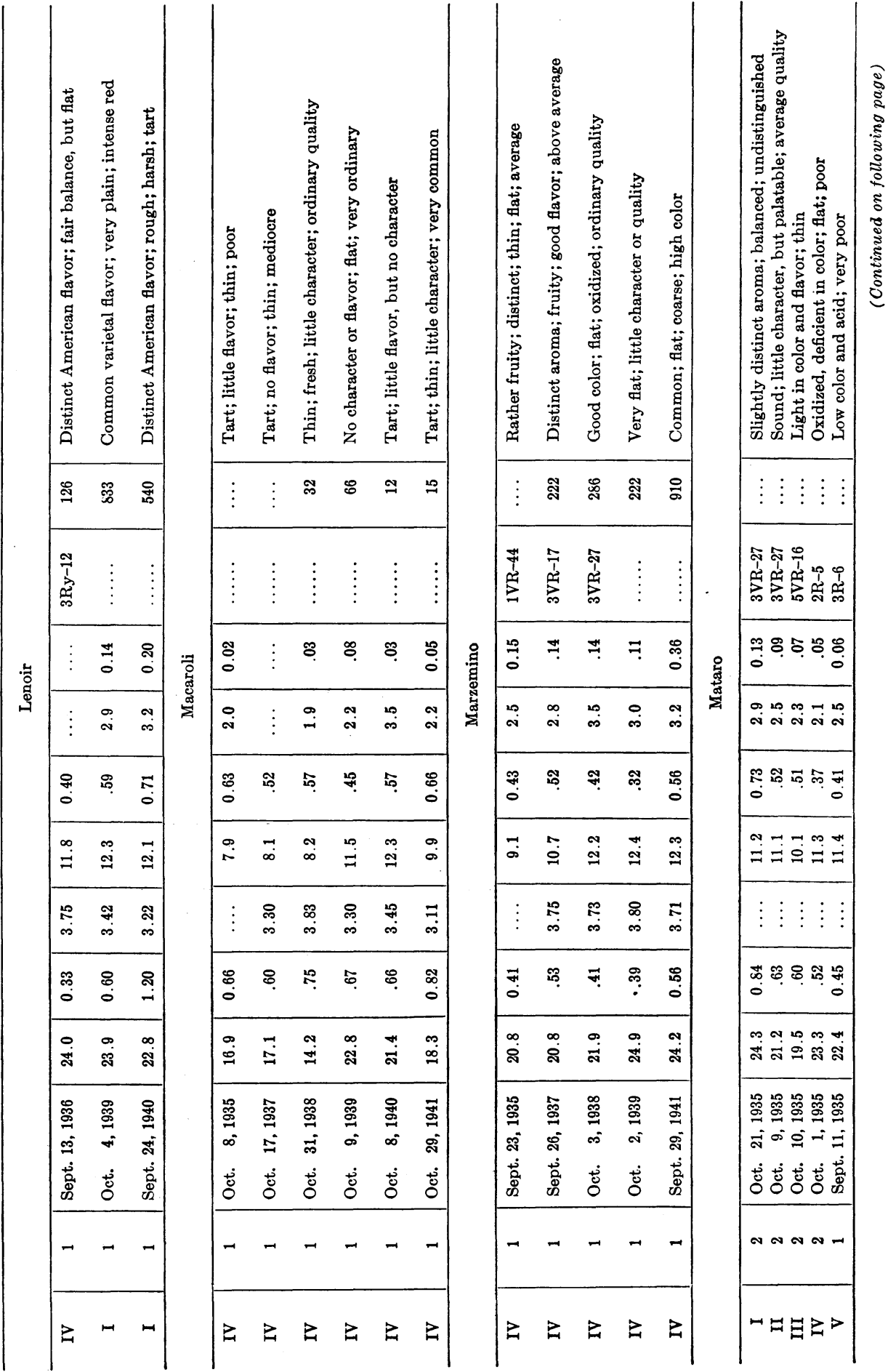




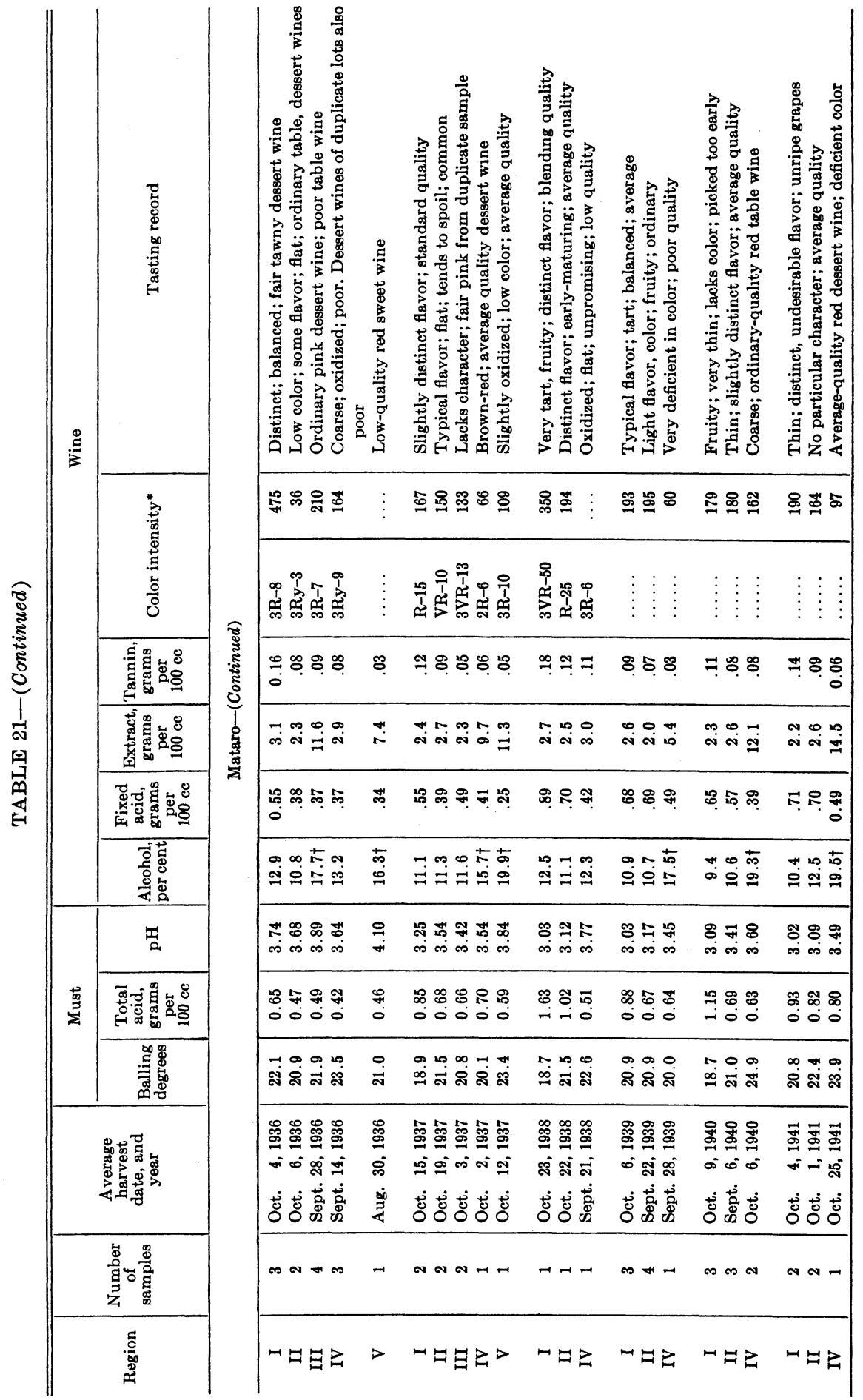




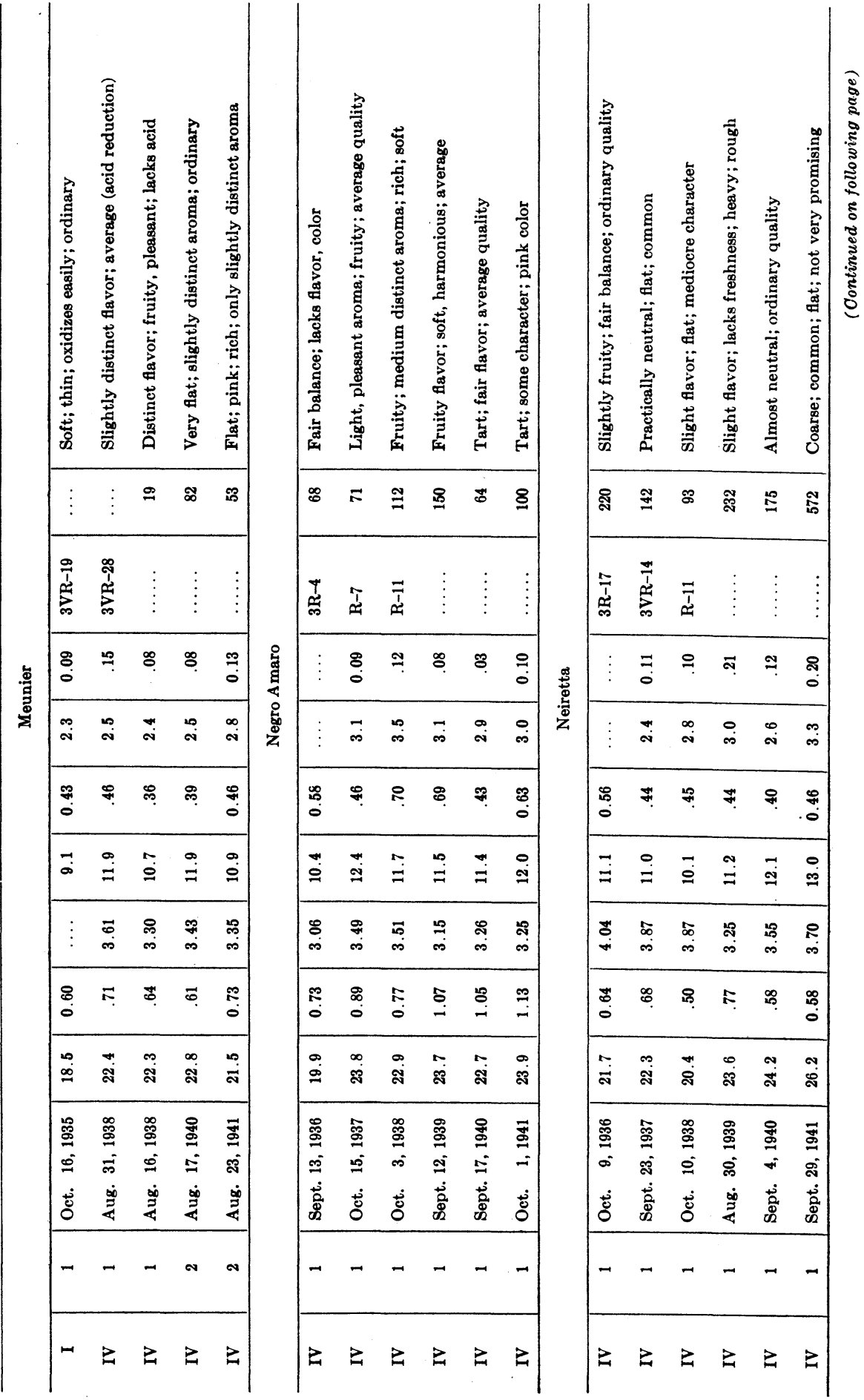




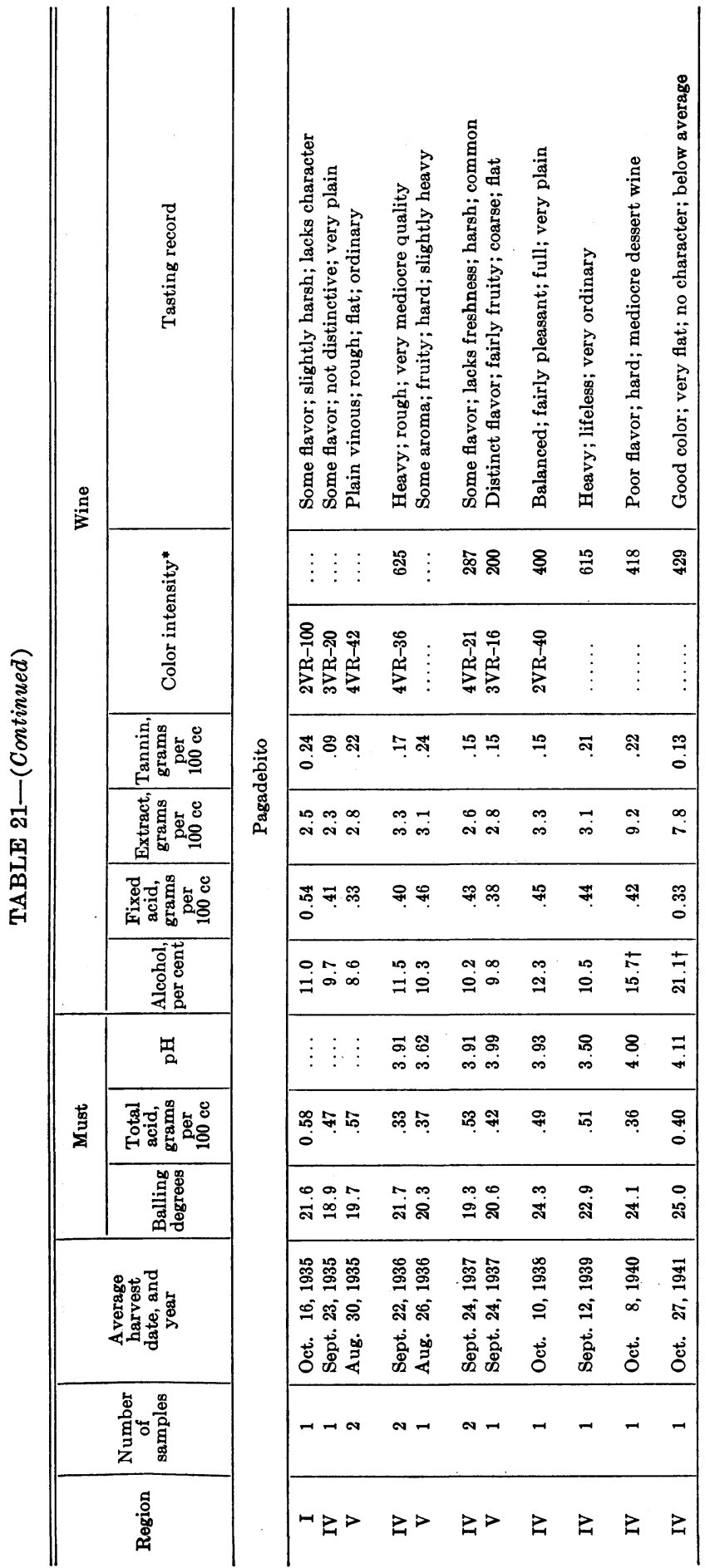

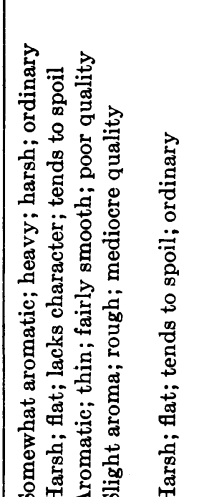

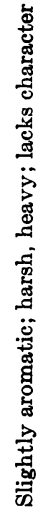

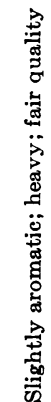

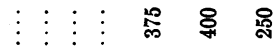

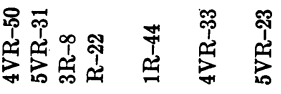

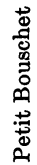

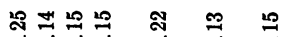

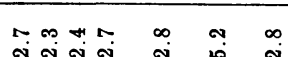

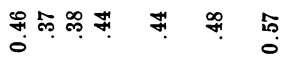

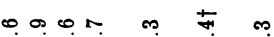

ํํㅇำ

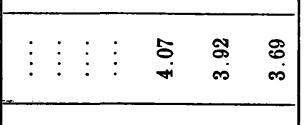

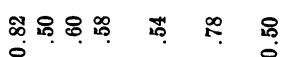

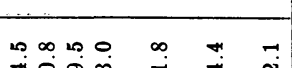

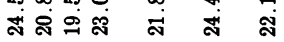

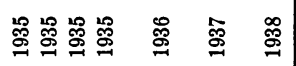

चn்

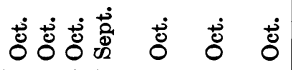

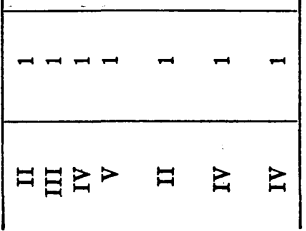




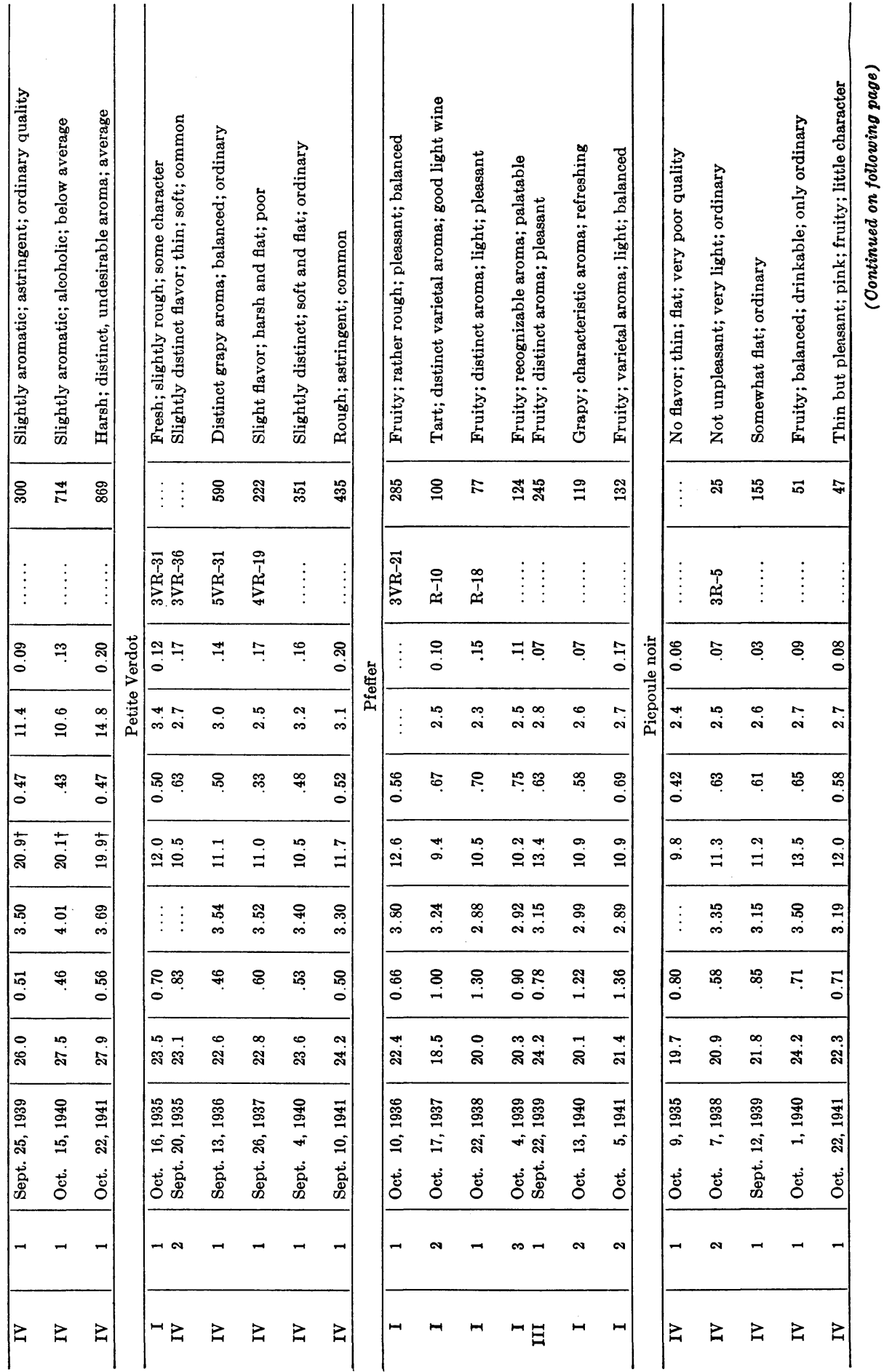




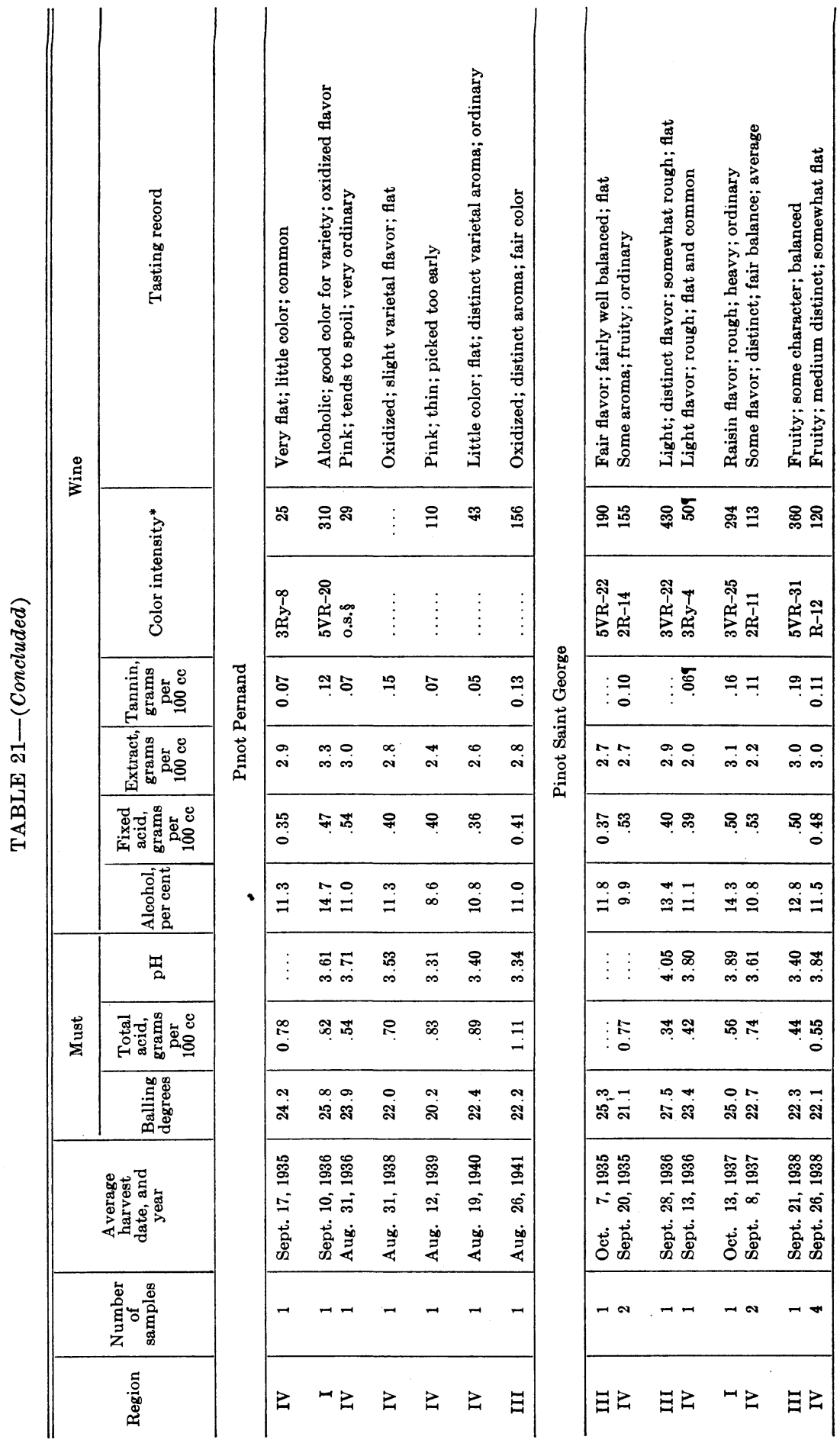




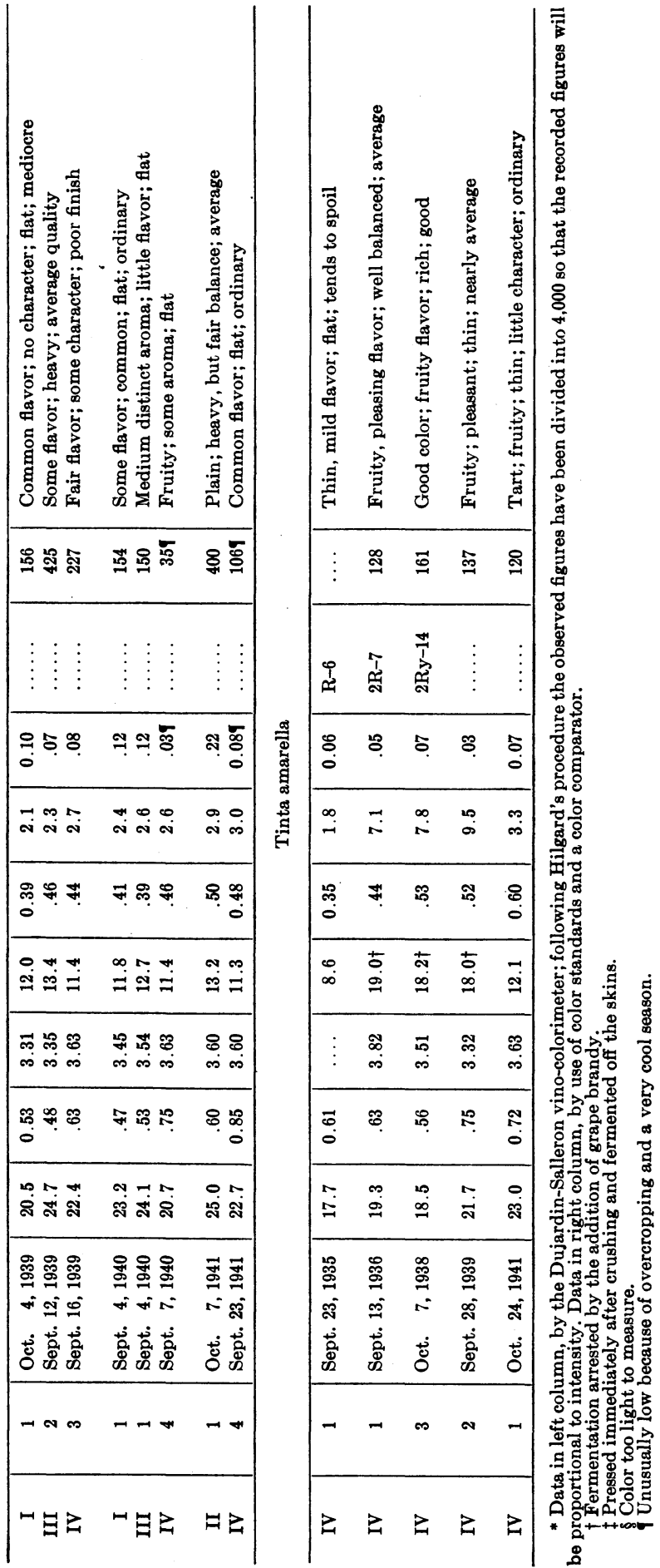


Black Hamburg.-The Black Hamburg is the Englishman's ideal table grape. But like the principal table grape of France, the Chasselas doré, it has not made a place for itself in California, since it will not carry to the distant markets and still be attractive to the consumer.

The vines are very vigorous and productive. The clusters are very large, long-conical, winged, and well filled with large, round, crisp, juicy berries. The peduncle is long. The grapes are easily crushed, and the juice yield is large. Ordinarily the grapes mature in excellent condition.

The figures of table 21 definitely show that the musts of Black Hamburg, regardless of locale, are poorly suited for table wines. Although none of the lots were very mature, the highest total acidity was 0.50 per cent. This was in a sample from Bonny Doon, which is among the coolest areas where grapes are now being grown in California.

The common fault of Black Hamburg table wines has been flatness and lack of freshness. In addition, they have had little if any flavor. In no case were there indications of distinctiveness. When fermented on the skins the product contains approximately enough color for normal pink or rosé wines.

The sherry sample was soft, of pleasing flavor and color, but only of average quality. The variety is, without question, much better adapted for dessert than for table wines. However, the observations indicate it to be much inferior to the Mission and Grenache for this purpose.

Black Hamburg is not recommended for wine production in California.

Black Prince (Rose of Peru).$^{80}$ - The Black Prince has been grown to some extent in California. In many old plantings of Flame Tokay and Mission it occurs as an occasional mix. The variety grows vigorously and, with not-tooshort spur pruning, will produce large yields. In the past it has been grown almost exclusively for table use; the crisp, juicy texture and mild, spicy flavor appeal to most consumers. The vine is not too resistant to mildew.

The clusters are large, conical, shouldered, and usually well filled to compactly set with large, round, firm, reddish-black berries. The veins beneath the skin are usually visible at maturity.

As with all other good table grapes, the must is too low in acid for a balanced table wine. Generally the product was flat, almost without color, lacking in character, and unbalanced, with only a slight grape flavor. Not one of the table wines rated above ordinary.

Judging from the composition of its must, this variety may be well suited for dessert wines. This view is supported somewhat by the red sweet wines of region III-soft, slightly fruity, with some grape flavor and a tawny color. The other red sweet wines, however, have been unbalanced, very deficient in color, and apt to oxidize or sherrify at an early age. The Angelica lot was pleasing, soft, and mellow, but too flat.

The tests definitely indicate that the Black Prince is surpassed by many varieties for both table and dessert wines. It should not be planted in California for wine production. Present plantings could more profitably be employed for table purposes. If delivered to the winery the grapes should be

${ }^{80}$ This is not the Black Prince of Europe, known also as the Trollinger, Frankenthaler, and Black Hamburg. The use of the name Rose of Peru may be questioned as well; hence the variety is listed under the name most common in California. 
pressed immediately, and the white must used for Angelica, sherry, or distilling material.

Blaue Elbe.-The vines of the Blaue Elbe are vigorous, hardy, and very productive. The clusters are large and are usually well filled with largemedium, round, reddish-blue berries. The tender skin renders the fruit subject to handling injuries and to damage by early rains.

At Davis the Blaue Elbe was too deficient in acidity and color to produce normally balanced red table wines. The wines were flabby and only orange red; they possessed but little flavor and no character ; and without acidification their quality was relatively low.

This variety has made a very poor showing in region IV. The character of its fruit and the considerable summation of heat required to mature it indicate that it will not be adapted in cooler regions. It should not be planted in California.

Bonarda.-The Bonarda is reported to be one of the strong-growing productive sorts of northwestern Italy. Its clusters are medium-sized, conicocylindrical, well filled with medium-sized, round, late-maturing berries. At Davis it has proved only a moderate producer.

Its musts have been only relatively well balanced for dry table wines in region IV, the $\mathrm{pH}$ being rather high. The wines have been heavy, astringent, of limited character, with only slight though pleasing aroma. They age slowly and keep only moderately well.

These tests, together with Hilgard's, ${ }^{61}$ definitely show that Bonarda is not a satisfactory producer of dry table wines in the regions from which it has been collected. It does not merit further tests.

Chauche noir.-This variety has small clusters and berries. It ripens early. Since the foliage is not dense, it raisins easily. The grapes are difficult to crush, and the juice yield is very poor in warm seasons. Its production is below average.

Hilgard found the variety to resemble the Pinot in several respects but to lack the requisite composition and character for red table wines. This observation is confirmed by the present studies. The musts were excessively sweet and lacked acid. The table wines were flat, easily oxidized, and completely unsatisfactory. The dessert wines have had too much raisin flavor and lacked color; otherwise they were not undesirable and somewhat resembled those of Trousseau. The variety is accordingly not recommended for California.

Chenin noir.-The Chenin noir has large, rather tight clusters. In humid regions this feature would probably be a disadvantage, but at Davis the grapes have reached the winery in good condition. Ripening is about midseason.

The grapes from region IV have produced poor table wines-plain, almost without aroma or character, unbalanced, and flat. Very ordinary would be an appropriate designation. The coloring is low, suitable only for pink wines.

This variety did not reveal sufficient quality or character in region IV to justify further testing in cooler regions, where color and acidity would be higher. The lack of flavor and the large tight clusters are the primary objections. It is not recommended.

Coristano.-The Coristano is a rather vigorous grower and a heavy pro-

${ }^{61}$ See citations in footnote 15, p. 496, and footnote 16, p. 496. 
ducer. Its clusters are large, long-conical, and well set with medium-sized, firm berries. It matures very late. The low-sugar musts were of only moderate acidity and above-average $\mathrm{pH}$.

The wines from region IV were in general unsatisfactory, having little flavor or character, and were unbalanced and deficient in acid. Not one lot merited a quality rating above ordinary.

This variety is not adapted to regions IV and V. In IV its fruit did not reach normal maturity, and still its acidity was low. In V it would mature fully, but the product would be too flat. Since it will not mature in regions cooler than Davis, further testing is unnecessary. The variety is not recommended.

Criolla Mesa and Criolla Vina.-These varieties came to California from Latin America, where they have been grown since the Colonial period. They closely resemble the Mission in their vegetative characters, vigor of growth, and cluster size, shape, and density. The same is true of the berries of the Criolla Vina, but those of the Criolla Mesa are half again larger than Mission. Also like Mission the grapes ripen late and remain in good condition. Their juice yield is only fair if pressed off immediately after crushing, as the fruit is rather fleshy and thick-skinned.

The dry table wines were complete failures-poorly balanced, with little aroma, flavor, or character. They were difficult to age or store, duplicating in this respect the experience with Mission.

The dessert wines, though much better, in no respect surpass the same types produced from Mission. They approach the quality of the Mission wines. Low color content prevents their use for red dessert wines by themselves; they must be blended or pressed off white for Angelica or sherry material. On the basis of these tests in region IV, neither variety can be recommended; the Mission is to be preferred.

Croetto Moretto.-The Croetto Moretto grows vigorously and produces large crops. The vines leaf out relatively late and resist mildew. The clusters are medium-sized, cylindrical, winged, and rather compactly set with mediumlarge, round, black berries. Because of the thick skin and firm texture, the fruit reaches the crusher in good condition. Late in the season, however, it shatters badly, and many berries may be lost in transport.

The table wines from regions IV and V have been unsatisfactory-almost neutral in aroma and flavor, low in acidity, only fair in balance, and poor to ordinary in quality. A number have spoiled, a tendency not surprising in view of the high $\mathrm{pH}$ of the musts.

This variety has failed badly in the location where it has been grown and should not be planted anywhere in the state. The statement checks with Hilgard's experience and with Bioletti's failure to mention the variety.

Dolcetto.-The Dolcetto came to us from northern Italy, where, according to Hilgard, ${ }^{62}$ it has been prized for its early maturing and good coloring. In California it has ripened about midseason, although in two years the alcohol yield indicates the presence of dried fruit in the clusters at crushing. Its wines here have shown only an average amount of color. The variety is vigorous and above average-in productivity.

The clusters are large, conical, winged, and well filled with round, thin-

${ }^{62}$ See citation in footnote 16, p. 496. 
skinned berries. The fruit is not very resistant to handling injuries. The grapes are easily crushed, and the juice yield is good.

In region IV the wines have been regularly deficient in acid. They have varied from rough to soft, from heavy to light, and none have shown a marked or distinctive aroma or flavor. A rating of common dry table wines is all they merit. The variability in their character largely results from difficulty in harvesting them before raisining sets in.

The variety does not fit into California conditions. In regions IV and V it lacks acidity, while in the cooler regions it will not show enough character to compete with equally productive varieties of higher quality.

Early Burgundy.-The correct name for this variety has not been discovered. It resembles the Pinot noir in its composition, but not in its vine characteristics. The clusters are medium-large; the berries above average in size. On the floor of the Napa Valley it is a good producer. The fruit is well protected by foliage and if picked in September reaches the crusher in good condition. The juice yield is good.

The musts from region II are of only moderate acidity. The wines have been uniformly deficient in acid even though harvesting was in mid-September; they have had a soft flavor, but not outstanding. Because of its low acid and undistinguished flavor the variety is not adapted to the production of red table wines of the Burgundy-type in California. It might possibly be of better composition in region I, but the flavor is not sufficiently distinctive to warrant plantings. The variety should not be planted further.

Grand noir.-The Grand noir is one of the four varieties commonly grown in California that have colored juice, the others being Petit Bouschet, Alicante Bouschet, and Alicante Ganzin. The juice is light red, and this is supplemented by abundant pigment in the cells of the skin. It is a vigorous and productive variety. The leaves are a dull green, with more tomentum on the underside, and more deeply lobed than in the Petit Bouschet, the only other red-juiced sort with which this might be confused. The clusters are large, heavy, conical, and well filled with medium-sized round berries.

Dry table wines were produced from Grand noir in regions I, II, III, and IV. On the whole these have been unsatisfactory. They have varied from slightly to distinctly aromatic and from slightly to rather harsh, with little flavor or character. Their aromatic quality is not desirable and to most tasters is more objectionable than pleasing. All in all, these wines were very common.

The color, for which this variety has been recommended, is not exceptional, except that a portion is in solution in the juice when the fruit reaches maturity. Many varieties tested have produced wines more intense in color and more pleasing in hue. The color of Grand noir also drops out more rapidly than in most varieties.

The red sweet wines from region IV have been objectionably aromatic and only ordinary. On the basis of results to date, Grand noir should not be planted for wine making.

Grec rouge.-The Grec rouge at Davis, though a fair producer, is entirely unsuited to wine production. The fruit is pinkish, but can usually be made into white wines by careful crushing and early pressing. The skins are fairly tough; grapes reach the crusher in good condition; but the juice yield is only 
moderate. Ripening is fairly slow, and at even moderate sugar concentration the acid content is below 0.5 per cent. The wines are accordingly thin and flat. Besides, they are practically devoid of flavor. Because of its failure to achieve a high sugar concentration, Grec rouge is not likely to be useful for wine making, even as sherry material. Since the variety is entirely unsuited for table wines, plantings are undesirable.

Grosse blaue.-At Davis this variety has ripened about midseason. Although the grapes were of fair acidity the wines, probably because of active acid reduction, were deficient in acid. They lacked distinction in other respects, too, not having much color, and taking on an oxidized flavor very easily. At Davis the vines have been small producers. No plantings are recommended.

Kadarka.-In California, Kadarka has not been tried under conditions that make it suitable for table wine. In Europe it is useful, especially in Hungary, ${ }^{\text {es }}$ where it is used alone or, when lacking in color, is blended with Blue Portuguese. In Hungary its wines, high in extract and alcohol, are among the most reputed. A possible explanation of its success there may be the cool growing conditions that counterbalance its natural deficiency in color content and acidity. The blending with Blue Portuguese is probably also to correct for the sugar deficiency. Under growing conditions as favorable as those of region IV in California it is deficient in acid, alcohol, and flavor. Having been very low in acid in the cool season of 1935, it is unlikely to prove suitable for regions II and III. It should, however, be tested in I.

The grapes reach the crusher in good condition, are easily crushed, and have a good juice yield. The table wine has all been undesirable in color, flavor, and acidity; and the single dessert wine made has likewise been below average.

No plantings are now recommended, since other varieties are more useful. This corroborates the experience of Hilgard, who failed to find a suitable location for Kadarka in California. Bioletti's recommendation ${ }^{64}$ of southern California as a suitable location was based on observation of the grapes and not on the wines.

Koptcha.-Koptcha, an early-ripening variety, has long clusters somewhat loosely set with small berries. The fruit reaches the crusher in good condition. The musts have a good acidity.

In region IV the Koptcha has produced mild, pleasing wines of distinct aroma and flavor. Beyond these properties they were not particularly harmonious. They have, however, shown sufficient promise to warrant further tests in somewhat cooler areas, provided the variety can be made to bear regularly.

Koptcha has unusual vigor. At Davis the vines have been very irregular in bearing. Long pruning with thinning to regulate the crop has been necessary to insure full crops season after season and to prevent overbearing in the years of favorable set.

The variety is not recommended for commercial planting until further trials have been made. It may not prove manageable enough, from the viticultural point of view, to be of much interest anywhere.

${ }^{63}$ Teleki, M. A. Le point de vue hongrois. Congrès international de Viticulture, Paris, 1937. p. 222-33. Librairie Universitaire, J. Gamber, Paris, France.

${ }^{84}$ See citation in footnote 17, p. 496. 
Lambrusche Langhre.-This is one of several seedling sorts grown in various parts of Italy. The principal area is the province of Emilia. It is a vigorous grower and produces well.

The variety has been tested in region V. Since, unfortunately, the lots were somewhat immature each year, the wines are deficient in alcohol; in addition, they have contained barely enough acid for balanced table wines. This lack of balance more than offsets the distinct, pleasing flavor.

The variety does not appear to offer any promise under California conditions, since it will probably not be sufficiently well balanced anywhere to produce more than an ordinary product.

Lenoir.-This grape is a very vigorous grower and when pruned to canes is highly productive. Its clusters are medium-sized, well filled with small thinskinned berries. The fruit, however, is resistant to unfavorable weather. The juice is intensely red.

The musts from region IV were decidedly deficient in acid. The wines were heavy, rough, and flat, with a distinguishable aromatic American flavor. The color was only moderately intense in the new wine and dropped rapidly.

Musts from region I were well supplied with acid. The wines were fairly well balanced, intensely colored, but rough, harsh, and very aromatic. They are entirely unsuited for marketing, since the consumers would not appreciate their peculiar flavor and aroma.

Even in blending, the aromatic properties come through. The color, too, is not sufficiently stable. In color, tannin, and body the Lenoir is far surpassed for blending by Salvador. The color of the latter wine is not only more intense, but far more stable. With Salvador, too, the per cent used in blending can be kept low enough to avoid tainting the blend with the aromatic American flavor.

The Lenoir did not succeed in any of the tests conducted by Hilgard or by the present investigators. It is not recommended as a fruiting sort. Its properties as a rootstock, especially for table grapes, are being tested.

Macaroli.--The Macaroli is a large-clustered, large-berried, late-maturing variety. The grapes are fleshy and the juice yield is small. The vines are vigorous and productive.

In four years out of six the Macaroli has failed to sugar its fruit sufficiently for balanced dry table wine in region IV. This was true even with very late (October 21) harvesting and with only moderately heavy crops.

The wines as produced at Davis have had but little flavor or character and have always been poorly balanced. They were thin and acid; or, when normal in alcoholic content, they have been flat-at best, very plain vin ordinaire.

This variety is wholly unsuited for California. In the cooler areas it will not ripen, and where it does ripen its acid content will be too low.

Marzemino.-The Marzemino, a midseason grape, produces only moderately well in region IV. The clusters are medium-sized ; the berries closely set, medium-sized, and black, with a fairly thick skin. Little difficulty is experienced in crushing unless the grapes are left on the vines so long that they shrivel or raisin. The juice yield is average.

Under region-IV conditions the musts are very low in acid and high in $\mathrm{pH}$. The wines taste rather fruity in spite of their low acid; but the balance is 
unsatisfactory, and the high $\mathrm{pH}$ of the must does not make for a product of low volatile acidity.

The Marzemino is unsatisfactory for dry red table wine in regions IV and $\mathrm{V}$, and probably in the cooler districts as well. It has not been, but probably should be, tested in III. Its composition in region IV indicates, however, that other varieties will prove better balanced for red table wine in such districts. Its low acid at only moderate Balling readings indicates poor ripening under cooler conditions.

Mataro.-The Mataro, a fairly late-ripening variety of good production, resists mildew somewhat better than the Carignane. Widely planted in California, it is easily recognized in the vineyard by the upright growth of its canes. The grapes do not easily sunburn or raisin, though they will do so in the San Joaquin Valley in hot years because of the lack of foliage. The clusters are large and winged; the berries medium-sized. The groups ordinarily reach the winery in good condition and crush easily, with a good juice yield.

In regions $I$ and II the color is seldom deficient, whereas in IV and V it is usually too low. The musts from I and II have been so deficient in sugar content as to produce an unbalanced wine. The wines from I and II have a slightly distinct, sometimes even recognizable, but not always agreeable flavor. At best they can be considered only satisfactory, average, red table wines. They have no particular merit over Carignane, which also has a slightly distinct and not too desirable character; and in fact the Mataro wines from the same vineyard are usually less desirable. Bioletti recommended against planting the variety in California.

An occasional good-quality red dessert wine has been produced in regions IV and $\mathrm{V}$, but in general the color is too deficient.

As far as vine growth and quality of the must are concerned, the Mataro may sometimes be substituted (chiefly in foggy districts) for the Carignane in regions I and II, but only for the production of average red table wines. It should not be planted under present circumstances.

Meunier.-The Meunier, an early-ripening variety, is probably related to the Pinots. It matures before other varieties, including the Pinot noir. The bunches are small and compact; the berries small, juicy, and usually clean and free from spoilage. The juice yield is good, and the grapes are easily crushed. In warm seasons they raisin badly even in early September. The variety is only moderately productive.

The samples from region IV have all been harvested in August. When picked early enough, Meunier has sufficient acidity for table wine; but the $\mathrm{pH}$ is high. The resulting wines lose their acidity rather rapidly, and the finished product is flat. It is moderate in color and has a fairly distinctive flavor.

The Meunier has no place in California vineyards except in the very coolest locations, and there only to extend the length of the picking season with an early-ripening variety. Under these conditions the quality would be satisfactory though not of the highest standard. The propensity to drop acidity shortly after fermentation may be associated with the high $\mathrm{pH}$ of the musts and the resulting mixed fermentation.

Negro Amaro.-The Negro Amaro retains high acidity and low $\mathrm{pH}$ in region IV at full maturity. As a result its table wines have been fruity, refresh- 
ing, and well balanced. They have also possessed sufficient aroma, flavor, and character for at least average quality, and some have been above average.

If this variety would produce economically, it might be very promising, especially in region IV. Unfortunately the fruiting habit is against it. The clusters are very small - only nubbins-and the vine must be pruned long to produce a full crop. Pruning and harvesting would therefore be expensive as compared with varieties of comparable quality. Negro Amaro is not recommended.

Neiretta.-The Neiretta came from northwestern Italy, where it is used extensively for common table wines. Productivity and intense color have been its chief merits.

The clusters are large, compactly set with medium-sized, thin-skinned berries. The fruit matures late, though in years of early hot conditions it ripens in midseason. It has regularly reached the crusher in good condition.

The musts from region IV have been poorly balanced for dry table winestoo high in $\mathrm{pH}$, too low in total acidity, or both. As a result they have been practically neutral, lacking in freshness and character, flat, and very common. Not one has merited a rating of standard. The extreme variation in color largely results from the irregularity of maturity at which the grapes have been harvested and from the difference in color standards when wines of low or high brightness are compared.

The variety is not recommended for California. In region IV and probably in III and V its wines are common; and in I and II it will not ripen regularly or sufficiently early.

Pagadebito.-The Pagadebito is a vigorous, heavy-producing sort. It leafs out somewhat later than the average, and its fruit matures after midseason. The clusters are medium-sized and well filled. The berries are small, round, and almost hard, with a very thick and astringent skin. The juice yield is barely average. The fruit resists disease and unfavorable climatic conditions and reaches the crusher in good condition.

The grapes attain only a moderate Balling degree and have a low total acidity. The $\mathrm{pH}$ of the musts is much too high for a red table wine, although no particular difficulty has been experienced in the fermentations.

The table wines from regions I, IV, and V have been characterized by lack of freshness and of acidity, by harshness or roughness, and by plain to ordinary quality. Their richness in both tannin and color might suggest usefulness as a blending wine. They are too harsh and flat, however, for this purpose, since a blending wine must add something without subtracting quality.

As a red dessert wine the product of the Pagadebito was ordinary at best. The flavor was poor, and the wine did not soften as it should for this type. The extremely high $\mathrm{pH}$ made the color an undesirable reddish blue. The variety is not recommended. Hilgard ${ }^{65}$ mentions it as a newly imported variety. Bioletti does not mention it in his review of the varieties suitable for San Joaquin Valley conditions in $1898^{68}$ but does recommend it for dry table wines in his 1907 report. ${ }^{67}$ This latter recommendation is therefore probably based on a limited amount of experience and is unwarranted in view of the present results.

\footnotetext{
${ }^{65}$ See citation in footnote 16, p. 496.

See citation in footnote 17, p. 496.

${ }^{67}$ See citation in footnote 18, p. 496.
} 
Petit Bouschet.-The Petit Bouschet produces well, is moderately vigorous, and has usually more hardy vines than Alicante Bouschet. Like the latter it has color not only in the skin, but also in the juice. The fruit is clean, but resists handling injuries only moderately. The fruit ripens before Alicante Bouschet and if left on the vines shrivels and becomes soft. Even so it crushes readily, and the juice yield is good.

The table wines have been coarse, heavy, astringent, and lacking in character regardless of environment. Even the wines from region II were deficient in acid. The slightly aromatic property, though not so pronounced as in Alicante Bouschet, is nevertheless objectionable. The dessert wines from region IV were just as devoid of interest as the table wines, being coarse and common.

The color was intense and appears somewhat more stable than that of the Alicante Bouschet.

The Petit Bouschet is not to be recommended anywhere, even for blending for color. From a viticultural point of view alone it is certainly less desirable than either Alicante Bouschet or Grand noir.

Petite Verdot.-The Petite Verdot is of only average vigor. On the more fertile soils the crops have been moderate; on the shallower soils, light. At Davis the vines are very small producers. Since the growth and foliage leave them open, exposing the fruit, sunburn is sometimes severe. The clusters are medium-sized, and the berries below medium. The grapes are easily crushed.

The table wines from regions I and IV have not been particularly good. Despite a distinct flavor, they have not been well proportioned in other respects, so that the quality has been commonplace. The color is satisfactory. The wines are astringent and somewhat coarse. Perhaps too few tests have been made in intermediate regions ; but no very good wine was produced. This checks with Hilgard's experience, which indicated it as being useful only for blending with wines requiring tannin.

In region I the Petite Verdot will produce a standard though slow-maturing and rough wine. In view of the low yields, this is not enough. Pending further tests, the variety should not be planted, especially not in the interior valleys and probably not in the cooler locations. Bioletti recommends a Verdot for red table wines in the coast counties; but whether this was the same as the variety tested here is not known.

Pfeffer.-Mr. W. Pfeffer first grew this variety in California. Its European antecedents have not been definitely established.

The Pfeffer is vigorous, but requires very long pruning for moderate crops. The clusters are medium-large, long-conical, sometimes shouldered, and rather closely set with short-oval, small berries. The fruit ripens late. It has reached the crusher in good condition.

Most of the samples came from region I. Only in the very warm year 1936 was maturity normal. On the whole the wines have not been satisfactory. Though distinct in aroma, fruity, clean, and pleasant, they have lacked fullness, balance, and finish. Even the sample of 1936 and the one from region III in 1939, containing 12 per cent or more of alcohol, were only average table wines. They, like the other lighter lots, had a hardness that never left them.

The aroma was distinctly recognizable in almost all lots. For this property, however, Pfeffer cannot compare in delicacy and excellence with Pinot noir, 
Cabernet, or even Gamay. The aroma does not blend in with the other properties and yield the harmonious end product expected. In fruit just turning color the aroma has a Cabernetlike pungency. Toward maturity, this property becomes less marked. It is recognizable in the wine.

For the most part these wines possessed only sufficient color to be acceptable as pink or rosé wines. Only the very heaviest lots approached the coloring of normal red table wines. Since these lots were from the coolest region of our state, there can be no doubt that the variety lacks color.

On the basis of its period of maturing, its productivity, and the character and quality of its wines, Pfeffer cannot be recommended for region $\mathrm{I}$. There it will be surpassed by several really quality varieties. The same will be even more true in region II.

In region III, Pfeffer is not sufficiently productive; and in IV and V it will produce only relatively small crops of poorly colored fruit.

Picpoule noir.-The Picpoule noir, a heavy-producing sort, has apparently never been grown in California, except in test plots. Its late ripening limits its adaptation abroad to the south of France, and in California restricts its possible adaptation to regions II, III, and IV. It is a vigorous, upright grower and fruits with short-spur pruning. It is very subject to mildew. Being fairly resistant to unfavorable weather conditions and handling injuries, it reaches the crusher in good condition.

The bunches are very large, and the berries above average in size and firm. The fruit crushes easily, however, and the juice yield is above average. No difficulty has been experienced in the fermentation. The wine, however, lacks almost everything except alcohol, acid, and body. It is mildly vinous, seriously lacks color, and has not even sufficient character for bulk pink wines. This variety should not be planted anywhere in California.

Pinot Pernand.-This closely resembles the Pinot noir and Meunier. It ripens about the same time, very early, and has practically the same composition of must. The Pernand differs from the Pinot noir in that its mature leaves are much rougher, show considerable contortion between the veins, and its clusters are more compact and heavier. The brilliant, dark green of its almost glabrous leaves distinguishes it from the dull, gray-green, heavily tomentose leaves of Meunier and Pinot Saint George.

The musts of region IV are of fair acidity at moderate sugar concentration when the grapes are harvested before September 1. Only a single sample from region I was tested. This had a high $\mathrm{pH}$ and too much sugar on September 10. The wines have all dropped their acidity very quickly; and the resultant product has been flat, unpalatable, and only ordinary. The new wines tend to become oxidized. In region IV the color has been too low for normal red wines. The product sometimes has a true Pinot aroma despite the unfavorable composition.

Hilgard's results ${ }^{68}$ support the conclusion that the Pinot Pernand should be planted only in the very coolest regions. Since Pinot noir has a slightly better color, there appears to be no reason for planting Pinot Pernand.

Pinot Saint George.-Pinot Saint George is probably a variation from the true Pinot-the Pinot noir, to which it is vastly inferior in all respects except

\footnotetext{
${ }^{68}$ See citation in footnote 16, p. 496.
} 
productivity. Indeed, the two varieties have nothing in common beyond the first part of their name.

The Pinot Saint George is a moderate grower and a good producer. The clusters are large-medium, long-conical, winged, and compactly set with small, round berries. The compact clusters are very susceptible to bunch rot. The fruit ripens 3 weeks to a month later than the true Pinot.

This variety can be distinguished from Pinot noir by the coloring of the shoots and leaves, the shape and size of the clusters and cluster parts. In the Saint George the shoots and leaves appear whitish green because of the hairy coating of the young leaves and the long hairs on the young shoots, tendrils, and leafstalks. The mature leaves have a mat of hair underneath. The young leaves of the Pinot noir have a fair coating of hair below and a few hairs above; but the young shoots, tendrils, and leafstalks are shiny, with only an occasional hair. The mature leaves are a glossy light green beneath, with but few hairs. The clusters of the Saint George are regularly winged; usually the wing is divided, while only a part of the Pinot noir clusters are winged. The peduncle or stem of the Saint George clusters is usually less than $3 / 4$ inch in length.

The musts of the Pinot Saint George were generally poorly suited for dry table wines. Irrespective of source, the fruit at normal maturity had a low acid content and a relatively high $\mathrm{pH}$.

Even the wines from regions I and II possessed a common flavor and were rough, without character, and flat. They were ordinary table wines.

The wines from region III had about the same quality as those of I and IIno properties that would tend to elevate them. The normal red table wines of region IV were generally somewhat heavier, rough, flat, and lacking in finish. They, too, were commonplace.

During 1940 and 1941 eight lots from region IV were harvested earlier and pressed immediately to produce pink wines. This treatment did not materially improve the aroma, flavor, or finish of the mature wines.

Because of general poor quality of its product the Pinot Saint George cannot be recommended for planting. Growers who wish to produce red Pinot wines should be sure to obtain planting material of the Pinot noir.

Tinta amarella.-The Tinta amarella is another variety from the Alto Douro Valley of Portugal. Its clusters are very compact, heavy, conical, and large to medium. The berries are medium-sized, black, round to slightly oval, firm but not tough. Ripening in late midseason at Davis, the fruit is often caught by unfavorable weather conditions and rains. At such times, decay in the very tight clusters is rapid and severe. Primarily for this reason the variety is not recommended.

In regions IV and $\mathrm{V}$ the Tinta amarella is unsuited for dry table wines. Its musts lack both acid and flavor for these types. Its fruit is too susceptible to decay for wine production in the coastal counties.

Well-matured grapes of regions IV and V are, however, almost ideally balanced for red dessert wines. The sugar is high, the acid moderate, the tannin low, and the flavor very pleasing. These dessert wines were full-bodied, well rounded, mellow, and nicely colored. They resemble those of the Tinta Madeira, but have not possessed an equally interesting balance. For viticultural reasons alone, the latter variety is preferred. 


\section{VARIETIES REQUIRING FURTHER TESTING}

Several varieties cannot be recommended or disqualified because only a restricted number of samples have been collected or only a few regions have been tested in the present studies. Some of the varieties listed here are probably of no value; but a few may, on further trial, prove useful. No plantings are recommended at present except on an experimental scale. A few of these varieties were recommended at one time or another by some previous investigator. The present studies have not been sufficiently conclusive to prove or disprove these earlier recommendations.

\section{WHITE VARIFTIES NOT FULLY TESTED}

Incompletely tested white varieties include Boal Madeira, Catarratto, Erbaluce Caluso, Ezerjo, Furmint, Grillo, Honigler, Muscat Terracina, Orleans, and Walschriesling. Analyses of musts and wines of these varieties are given in table 22.

Boal Madeira.-The Boal Madeira, a vigorous grower, has produced large crops regularly at Davis. It requires short-spur pruning. The clusters are large, heavy, short-conical, and well filled with medium-sized, short-oval, yellow-green berries. The fruit ripens in late midseason. With careful handling it reaches the crusher in good condition; but it will not withstand wet weather and is subject to mildew. In case of early rains the fruit rots very badly.

In the more favorable years 1935 and 1937, the dry table wines were slightly distinct in aroma and fruity in flavor. They were average, common wines with little character and none too fresh a flavor. In the other years1936, 1938, and 1939-the wines were bland, flat, and markedly subject to oxidation.

When baked, the sherries proved light, rather well balanced, and palatable. They, too, have suffered from plainness. Hilgard found the Verdelho generally superior to the Boal Madeira, but Bioletti recommended the Boal and omitted Verdelho as a dessert-wine grape-probably because of the small production of the latter.

The dry table wines of the Boal Madeira have not shown sufficient character and quality to warrant plantings. The sherries have not equalled those of Palomino or Inzolia. These other varieties are equally or more productive; hence there also appears to be little place for the Boal in California for producing this type of wine. The conditions in regions IV and V should be investigated more carefully for a possible favorable habitat for this variety.

Catarratto.-The Catarratto is grown extensively in western Sicily. Although probably introduced before 1890, it has no record in California. The fact that Bioletti (1907) recommended other varieties introduced at the same time, but failed to mention the Catarratto, may be significant. Its country of origin would indicate an adaptation to warm locations.

The vines are vigorous and productive; the clusters large, long-conical, shouldered, and compact. Often the tendril on the peduncle is fruitful enough to form a wing of the cluster. The berries are small to medium, round, and greenish yellow, with a rather thick, tough skin. The fairly firm pulp, the tough skin, and the firm attachment render this fruit resistant to unfavorable 


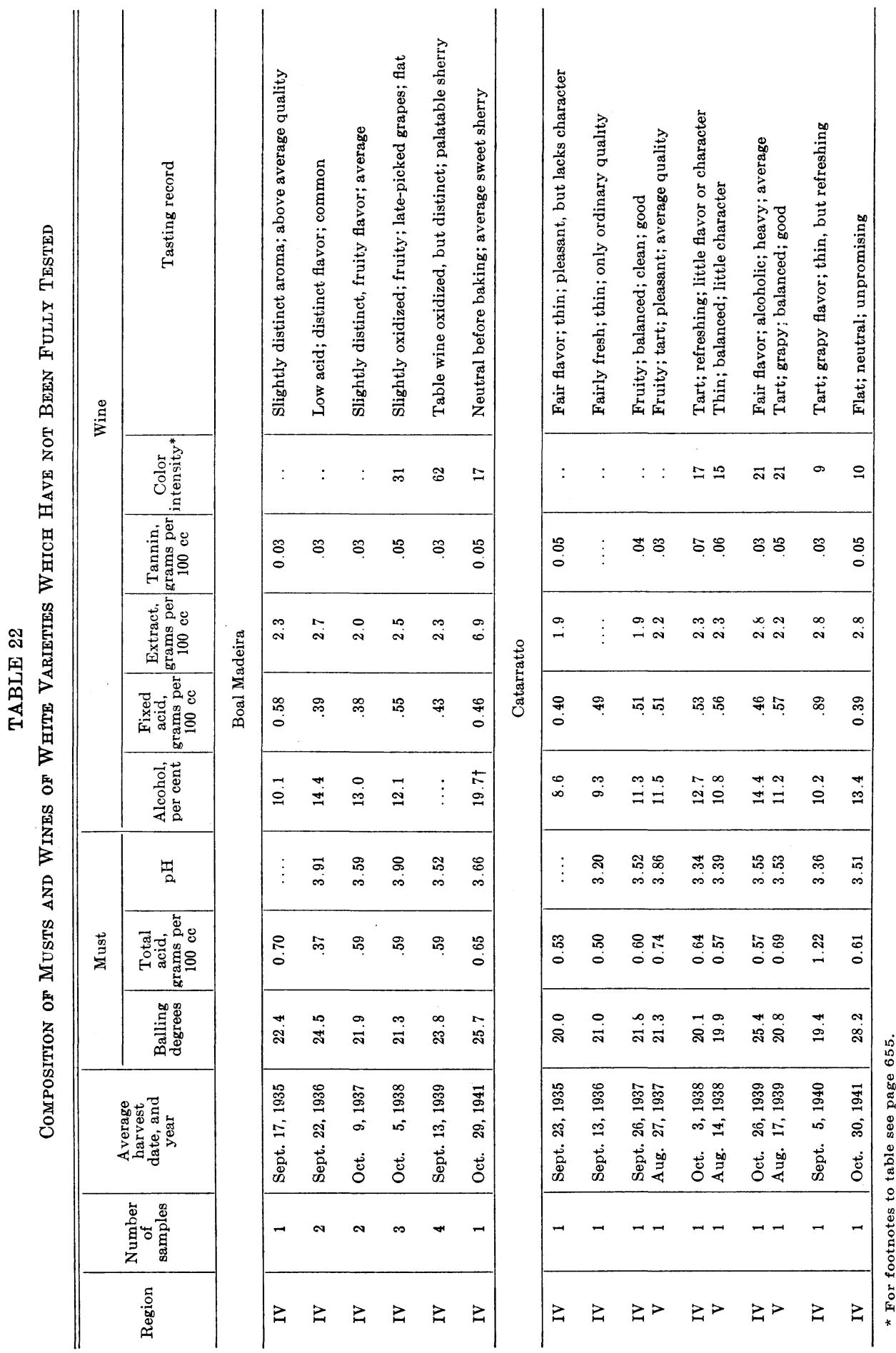




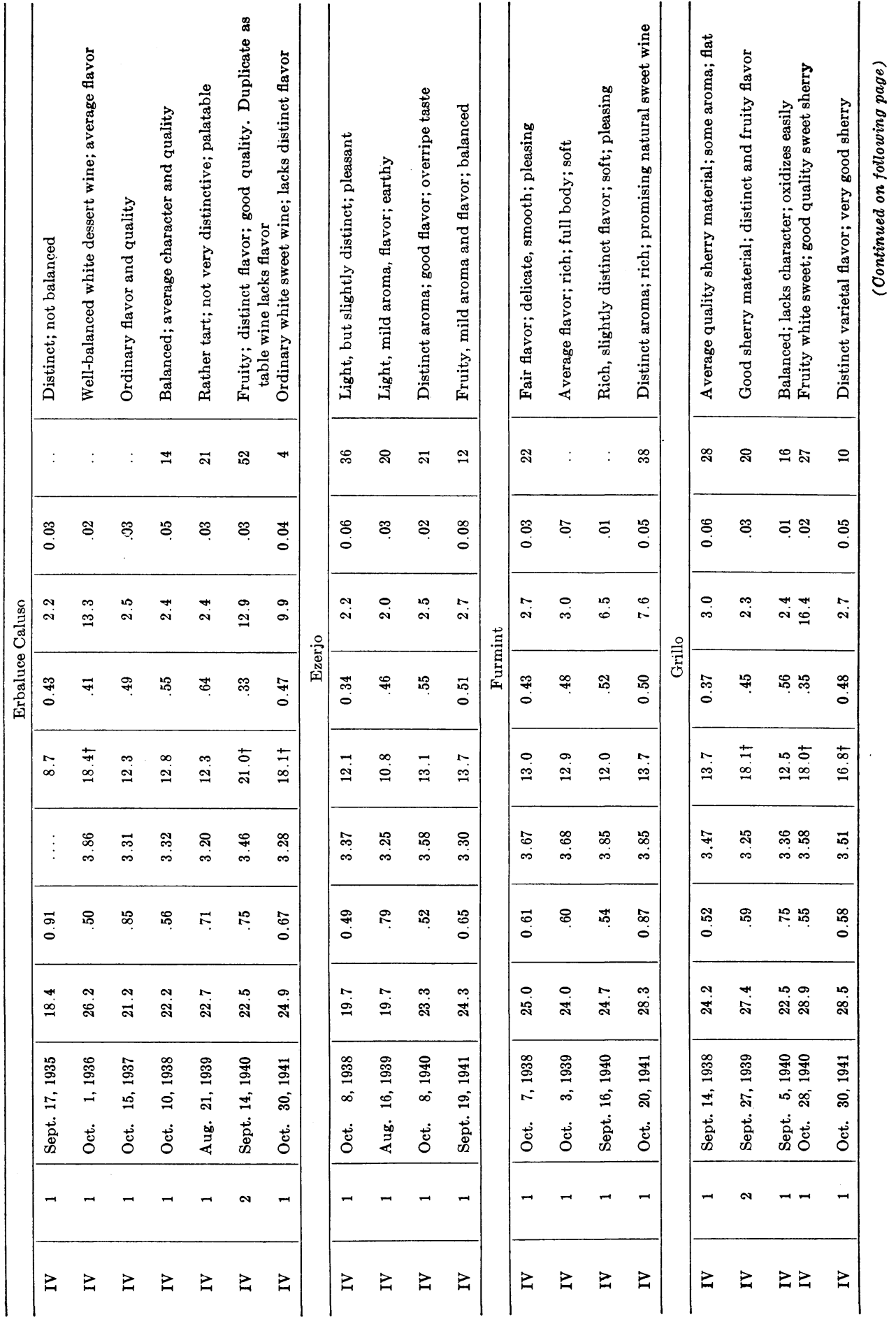




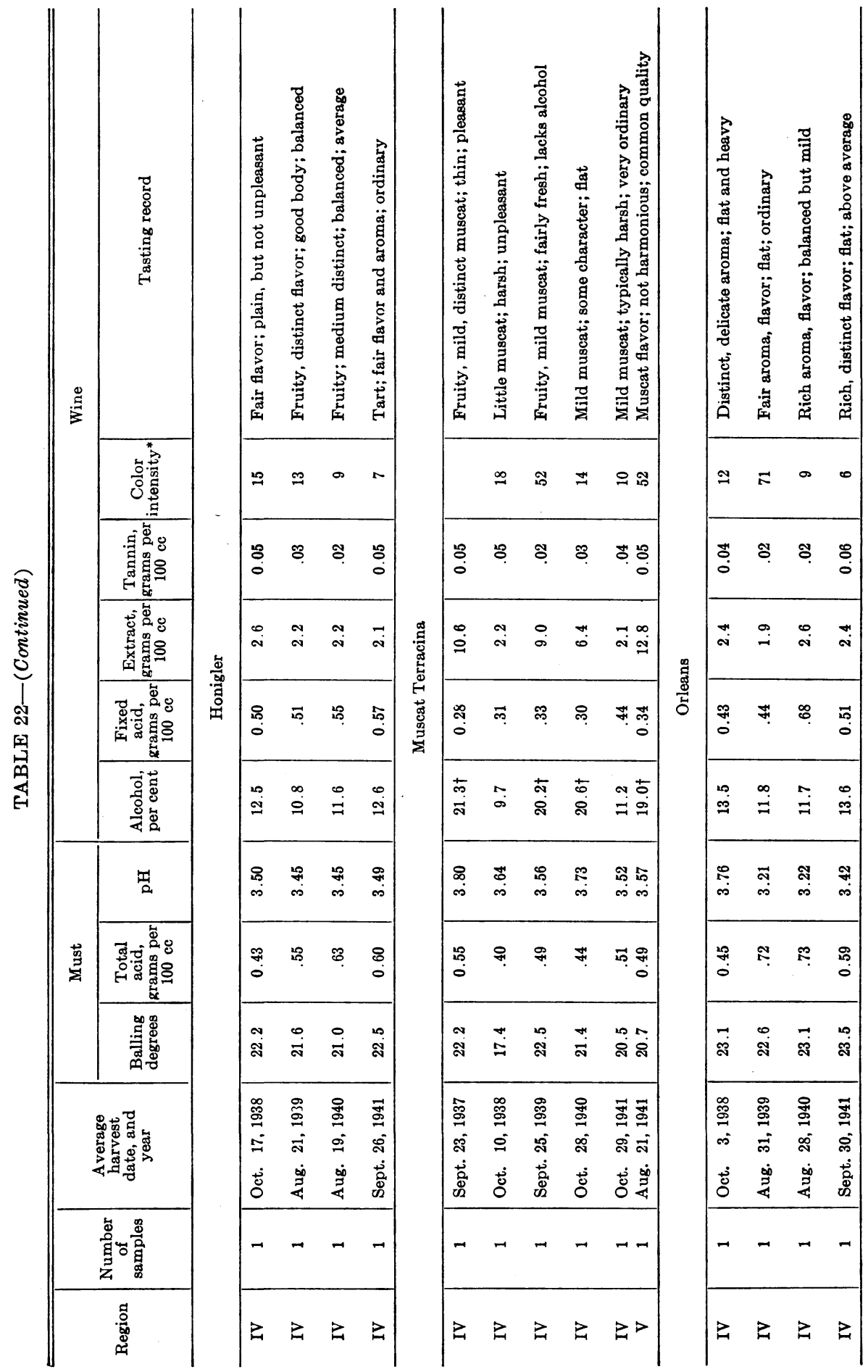




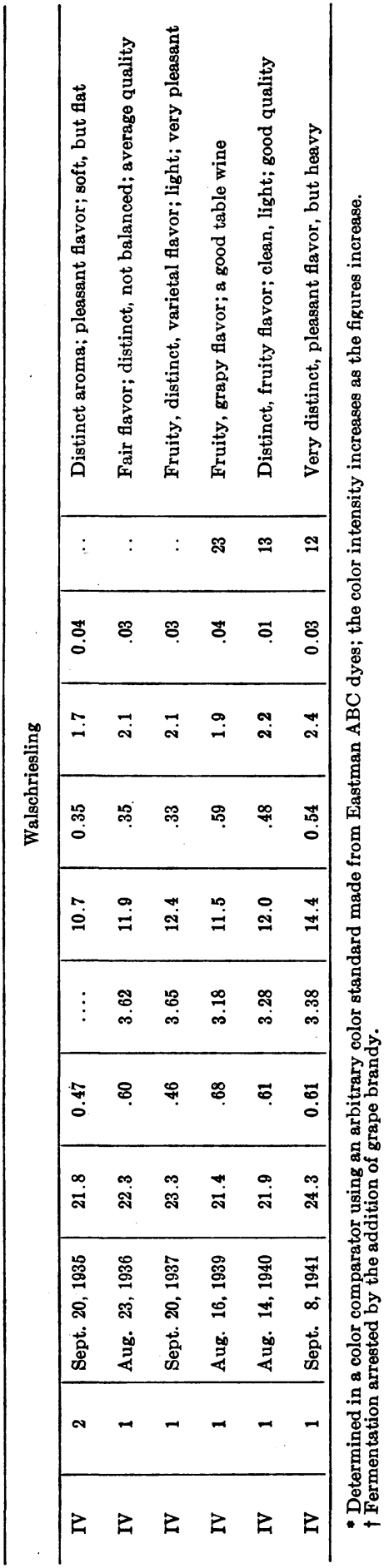


weather and to handling injuries. The variety matures late; but except for failure to mature in cool locations this disadvantage is not serious.

The wines from regions IV and V have been uniformly neutral in flavor, mild in character, but fair in acidity. The grapes, although late maturing, have been sound, the musts have fermented well, and the wines have aged rapidly and without difficulty. Catarratto should be tested further for brandy and sherry. With careful timing of the harvest it may produce a must fairly well balanced for commercial brandy. The neutral character of the product indicates that the greatest value may be for blending. In warm seasons in region $\mathrm{V}$ Catarratto may also prove useful for dessert wines.

Its neutral character and its late maturing make it undesirable for table wines.

Erbaluce Caluso.-The Erbaluce Caluso is a white variety, used in northern Italy to produce the natural sweet and distinctive wine of Caluso. The vines, though vigorous, are only fairly productive unless cane-pruned. The clusters are medium-sized, pyramidal, and well filled with medium-sized, round, thick-skinned berries, which may take on a rose color or blush when mature.

At Davis the wines have been variable-in some seasons distinctive in flavor and good in quality, in other years just ordinary and not too well balanced for either table or dessert wines. The variation in crop is partially responsible for this condition.

In region IV the musts have usually good acidity when normally mature. This, together with the distinctive flavor obtained in the 1935 and 1940 wines, may justify further testing. Possibly the variety will be best in region $\mathrm{V}$ for dessert wine. At present, however, it cannot be recommended for California. This view is partially confirmed by the fact that this grape had been introduced by Hilgard and was therefore presumably known to Bioletti, who in 1907 does not list it among his nineteen recommended white wine-grape varieties. Earlier, however, Bioletti ${ }^{69}$ mentions it as producing good crops in region IV in southern California.

Ezerjo.-Ezerjo is vigorous but only moderately productive. According to Teleki $^{70}$ it is a native of Hungary, where it produces quality white wine. The clusters are large, branching, and compact. The medium-sized, short-oval berries have a thin, tender skin that does not resist handling injuries. Unfavorable weather at maturity will cause rot. The variety is subject to raisining.

The wines from region IV, despite a pleasing aroma and flavor and some character, have not been too well balanced generally, their acid content being especially low. They have lacked fruitiness and life. The variety is therefore not adapted to such climatic conditions as those in region IV.

Nevertheless, this variety shows sufficient promise as regards character to warrant further testing in somewhat cooler areas. Its compact clusters, tender skin, and period of maturing will no doubt exclude it from region $I$ and the cooler parts of II, but further tests in II and III are indicated. It is not suited to IV and V.

\footnotetext{
${ }^{68}$ See citation in footnote 17, p. 496.

${ }^{70}$ Teleki, Sigmund. Weinbau und Weinwirtschaft in Ungarn. 127 p. (See especially p. 83.) Oesterreichischer Wirtschaftsverlag. Kommanditgesellschaft Payer \& Co., Vienna. 1937.
} 
Furmint.-The soil and climate in a limited zone on the Hegyalia plateau of Hungary, the nature of the Furmint grape, and the particular method of wine making utilized make such a combination that a wine of distinction results. This is the Tokai of Europe (Tokaj or Tokay). Since the Furmint has a very thin skin, the fully mature berries dry rapidly, yielding a juice of high concentration. Tokay, the natural sweet wine of low alcohol content, is world renowned for lusciousness and perfume.

'This variety is a strong grower and a moderate producer. Unfortunately its thin skin and soft texture, which have added much to its quality in Hungary, do not function to advantage here. The fruit is subject to attack by insects, which feed on its rich sweet juice, and to rot and decay. Rapid loss of water by the mature fruit also leads to raisining and objectionable flavors under most California conditions.

The musts from region IV have been high in sugar, with barely sufficient acid for a well-balanced natural sweet wine. The wines have been full-bodied and soft, delicate in flavor and mildly distinctive in aroma. The natural sweet wines, though of good quality, have lacked the pronounced perfume of the real Tokai.

The great difficulty, however, is susceptibility to rot at maturity. The cost of preventing rotten grapes from getting into the crusher would be very high, and much fruit.would be lost. At Davis the grapes have had to be covered with cheesecloth and then hand-sorted before crushing. Even so, it is difficult to deliver only good grapes of high sugar content to the crusher.

On the basis of our present knowledge, Furmint cannot be recommended for California. Its outstanding quality where it succeeds may well justify further tests in cool regions by growers who are interested in it as an experiment.

Grillo.-The Grillo has found recognition in Sicily as a constituent of most Marsalas. It represents, however, the smaller part of the blend. There it is supposed to lend softness to the product. The vine is vigorous and produces good crops. The fruits are rather hard-textured and mature in good condition. The juice yield is below average.

Both table and dessert wines of average quality have been produced at Davis. The table wines were low in acidity and lacking in aroma and character. The sherries were slightly distinct, fruity, and well balanced. The fruitiness is the most valuable quality. The variety should be tested further for sherry production, especially in region V. It has not shown sufficient promise over several standard varieties, especially Palomino, to justify plantings at the present time.

Honigler.-Like the other white Hungarian varieties tested, the Honigler has a thin, tender skin. In unfavorable weather the crop will rot. Its fruit, however, has not been so much attacked by insects as the Furmint.

The musts of the fruit grown at Davis have contained barely enough acid for dry table wines and too little sugar for dessert wines. Their $\mathrm{pH}$ has been high. The product, however, has been moderately distinctive in aroma and flavor, clean, pleasant, harmonious, and well above average in general quality.

Because of its high productivity and the good qualities of its wines, the Honigler should be tested in regions II and III. It cannot be recommended for regions IV and $\mathrm{V}$. 
Muscat Terracina.-The Muscat Terracina is a medium grower and a heavy yielder even with spur pruning. At Davis an irregularity in bearing has made it difficult to prune for full crops each year without inducing occasional overbearing.

The clusters are medium-large, long-conical, shouldered, and completely set with medium-sized, short-oval, thick-skinned berries. When the crops have been such that the fruit has matured normally, it has reached the crusher in good condition.

The dry wines were entirely unsuccessful because of the typical muscat harshness that they showed in marked degree and because of their poor composition.

Muscatels from regions IV and V have not been wholly satisfactory. They have possessed a distinct yet only mild muscat aroma, with a rather limited character, and have been thin and not too well balanced. Some of the shortcomings can be charged to the low sugar content or immaturity of the fruit at harvesting. If this condition has resulted from overbearing, as seems to be the case, the variety should not be condemned without further testing.

The aroma and the flavor, even under the conditions of these tests, have surpassed those of Muscat of Alexandria. In these properties, however, Terracina was surpassed by Muscat Canelli and Orange Muscat. Again the matter of crop must be considered. The Terracina has consistently outyielded the Alexandria at Davis, and its yields have been more than double those of the Canelli and one half more than those of the Orange.

Further tests, evidently, should be made, with greater emphasis on yield. Without such tests no decision can be reached. Meanwhile, the variety is not recommended for planting.

Orleans.-The Orleans is grown in certain parts of Germany, primarily as a table grape. In earlier times it was used for wine, but now it has been all but displaced by the White Riesling or by the Sylvaner. With spur pruning it bears somewhat better than the former and about the same as the Sylvaner. The clusters are medium-sized, long-conical, fairly compactly set with firm, medium-sized, short-oval berries. The fruit has reached the crusher in good condition. The musts were, in general, of good acidity for the region. The juice yield was only fair. Because of its firmness the fruit withstands handling injuries.

Wine was produced from region IV in four seasons. In three of the years the product had a pleasant aroma and flavor and some character, but was deficient in acid. In the other season the wine was rich, with a delicate Rieslinglike aroma and flavor, good balance, and good finish.

Judging from these results this variety is not well adapted to the warm conditions of region IV. Further tests may show, however, that the Orleans will produce above-average quality table wines in regions II and III. Pending such tests, the variety is not recommended.

Walschriesling.-The Walschriesling is a weak grower, but very productive. The small vine, however, limits the yield. Under our conditions of wide spacing, this fact alone all but eliminates the variety from consideration.

The present tests were made only in region IV. Here the product usually had a distinct though mild varietal aroma and flavor and was soft and pleasant 
in the cool seasons. In the warm seasons the wines were flat, somewhat heavy, and less pleasing. At best, these were only good table wines.

Although it has produced some very acceptable table wines in region IV, Walschriesling cannot be recommended because of its low yields. In the cooler regions the quality would no doubt be higher; but production would drop. In no case will the aroma and flavor approach the richness of a good White Riesling. The variety should not be planted anywhere without special prior testing for quality and yield.

\section{RED VARIETIES NOT FULLY TESTED}

Red varieties insufficiently tested include Affenthaler, Aglianico, Corbeau, Fogaruna, Malbec, Merlot, and Robin noir. Analyses of musts and wines of these varieties are given in table 23.

Affenthaler.-In the earlier work with Affenthaler, Hilgard ${ }^{\text {th }}$ was impressed with its capacity of producing quality red wines in California. $\mathrm{He}$ made eighteen lots of it: two from Fresno, two from the Amador station, and the remainder from the coast counties. Except for the warmer locations in the coast counties and the interior, these wines were found to contain ample acid and color, were well balanced, and appeared somewhat distinctive. Near the coast they were somewhat rough, when young, but with sufficient aging developed into quality wines that kept well.

In the coastal areas the variety proved average in vigor and production, but in the interior it did not bear so well. At Davis it is a moderate producer. Despite these early favorable results, Bioletti ${ }^{\text {t2 }}$ in 1907 failed to recommend it for California.

The clusters are medium-sized, conical, winged, and well filled with small, round, thin-skinned berries. With moderately careful handling, the fruit reaches the crusher in good condition.

As regards must composition, the present results agree well with previous work on grapes of the interior. The wines, however, have lacked the definite character and high quality ascribed to the earlier ones. Despite a slightly distinct aroma and a fruity flavor, they were deficient in acidity and color, only average in quality. In no case have they been distinctive. The color has been approximately that of a normal pink wine.

These results definitely indicate that the Affenthaler is not adapted to region IV or warmer areas. Under such conditions the quality is not high enough to offset the moderate-to-low yields. The variety may, on the basis of earlier work, deserve a place in region II and the cooler parts of III. Without further testing it is not recommended. In region $\mathrm{I}$ it will probably ripen too late.

Aglianico.-The Aglianico is an old variety. According to history, it was taken from Greece to Naples about the sixth century B. C. and it has been grown on the slopes of Mount Vesuvius ever since. To enjoy such a long period of culture it must possess something more than a tradition.

The variety ripens late. At Davis it has produced well. The clusters are large and closely set with small berries. The variety is fairly resistant to dis-

\footnotetext{
${ }^{\pi}$ See eitation in footnote 16, p. 496.

${ }^{72}$ See citation in footnote 18, p. 496.
} 


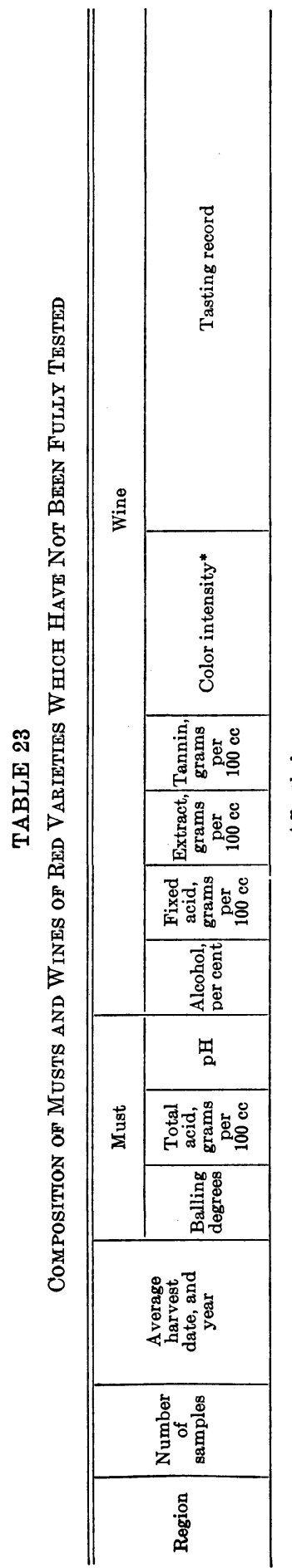

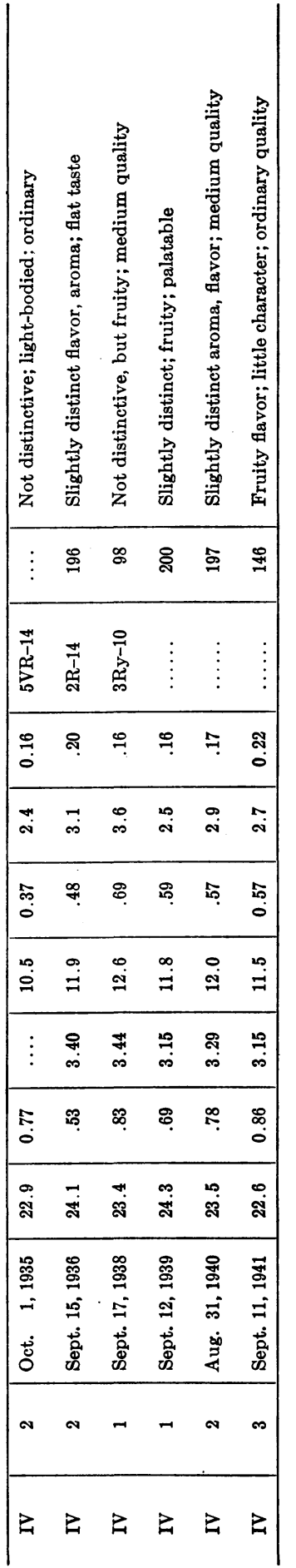

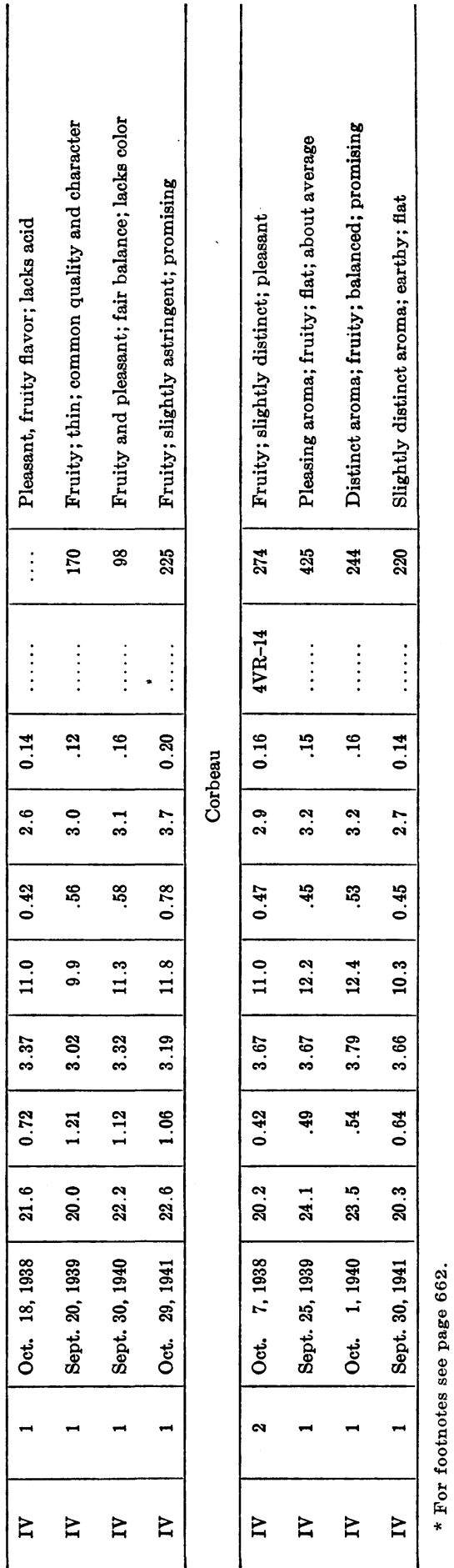




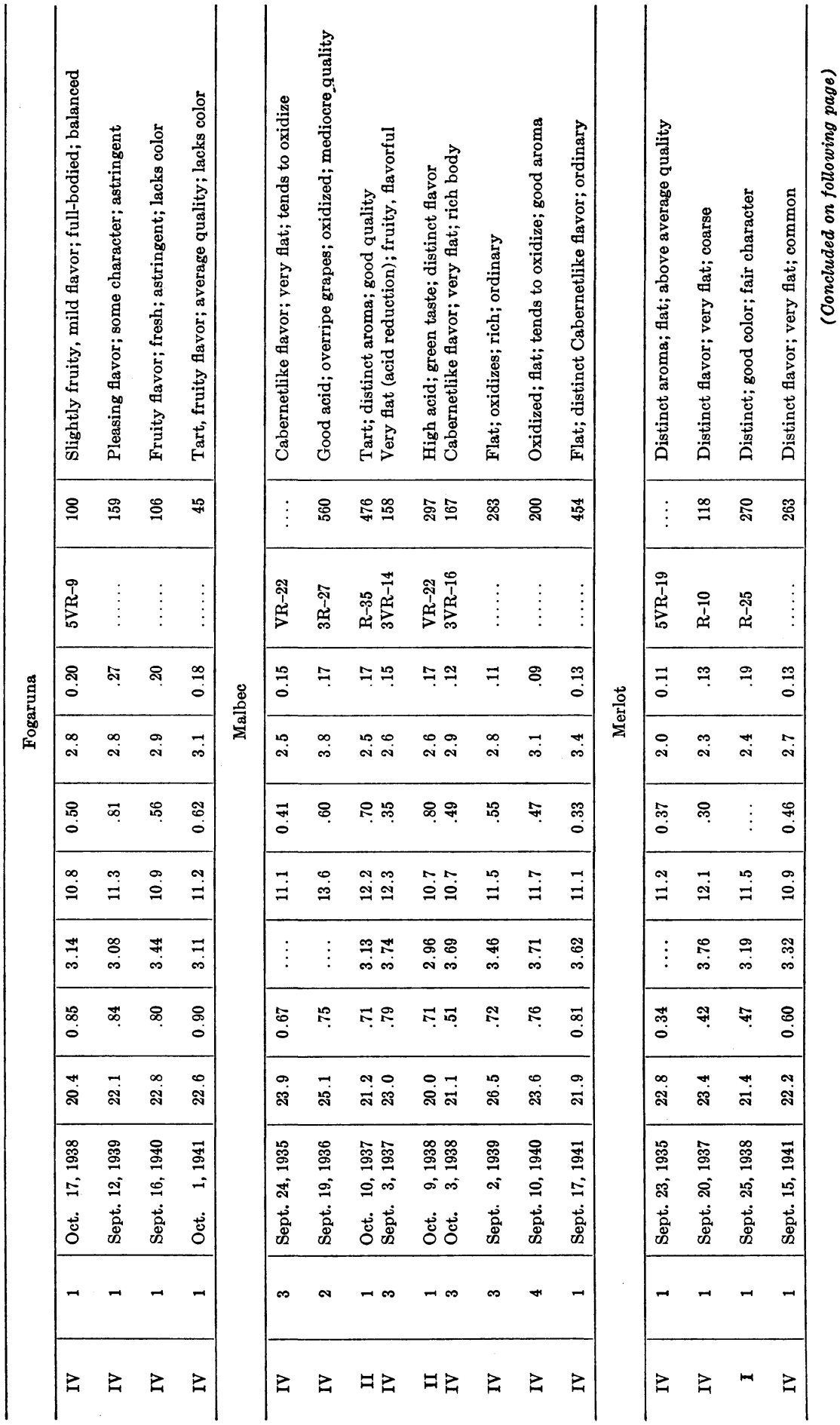



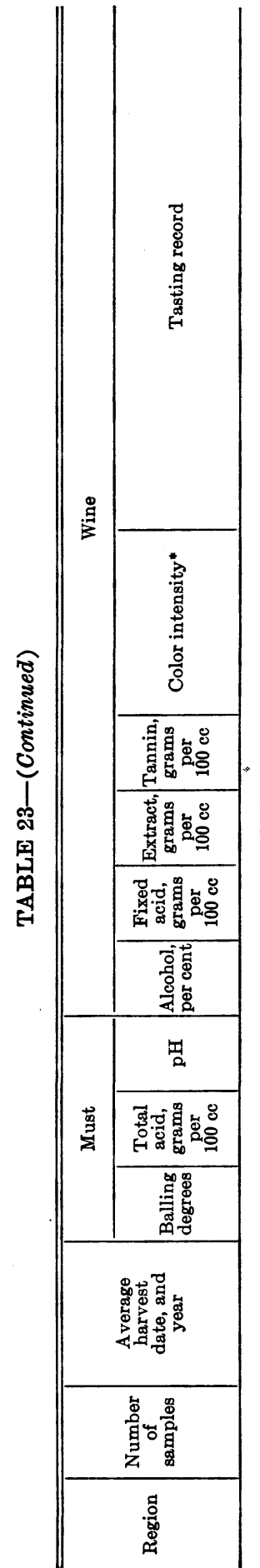

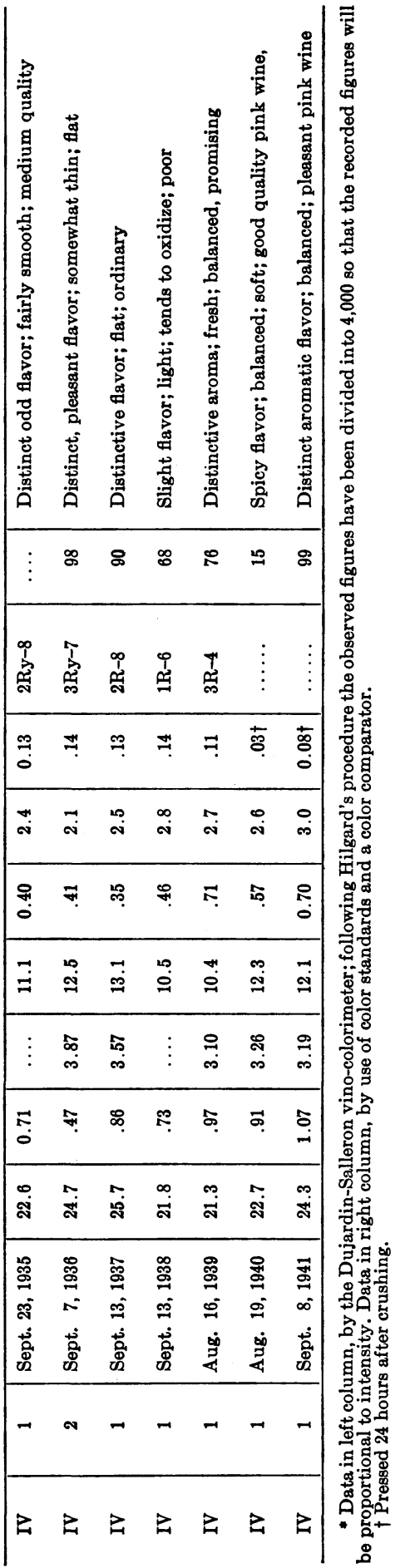


eases and handling injuries and reaches the crusher in good condition. The juice yield is good. The musts are of excellent acidity and, for region IV, of moderately low $\mathrm{pH}$.

The dry table wines from region IV have not been impressive. Though fair to good in balance, they have lacked the flavor, aroma, and character necessary for distinction. Only in the last year did the product contain a normal amount of color. For some reason the young wines seem to be subject to acidreducing bacteria and lose a large percentage of their acidity.

Thus far the Aglianico has not proved adapted to region IV, even though the temperature is somewhat lower than in the area where it is grown in Italy. Further tests should be carried out both at Davis and under warmer conditions. With a somewhat better-balanced must-that is, of less acidity-the resulting wines may show greater promise. In view, however, of the more stringent color restrictions for wines in this country, its color deficiency is unlikely to recommend it to the wineries even if a better-balanced wine should be produced in another location.

At present Aglianico is not recommended for California.

Corbeau.-Corbeau is vigorous and, at Davis, very productive. Its mediumlarge clusters handle so well that the fruit usually reaches the crusher in good condition. The fruit is of medium size and closely set. It crushes easily and the juice yield is good.

In region IV the must has been rather low in acid, so that the dry table wines have not been balanced or fresh. Despite this defect their distinct aroma and flavor have been pleasant and desirable. In view of these latter properties, the variety should be tested in cooler areas. Judging, however, from its late ripening in Davis, its fruit may not mature properly in regions where the grapes retain sufficient acidity to be well balanced. Regions II and III offer the best possibilities. Late ripening also prevents use of Corbeau for red dessert wines. The color is sufficient and of a good tint despite the high $\mathrm{pH}$.

Fogaruna.-The Fogaruna is moderately vigorous and productive. Its clusters are medium-sized, conical, and compactly set with medium-small, very firm berries. The firm texture and the thick, relatively tough skin make the berries resistant to handling injuries and unfavorable weather. The fruit each year has reached the crusher in excellent condition. It does not color till fairly late, but has ripened in sufficient time at Davis.

The musts from region IV have possessed a relatively high acid content and a low $\mathrm{pH}$. The wines have been tart and fruity, with a pleasing flavor and some character. They have not been quality wines, but are interesting for their general balance and their mild but distinctive character. The variety should be tested further under conditions similar to those at Davis to determine its best adaptations.

In a slightly cooler region where it would still mature, the color should be more intense, the aroma and flavor more pronounced, and the product better balanced. Under such conditions the wine should have value not only for itself, but also for blending. At present Fogaruna is not recommended for regions I, II, and V. Further tests should be made in III and IV.

Malbec.-The Malbec is an early-ripening variety commonly used in the Bordeaux region of France to blend with the Cabernet Sauvignon variety. As 
Peynaud $^{73}$ has shown, the blending of Bordeaux grapes may be intended not only to soften the predominant flavor of the Cabernet but also to balance the acidity of the must and more particularly to get the proper ratio of tartaric and malic acids.

The variety produced well at Davis, but Hilgard found it a very poor producer in other localities. Although the skins are rather thin, the grapes do not spoil easily. The clusters are medium-sized and the berries loosely set. The juice yield is good.

The wines have a surprisingly distinct flavor, strongly suggestive of Cabernet, though neither so strong nor so well balanced. Although of good flavor, the product does not regularly have a high enough acid for making red table wine in region IV. It should probably be tried for a red dessert wine under these climatic conditions. On the other hand, the musts from region II are of good acidity and produce standard though not high-quality wine.

The studies thus far justify a further examination into the possibility of growing this variety in cool locations such as regions I and II, and of utilizing it for red dessert wine in IV and V. At present plantings are not recommended, since other varieties have equal or greater potentialities. Hilgard's failure to secure production, because of coulure, should also be considered.

Merlot.-The Merlot has been insufficiently tested in California. It is a Bordeaux variety; which in France produces an average wine.

Here it is a small producer and, under region-IV conditions, very deficient in acid. Hilgard's reports are similar in this respect. The flavor, however, is distinct, reminding one faintly of Cabernet.

Merlot should be tested further in regions I and II, where its mild-flavored but slightly distinctive wines may find a place. Indications are, however, that it will not make a high-quality wine even in a district where its musts will be well balanced.

Robin noir.-The Robin noir is moderately productive and matures early. The clusters are long and medium-large, and they handle well if picked early. The fruit, if left on the vines till midseason, is subject to raisining. The juice yield is good.

In region IV the balance of sugar and acid in the mature fruit adapts it for table-wine production except in a very warm season such as 1936, when it is too low in acid. The color intensity has been low, sufficient only for wellcolored pink wines. The tannin content, after several days of fermentation on the skins, has also been equal in magnitude to that of normal pink wines. The product tends, as with Pinot noir, to lose considerable acidity. Acid-reducing bacteria are apparently involved. Earlier racking from the lees and addition of a little sulfur dioxide after fermentation may prevent this difficulty.

The wines were distinctive and pleasing in flavor, well balanced, fresh, and smooth-good pink wines.

On the basis of results to date the Robin noir should be tested further in regions I, II, and the coolest parts of III. There it may develop sufficient color and tannin for a delicate, well-balanced, red table wine. Such tests may show, however, that it has other faults, not now apparent.

${ }^{73}$ Peynaud, E. L'acide malique dans les moûts et les vins de Bordeaux. Société des Sciences Physiques et Naturelles de Bordeaux, Procès-Verbaux 1937-38 : 75-79, 89-94. 
In regions III and IV it is adapted for pink wines only. Moreover, the pink wines of several high-yielding, standard black varieties are almost or fully equal to these in quality. Its planting in these regions is therefore not recommended.

This variety should not be planted in region $\mathrm{V}$, where it will lack both color and acid.

\section{USE OF TABLE GRAPES FOR WINE}

The deficiency of wine grapes during the post-Prohibition period has led to the widespread use of table grapes for wine making. So long as these varieties are used solely for distilling material to produce nonbeverage grape brandy for use in the arresting of the fermentation of dessert wines, their winemaking quality is of minor importance. Not all the musts of the table-grape varieties, however, are fermented solely for the above purpose; some are used for making dessert wines, beverage brandy, or even table wines. The utility of the table-grape varieties will therefore be briefly considered. Since all, or nearly all, the table grapes of California are grown in regions IV and V, the problem of their composition is restricted to these areas. Limited amounts of Chasselas doré are found in II and III.

The chief characteristics of table-grape varieties are their mild flavor, their eating quality, and their low acidity at rather low sugar concentrations. The Balling-acid ratio of this type of grape is therefore high. Their ultimate sugar concentration is likewise low. Even an early-ripening table-grape variety such as Luglienga rarely attains a Balling reading of more than $23^{\circ}$ or $24^{\circ}$. Since table-grape varieties also usually have a high $\mathrm{pH}$, they are more susceptible to spoilage during and after fermentation than musts of lower original $\mathrm{pH}$.

Another disadvantage of table grapes has been the fact that all the packingshed culls have been diverted to winery use-frequently when bruised and several days old. Likewise the clusters not up to shipping quality are left on the vines and later diverted to the winery. Still another handicap of table grapes is that notable quantities have been shipped in gondola trucks over long distances. Under these circumstances they bruise badly despite their naturally firm texture.

The flavor of wines produced from table grapes is uniformly poor. Because of their low acidity they frequently develop bacterial contamination during fermentation or storage. The low acidity of their musts results in flat-tasting wines. Finally, their natural mildness of flavor can produce only mild-flavored wines. That the lack of acidity is not the only shortcoming can be proved by ameliorating the must with acidity before fermentation: the wines, though better balanced, are still neutral and ordinary. From the standpoint of the winery it would be better if no table grapes, except perhaps Thompson Seedless, were ever crushed. For economic reasons, however, many will probably be used. As far as possible, they should be utilized for distilling material. The next most practical use is for sherry material.

\section{WHITE TABLE-GRAPE VARIETIES}

White varieties include Almeria (Ohanez), Chasselas doré, Malaga, and Thompson Seedless. The Servant, which may also be considered as a table grape, has been previously discussed. Representative analyses of musts and 


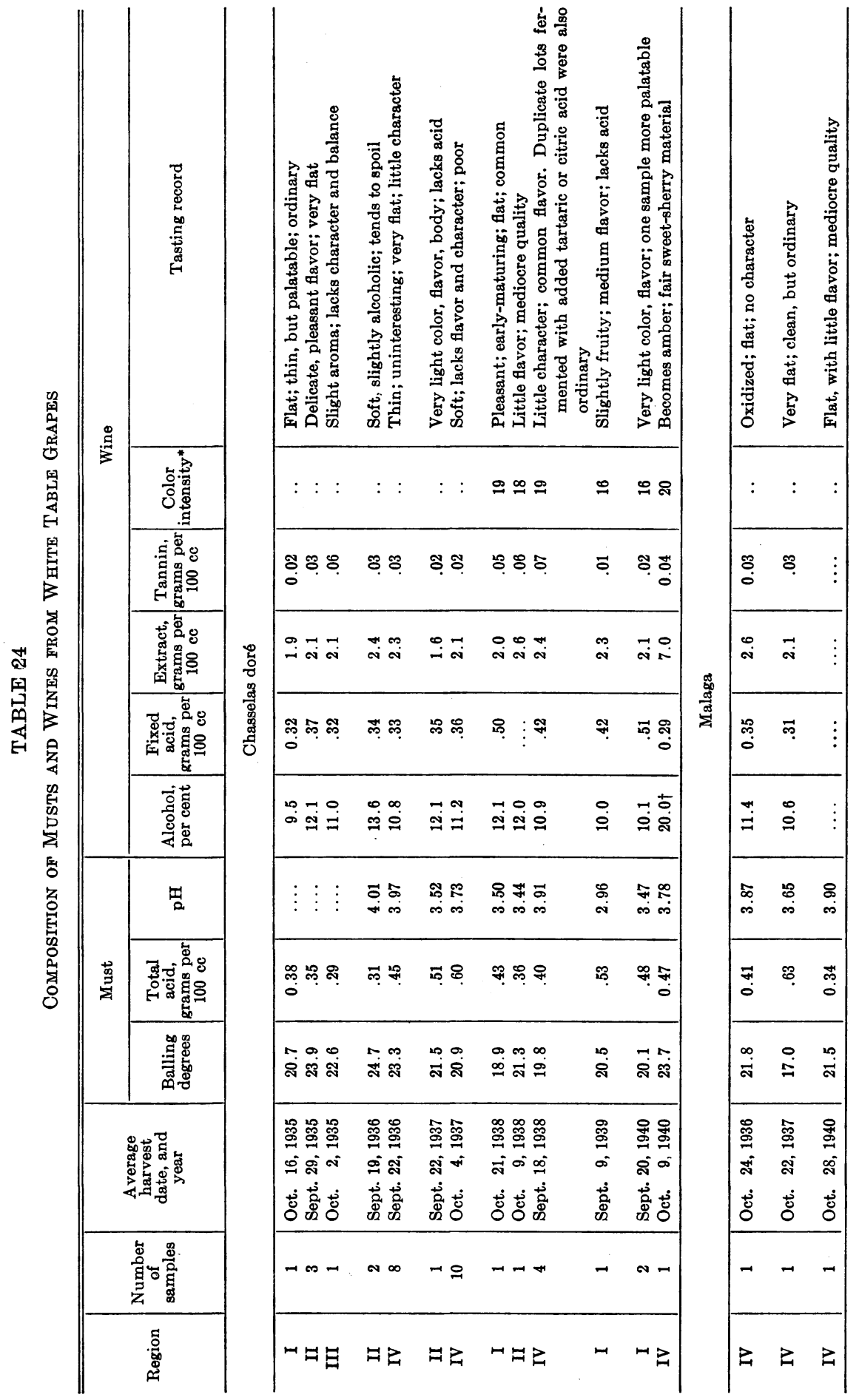




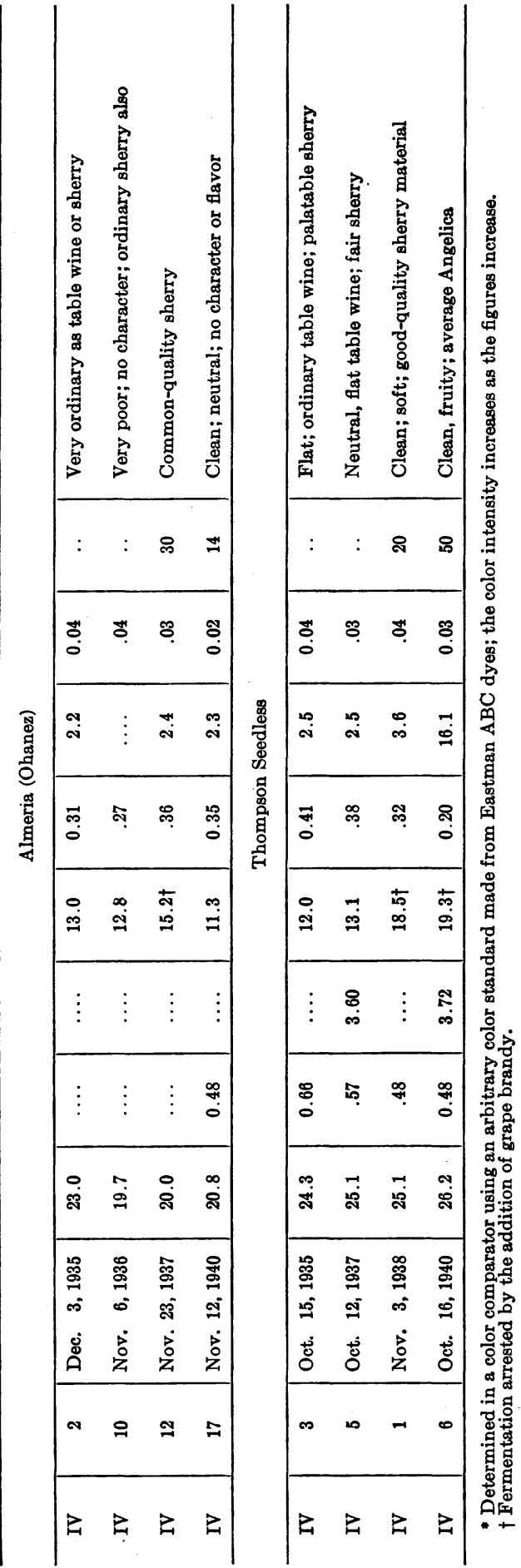


wines of these varieties appear in table 24 . Only a few are presented, since the lack of sugar and acid is so obvious and so uniform. ${ }^{74}$

Almeria.-This variety is more correctly called Ohanez, but it has become established commercially as Almeria. It ripens very late, reaching harvesting maturity in late October or November. Since the clusters are loose, the pulp firm, and the skin thick and tough, the grapes ordinarily remain in good condition. The demand for shipping is usually satisfactory, and only culls are ordinarily received by the wineries. The Balling reading rarely exceeds $20^{\circ}$ or $21^{\circ}$, and the acidity is very low. In the winery the grapes should be used-if at all-only for the production of distilling material.

Chasselas doré.-The Chasselas doré is the best known of the many Chasselas varieties in the state. A true Chasselas, it should not be confused with Palomino, which is called Golden Chasselas in Napa and the adjacent counties. Palomino is a totally different grape, adapted for sherry production-in no sense a Chasselas. (See p. 546.) The common Chasselas found in California is frequently called Sweetwater and Gutedel.

The Chasselas doré vines are small and only moderately productive. The clusters are medium-sized, long-conical, shouldered, and compactly set with medium-large, tender berries. With maturity the fruit softens and may be difficult to handle. Ripening early, it is attacked by deer in the foothill regions.

This is the leading table grape of France. There it is used very little for wine production except in certain northern districts, where its low acidity makes it useful for producing palatable wines. Before 1918 the Chasselas (Gentil) wines of Alsace were sometimes used in Germany to reduce the acidity of the Riesling wines. The Gutedel wines of Germany and the Fendant wines of Switzerland, made from this variety, are light and pleasant. But the areas in which Chasselas doré is used for wine making are among the coolest where the grape is grown, and nowhere, here or abroad, does it produce a quality wine. Here this variety never has enough acid for a satisfactory table wine. Even in region I, where the wines have been light, mildly delicate in aroma, and pleasantly flavored, they are flat. The warmer the region, the flatter and poorer the product.

One lot of wine handled to produce material for sweet sherry was fair, but became dark very early. Under California conditions-judging from the composition of the musts - this variety is best suited for dessert wine of average quality, but its low productivity would prevent it from competing with other acceptable varieties.

Hilgard's analyses showed very low acidity and only average wines. In 1907 Chasselas doré was not among the varieties recommended by Bioletti. On the basis of these and the present tests it is not recommended for California. It is not flavorful enough for quality wine nor productive enough for ordinary wines.

Malaga.-The Malaga is well known in region V in the San Joaquin Valley. Up to 1930 it was California's leading table grape. The fruit will not ripen normally in regions I, II, and III in the coastal counties.

The table wines have been flat, without character, and with little flavor. The

${ }^{74}$ Viticultural information on these varieties appears in: Jacob, H. E. Grape Growing in California. California Agr. Ext. Cir. 116:1-80. 1940. 
variety is also of little use for dessert wines, since the products have been hard, coarse, and almost devoid of flavor or aroma.

The Malaga is and should continue to be a table grape of importance in certain limited areas. It should not be used for wine production, and the acreage should be reduced in favor of good white-wine varieties. When the grapes do reach the winery they should, if possible, be used for distilling material. If they must serve for wine, they are better adapted for sherry than for any other type.

Thompson Seedless.-This is California's most extensively planted grape variety, nearly 180,000 acres being in production. Although primarily a raisin grape, it is also extensively used for shipping. The fruit reaching the winery comes from packing-shed culls, grapes left on the vines as unsuitable for shipping, or, especially in years of low prices, the whole crop.

The fruit can withstand considerable handling without severe injury, since the berries are small and firm. It crushes only moderately easily and if pressed immediately has a juice yield below average. In actual practice, however, the free-run is usually taken off, and the pomace fermented with water for distilling material. Under these ennditions the yields are better.

Thompson Seedless was tested by Hilgard and others for wine production, but the results were apparently discouraging; no recommendations were made by Hilgard or Bioletti.

Although the acidity is not so low as for other table-grape varieties, it is not high enough to produce sound table wines without amelioration. Even when acid is added and the best possible care taken during fermentation and storage, the resulting wines are neutral-flavored, almost devoid of character. Even when clean, they are very ordinary.

The only rational use for Thompson Seedless in the winery is for the production of distilling material and for sherry material. The neutral flavor is less of a handicap in sherry production; and the flavor after baking is soft, albeit neutral.

If the grapes are harvested very early, they are not unsuited as distilling material for beverage brandy.

\section{RED AND BLACK TABLE-GRAPE VARIETIES}

The red and black table-grape varieties commonly grown in California include Cornichon, Emperor, Flame Tokay, Hunisa, Red Malaga, and Ribier. Analyses appear in table 25.

Cornichon.-This variety has a rather thick skin but very juicy pulp, hence if handled in the same manner as other table-grape varieties will suffer proportionately more. The juice yield, however, is very good. The color of the skins is only sufficient, under region-IV conditions, to produce a pink wine even by fermenting on the skins for several days. White wines can be produced by early pressing, since the juice is colorless. The low sugar and acidity and the lack of flavor predispose the variety to use as distilling material only should it be delivered to the winery.

Emperor.-This very late-ripening variety reaches harvesting maturity in late October or November. The skins are so tough and the texture so solid as to withstand early rains fairly well; the grapes reach the winery in good condi- 


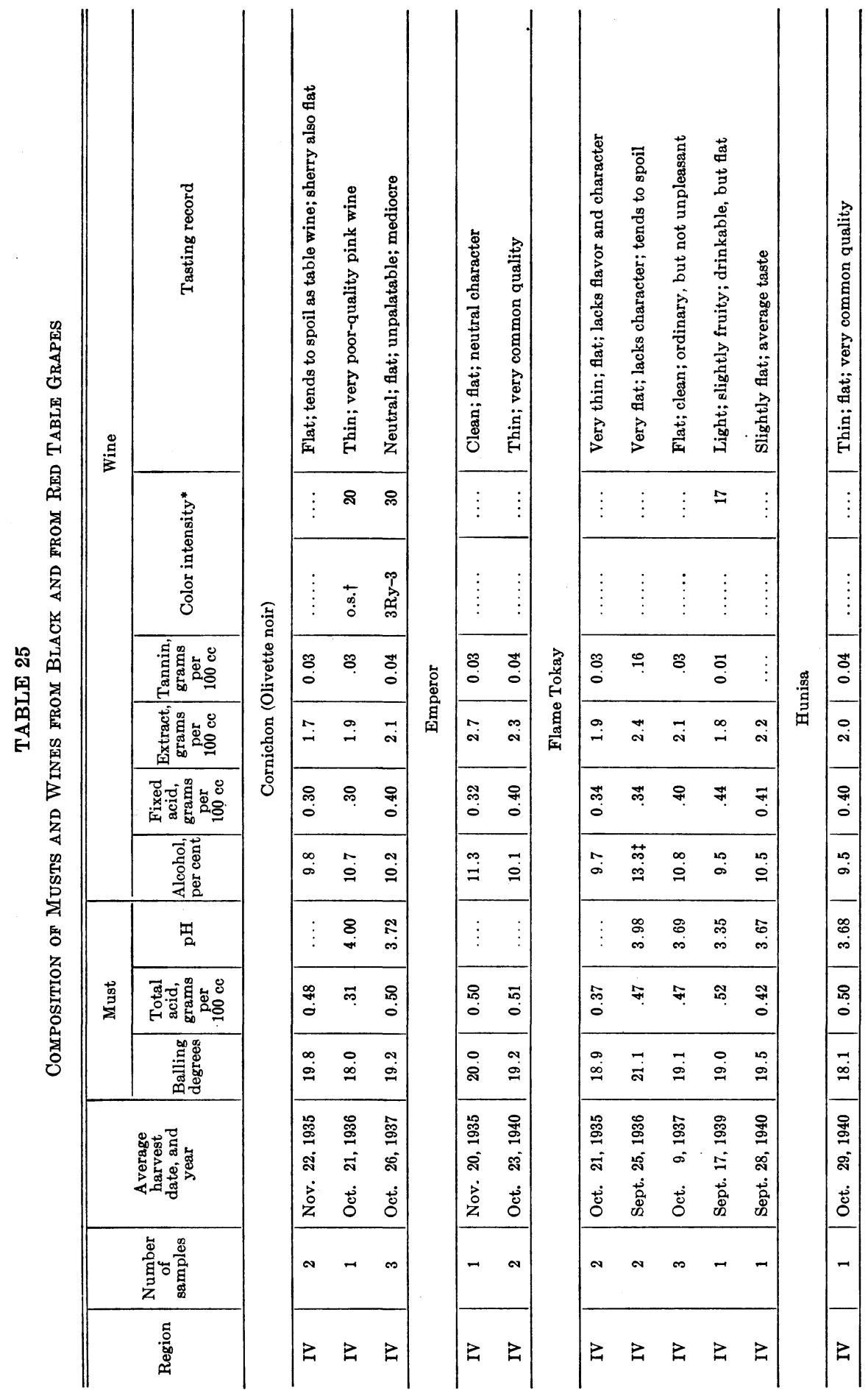




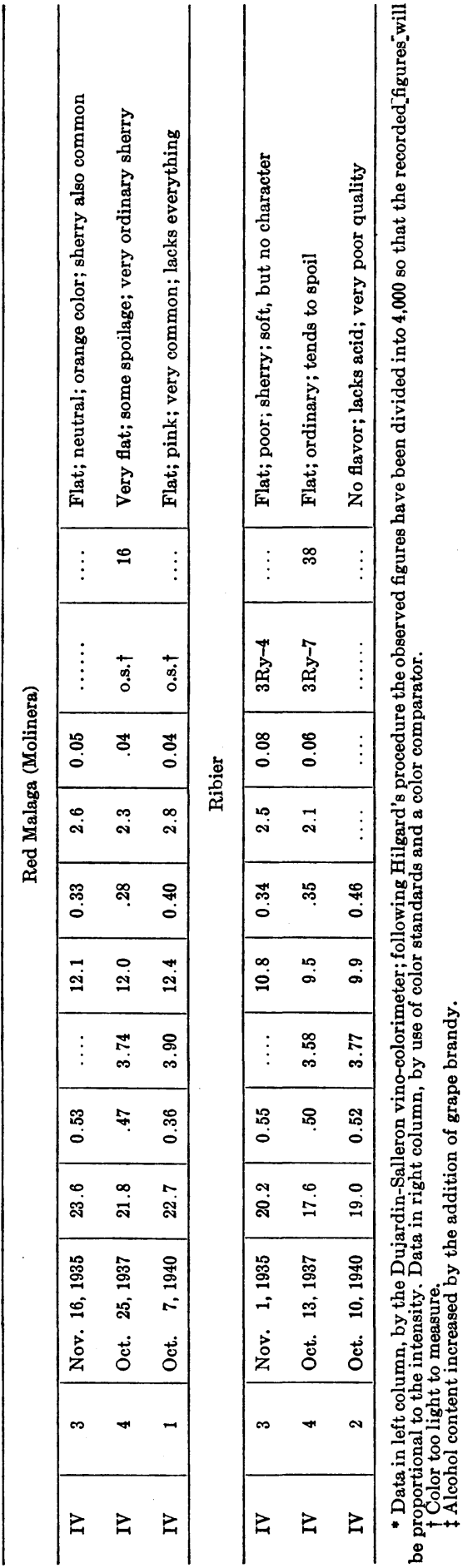


tion. In view of their late ripening they seldom have a Balling reading of more than $20^{\circ}$ or $21^{\circ}$ and their acidity is very low. The wines have been ordinary even when the musts were acidified. Fermenting on the skins for several days gives only pale pink-colored wine. If delivered to the winery, Emperor should be used only for the production of distilling material.

Flame Tokay. ${ }^{7}$ - The Flame Tokay, one of California's leading table grapes, appeals to the consumer because of its very delicate, brilliant, light-red color. In wine production, however, it is stripped of this most valuable property, since its wine must be made white. When fermented on the skins its wines have only a slight pink tinge, which has only a nuisance value.

The vines of Flame Tokay are very vigorous, eventually attaining enormous size. They are among the most productive of all vines. The clusters are very large, heavy, and conical, compactly set with very large ovoid-truncated berries. The variety grows well in all but the coolest and the hottest locations, but for producing the best table grapes the present acreage is chiefly in the Lodi area of region IV.

The table wines of this variety produced at Davis, and commercially, have been unsatisfactory. All were consistently flat, lacking in character, but clean and not unpleasant-that is, just ordinary wines. Their lack of acidity has been the primary but not the only deficiency.

The variety is less objectionable when used for dessert wines. Even so, its wines of these types are only average. Their main defects are a lack of character, a tendency to be sharp and coarse. They are surpassed by wines of other varieties such as Palomino, which is also a good producer. If Flame Tokay grapes are delivered to the winery, their best utilization is for distillation.

There should be no thought of expanding the acreage of Flame Tokay for wine making. The present (1942) surplus over the amount required for fresh consumption should be utilized primarily for distillation. If the surplus continues year after year, it should be eliminated by a shift to wine grapes of proved quality for the region.

Hunisa.-Only very small plantings of Hunisa are available in California. The fruit is large except that the variety frequently sets many small, seedless berries. The berries are firm, and the juice yield is small. Either white or pink wines can be produced. They are uniformly flat, oxidize easily, and lack alcohol. They should be used only in the production of distilling material.

Red Malaga.- This variety, also known as Molinera, ripens sufficiently for eating in midseason but will gain in sugar if left on the vines. The acidity is low, however, at $19^{\circ}$ or $20^{\circ}$ Balling; hence utility in the winery is restricted. The grapes are light red, but only pink wines can be produced by fermenting on the skins. White wines can be produced by pressing after crushing. The juice yield is below average. The grapes are of good quality until slightly after midseason, when they begin to rot. Should some of this variety have to be sent to the winery, it should be picked fairly early. Although it is better balanced for producing distilling material, an occasional sample harvested late in the season in years of dry, hot, ripening periods can be used for sherry material.

${ }^{75}$ This variety has no relation to the grape used for producing the natural sweet wine known as Tokay in Hungary. The variety used there is a white wine grape (see p. 657). Likewise the California wine type known as Tokay does not resemble the Hungarian wine. Ordinarily it is not even produced from the Flame Tokay grape and is a blended dessert wine. 
Since, however, the flavor is rather neutral, such uses should be gradually eliminated.

Ribier.-This is the principal black table-grape variety in California. Its clusters are large-sized, conical, shouldered, well filled with very large black berries. The fruit handles and ships well. The variety is best adapted to warm locations. The juice yield is very good.

The musts of region IV were poorly suited for wine, being low in total acidity and sugar and with a relatively high $\mathrm{pH}$. The table wines possessed no character or flavor and were flat and difficult to keep. The color was a particularly undesirable orange tint. Sherries produced by baking were no better than the dry wines, being too low in acid, flavor, and particularly in body.

This variety should not be employed for wine making. If the fruit arrives at the winery, it may go into distilling material.

\section{ACKNOWLEDGMENTS}

The authors wish to express their appreciation to the following companies and growers for their coöperation in securing the many lots of grapes : Almaden Vineyard, J. Arakelian, George Bear, Bear Creek Vineyard Association, Beaulieu Vineyards, Bedford Winery, George Barbero, George Borra, Mrs. Bridge, Carl Bundschu, California Grape Products Company, W. Cerps, Costa Brothers, F. Cribari and Sons, Cresta Blanca Wine Company, W. A. Dilley, The El Solyo Ranch, George Ferrara, E. Ferrario, Fountaingrove Vineyard, E. Fusaria, F. Garatti, S. Garberoglio, F. C. Gulla, A. Haentze, P. Hopper, Hopper Ranch, L. Iacopetti, Inglenook Vineyard Company, Italian Vineyard Company, Italian Swiss Colony, F. T. Kirschenmann, Korbel Bros., A. Kunde, S. La Fata, N. E. Leed, D. Leer, Lombardi Winery, Madera Winery, C. Mangels, L. K. Marshall, L. M. Martini Grape Products Company, A. Mattei Winery, Merkey Vineyard, P. L. Mirassou, E. Meyer, Mont La Salle Vineyards, R. E. Nelsen, L. Nerelli, Novitiate of Los Gatos, J. Ohrwall, J. Osborn, A. B. Parducci, E. W. Peterson, E. Piccioni, V. Pirone, J. Podesta, C. E. Quistorf, Martin E. Ray, The Riehr Vineyard, S. Riesland, H. L. Rixford, V. Rizzo, Roma Wine Company, Rusconi Bros., F. Salmina and Sons, C. Saroglia, Mrs. A. D. Seghesio, F. W. Silvear, W. Sink, Stanley Estate, U. S. Department of Agriculture Bureau of Plant Industry, E. Valliant, J. A. Verazzo, Wente Bros., W. Wildhagen.

Thanks are also due our colleagues for advice and consultation during the course of this investigation and for suggestions and criticisms in the preparation of this report. 


\section{INDEX ${ }^{76}$}

Acknowledgments, 673

Affenthaler, 516, 659, 660

Aglianico, 516, 659, 663, 660

Aleatico, 510, 512, 586, 540, 551-52, 599

Alicante Bouschet, 504, 505, 510, 511, 512, 560, 592, 601, $603,624,625,626,643,648$

Alicante Ganzin, 512, 577, 592, 578, 643

Aligote, 512, 563, 564

Almeria (Ohanez), 665, 667, 668

Antibo, 512, 624, 625, 627

Aramon, 512, 577, 578, 592-93

Aroma, effect of warm climate on, 503

Aspiran noir, 512, 624, 625, 627

Bambino bianca, 512, 606, 608

Barbera, 510, 512, 530, 540, 541, 552-53, 594, 600

Beclan, 512, 577, 579, 593-94

Best variety, factors influencing selection, 507-17

Bioletti, F. T., work, 496-97

Black Hamburg, 512, 624, 627, 640

Black Malvoisie, 495, 510, 512, 541, 577, 580, 594

Black Prince, 512, 624, 627, 640-41

Black table grapes, use for wine, 669-73;|black wine varieties see red varieties

Blaue Elbe, 512, 624, 628, 641

Blends, as a factor in selecting varieties to plant, 509-10

Boal Madeira, 516, 651, 652

Bolgnino, 512, 577, 581, 594-95

Bonarda, 512, 624, 628, 641

Burger, 495, 504, 505, 511, 512, 533, 543, 563, 571, 564, 576, 577

Cabernet Sauvignon, 503, 504, 507, 510, 512, 520, 533, 553-54, 555, 558, 594, 602, 649,663

Carignane, 504, 505, 510, 512, $531,540,541,554-55,556$, $559,560,595,597,603,646$

Catarratto, 511, 516, 651, 656, 652

Charbono, 510, 512, 577, 581, 595

Chardonnay, 511, 512, 518,533, 541-42, 546, 572

Chasselas dore, 509, 511, 512, 640,666, 668

Chauche noir, 512, 624, 628, 641

Chemical tests, 499-501

Chenin blanc, $512,533,562,563,565,571-72$

Chenin noir, 512, 624, 629, 641

Clairette blanche, 511, 512, 606-7, 608

Classification of wines, 502

Climate, effect on wines, 503-5

Climatic regions of California for wine production, 504-5

Collecting samples, 497-98

Composition of musts, effect on type of wine, 508-9

Composition tables for musts and wines, of black va rieties, $670-\gamma 1$; of red varieties, $520-21,526-27,530-32$. $536-\$ 9,578-91,626-\$ 9,660-62,670-71$; of white varieties, $518-19,528-25,528-29,534-35,564-70,608-17$, $658-55,666-67$

Corbeau, 516, 659. 660, 663

Coristano, 512, 624, 689, 641-42

Cornichon, 669,670

Criolla Mesa and Vino, 512, 624, 629, 642

Croetto Moretto, 512, 624, 629-30, 642

Degree-days in grape-growing regions, 504-5, 506 Dessert wines, climatic conditions suited to, 503-4

Dolcetto, 512, 624, 630, 642-43

Early Burgundy, 512, 624, 630, 643

Emperor, 669, 672, 670

Environmental conditions, effect on wines, 503

Erbaluce Caluso, 516, 651, 653, 656

Ezerjo, 516, 651, 658, 656

Factors influencing the selection of the best variety, 507-17

Feher Szagos, 511, 512, 606, 607, 609

Flame Tokay, $640,669,670,672$

Fogaruna, 509, 516, 659, 661, 663

Folle blanche, 511, 513, 522, 533, 542-43, 576, 622

French Colombard, 511, 513, 528, 540, 543-44

Fresia, 513, 577, 582, 595-96

Furmint, 516, 651, 658, 657
Gamay, 510, 513, 521, 533, 555-56, 649

Grand noir $510,513,560,601,624,631,643,648$

Grape-growing regions of California, 50

Gray Riesling, 511, 513, 563, 565-66, 572

Grec rouge, $513,624,631,643-44$

Green H ungarian, 511, 513, 543, 577, 606, 607, 618, 609

Grenache, 510,513,533, 538, 541, 556-57, 594, 640

Grignolino, 510, 513, 540, 577, 582, 596

Grillo, 516, 651, 653, 657

Gros Manzenc, 510, 513, 540, 577, 583, 596-97

Grosse blaue, 513, 624, 631, 64

Heat summation in grape-growing regions, 504-5, 506

Hibron blanc, 513, 606, 610, 618

Hilgard, E. W., work, 494-96

Honigler, 516, 651, 654, 657

Hungarian Millenium, 513, 606, 610, 618

Hunisa, 669, 670, 672

Influence, of environmentalconditions, 503 ; of climatic conditions, 503-5; of seasonal conditions, 505-7

Inzolia, 511, 513, 563, 566, 572-73, 651

Kadarka, 513, 624, 632, 644

Kleinberger, 513, 606, 610, 618

Koptcha, 513, 624, 692, 644

Lagrain, 513, 577, 583, 597

Lambrusche Langhre, 513, 624, 682, 645

Lenoir, 513, 624, 638, 645

Limberger, 513, 584, 597-98

Macaroli, 513, 624, 633, 645

Malaga, 665, 666, 668-69; see also Red Malaga

Malbec, 516, 659, 661, 663-64

Malmsey, 513, 606, 611, 619, 624

Malvasia bianca, $511,513,534,540,541,544-45,574$

Malvoisie, see Black Malvoisie

Mammolo Toscano, 513, 577, 584, 598

Marsanne, 513, 606, 611, 619

Marzemino, 513, 624, 633, 645-46

Mataro, 504, 510, 513, 560, 624, 583-\$4, 646

Mathiasz y-ne, 513, 606, 611, 619-20, 621

Maturation, time of, effect on selecting a variety, 509

Merlot, 516, 659, 661, 664

Methods, 497-502

Meunier, 509, 513, 577, 624, 685, 646, 649

Mission, 494, 509, 510, 513, 536, 540, 541, 557-58, 594, 640, 642

Molinera, see Red Malaga

Mondeuse, 495, 510, 513, 533, 560, 577, 585, 598-99

Mourisco branco, 513, 606, 611, 620

Muscadelle, 513, 533, 563, 567,573

Muscat Canelli, 511, 513, 528-29, 533, 540, 541, 545, 546, $573,574,599,620,621,658$

Muscat Hamburg, $511,513,577,585-86,599$

Muscat of Alexandria, $511,513,544,545,563,567,573-74$ 599,658

Muscat Pantellana, 514, 606, 612, 620

Muscat Saint Laurent, 514, 606, 612, 620-21

Muscat Terracina, 516, 651, 654, 658

Nasa Veltliner, 514, 606, 612, 621

Nebbiolo, 510, 514, 562, 577, 586, 599-600

Negrara Gattinara, 514, 577, 587, 600

Negro amaro, 514, 624, 635, 646-47

Neiretta, 514, 624, 635, 647

Nicolas Horthy, 514, 606, 613, 621

Notes on varieties, 541-63, 571-77, 592-607, 618-25,

$640-51,656-59,663-65,668-69,672-73$

Ohanez, see Almeria

Orange Muscat, 511, 514, 534, 540, 541, 545-46, 573, 574 620,658

Organoleptic tests, 499, 501-2

Orleans, 516, 651, 654, 658

Pagadebito, 510, 514, 624, 686, 647

Palaverga, 514, 606, 61s, 621

Palomino, 505, 511, 514, 585, 540, 541, 546, 573, 577, 607 $620,651,657,668,672$

${ }^{76}$ Pages on which composition is tabulated are indicated by italics, and those containing notes on specific varieties by boldface type. 


\section{Index}

Pavai, 514, 606, 613, 621-22

Petit Bouschet, 510, 514, 560, 624, 636, 643, 648

Petite Sirah, 504, 505, 510, 514, 526, 533, 558-59, 597, 601

Petite Verdot, 514, 624, 637, 648

Peverella, 511, 514, 540, 563, 568, 574-75

Pfeffer, 514, 625, 637, 648-49

Picpoule noir, 514, 625, 637, 649

Pinot blanc, 511, 514, 528, 533, 541, 546-47, 572

Pinot noir, 503, 510, 514, 521, 533, 541, 555, 559, 643, 646, $648,649,650,664$

Pinot Pernand, 514, 625, 638, 649

Pinot Saint George, 510, 514, 625, 698, 649-50

Previous studies, wine-grape-variety situation in California, 493

Production, as a factor in selecting a variety, 507-8

Raboso Piave, 509, 514, 577, 587, 600-1

Recommended varieties, 517-62; for region I, 517-21, 533; region II, 522-27, 533; region III, 533, 540; region IV, $540-41$; region V, 541

Red Malaga (Molinera), 669, 671, 672-73

Red Traminer, $509,511,514,533,568,575$

Red varieties, composition of musts and wines, 520-21, $526-27,530-32,536-39,578-91,626-39,660-62,670-71$. not fully tested, 659-65; not recommended, 624-50; of limited recommendation, 577-605; recommended for specific regions, $520-21,526-27,530-32,533,536-41$; recommended, notes on, 551-62; relative value, 510; table grapes, 669-73

Red Veltliner, 514,533,569,575-76

Refosco, 510, 514, 527, 533, 540, 541, 559-60

Regional adaptability of varieties, 512-16

Regions, grape growing, in California, 504-5; varieties recommended for, 517-41

Relative value of varieties, $510-11,517$

Ribier, $669,671,673$

Robin noir, 516, 659, 662, 664-65

Roussette, 511, 514, 606, 618, 622

Saint Emilion, 511, 514, 606, 614, 622

Saint Macaire, 510, 514, 577, 587-88, 601

Salvador, 514, 589, 541, 560-61, 592, 645

Sangioveto, 510, 514, 540, 577, 588, 601-2

Sauvignon blanc, 511, 514, 518, 533, 547

Sauvignon vert, 504, 511, 514, 606, 615, 622-23

Scoring wine, 501-2

Seasonal conditions, effect on wines, 505

Selection Carriere, $515,606,616,623$

Selection of the best variety, factors influencing, 507-17

Semillon, 504, 511, 515, 523-24, 533, 547-49, 572

Servant, $\mathbf{5 1 5}, \mathbf{5 6 3}, 569, \mathbf{5 7 6}$

Steinschiller, 515, 606, 616, 623

Sylvaner, 511, 515, 525, 533, 549-50, 658
Table-grape varieties, use for wine, 665-73

Tannat, 510, 515, 533, 577, 589, 594, 601, 602-3

Tasting procedure and scoring, 501-2

Temperature, in grape-growing regions, 504, 506

Terret, 515, 606, 617, 623

Thompson Seedless, $665,667,669$

Time of maturation, as a factor in selecting a variety, 509

Tinta amarella, $515,561,625,639,650$

Tinta Cao, 515, 540, 541, 561, 562, 577, 589, 603

Tinta Madeira, 509, 510, 515, 587, 540, 541, 561, 562, 594, 603

Trousseau, 510, 515, 532, 540,541, 561-62, 641

Types of wine recommended for varieties, 512-16

Utility of varieties for wine production, factors influencing, 493

Valdepeñas, $510,515,540,577,590,603-4$

Varieties, adaptations to regions and wine types, 512 16 ; black table, 660-73; limitedly recommended, 562-605; not fully tested, 516, 651-65; not recommended, 606-50; recommended, 517-62; red, see red varieties; regions recommended for, 512-16; relative value, $510-11,517$; table, $665-73$; white, $s e e$ white varieties; wine ty pes recommended for, $512-16$

Verdelho, 515, 540, 563, 570, 576-77, 651

Vermentino Favorita, 515, 606, 617, 624

Vernaccia bianca, 515, 606, 617, 624

Vernaccia Sarda, 515, 563, 570, 577

Viticultural regions of California, 504-5

Walschriesling, 516, 651, 655, 658-59

White Riesling, 503, 511, 515, 519, 533, 550-51, 658, 659

White varieties, composition of musts and wines, 518 $19,522-25,528-29,534-35$; not fully tested, 651-59; not recommended, 606-24; of limited recommendation, 563-77; recommended for specific regions, 518-19, $522-25,533,534-35,540,541$; recommended, notes on, 541-51; relative value, 511 ; table grapes, 665-69

Wine classification, 502

Wine making, 498; crushing, 498; fermentation, 498; must analyses, 498; pressing, 498; temperature control, 499 ; storage, 499

Wine types and regional adaptability of varieties, 512-16

Zinfandel, 494, 504, 505, 510, 515, 562, 577, 591, 596, 597, 599, 604-6 